
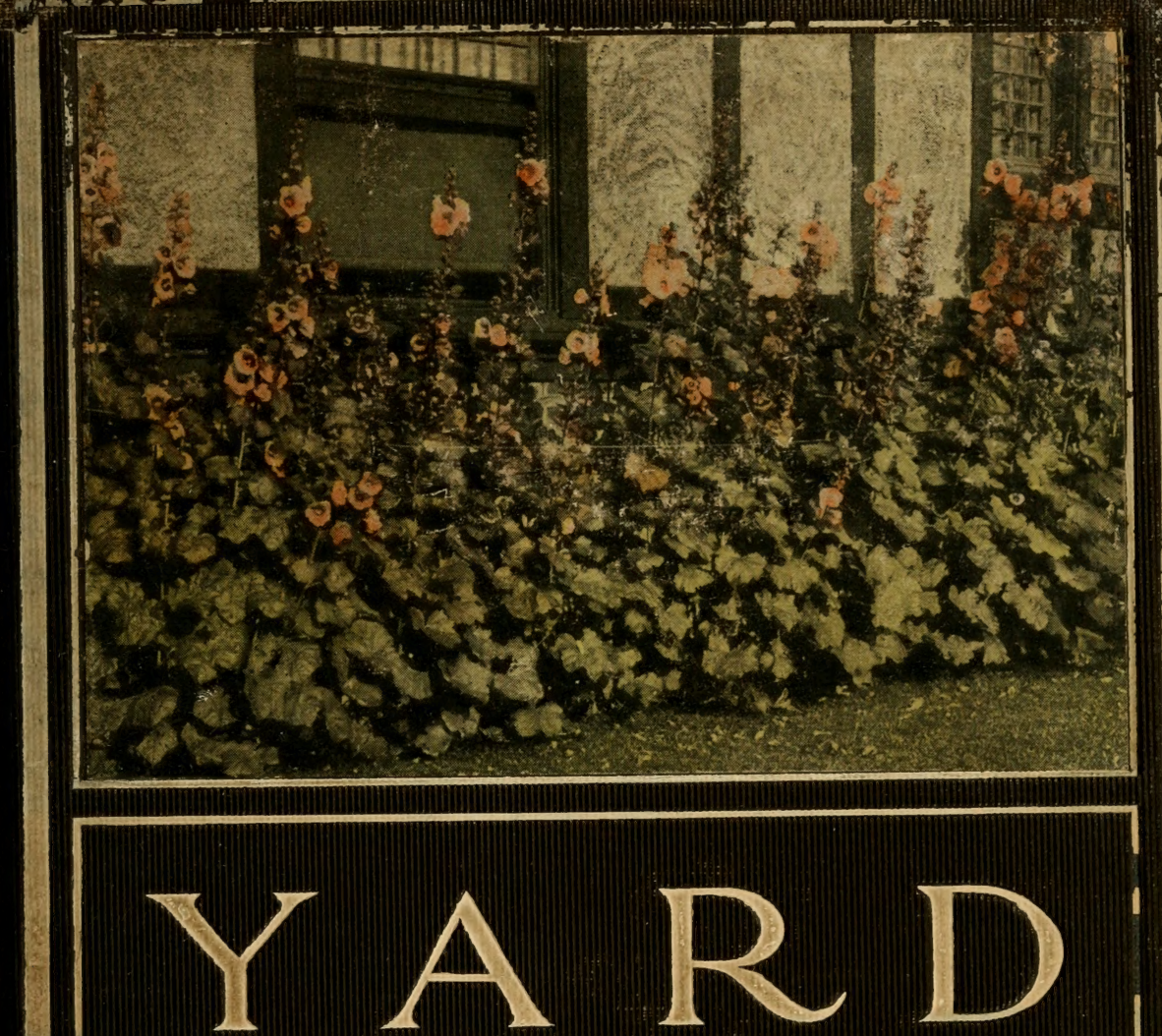

\title{
and
}

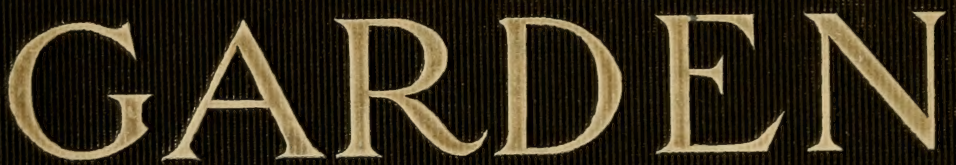

\section{TARKINGTON BAKER}



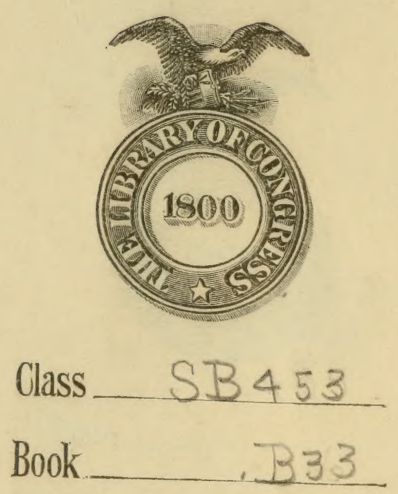

Copyright $\mathrm{N}^{0}$.

COPYRIGHT DEPOST. 





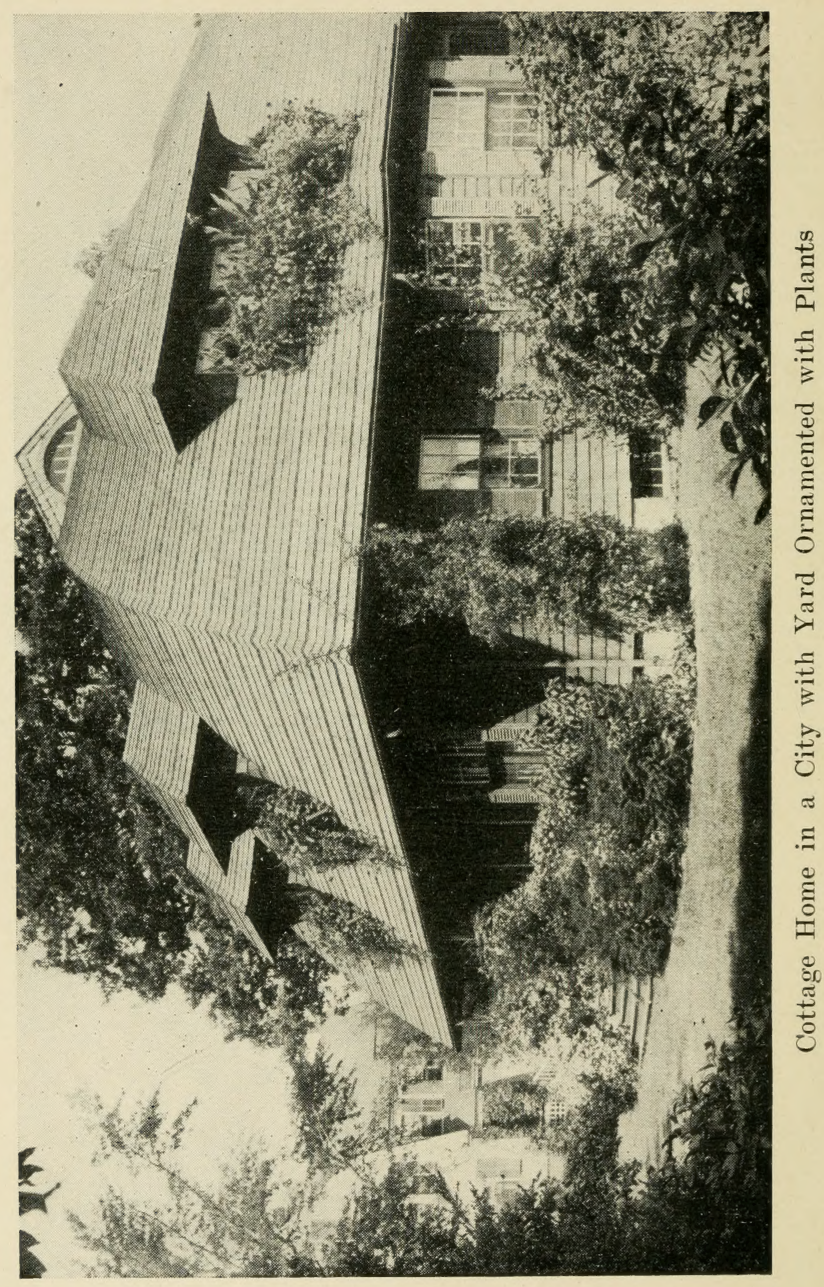




\title{
YARD AND GARDEN
}

\author{
A Book of Practical Information \\ for the Amateur Gardener \\ in City, Town or \\ Suburb
}

By

\section{TARKINGTON BAKER}

1llustrated with Photographs

and Diagrams

INDIANAPOLIS

THE BOBBS-MERRILL COMPANY

PUBLISHERS 


\section{Copyright 1908 \\ The Bobbs-Merrill Company}

February
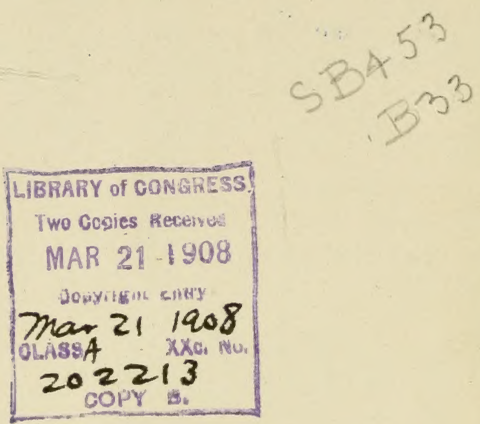

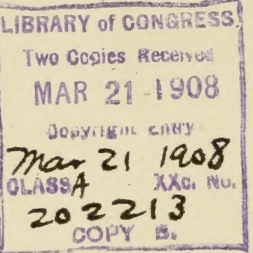

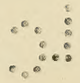

PRESS OF

BRAUNWORTH \& $C O$.

BOOKBINDERS AND PRINTERS

BROOKLYN, N. Y. 


\section{CONTENTS}

CHAPTER

PAGE

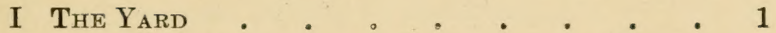

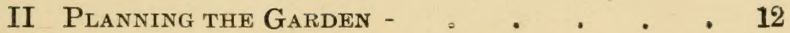

III How to Plan + 。 。 . . . . 31

IV LawnS • • • • • • • • • . 44

$\mathrm{V}$ VINES . . . . . . . . 75

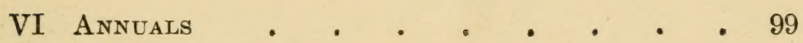

VII Hardy Perennials . . . . . . 134

VIII Some Popular Perennials . • • . 157

IX Bulbous- and Tuberous-Rooted Plants • • 170

X Some Popular Hardy Bulbs . . . . 194

XI Irises and Tender Bulbs . . . . . . 219

XII Shrubs • • • • • • • • . 240

XIII Trees . • . • • . • • . 266

XIV Soll and Fertilizers. . • . . . . . . 293

XV Insects and Diseases . . . . . . 309

XVI The Indoor Winter Window Garden 329

XVII A Chapter of Specialties • • • . 357

Appendix . . . . . . . . 379

INDEX . . . . . . . . 405 



\section{LIST OF ILLUSTRATIONS}

PAGE

Cottage home in a city with yard ornamented with plants -Frontispiece

Small space of city yard converted into formal garden . 3

Beginning the improvement of a city back-yard $\quad$. $\quad 9$

The same yard three months later . . . . $\quad$. 9

Making the most of meager space for flowers . . 15

Grounds of a factory ornamented with plants $\quad$. 17

Example of planting in limited space . . . . 20

Side-yard planned and planted by the owner . . . 24

Elaborate planting in city yard-pergola in center . 27

Example of simple but effective planting . . . 33

Yard-planting in which tree is made the center . $\quad 39$

Wall-planting-result of careful planning . . . 43

Hedge of privet as a city yard boundary . . . 47

Sun-dial in corner of city lawn . . . . 50

Hedge of climbing roses defining limit of lawn . $\quad 57$

Colony of iris established in lawn . . . . . . 61

Unsightly corner of yard ornamented with plants . . 65

Garden seat at end of small city lawn . . . . 70

Wild grape from woods in eity yard . . . $\quad$. 79

Flowers of the clematis . . . . . . 84

City residence covered with woodbine . . . $\quad$. 89

Flowers of the fragrant honeysuckle . . . . 93

Annual phlox . . . . . . . . 100

Single and double zinnias . . . . . . 102

Snapdragon . . . . . . . . 105

China aster . . . . . . . . 105

Transplanting seedlings to "thumb-pots" . . . 107

Stocks . . . . . . . 110

Shirley poppies . , _ . . . . 110

Sweet peas o . . . 112

Petunias . . . . . 114 


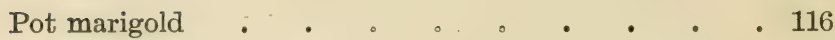

Sowing seeds of annuals . . . . . . 118

Plants in porch box combined with hardy ferns to make

solid wall of foliage and flower . . . . . 121

Porch boxes filled with plants suitable for eastern

exposure . . . . . . . . 124

Porch box newly started but with plants in bloom . . 126

Effective grouping of single plants . . . . . 129

Porch boxes exposed to full sunlight _ . . . . 131

Meadow Sweet . . . . . . . . . 135

Catchfly . . . . . . . . . . 137

Achillea . . . . • . . • • . 139

Columbine . . . . . . . . . 139

Globe Flower . . . . . . . . . 141

Swamp rose . . . . . . . . 143

Oriental poppy . . . . , . . . . 145

Stoke's aster . . . . . . . . . 147

Bee Balm . • . • . . . . • . 148

Balloon Flower . . • • • • • • • 148

Larkspur . . . . . . . . . . 150

Golden Marguerite . . . . . . . . 152

Sweet William . . . . . . . . . 154

False Dragon-head . . . . . . . . 154

Spiræa • . • • . • • • • 155

Golden Glow • • • • • • • • 158

Boltonia . . . , . . . . . . 159

Monkshood . . . . . . . . . 161

Foxglove . . . . . . . . . 161

Chrysanthemum, "Shasta Daisy" . . . . . 163

Veronica . . . . . . . • • . 165

Plantain lily . . . . . . . . 166

Yellow Day lily . . . . . . . . 166 
Transplanting hardy perennials . . . . . 167

Narcissus days in a city yard garden . . . . 171

May-flowering tulips on Decoration Day . • • . 174

Dahlia . . . . . . . . . . 176

Canna . . . . . . . . . 176

Flowers of tuberous-rooted begonia . . . . . 178

Flower of the canna . . . . . . . . 181

Torch lily . • . . . . . . . 185

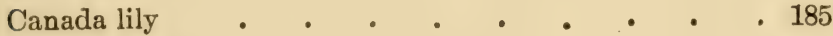

Kramer's lily . . . • • • • • . 187

Single dahlias . . . . . . . . . 189

Madonna lily . • . • • • • • . 191

Erythronium . • . • . . . . . 196

Poet's narcissus . . . . . • • . . 196

Trumpet varieties of narcissus . • . . . . 199

Hyacinths . . • . . . . . . 201

Parrot tulips . . . . . . . . . 203

May-flowering tulips . . . . . . . . 203

Gladiolus • • • • • • • • • . 206

Montbretia • . . . • . . . . 206

Tiger lily . . . . • • • • . . 211

Thunbergian lily $\quad$ • _ . • • • . 216

Japanese iris . . . • . • . . . 221

Spanish iris . . . . . . . . . 225

White Siberian iris . . . . . . . . 230

German iris . . . . . . . . 230

Siberian iris . . . . . . . . . 234

English iris . . . . . . . . 234

Bridal Wreath . . . . . . . . . 241

Hydrangea laden with flowers . . . . . . 244

Blossom of the tree peony in early spring . . . 247

Shrubbery walk in small city yard . . . . : 249 
Flowers of the Mountain Laurel . . . . . 255

Hardy azalea in bloom . . . . . . . 258

Rhododendron in bloom . . . . . . . 260

Flowers of the tall-growing Bird Cherry . . . . 262

Planting a tree . . . . . . . . . 267

Tree that has never been pruned . . . . . 272

Trees ruined by ignorant pruner . . . . . . 272

Fruit trees for shade and fruit in city yard . . . 279

Effective grouping of evergreen trees . . . . 287

Decorative value of the haw . . . . . . 294

Colony of Sedum spectabile in poor soil . . . . 299

Blue Day lily growing in soil which the owner considered

"impossible" . . . . . . . 306

Spraying easily done in the average city yard . . 311

Typical chewing insect (Cecropia moth) . . . . 312

San José scale . . . . . . . . . . . 318

Oyster shell scale . . . . . . . . 318

Fall web-worm . . . . . . . . . . 320

Scurfy scale . . . . . . . . . . 320

Work of the catalpa sphinx moth . . . . . 325

Paris daisies . . . . . . . . . 330

Root growth of narcissus . . . . . . . 333

Azalea Indica in bloom . . . . . . . . . 333

Ornamental-foliaged begonia . . . . . . . 336

Foliage plants suitable for a window garden . . . 338

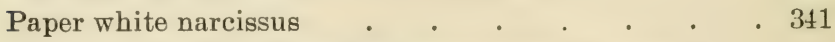

Hyacinths, cyclamen and lily, products of a sunny

window garden . . . . . . . 345

Freesias in bloom . . . . . . . 347

Group of plants suitable for shaded window . . . 349

Geraniums in bloom indoors in mid-winter . . . 350

Tender hydrangea . . . . . . . 353 


\section{LIST OF ILLUSTRATIONS-Contimed}

PAGE

Lace fern . . . . . . . . . . 354

The Maidenhair fern . . . . . . . 355

Rose-General Jacqueminot . . . . . . 359

Border of hardy ferns as screen for foundation . . 365

Ostrich ferns in narrow border . . • • 366

Double peony . . . . . . . • . 369

Single peonies . . . . . . . . . 371

Flowers of the tree peony . . . . . . . 372

Hardy phlox . . . . . . . • . 375

Wild Sweet William . $\quad$ • . . • • 377 



\section{YARD AND GARDEN}





\section{YARD AND GARDEN}

\section{CHAPTER I}

THE YARD

The owner of a city or town lot, of a suburban home or of a country estate is usually interested in affairs which he considers more important, or at least more practical, than the abstract principles of gardening, no matter in what form they are presented or what application is to be made of them. His immediate requirement, if his attention be directed at all toward the subject, is practice and not theory. He wants planting and not principle; his main desire is to employ the speediest and safest process to make his yard, his grounds or his estate-if we can distinguish property sizes by these common though vague terms-as harmoniously and effectively beautiful as trees, shrubs, plants and vines and his financial resources will permit.

In a sense he is justified and, in any event, 
he is but responding to a common and natural impulse, to obtain for himself that which has pleased or interested him. He is impatient of theory and eager for results. Disquisitions on the fundamental laws of gardening or landscaping are tedious if not perplexing and, in his judgment, of little value. His conclusion may be hasty but to some extent it is entirely correct. There are no hard and fast rules for gardening and particularly for the art of ornamental gardening, whether it be conducted on large or small scale, on a country estate or the back-yard of a city lot.

There are some principles best remembered but even they are not without innumerable variation in application. In gardening, as in house building, individual taste, temper and aspirations are reflected and each garden, consequently, is a law unto itself. Still, underneath this disclosure of the gardener's own nature and individuality there are broad principles, applicable to all and the foundation of all. They are simple, obvious and natural. The beginner can make fair progress with nothing more than an instinctive knowledge of them. Any day in the year, in any wood or meadow, on the banks of any stream, even by the coun- 


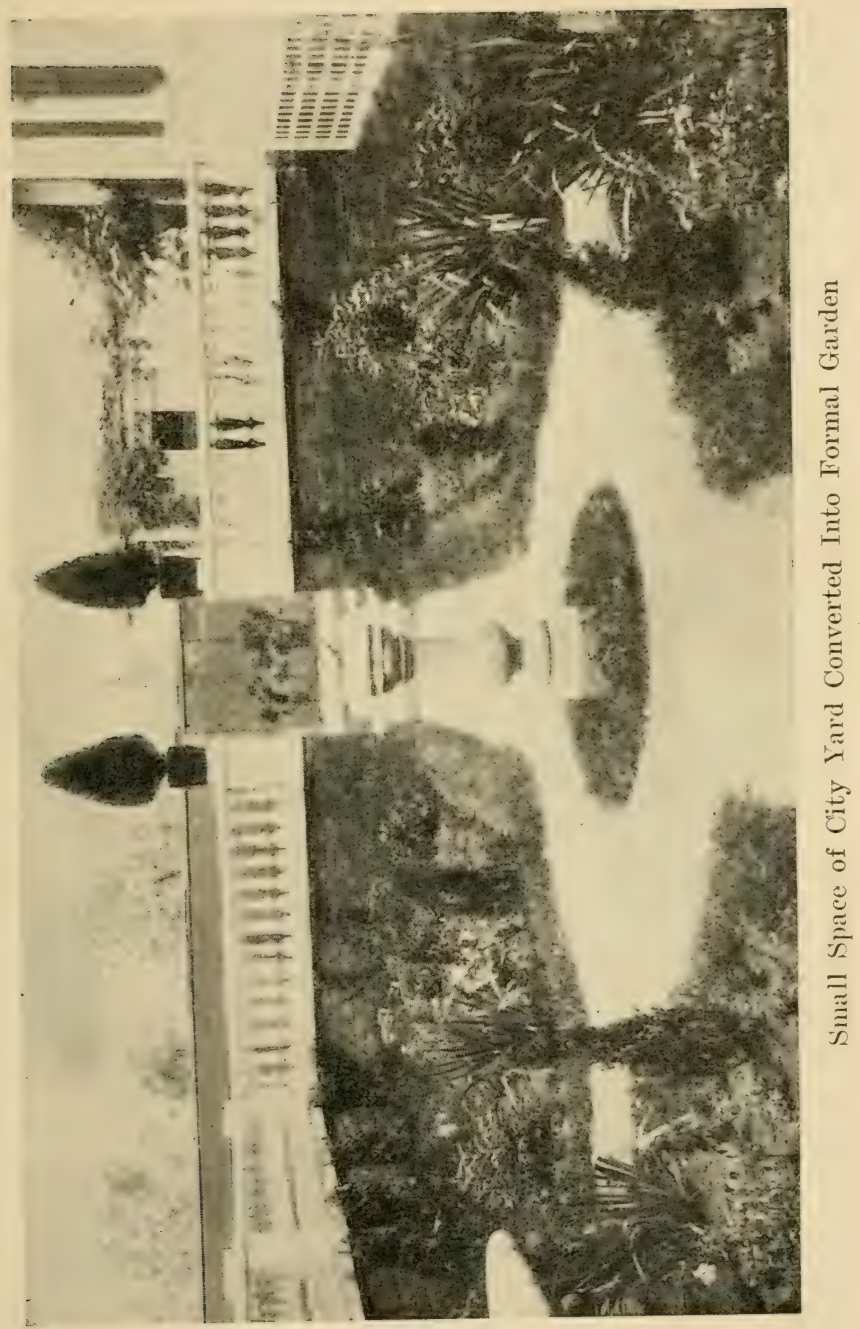


try roadside, any place where natural conditions remain in some measure undisturbed, every principle necessary for the most elaborate gardening procesies is disclosed by nature itself.

If the beginner will bear this in mind and at the same time remember that there is no space too confined for the application of nature's principles, he will have mastered all the fundamental law that it is necessary for him to master. With this as a hasis, he will quickly observe that ornamental gardening, whether: it be by the formal method, the natural method or a combination of the two, is only a simple application of this common law. He mar himself choose to copy the Italian garden, derise some modification of the English wall garden, elahorate the miniature gardens of Japan or content himself with duplicating and exalting nature in natural gardening, hut whicherer course he elects to pursue he will find the principles the same.

\section{GARDENING}

The orner of a home, whether it he on extensive grounds or set on a narrow and shaliow city lot, need not hesitate, therefore, to begin 
gardening-and by gardening is meant the laying out and cultivation of gardens, whether they be large or small, a square yard or an acre, open or inclosed, a part of an estate or all of it. The first important consideration to him is the understanding of what can be done with his own home grounds. It is important to comprehend the value of improving them, even where the area is so small as to seem to preclude all opportunity for such effort. Most of us realize what paint will do for an old house, but few of us realize what a well-kept lawn 0 : well-planted yard will do. Tet there are a number of examples.

There is, for instance, the case of the owner of a city home who was anxious to dispose of it. The house was old and not attractive and interested inquirers were few. The owner painted the house but still no sale was effected. Next, upon the suggestion of a friend who knew the value of shrulss and vines and flowers, the yard was planted at a cost considerably less than the painting had entailed; hedges rere substituted for ugly division fences and a general transformation was effected in less than a season's time. The orrner then found not only that there were a number of 
purchasers eager for the property but, moreover, that he no longer desired to sell.

This experience is not as exceptional as it might at first thought appear. As a matter of fact very few persons are found nowadays who deny that value, of the sort estimable in dollars and cents, as well as beauty, can be added to a home by the judicious planting of the yard. No matter how imposing a house may be or how perfect and harmonious the lines of its architecture, or how well its interior may be finished and furnished, all suffer when the yard is neglected. On the other hand, though the house itself be old and weather-worn, it can be made to assume an attractive appearance if it be surrounded by trees, vines, shrubs and flowers, carefully selected, wisely situated, patiently cultivated.

These facts are no longer questioned, if, indeed, doubt of a serious nature was ever opposed to them. All of us have learned the value of a city beautiful, and most of us admit the value of a home heautiful. If we do not contribute to the one or disregard the other, it is not for lack of knowledge but rather because of indifference. But even this indifference is gradually disappearing and to-day we 
have owner's of houses, factories and other buildings of a semi-public character, beautifying their grounds by the liberal employment of nature's materials.

\section{VALUE OF EXAMPLE}

Moreover, we have examples to encourage us; we have city parks and streets or avenues, city yards, suburban homes and country estates planted or landscaped. And these are not without valuable influence, for it seldom happens that the residents of a neighborhood surrounding a place, large or small, that has been effectively planted, lag far behind the pioneer. Before his advent, or before his operations were begun, it might be that lawns were unkempt and flowers were unknown, but it does not require more than a season or two for the one improvement to arouse others to action and for the movement thus started to gain in extent until it amply justifies all the faith placed in the power of example by such bodies as civic improvement societies.

Planting, from whatever cause it may spring, once begun is not quickly abandoned. Gardening begets gardening-the more one plants the more one desires to plant. But the fascination 
of the pursuit is not alone sufficient to account for this. In addition to exercising that universally instinctive desire to raise things, to see them grow and thrive on the care and attention one bestows on them, no field of endeavor, as has already been suggested, promises a broader scope for the expression of an individual's taste, temper and aspirations. We seek to have the houses we build express something of our own personality, but, were we only aware of it, the yard presents a far more favorable field for such effort. Who can not, for instance, judge of the intellectual and moral, as well as of the sanitary status of a community, of a neighborhood, or of the owner of a private drelling by its external conditions?

Nothing can be more incongruous than the littered back-yard of an imposing city residence. Within dwell persons who are fond of comfort, if not of luxury, intelligent and educated, and it seems wholly impossible that they would not avail themselves of the opportunity to add so much enjoyment for themselves and for other's by improving the ground at their disposal, instead of making it a place for the deposit of old barrels, boxes, tin cans, and other rubbish. The only possible argument against 


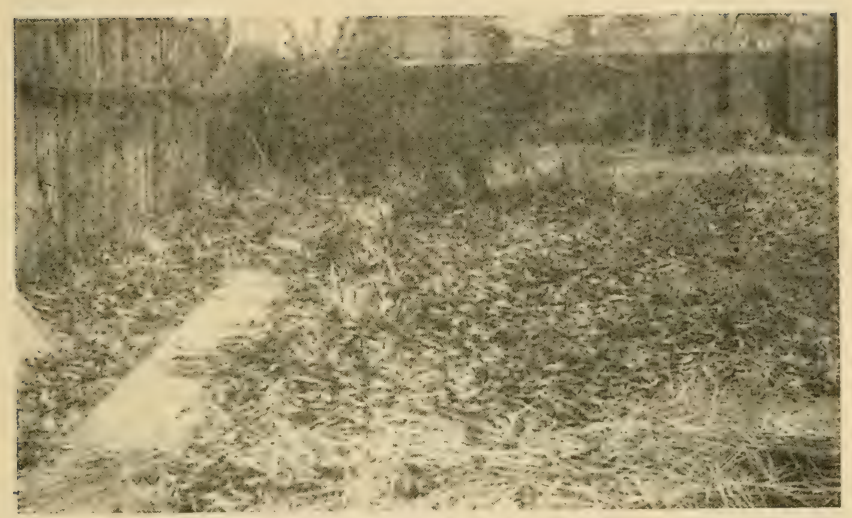

Becrimning the Improvement of a City Back-Yard

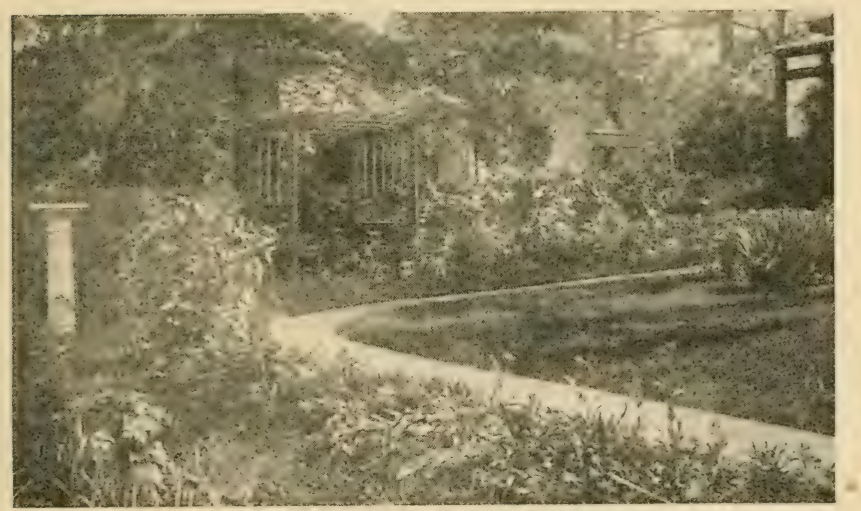

The Same Yard Three Months Later 
such improvement, and, indeed, the argument that is most frequently advanced, is the lack of space. But it is not space that is wanting, but -taste, temper and aspiration. Even in a space that is not more than twenty feet square, there is sufficient ground for an attractive garden.

How much more opportunity is there then for that owner of a city lot of the usual size upon which he has erected a house of the usual dimensions? Instead of confining his efforts to the making of a small garden he has, comparatively speaking, a vast domain at his disposal. His lot, perhaps, is forty feet wide and one hundred feet deep. His house at most occupies half of this; occasionally some other building-a stable, a garage-may occupy a few feet more, but, withal, he has remaining six hundred, eight hundred or a thousand square feet upon which to plant vines, and shrubs, and trees, and flowers. By employing to advantage this available space, he can contribute to his own pleasure, to the pleasure of his neighbor's and of passers-by; he may set a good example and he may materially increase the value of his property. The latter is not a matter of theory but a matter of fact. Nor 


\section{THE YARD}

is the increase to property value confined to the property improved; on the contrary all surrounding property is in a measure affected. Unfortumately, however, we lear'n this too often only through the demonstration of the negative of it. It is quickly enough realized when some neighborhood suffers a direct depreciation in property values through the carelessness, selfishness, ignorance or downright stubbormness of a single property owner who persists in maintaining an $\mathrm{ug}_{\mathrm{g}} \mathrm{y}$, unsightly yard which is little less than a legal nuisance and most certainly a positive eyesore.

If all these facts were more extensively understood and their true worth and full significance were better known by individuals and communities, public health would be better conserved, cleanliness would be insured, fewer sanitary inspector's would be necessary and the beauty of town or city would be materially enhanced. The individual himself would no longer be the possessor of a house and lot, but he rould become the orner of a home, with a yard harmonizing with the house and affording, in summer at least, an additional pleasant, healthful and attractive living-room. 


\section{CHAPTER II}

PLANNING THE GARDEN

Before there were gardener's there were gardens. The first gardener, no doubt, was a fence-builder; he appropriated whatever he found growing, that was of use or benefit, inclosed it to exclude marauders and to protect and safeguard it the better. Consequently in the beginning a garden was an inclosed space. It is easily conceivable that in this inclosed space not all the native plants which might prove of value to this primitive gardener were to he found. He inclosed, doubtless, what he could, but some were too remotely situated to be included. It hecame his problem, therefore, to introduce such of these as he desired into his protected area and, in the subsequent o1erations, we have the first garden planning and the first actual gardening.

This primitive ancestor was not without definite plan when he rent beyond his crude pale and brought into his inclosure some plant 
which he had failed to include when he laid his barricade. And no more are we without plan when we transplant a tree, sow seeds or set out shrubs, vines or flowers. We put them where we believe they will prove most effective in attaining the end desired.

This is the beginning of planning, and, even when it is elaborated, it is neither difficult nor complex, though it has, unfortunately, been made by professional gardeners to seem both. Nor is it uninteresting. On the contrary, it is simple and fascinating and no small part of the delight and interest in gardening, especially in planting to ornament a small place, owes its origin to the operation. Moreover, the picture thus produced is our own, not another's; it is of our conception and our making, expressing our own ideas and our own feelings as well as our individual natures. And, being not only a simple but an absorbing process, why, when so easily and cheaply engaged in, employ another to undertake the work for us?

\section{PRINCIPLES INVOLVED}

Let those who own ground start with the premise that every place can be improved. No yard is too small and no estate too large 
to make impossible its improvement by the use of plants of some sort, and, large or small, the principles involved are invariably the sameit is only the scale upon which they are applied that differs. Often one may see plants in tubs standing in front of store or office building, or set about the entrances and corridors in the busiest section of down-town districts of large cities. Wherever these are in evidence the passer-by does not fail to take note of them or to observe gratefully the effect they produce.

There are also other instances where gardening is practised in almost impossible places. In some sections of some cities private residences are without front lawns of any description, and apparently there is no opportunity for planting. Still these homes are not without their flower's, for window boxes have been fitted in place and in these vines and flowers thrive and bloom. Then again-it is always a hopeful sign-in the most densely populated districts of the slums of our larger cities, one may frequently observe a plant struggling for life in some dust-streaked window of a home where dire poverty, only too evident, would seem to prohibit even the most feeble exhibition of a love for something green and growing. 


\section{PLANNING THE GARDEN}

15

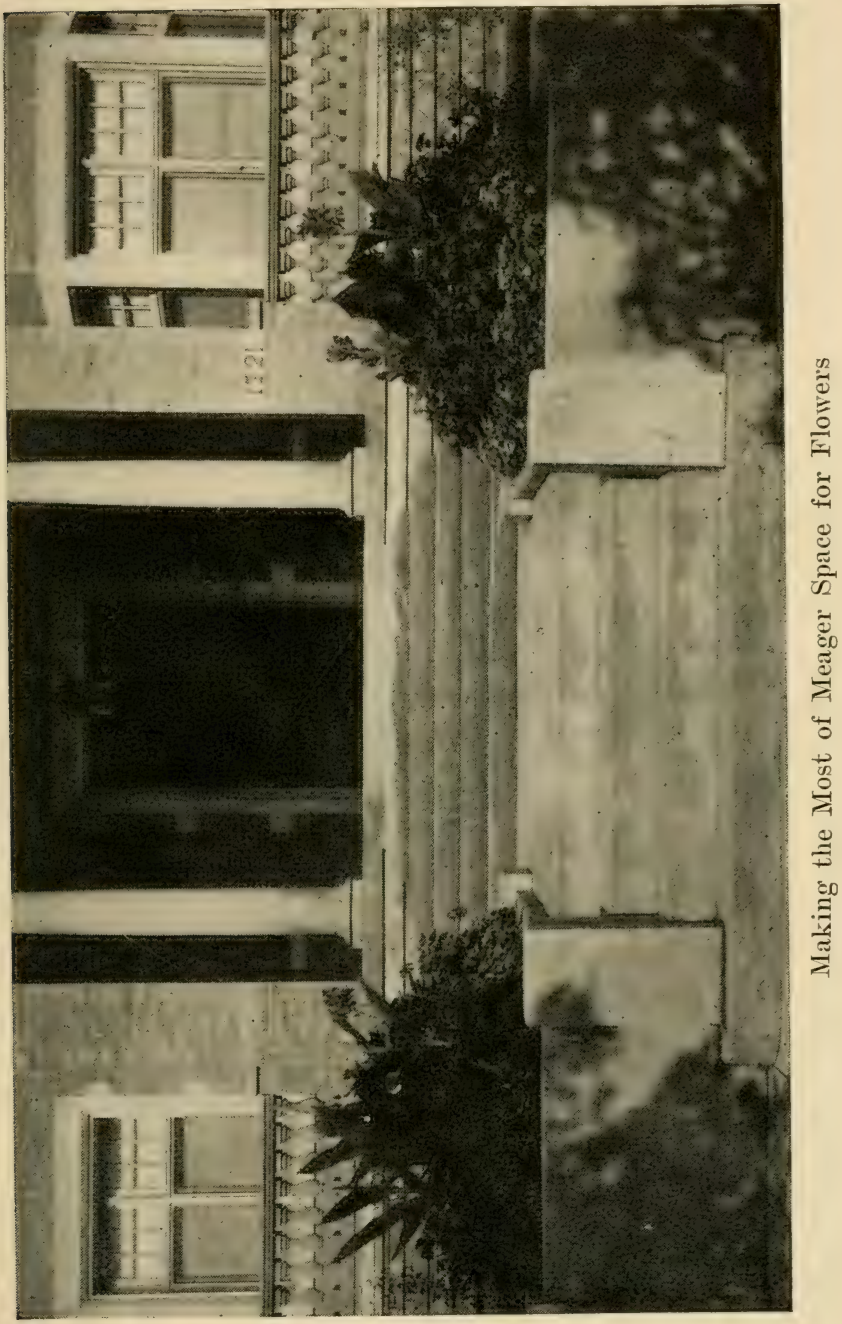


One may turn also to the manufacturing center's and here he will find frequently that the practical business sense of the owner has led him to employ vines, shrubs and flowers to make his work-shop a healthier and more enjoyable place for his employees.

If one will consider for a moment what the purpose of a yard is, perhaps a sense of logic will induce him to see clearly 'why an effort should be made to get as much out of it as space and other conditions will allow. The yard surrounding a house, whether large or small, contributes directly and indirectly to the health and comfort of the occupants of the home; it insures light, air and sunshine; it affords for the most of us at least a glimpse of nature. If we should determine to embellish this area with plants we should lose none of the advantages it affords but, as a matter of fact, we should add considerably to them. Individually, we should get more light and more air and more sunshine, for gardening means outdoors life for the man or woman who begins it and takes an interest in it. It means ten or fifteen minutes a day, or more perhaps, beneath the sky, and ten or fifteen minutes less beneath the roof. It means healthful exercise, a closer 


\section{PLANNING THE GARDEN}

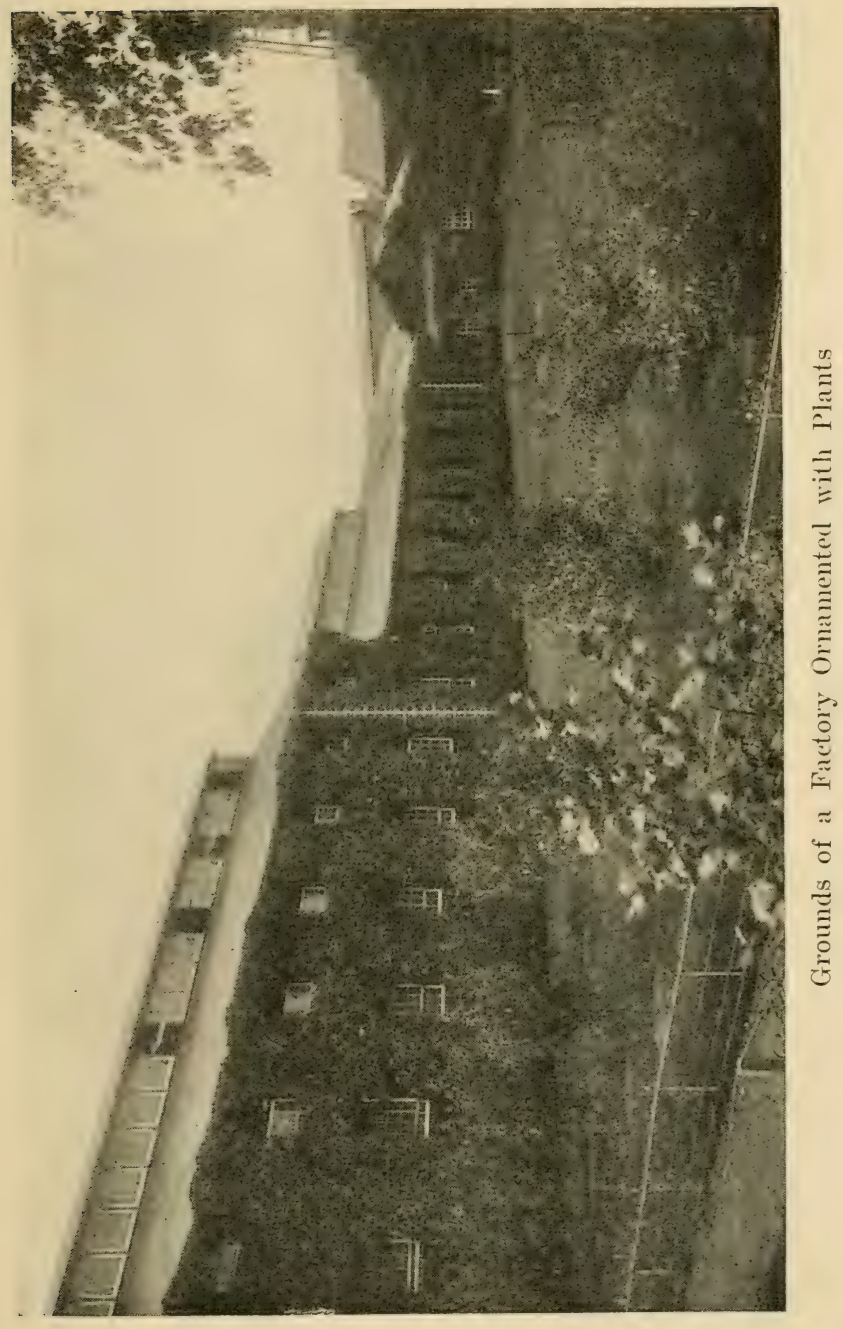


acquaintance with nature, a broader glimpse of nature's methods, and a deeper aploreciation of nature's handiwork.

It is worth while to have a yard but it is worth infinitely more to make use of it, and if one will tend it with interest and some regard for the fitness of things, surprising results can be accomplisher. And when mention is made of the yard it must not be deduced that the spacious lawns and gardens of large city or suburban homes are in mind; on the contrary the reference is rather to the little strip of ground behind the house, and the smaller strip in front of it which answer for breathing spaces for most of us who dwell in cities and towns. The city yard, of course, is deplorably small, and year by year, as population increases it seems to become smaller. It used to be that we considered one house to a lot enough, but now the builder, anxious to make his property pay him goodly dividends, has developed the habit of doubling the building without increasing the size of the lots. It might be possible to show even to him that there are advantages often from an investment point of rier in more ground and less building, but, while this is at best a difficult task-for it affects too intimately 
the immediate revenues-it should not be diffcult to prove that provision made for planting and the planting itself are both wise investments that will not fail to yield substantial dividends.

\section{EXAMPLES OF PLANTING}

Let us take, as a basis to illustrate what can be done, the sort of lot one finds oftenest in the residence sections of cities. In one of the larger cities of the Middle Trest there is a small home on a lot forty feet wide and one hundred and fifty feet deep. To be exact, the house is situated twenty feet from the property line, four feet from the north line of the lot, ten feet from the south line and fifty feet from the west line. Around the porch, screening the foundations, are dwarf shrubs and ferms; along the south line of the house, in a border two feet wide between the walk and the house, there are lilies of various species growing among funkias or "plantain", lilies-here again the brick foundations are entirely hidden from view. Boston ivy climbs up the pillars of the porch, and porch boxes are filled with flowering and foliage plants and rines. On the north side are more ferns and a few shrubs and these in their 
turn completely hicle the foumdation walls. We have, therefore, to hegin with, a house that is not "bare-footed." The front yard is a lawn with no flowers growing upon it, but a hedge, kept trimmed to a height of three feet, incloses the premises. In the rear there is a central lawn fifteen feet square; around this are groupell

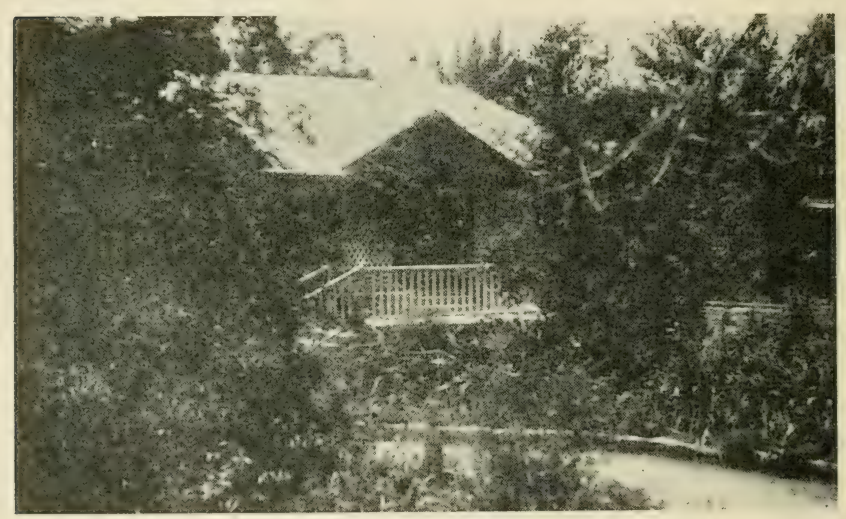

Example of Planting in Limited Space

beds and borders of perennials and shrubs. Amongst these, annuals are planted each season to afford additional bloom and a surer succession.

On this place, from the earliest days of spring intil the first killing frost in the fall, there is never a time when an armful of flowers can 
not be gathered. The planter of this place began his work when he was in wretched health, but through his gardening operations he recovered from his illness, gained strength and vigor, made his home more beautiful and, at the expense of a few minutes each day, and a. few dollars, he increased the value of the property nearly twenty per cent.

If the owner of a city lot is not impressed by examples of this kind but still finds it difficult to rid himself of the idea that the small space at his command means an end to all thought of ornamental planting, let him make a sketch of his yard on paper, drawn to scale, and with this before him undertake an exploratron of the possibilities. It is not unlikely that this method of procedure will disclose opportunities for gardening which, as a beginner, not yet either deeply interested or enthusiastic, he might otherwise overlook. Gradually, as these become apparent, the fact also will develop that it is not more impracticable to create a pleasing picture within an area of a few square yards than in the space of a mansion garden. Indeed, it may prove that limitation of space will contribute to fine if not broad expression of the best gardening, for it is evident that it must 
test to greater degree one's taste and skill; in the contracted area more selection and more rejection, better judgment and more care in arrangement must be exercised, whereas, in a hig place, trees, shrubs and broad expanse of lawn are frequently sufficient in themselves to create the picture.

\section{ELEMENTARY PLANNING}

The person who has grown flowers for a year or two is in little need of the suggestion that even a season's garden should be planned. There is enough delight in the work-in the anticipation to which it gives rise-to make it reasonably certain that the garden will be planned in some fashion before the planting time is at hand. In fact, all of us, even the novice, do more or less planning before we plant. Frequently we do not recognize it and really persuade ourselves that we plant as the desire seizes us. But, when it is considered that beds must be dug in the spring, it must be apparent that, in determining where they are to be situated, we have, in an elementary manner at least, planned our garden.

It may seem absurd to speak of planning a single bed. One desires to plant so many 
nasturtiums or, as May days come with their assurance that frosts are over, one begins to think of setting out geraniums. Well and good; no plan on paper is needed. The planter has only to determine upon the location of the bed and the work is done. But, even in so simple a process, one has to take into consideration the very same things that must be considered in planning a large garden. One must give some attention to surrounding objects, to the proximity, for instance, of buildings, of trees or shrubs or fences. One must ponder whether this color or that will war with the color of the house, or whether tall-growing or dwarf flowers shall he planted, or whether foliage or blossom is the more desirable.

So, in a measure, in planning even this single small bed, consideration is had for conditions which must be taken into account when one is planning on a more extensive scale. But in the latter case, the planner has also to deal with other details. He must learn all there is to be learned of the situation and the conditions governing it; he must take into consideration all surrounding objects-fences, houses, trees, shrubs or whatever there may be of a permanent nature, for which provision must be 


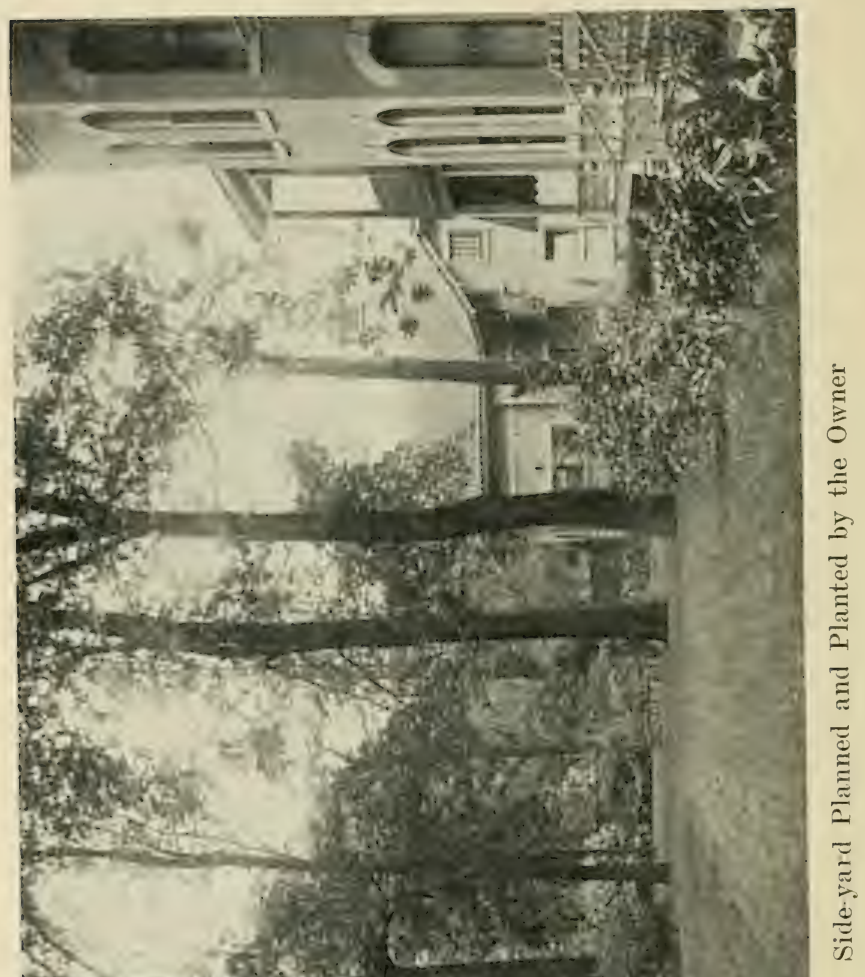


made. He must consider what plants will thrive best under the conditions into which he purposes to bring them and he must consider what plants will harmonize in color and what will not. He must select and reject and rontinue the process until he has not only a list of plants suitable to the site but one also which includes as many as possible of those he most desires. It is by such means that a plan becomes an expression of the planter's own individuality and the garden whish is planted in accordance with it reflects the character of its maker.

\section{PLANNING BEFORE BUILDING}

In many instances one of the first discoveries that will be made is that the ornamentation of the home grounds could have been accomplished far more speedily, effectively and economically if, before building, some thought had been given to the matter and some comprehension of the real value of a yard had been gained. In America, too often the hlunder is made of building a house on a site which presents numerous difficulties in the way of adornment when other sites more farorahle might he obtained, at no greater expense than a little 
more forcthought and search. This is frequently followed by another blunder which results in the location of the house on the site in such manner that even the few possibilities for ornamentation which might have existed at first, are almost entirely eliminated. It is not uncommon to observe, as an illustration, the destruction of some splendid tree, cut down without thought of its value, when by setting the house a fer feet in one direction or another, the sacrifice could have been easily avoided and a natural ornament requiring perhaps a half century for its growth and development preserved.

In this connection it may be well to observe that it is not always either advisable or desirable to set the house on a line with adjoining structures, and certainly it is not necessary. A neighhor may protest if you suggest projecting your house beyond his, but surely he will offer no objection to your setting it farther back if you wish, and often you will be the gainer if you adopt this course. It is difficult to account for the idea, which seems firmly fixed in some cities and towns, calling for the usual military-like alignment of houses. It means frequently a waste of yard possibilities - a neg- 


\section{PLANNING THE (G.IRI)HN 27}

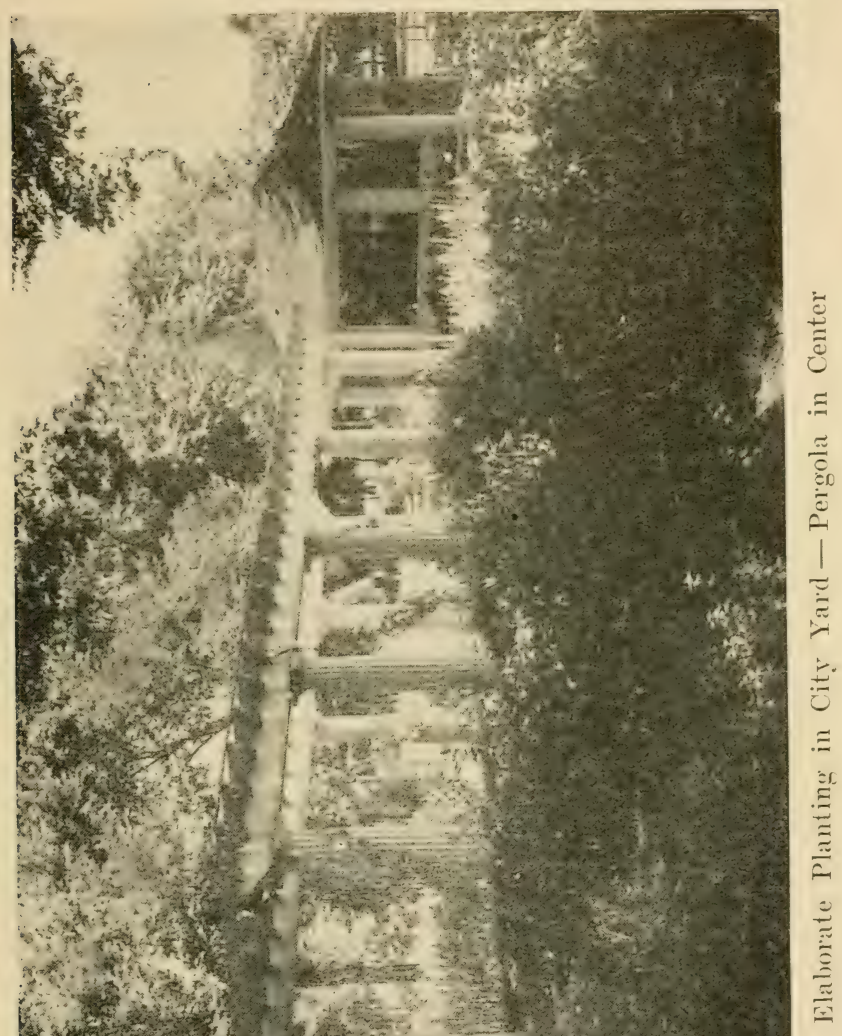


lect of genuine natural resources-with no apparent gain to overcome the loss.

The preservation of continuity of the property line is sometimes, of course, a necessity in large cities, especially where land is expensive and where every foot must be covered by building, but where lots are large, comparatively speaking, make sure that to establish the house on the line will contribute to the general appearance of the place as a home before the step is taken. If it may seem that more is to be gained by setting it farther back from the street than neighboring houses, do not sacrifice your originality as an offering to conventionality, but build your foundations accordingly, use the rear yard as a service yard only and make the most of the front area that as a result will be at your disposal. Bear in mind that the house itself will show to better advantage when it is set, as it eventually should be, in a frame of blooming plants, green shrubs and climbing vines.

\section{PROVIDING FOR WALKS}

Especially give attention to the location of walks. First consider where the street entrance or entrances are to be, deciding this on 
the basis of practical usage and convenience. Then direct the walks by the shortest route to their objective point. Avoid senseless curves, especially in a small yard, and have no more walks than are absolutely necessary, nor walks that are wider than necessary. If the grounds are large-half an acre or more in extent-then walks serving no practical ends may be introduced if desired. These may lead by devious course to retired seats or summer-houses or may conduct to shrubberies or to artificial garden ornaments, as, for example, a sun-dial. But if such walks are wanted, let the planter go forth to some remote wood or old meadow and, finding a path worn by the foot of man or beast, study its outlines and curves. He will not be long in observing that its irregularities are not without purpose-it avoids obstacles, a tree, a shrub, a stump, a stone, a bog; it circles knolls or follows the meanderings of a stream. But always it changes its course for reasons that are obvious. And for such reasons and these alone should the direction of walks laid on residence grounds be changed. The obstacles, of course, may be provided, but in any event they should be present and visible. A grouping of shrubbery, a large boulder, a 
tree or similar object, artificial as well as natural, may be employed to gain the end desired and will not fail to prove effective as well as logical.

Each year finds Americans giving more and more attention to all such details. The house no longer receives attention to the entire exclusion of its surroundings; it has come to be considered a part of the home, not all of it. And this is equally true when the house is already erected, as it is in a majority of instances, and we must make the most of conditions as we find them. This, of course, is more difficult, but it is never impossible. It means only that all the more planning is necessary and it presents no cause for discouragement, but, on the contrary, an incentive to greater effort. 


\section{CHAPTER III}

\section{HOW TO PLAN}

Though where art is concerned, rules are frequently "more honored in the breach than in the observance," still there are certain principles, all general in character, which, if followed, will lead the beginner safely past the commoner faults observed in yard ornamentation. These principles are as simple and obvious in point of reason as they are few in number and all of them are so fundamental that no grounds, of whatever size, can be tastefully embellished without observing them. They might be called, as they are here set forth, the "ten commandments of ornamental gardening."

\section{PRINCIPLES OF ARRANGEMENT}

I. Preserve unbroken stretches of lawn of as great length as possible in one or more places, according to the size of the lot.

II. Set the tallest-growing plants nearest the boundaries of the rard and those of shorter 
growth so that the range of height will be upward and outward from the center of the lawn.

III. Avoid planting next the street or avenue sidewalks unless seclusion is the object. Tallgrowing trees, that head high, may be excepted, for these, when they have attained fair height, do not obstruct the view.

IV. Plant no tall-growing trees or shrubs so close to the dwelling that light and air will be excluded and avoid their use in small lots where good lawns and flowers are desired. But if sturdy, healthy trees are already established on a lot upon which no building has been erected, make every effort to save them and arrange other plans, both of building and planting, accordingly.

V. Avoid the formation of numerous separate flower-beds. Avoid beds of geometric designs on the lawn. Avoid scattered and gaudy. effects and "specimen", planting.

VI. Plant in a manner that will insure pleasing vistas from the principal windows, the entrances or porches of the dwelling.

VII. Keep in mind the season of bloom of different plants desired as well as their height at maturity and aim for a succession of flowers. 


\section{HOW TO PLAN}

33

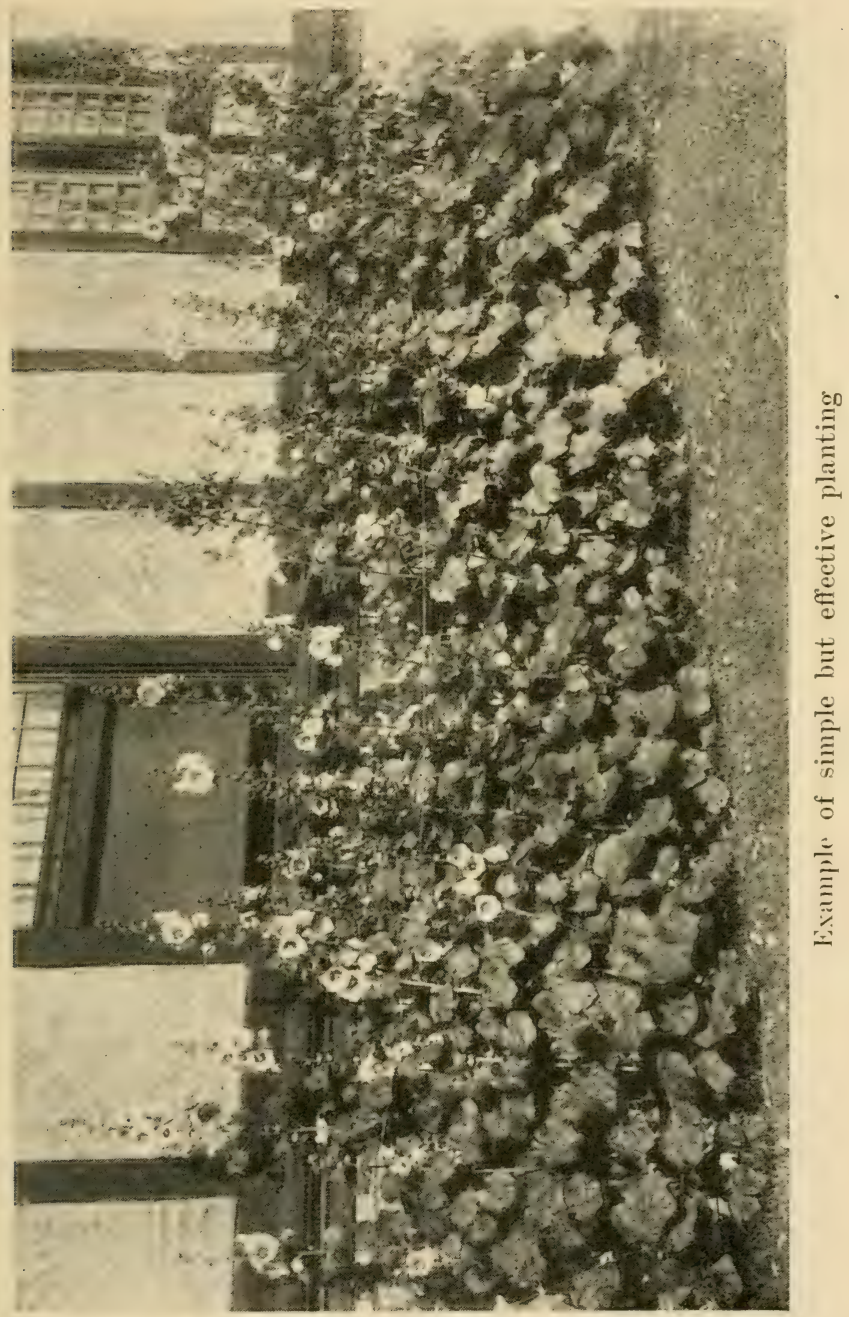


Keep the color of bloom also in mind to avoid color discords.

VIII. Avoid overplanting as well as underplanting. Simplicity rather than ornateness should be the aim. The smaller the area to he planted, the smaller should be the materials employed. Do not attempt too much; consider the space available and do not overload it, reckon the time that can be devoted to gardening and do not overtax it.

IX. Do not establish purposeless walks on small grounds. C'urve or hend no walk without some apparent reason, as, for instance, to avoid an obstacle. Do not make purposeless use of garden ornaments or structures-pergolas, arbors, summer-houses, sun-dials, etc.

X. Plan before you plant, for planting without a plan is as certain to beget er'ror as building a house without the architect's blue-print; and plan to make a picture.

The novice may feel that, if it is necessary to keep these rules in mind, planning is not the simple matter it has heen represented to be. Still, once he begins, he will find that it is prosaic common sense which dictates these principles and that, in no small measure, practical and economical considerations enter into 
their conception. He will find also that he is bound to observe most of them, consciously or unconsciously, in planning even the smallest yard or garden. For instance, it is hardly necessary to caution him against setting dwarf plants behind those of taller growth, and it should be similarly superfluous to advise him to consider color, character and season of bloom. He could not progress far with his planning before questions would arise involving all these points and, at the same time, a majority of the other rules of the ten recited.

\section{PLAN ON PAPER}

So far as the actual work of planning is concerned, it is best begun by obtaining paper ruled to scale or else by ruling paper to use as a substitute. A convenient scale is one where the lines are one-eighth of an inch apart and so ruled horizontally and vertically that oneeighth inch squares are formed. Let each division thus obtained represent a square foot of the yard. If the lot is fifty feet wide, there should be, of course, fifty lines as long in eighths as the lot is long in feet. If, however, the lot is small, larger divisions with the lines farther apart may be employed, or if the grounds are 
too large to make the eighth-inch scale practical, two or three feet instead of one may be allowed to each division.

Carefully indicate on the plan the location of all objects which are to remain permanently, allowing to each the exact amount of space it occupies. If a house is standing on the lot, or a stable, shed or other building, show on the plan the shape and size of each. If a tree is among these permanent objects, indicate not only its location, but also the area of ground sheltered by its spread of branches. Irregularities in the surface of the ground, if they are to remain, should also be clearly outlined.

Make sure that everything designated to remain is necessarily permanent, and, in this connection, once more let the fact he emphasized that in small city yards trees are not always of first importance. It is better in many instances to rid the ground entirely of a half-lifeless, shapeless specimen than to arrange everything else to fit its requirements.

When all ohjects and surface irregularities of a permanent nature have been finally indicated upon the diagram, the planner can turn his attention to the making of his picture. And let him hear in mind that it is a picture he 
is making. It is to be an individual whole, an area separate from other areas, possessing its own character, with every part and feature contributing its value to the homogeneous effect. House and yard are to become a united whole; ornamentation is to harmonize with architecture; there is not to be a house and lot, but a home.

\section{HARMONY OF EFFECT}

Planning with this end in view at once recalls what has already been said of purposeless planting. Do not imagine that it is enough to scatter trees, shrubs and flowers promiscuously over the place, for a yard planted in such a fashion is without central idea and betrays a lack of judgment, care or creative ability on the part of the planter. Nere planting without purpose is almost invariably without value as ornament.

Naturally, on small lots, the residence will be the central figure. Plan, then, to keep it so. Nake it unlikely that any one will remark any individual feature surrounding it or even the house itself-it is the home that is to be remarked. Strive to do for this house what a camera lens does frequently for a landscape. It reduces the importance of prominent or indi- 
vidual objects, it will he remembered, and brings into immediate view in the resultant picture all the details as a whole and, more than this, shuts off extraneous and irrelevant surroundings, which might serve to distract attention. One sees first on the photograph the whole of the picture and later he sees the details.

Plan, therefore, for the whole. This naturally means planning for harmonious effect which, in time, suggests careful consideration of the value of each plant selected in its relation to the whole and not in the light of its own individual value. This is the difficult point for the beginner to master. He reads alluring descriptions of various plants and, forgetting his picture, remembers only these details; he magnifies the part and detracts from the composite. As a result we have not only the scattered planting so often seen but that other barrier to effective ornamentation of the home grounds, senseless specimen-planting.

Opposed to such methods is the mass planting which alone will add character and strength and a sense of unity to the place. Once the ralue of this is grasped the beginner is not likely to go far astray in his planning. He 


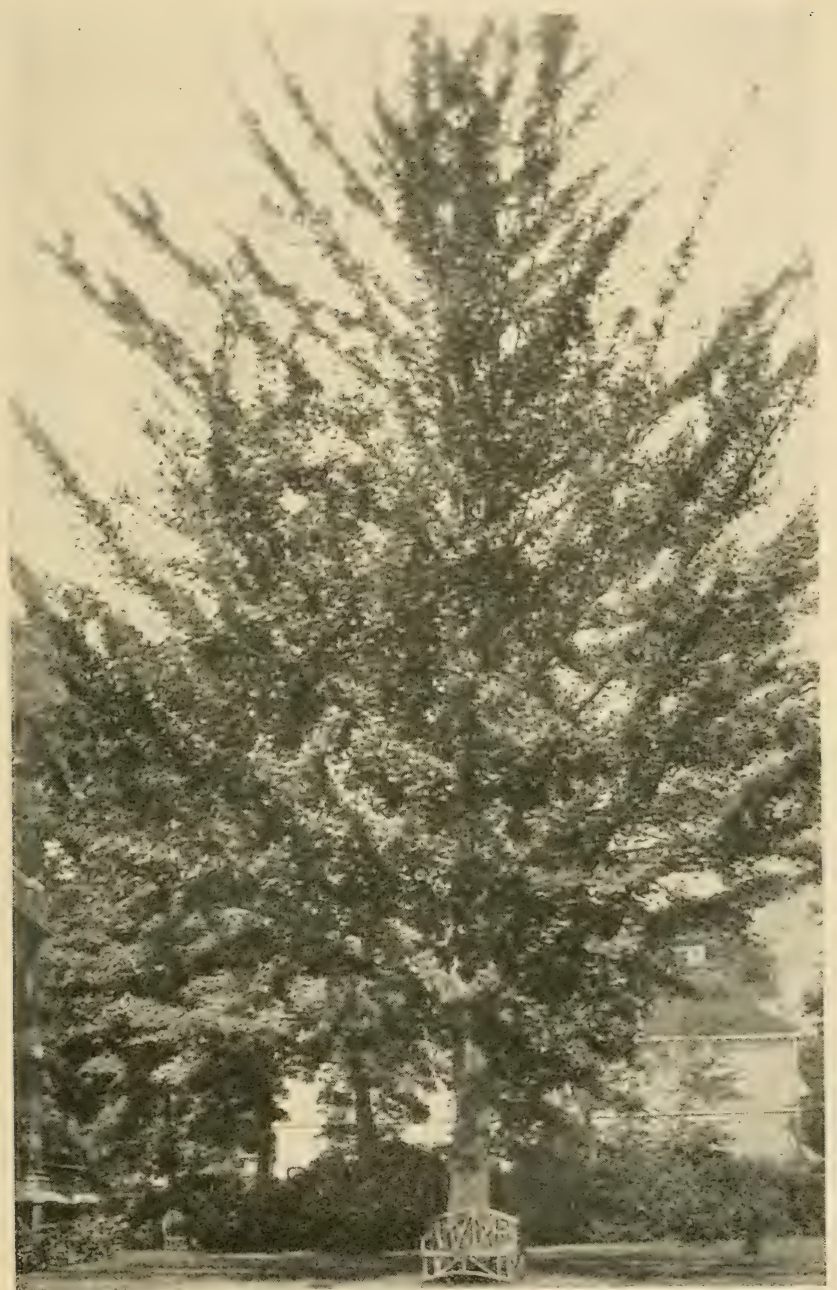

Yard Planting in which Tree is made the Center 
would, for instance, no more think of cutting a geometric flower-bed figure in the center of his lawn than he would think of planting a secretorder emblem of scarlet geraniums and coleus in the heart of a forest landscape. On the contrary the greensward would appeal to him as his canvas upon which, painter-like, he is to produce his picture. He would demand, not isolation for his flowers, but a neighborly background, and an informal border rather than a formal bed in which to grow them.

\section{HEIGHT AND COLOR}

Begin the plan, then, with the yard boundaries. Establish here the backgrounds, and plant from them toward the center. Should a board fence serve as one boundary, vines may be trained over it, converting it into as effective a background as one. could desire. A line of shrubs or of tall-growing perennials could serve as another, a hedge of roses or privet as still another, or indeed, anything of the sort that the planner may desire.

Carefully indicate on the diagram where each is to be planted and the space it is to occupy. Designate each mark set down by a number or letter and, at the bottom of the plan, or on sep- 
arate paper, set down the number or letter and after it the name of the plant it indicates. The number required of each can be readily ascertained by allowing for necessary distance between plants on the plan itself.

The planner will not proceed far with this process before he will find it necessary, for the sake of harmony in height and color, to consider both qualities when he selects the various plants he may desire. He will also be obliged to consider soil and light conditions. He might find, for instance, that what he desires is a hardy perennial attaining a height of twentyfour or thirty inches, whose flower is white, and which will thrive in a heary soil in a situation exposed to the full rays of the sun. If such be his requirement, based upon the idea of the effect as a whole, would it not be manifestly absurd for him to select a plant attaining a height of six inches or six feet, demanding half shade for its welfare and producing a red flower? Yet, absurd as the idea is, this is frequently done and the planter, moreover, wonders why he is not satisfied with the result produced.

So the planner, in selecting his plants, must keep in mind not only the requirements of his 
picture but he must have consideration, too, for the requirements of the materials with which he works. He should remember also that there are five or six months in the year when his yard should be like another room to his residence, and he should strive to provide a succession of bloom. It is inadvisable, however, to sacrifice unity to gain this end. In other words, a succession of bloom is not as important as is the exclusion from the plan of too many varieties of plants.

\section{SLOW PLANNING AND PLANTING}

It is best to proceed slowly with planning and still more slowly with planting. A yard can not be effectively embellished in a season-the picture can not be painted in a summer. It is advisable to plant the boundaries first, setting out the heavier stock, carefully cultivating it until it is well established and comes in turn to suggest to the gardener many opportunities for effective planting against the background it affords. Too often the error is made of planting all at once only to gain as a result an unsatisfactory effect. Rather than encounter the discouragement that such an unfortunate outcome may cause, and to avoid, also, useless 
loss of time, money and labor, it would be far better to postpone some of the planting until the following season. By then a better estimate will be had of the effectiveness of the work already done and a more complete idea may be formed of the planting still to be done.

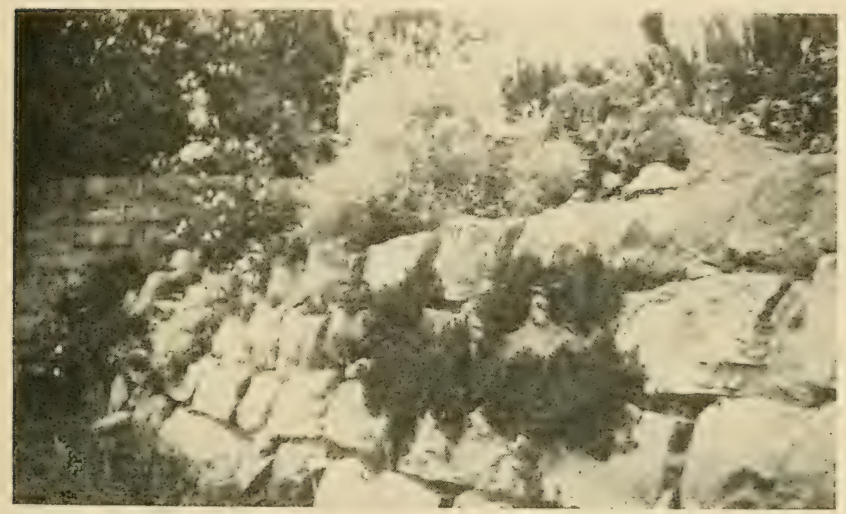

Wall-planting - Result of Careful Planning

This sugerests the advantage of the plan that is carefully drawn and executed. It can be added to from time to time, from season to season, as the picture derelops in the planner's mind, and almays it will serve as a raluable and almost indispensable key to the names of the various plants employed. 


\section{CHAPTER IV}

\section{LAWNS}

Nothing adds more to a city home than a fresh and velvety lawn. Nothing, however, is more seldom seen. Still, if properly planted and tended, good lawns are not difficult to achieve. The chief cause of failure is in permitting hasty turfing immediately upon the completion of building operations.

\section{PREPARATION OF THE SOIL}

No proper consideration is had for soil conditions. It may be that in excavating for the cellar, sand or clay has been thrown upon the old surface soil to a depth of a foot or more. Mixed with this are pieces of hoard and brick, chips of stone, and not infrequently concrete. It should be apparent to any one that turf laid on such soil as this can not succeed, yet in almost three-fourths of the instances where grass "refuses to grow" this is the immediate cause of the trouble. 
To make a good lawn from turf or from seed, the first essential is to give it a foundation of good soil worked to a considerable depth. It is really impossible to get soil too good for a good lawn, and while the cultivation of this soil to a depth of one foot is absolutely necessary, it is far better to work it thoroughly to a depth of two feet. If the ground about the home is good and this good soil runs to a depth of a - foot, the first thing to do is to plow or spade it thoroughly. But if the ground be poor the preliminary step must be its improvement.

When it is considered that the grass of the lawn is a permanent crop, the necessity for thorough cultivation at the start is apparent. Go about this by removing, as far as possible, such soil as offers no encouragement to cultivation and substituting for it soil that is rich and fertile enough to insure a thick heavy crop of grass. The thorough working of all soil which is to be the foundation of the lawn, means first to rid it of foreign substances which are detrimental to plant growth of any sort-split and torn roots, stones, bricks and such rubbish. Then plow or spade, going to a depth of at least one foot, and pulverize the soil by using a spade, hoe or harrow, adding while this last 
process is carried forward, fertilizer in the form of manure.

\section{FERTILIZING AND PLOWING}

Trell-rotted cow manure is the best fertilizer to apply; it imparts humus as well as plant food, and adds something to the ground upon which the plants may feed season after season. It is often advisable to apply also a thin dressing of air-slacked lime, plowing this in or spading it in at the time the ground is first broken, or adding it later after the fertilizer has been thoroughly incorporated with the soil. In getting the soil in condition for turfing or the sowing of seeds, bear in mind always that the lawn, if it is to he successful, must be properly started. Flowers can he planted each season, lifted and transplanted, shrubs can be reset and all with comparatively little bother and little work. But not so with the lawn. If it has to be remade the operation means not only much trouble and much labor but, for a considerable period, an unsightly yard.

If the place to be planted in grass is small, the cultiration, of course, can be more thorough-it can not he too thorough in any event. On larger areas, though, nothing suggested 


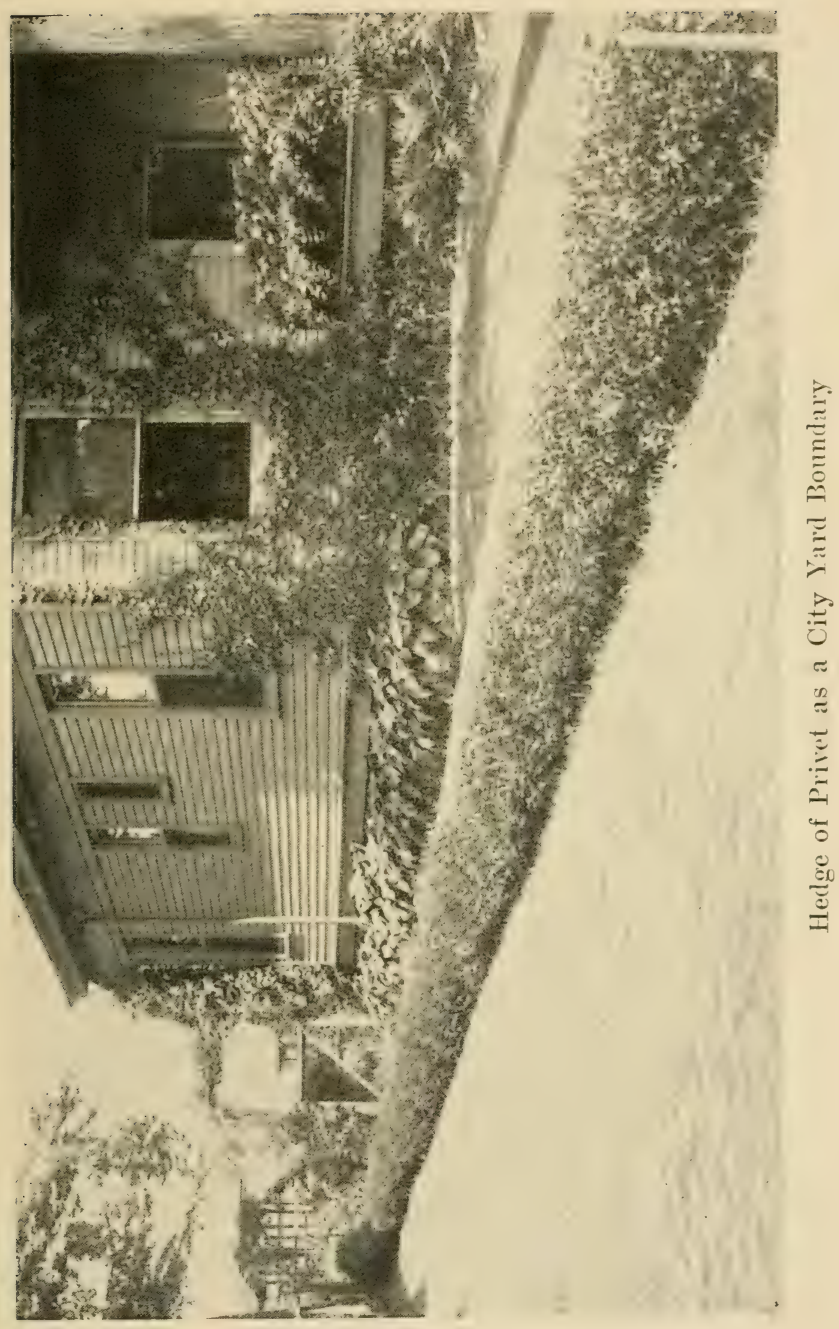


should be overlooked. Plow deeply and harrow thoroughly. If, to begin with, the land appears to be impossible, make every effort to render it as fit as can be while the plowing and harrowing are in progress. If the soil is deficient in humus begin the foundation of the lawn fully a year before it is desired to seed it. Plant a crop of cow peas and in the fall plow it under, adding immediately a dressing of lime. In the early spring following, apply a dressing of wellrotted manure, and plow and harrow again. Make the surface soil fine and level. It is always best to let the ground stand for three or four weeks untouched, so that any weeds may germinate and show themselves and be eradicated by another harrowing.

When the area to be put to lawn is limited, as it is in the case of small city residences, it is necessary, first of all, to determine whether the soil, as it lies, is suitable for a good lawn. If it is not, waste no time with it but have it carted away and good loam substituted. Work this thoroughly and if it is in the fall-the best time to begin lawn-making-top-dress it with manure and let it remain somewhat roughly heaped, that is, without pulverizing or smoothing. The winter's frost and the alternate 
freezing and thatwing will do more to put the soil in excellent condition than a month's spading, hoeing and raking.

\section{TURF}

Once the ground is got into shape, the planter may proceed to estahlish his lawn by one of two methods; he may use turf or seed. The former is probably most frequently employed in cities becanse it gives immediate results. It is quickly laid and quickly establishes itself, and if properly laid, is usually satisfactory, provided, of course, it is well-selected turf, free from weeds or rank grasses that are unsightly and difficult to manage. In laying sod be sure that the edges of the turf are brought closely together and later fill in the spaces that may remain with loose soil. The chief advantage of turf is the fact that it can be laid at any time when the ground can be worked, and if established on such a foundation of cultivated soil as has been described as necessary for either turf or seed, it will grow. But it must he watered persistently and thoroughly and it demands, moreover, much attention during the first year while it is establishing itself.

It is important in making the lawn from turf 
to select the turl arefully. Too often this is intrusted to ignorant laborers who use no judgment but take whatever is closest at hand and easiest to ohtain, regardless of whether it is overgrown with weeds or spotted with undesirable grasses. Once satisfactory turf is obtained, laid evenly and closely and the mions

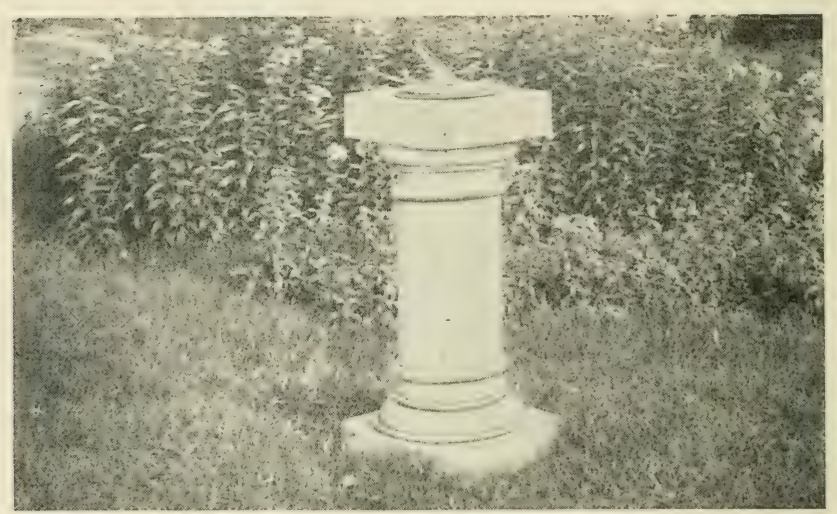

Sun-dial in Corner of City Lawn

are filled with loose earth, it is necessary to beat it. This is essential in order to insure intimate contact with the underlying soil, and if this is not secured the planter of the turf will have gained nothing. The roots will refuse to take hold of the under-soil, and the grass after a few days will die. Watering, of course, will tend 
to prevent any such disaster and may be the means of nursing the turfs to healthful and rigorous growth, but more frequently, if the grasses do not die, they will struggle slowly before they finally show signs of health and vigor.

As a matter of fact, it is almost impossible to obtain really good sod in any quantity. Usually the turfs that are laid are filled with weeds and once the sod is down and established, it is almost impossible to exterminate them. Then it is extremely difficult to prevent patches from failing utterly and leaving bare spots, where new grass is established only with the most painstaking care and persistence. As a general thing a turf lawn can not be established for two or three years and during that time it will almost invariably appear uneven and patchy, lacking uniformity of color and wanting in that freshness and texture which comes from proper seeding alone.

\section{THE SEEDED LAWN}

The seeded lawn established on a foundation of soil properly prepared is usually the most satisfactory lawn in the long run. Prepare the seed bed-after working the soil as already out- 
lined-by finely pulverizing the surface and making the top soil perfectly smooth. It should, of course, be freed from all rubbish, such as roots, stones and the like. Sow the seed in April or May or in September. In the South, however, seeding can be done in February and November. If the spring is selected sow the seed as soon as the ground can be got into fit condition. Broadcast the seed. Distribute it evenly over the entire surface of the ground and at the rate of not less than four bushels to the acre-five would be better. For smaller areas use at least one quart of seed to every 300 square feet. In England, noted for its fine velvety lawns, 11/. cwt. is used per acre and one pound per square rod.

It is hardly necessary to suggest that a day should be selected for the sorwing that is quiet, for wind will bear the fine seed away and half of it will be wasted, while an even distribution will be practically impossible. Then sowing keep the hand close to the ground and swing the arm freely, taking care to scatter the seed thoroughly, not allowing it to bunch. Do not hesitate to sow thickly. Thick sowing is an advantage in more ways than one. In the first place it prevents reeds from getting a firm foothold, 
for they are crowded out by the grass seedlings, and in the second place it insures a finer grass leaf which in turn means a "velvety" lawn. Usually it is advisable to go over the ground twice. The first time sow from east to west and the second time from north to south. After the seed has been broadcasted, rake or harrow lightly the entire area so that the seeds are covered very thinly. Follow this hy rolling and if you desire the best results never omit this finishing process; it firms the ground and insures germination of the seed, while it gives the seedlings a firm foot-hold when they send their roots forth in quest of food.

\section{SEED FORMUL $\mathbb{E}$}

Buy good seed. This is an economy and an essential for good lawns. The well-known Kentucky blue-grass is the best of all for the lawn. It is not difficult to grow; indeed, where it refuses to grow, soil conditions are such that no permanent grass will thrive. Kentucky blue combines more desirable qualities, probably, than any other grass, and on this account it should be made the foundation and principal ingredient of any mixture that is applied. The other ingredients of the mixture are important 
for various reasons. Chief among these is the fact that Kentucky blue-grass does not germinate quickly; if it is planted in the fall, for instance, there will be no results until the next spring, and if sown in the spring it will be some time before it makes even a light covering for the soil.

Various formulæ are offered by dealers in seeds, and where the dealer is known to be reliable and is willing to furnish the purchaser with an analysis of his mixture, it is safe to purchase it and probably the best thing, all circumstances considered, to do. But be sure in any event that the Kentucky blue-grass which should form the bulk of the mixture is "recleaned fancy,', and do not accept any seed that weighs less than twenty pounds to the bushel. The object of the mixture is to insure immediate results from the sowing while the bluegrass is germinating, but incidentally the extra grasses mixed with the blue-grass serve additional purposes. In the first place mixtures result in a denser turf because grasses thrive better when grown in variety. Then, too, the Kentucky blue-grass has some undesirable features and it is these that the other seeds in the mixture will correct. The Kentucky blue, for 
instance, does not carpet the ground as closely as other varieties and when mowed shows patches of soil and brown.

The best formula for general purposes is as follows :

Kentucky blue-grass................. 10 lbs.

Rhode Island bent................... 3 lbs.

English rye.......................... 3 lbs.

Fancy redtop........................ 4 lbs.

In any event this can be used as a basic mixture and by substituting various grasses suited to various situations for a portion of the Kentucky blue-grass, the mixture will be found generally effective.

Other mixtures are as follows:

\section{FOR SHADED SPOTS}

Poa pratensis (Kentucky blue) ................ 40\%

Poa nemoralis (wood-meadow grass) ............ 40\%

Cynosurus eristatus (crested dog's-tail).......... 15\%

Festuca heterophylla (various-leaved fescue)......... $5 \%$

FOR SANDY SOILS

Poa pratensis (Kentucky blue).............. 20\%

Agrostis canina (Rhode Island bent) ............. $35 \%$

Agrostis alba, var. stolonifera (creeping bent) ....... $35 \%$

Festuca ovina (sheep's fescue) ................. 10\%

FOR CLAY SOILS

Poa pratensis (Kentucky blue).............. $45 \%$

Agrostis alba, var. vulgaris (Redtop) ............ $35 \%$

Lolium perenne, var. tenue (fine-leaved English rye) .... $20 \%$

\section{FOR SLOPES AND TERRACES}

Poa pratensis (Kentucky blue)............... 15\%

Agrostis alba, var. stolonifera (creeping bent) ....... $35 \%$

Cynosurus cristatus (erested dog's-tail) ........... $30 \%$

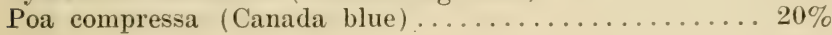




\section{FEEDING THE GRASS}

When a lawn is properly treated in the preliminary stages and manure is incorporated with the soil as it is spaded or plowed and raked or harrowed, little need be done in the way of feeding the grass for six or seven years, but where the soil is thin or the lawn has been established for some time fertilizer of some sort is necessary. It should be remembered that the grass is feeding continuously and exhausting the plant food of the soil. What it is taking from the soil is not given back in any degree, because the grass is mowed and the mowings carted away. Then, too, it should be rememhered that grass is a permanent crop and it is impossible, once it is established, to assist it by the cultivation which it is possible to give to other crops, whether they be flowers or vegetables.

Fertility can be added by spreading orer the surface a dressing of organic manure. Use cow manure if it is possible to obtain it and place it on the lawn after the ground is frozen - this prevents the cutting of wheels of the cart or wheelharrow into the sod. Be sure that the manure used is well rotted, that it is old. 


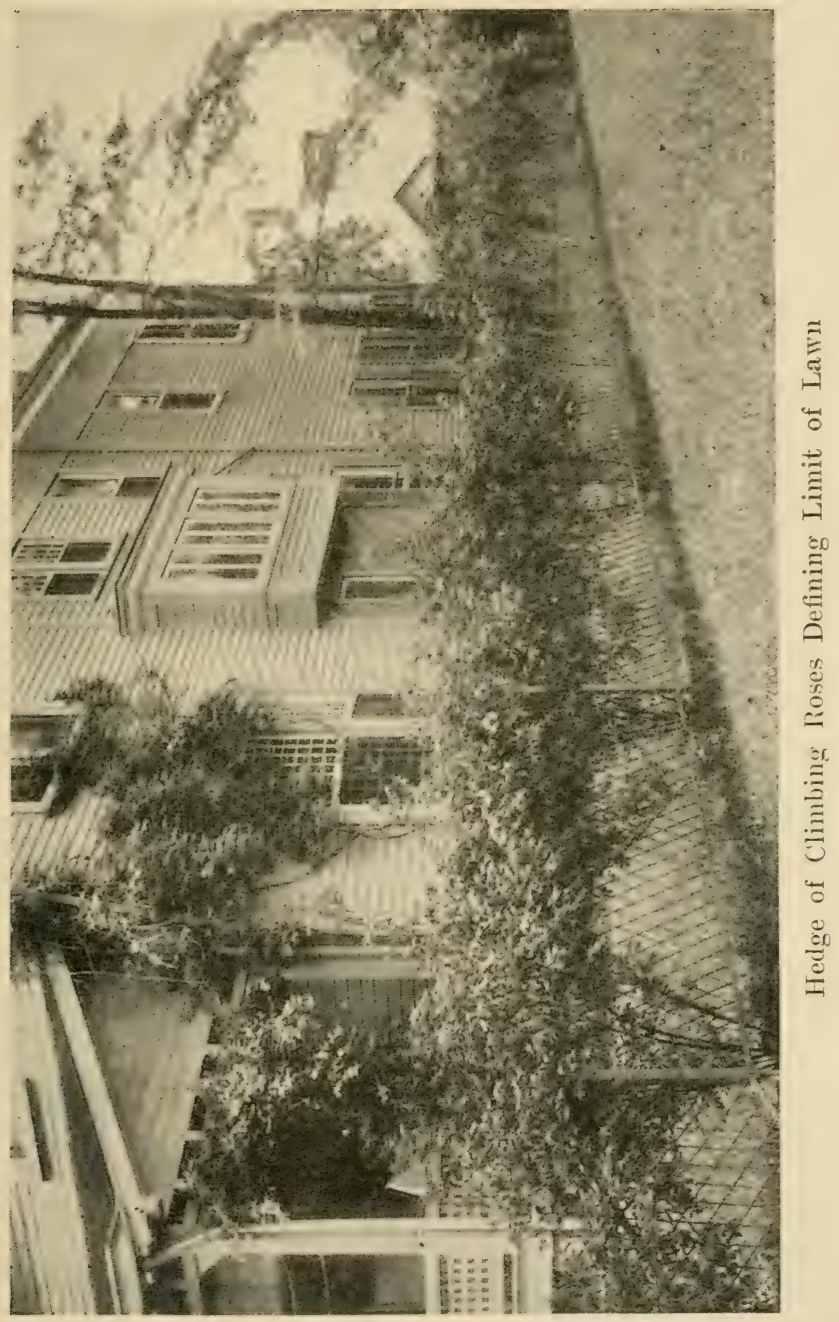


Fresh manure is not only damaging to the grass but is almost certain to be filled with minute seeds of various weeds. Let the manure remain until early spring and a double benefit will be derived from the dressing. It will not only impart plant food to the soil, but it will serve as an effective mulch which will to a great extent overcome the injury caused by the alternate thawing and freezing during the winter. When the grass shows a vigorous growth in the spring, rake the coarser material from the lawn and follow this by rolling.

In the spring it is best to top-dress the lawn with an application of finely ground bone meal mixed with hard-wood ashes. Combine the mixture by using equal parts of each by weight, and spread the fertilizer on the lawn until it takes upon itself a grayish appearance, or to be more exact at the rate of one ton to the acre. It is best to select a day for applying this top dressing that is still and promises a light rain. Another fertilizer that has a beneficial effect on lawns is nitrate of soda. Apply this at the rate of one ounce to the square yard, and make sure, if it is applied in dry form, that it is broadcasted immediately preceding a shower. It is perhaps best to apply this to the lawn by dis- 
solving it in water, using one pint to forty gallons of water. The effect of nitrate of soda will be observed almost immediately; the grass will take on a fresher color, a deeper, richer green, and will make vigorous growth. Hardwood ashes, however, are especially valuable as food for lawns of Kentucky blue-grass. Bone meal is one of the most permanent fertilizers, and is chiefly valuable, so far as grasses are concerned, for its phosphates. Lime used on the lawn should be air-slacked; it is best as a winter dressing, and should be applied at the rate of a pint cup full to the square yard.

\section{ROLLING THE LAWN}

The application of fertilizer is by no means the only thing necessary to maintain a lawn in good condition. The turf must be rolled and the grass mowed and watered. Some indication of the value of rolling has already been given in this chapter. It is important and should never be neglected where the best results are sought. The rolling is necessary in order to make the roots as firm as possible and should be applied frequently. The heavier the roller the better it is for the lawn. In the spring as soon as the ground becomes work- 
able and the grass starts into growing, the entire surface of the lawn should be rolled to overcome the effects of the alternate freezing and thawing during the winter months, which has a tendency to loosen the surface soil. It will be readily observed that the heavier the soil and the more moist it is the more necessity there is for rolling. In using the roller it is best to roll in two directions at least, as was suggested for broadcasting the seed-that is, from north to south and from east to west. In selecting the roller obtain one that will represent a weight of a thousand pounds at least. Very frequently it will be found that old lawns which appear to be beyond the power of cultivation to bring back into condition, require nothing more than repeated applications of the roller, and in the case of new lawns very poor and disappointing results will follow the failure of the planter to make use of this essential lawn device.

\section{MOWING}

No lawn can be kept in good condition unless it is frequently moved. The best method to follow in cutting the grass is to mow it once a week with the knives of the machine set high. 


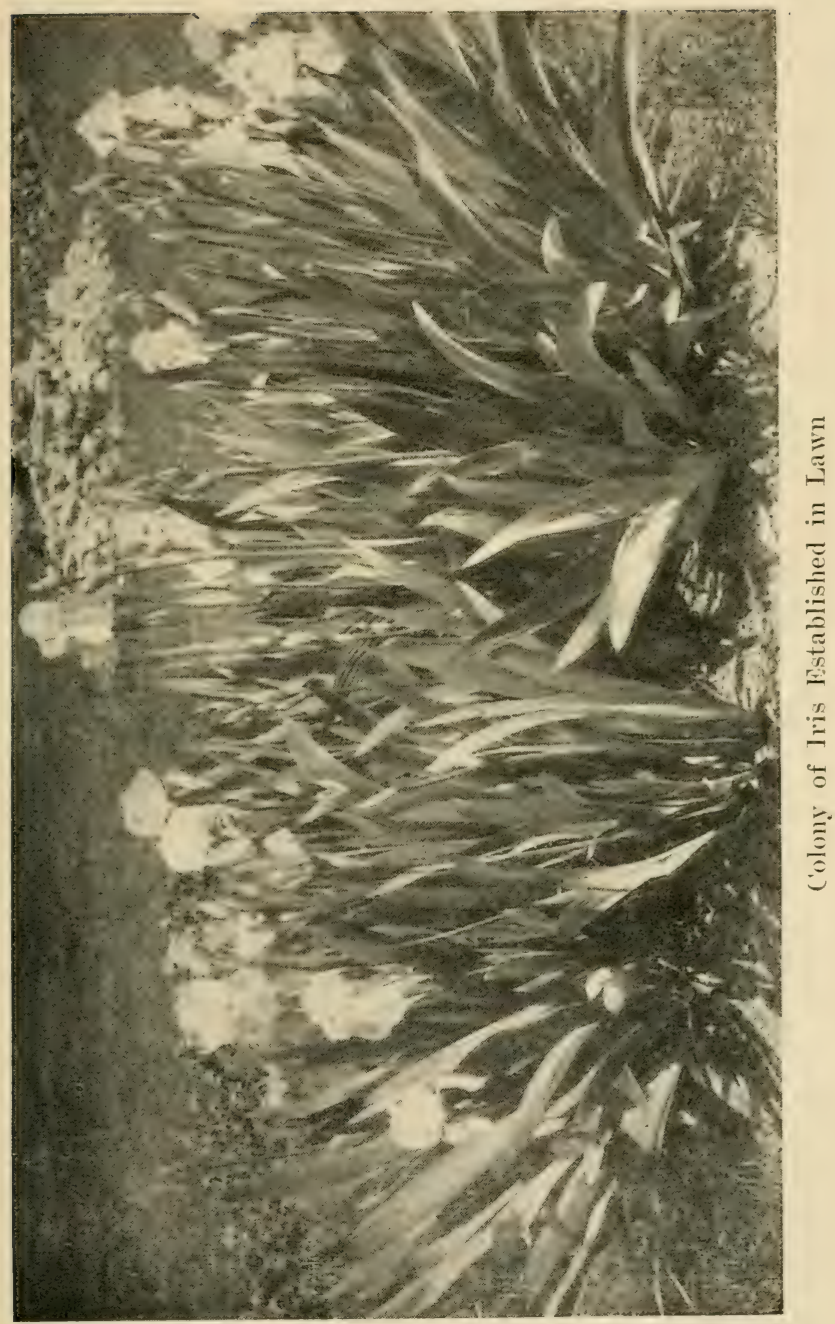


This is much better than mowing it at intervals of two weeks with the knives set low. Still it must not be considered that any regular interval can be designated for the mowing process; conditions must govern the cutting. If the growth is rapid, mowing may be necessary oftener than once a week, but where the lawn can be gone over with the machine at least once every six or seven days, the knives on the mower should not be set closer than two inches to the ground. In cases where the grass has been allowed to get unusually long, the knives should be set even higher for the first two or three mowings and then brought gradually lower until the proper distance from the ground is obtained.

It is often a question whether the clippings resulting from the use of the mower should be left on the lawn or removed. If, however, the lawn is mowed frequently and the grass is kept at a uniform height of about two inches the clippings if left on the lawn will do no harm, but, on the contrary, very often will prove a benefit inasmuch as they will act, in some degree at least, as mulch and protect the roots, especially in the early spring, from the scorching rays of the sun. But if the grass has been 
allowed to gain a considerable growth, it will be positively detrimental to permit the clippings to remain. This is especially true where the soil is inclined to be heavy and the moisture it contains is not quickly given off. In such instances the cut grass hanging closely about the roots and there rotting will be the cause of not a little subsequent trouble. On lighter soils there is less danger from leaving the clippings on the lawn, and in some instances it is even better to do so.

Grass that is cut on dull cloudy days will be found to yield itself more readily to the knives of the mower, and in addition to this will show less disposition to resent even close mowing than when a bright hot day is selected for the operation.

\section{WATERING}

It is a fallacy to proceed with the watering of a lawn on the basis that it is not good for the grass to wet it while the sun is shining. If watering is done as it should be it will make very little difference whether the day is bright . or cloudy. Mere sprinkling is detrimental in any event and is to be aroided, especially on bright days. This method of "watering" a 
lawn is undoubtedly the cause of much of the trouble experienced in obtaining the best results where conditions would seem to indicate that they should be easily attained. Instead of playing a thin mist-like spray over the lawn, see to it that the ground is soaked; in other words, when you do water, water well. Apply enough so that the water will soak in the ground, saturating it for a depth of two or three inches at least. Remember that the roots of grasses as well as of other plants seek moisture where it is to be found. If you persist in lightly sprinkling your lawn the roots, instead of penetrating to the cooler depths, will persist in remaining on the surface, where they soon hecome dry and baked by the sum. If, on the other hand, the roots find what they require at a depth of six or eight inches or a foot below the surface of the soil, they will make a growth in that direction to obtain it.

In most cities, unfortunately, there are regulations maintained by companies supplying water making it practically impossible to water a lawn as it should be watered. These regulations prohihit the use of a hose without the nozzle, and this in itself is a positive handicap for the owner of rity property who is anxious 


\section{LAWNS}

6.5

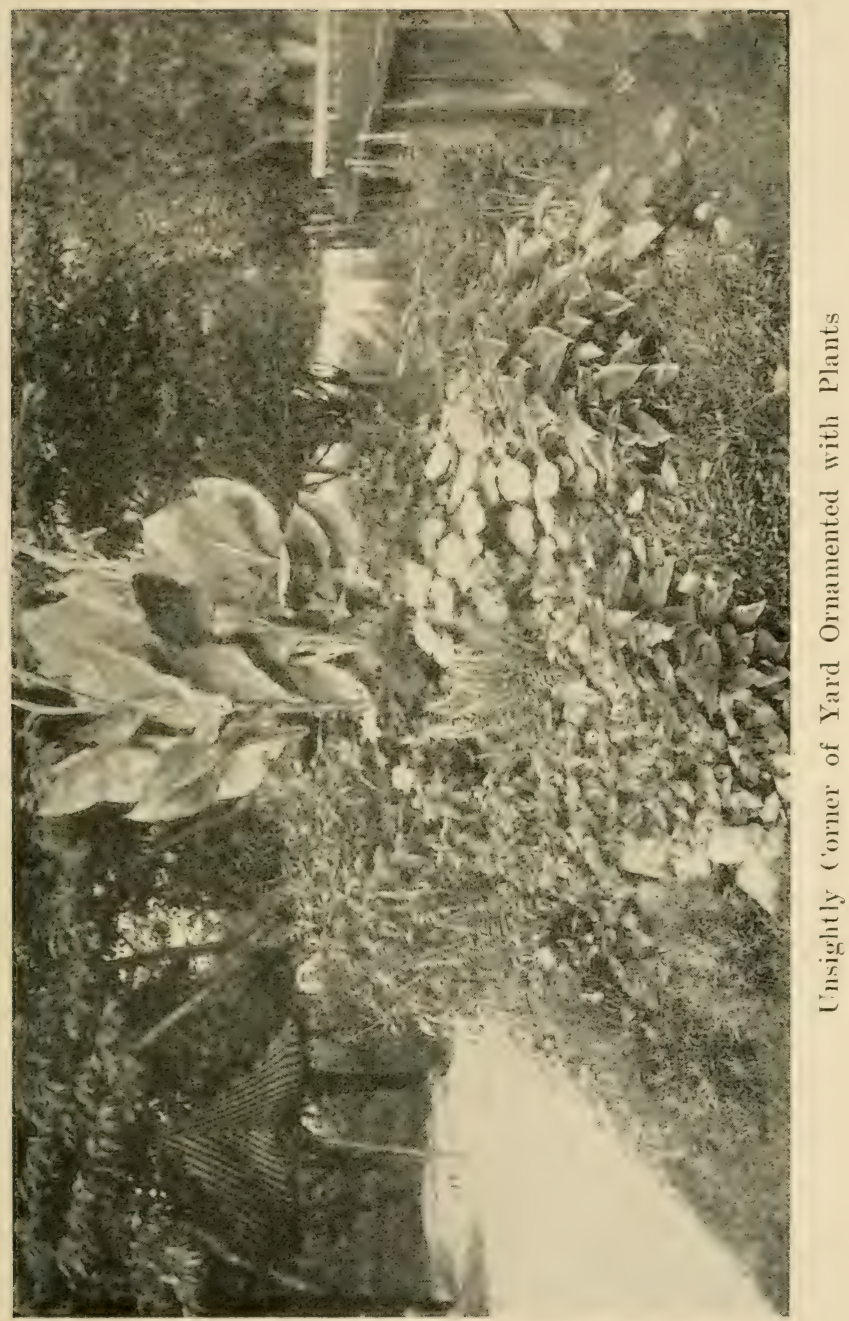


to obtain a soft and velvety lawn. Where, however, regulations do not interfere, it is best to water without a nozzle, letting the water emerge unchecked from the hose and with the force of the stream so regulated that it will not wear holes in the turf. Let the end of the hose rest on the grass and as the ground becomes saturated with the water move it about from place to place until the whole area is thoroughly wet. Watering in this manner can be carried on at any time of the day whether the sun is bright or clouded.

\section{WEEDS}

The weed problem is one not so easily disposed of. Frequently a splendid lawn is ruined in a comparatively short time by allowing the weeds to gain a foothold, and permitting them to spread. Guard against any such catastrophe by keeping ahead of the pests. Remember that where a lawn is well kept, planted on a foundation of suitable soil, weeds will have a difficult time to establish themselves. Be sure each time the lawn is mowed to look carefully for the weeds. It is best always to dig out the dandelions and plantains before the mower is run over them. 


\section{LAWNS}

Occasionally an effort is made to save a lawn that is overrun by these reeds, and the perplexed owner seeks for some solution which, when applied, will kill the objectionable intruder's and do no harm to the grass. Let him understand now, once for all, that the only sure and safe method of eradication is by removing the weeds, root and all, by digging them out with hand tools. No other method will relieve the turf of dandelions, plantain or dock. Mowing does not kill them nor does cutting them off an inch or two below the surface of the soil. Both dandelions and plantains seed very rapidly and multiply at an enormous rate. They must not, therefore, be allowed to come to seed. Remove them or such of them as can be reached by the use of some tool, and if all the root, by this process, is not obtained, drop a crystal of sulphate of iron in the hole made by the operation and this, dissolving, will kill the root remaining. A drop or two of gasoline, if more convenient, can be used in place of the green vitriol. It is better, however, to get out the root in its entirety, than to rely on this or any other chemical of strong corrosive powers, which, in deadening the weed root, may also injure the grass. Have at hand a box of loose 
soil and, if necessary, when the root is removed, fill up the hole and firm the soil so that the damage done is immediately repaired.

\section{WEED GRASSES}

Crab-grass is probably the worst and most objectionable weed that attacks lawns. It holds itself so close to the surface of the soil that the blades of the mower very seldom reach it, and, though it is an annual, it resows itself year after year and appears in early August to render almost unsightly any lawn where it has gained a foothold, no matter how persistently the lawn may be tended. It has broad, pale green leares, and gives a patchy appearance to the general surface of the yard wherein it shows itself. When cold weather approaches, the crab-grass assumes a dead brownish-red color, and lends to the whole area a rusty appearance which very often leads the cultivator to believe that his grass is parched for lack of water. But no amount of watering will overcome the unsightly appearance oceasioned by the presence of crab-grass. Only one method of eradicating this pest is effective and this is one which is more troublesome than expensive. Obtain a steel rake with sharp pointed teeth, and 
by means of this tear up the (reepring stems of the weed, lifting them clear from the soil and with a lawn-mower-after setting the knives very low-run over the grass, cutting off the flowering heads of the intruder to prevent its seeding itself.

If this operation is performed persistently for one or two seasons it is possible that the crab-grass can be eliminated. It is, as already said, an annual and, of course, is killed by the first heary frost. If by the process outlined it is prevented from seeding itself, it is likely that the lawn will subsequently be free of it, but it must be remembered that it is utterly futile to run the mower over the grass without first destroying the hold of the creeping stems on the surface soil and lifting them within the reach of the blades of the machine.

Other weed grasses which prove annoying are the well-known orchard grass and Bermuda grass and occasionally timothy. The Bermuda grass is chiefly objectionable because it is discolored by the first touch of frost and leaves the lawn that it has invaded with brown patches on its surface which continue to be unsightly until winter's snow spreads a concealing mantle orer the surface. In the South, 


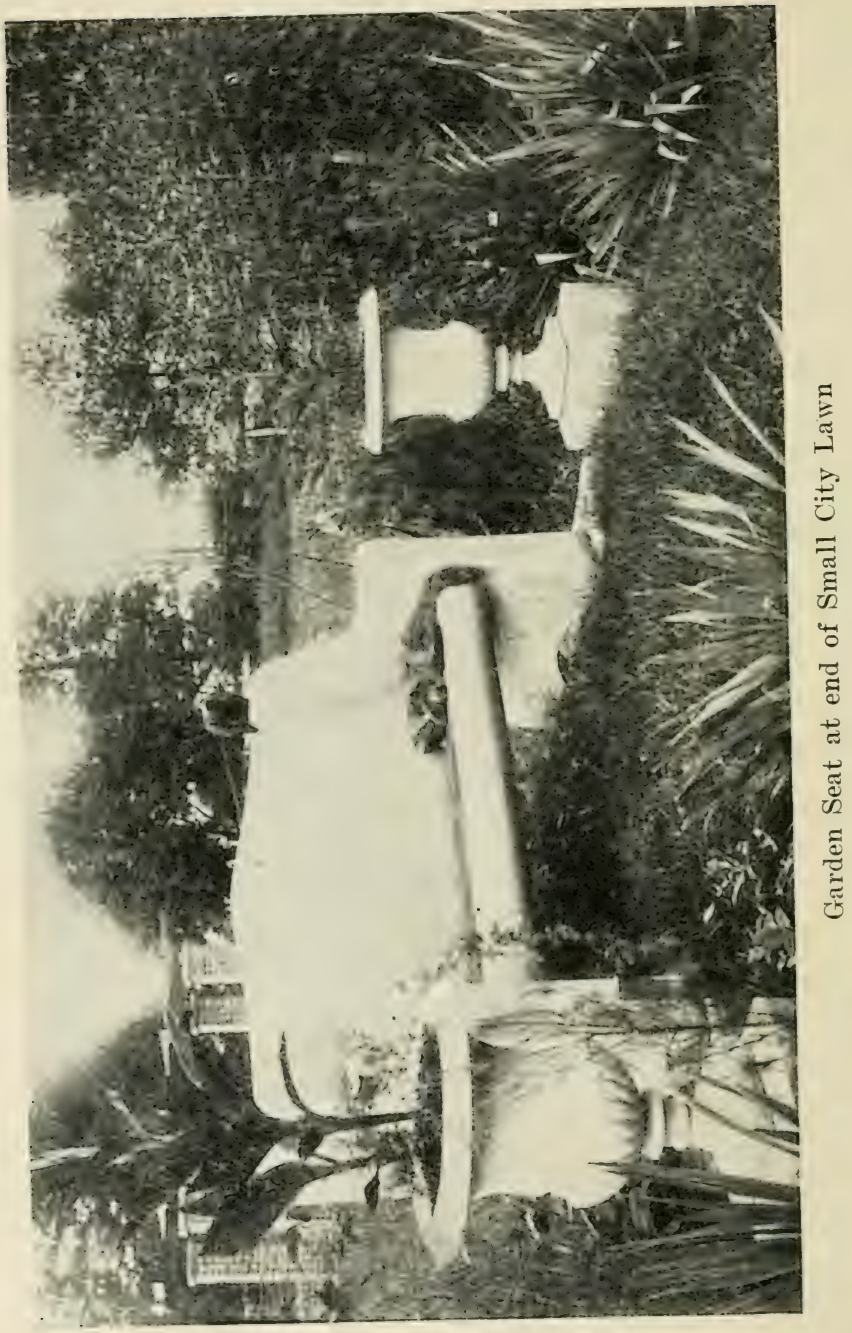


Bermuda grass is not objectionable, but, on the contrary, is really the main dependence of those desiring good lawns where the soil is light and sandy. But wherever orchard grass or timothy make their appearance they should be immediately dug up, and if this process involves the rendering of the surface uneven, fill in with soil as already advised and scatter lawn grass seed on its surface.

\section{INSECTS AND MOLES}

Ants are the most serious of the minor insects that infest lawns, and though they do not directly attack the grasses themselves they do no end of injury by loosening the soil and tunneling under the roots. Usually the pests are killed by the application of boiling water, but, as this means a subsequent resowing of seed, it is best to proceed against them by a method at once simple and effective. Use bi-sulphite of carbon; it is a heavy volatile liquid which sinks quickly into the opening in the ant-hill and immediately gives forth fumes which, being heavier than the air, penetrate at once to the remotest sections of the runs in the home. Apply it by pouring into a hill of average size a tablespoonful of the liquid and laying over 
the opening a damp cloth or some substitute that will serve to prevent the insects from escaping. In purchasing the bi-sulphite of carbon remember, if your druggist does not warn you, that it is highly inflammable and easily exploded; keep it away from the neighborhood of an open fire. It can be used as effectively in fighting other burrowing and tunneling insects as in the eradication of ants.

The mole, while not often appearing in cities, is frequently the cause of considerable trouble to the suburban and country resident. In the course of a night or two a very few of these animals, once they start their tunneling process on a lawn, can cause damage that is not likely to be repaired in the comrse of a month or' so. They seldom appear', however, where the roller is properly used, for they prefer to follow the line of least resistance and will betake themselves to sections of the ground less forbidding if the roller has packed the soil as it should. Poisoned bait is sometimes used in ridding a lawn area of these animals, but as the mole is carnivorous, avoid applying the poison in the form of grain. Poison in any event is dangerous, for it may be eaten by household pets or poultry instead of by the 
animals for which it is intended. Mole traps are the safest and surest derices for ridding the lawn of the intruders.

\section{RENOVATING OLD LAWNS}

Old lawns are quite as often problems as new lawns. There one person is inquiring how he may establish a close soft turf for his yard, nine are asking what to do to renovate their old lawns. In many instances renovation is impossible and where such is the case the only sure method to pursue is to proceed as though no lawn had ever existed on the area under consideration. In short, renovate the old lawn by plowing it up and planting a new one. It is not meant, of course, to advise any one to proceed on such a radical course without due thought, but to wain him against wasting time and energy in mork that will poorly reward him in the end. When a lawn is overrun by weeds -dandelions, plantains, docks or weed grasses - and it appears that the eradication of these will practically destroy the lawn surface, it is best to begin by using at once the spade or the plow.

But if the grass is not attacked by these weeds and the soil appears to he in a good state 
of cultivation and of a proper depth, it is probable that the problem can be solved by loosening the surface soil with a steel rake and sowing seed. Seed-sowing, however, will avail nothing if the lawn owes its deterioration to an exhaustion of the plant food in the soil. Nor will the application of fertilizer help; mere dressings of bone meal or barnyard manure, no matter how abundant, will not serve the purpose. It is cheaper and quicker to put the soil in "good heart" by submitting it to such treatment as would be meted out to virgin ground. 


\section{CHAPTER V}

VINES

No plants lend themselves more gracefully to the improvement of the small city yard than vines. With these, most remarkable and surprising effects can be attained with little expense and little care. Wherever they are grown they add beauty to the scene, acting as harmonizing agents, relieving the general effect of any appearance of stiffness or formality. Beautiful and graceful in themselves, they conceal all the unsightly places and objects and obliterate all the harsh outlines or the straight lines which are nature's abhorrence. They convert into a thing of beauty a dilapidated fence, turn a stone into a veritable mound of foliage, twist and twine themselves about a dead tree and make of it a pillar of leaf and flower, or, hanging in festoons from porch or window boxes, they produce a picture 
that varies in its form and charm with every vagrant breeze of a summer's day. Trained over arches, gates, or pergolas, they shed a grateful shade and afford some shelter from sudden showers.

\section{EFFECTIVENESS OF VINES}

Much of the picturesqueness of the old ruins of European castles owes its existence to the kindly offices of the vines grown to their walls. They mellow the defects and impart an atmosphere of age and permanency, and always the dense green of their foliage is a relief to the eres in summer and soothing to tired and discordant nerves. They will grow very frequently where other plants will not thrive and, once gaining a foothold, they may thrust their stems even to the highest point of a brick wall of some city office building. Here, clinging to the masomry, they weather erery storm, resist the burning rays of the sun and transform the building as neither carpenter nor painter can do. Whether they are grown on the walls and terraces of the mansion or on the limited grounds of the cottage they nerer fail to produce an effective picture. Noreover, with their dense green foliage as a hackground, the artis- 
tic planter can work wonder's with flowers and shrubs which otherwise might prove too bizarre for use in small yards.

Indeed, the owner of a city lot who is intent upon its ornamentation can do no better than to start upon his work with the planting of vines. Before he finally determines to remove some object which he considers an eyesore, let him first consider whether a vine would not only conceal the ohject but convert it into something to be desired as an acquisition in his general plan of operations.

Vines are cheap and easily obtained. They are to be had wherever a wood is to be found, or, lacking such natural nursery, they quickly respond to the treatment which even an inexperienced amateur can afford them, as they root readily from cuttings, or "slips." They can also be grown from seed, all the annuals being obtained by this method almost exclusively and many of the perennials doing almost equally as well when similarly treated.

\section{CLASSIFICATION OF VINES}

Vines mar be roughly divided into twiners, leaf-twisters, tendril-bearers, those with aërial roots and those which gain support by means 
of prickles or hooks and which usually require tying to a trellis or support of some sort. The morning-glories are familiar examples of the first, the clematis of the second, the grape of the third, the ivy of the fourth and the climbing, or to be more exact, the scrambling rose of the fifth.

The larger number of the climbing plants that are cultivated, are those which make their ascent by twining about their supports or employing special organs in the form of roots or tendrils with which to effect their rise. It is interesting to note that each species of twining plant winds in its own direction about its support, following this course under all normal or ordinary conditions. The morning-glories, for instance, twine in a direction which is opposed to the movement of the sun, while the hops prefer a course which is in the direction of the sun's movement.

With this rough classification as a basis a long list of climbing plants suitable for cultivation on the home grounds might be given. All are well equipped in foliage, flower or berry, suitable for use in the city yard. And of these there are varieties for almost every situation and every purpose. There are annu- 


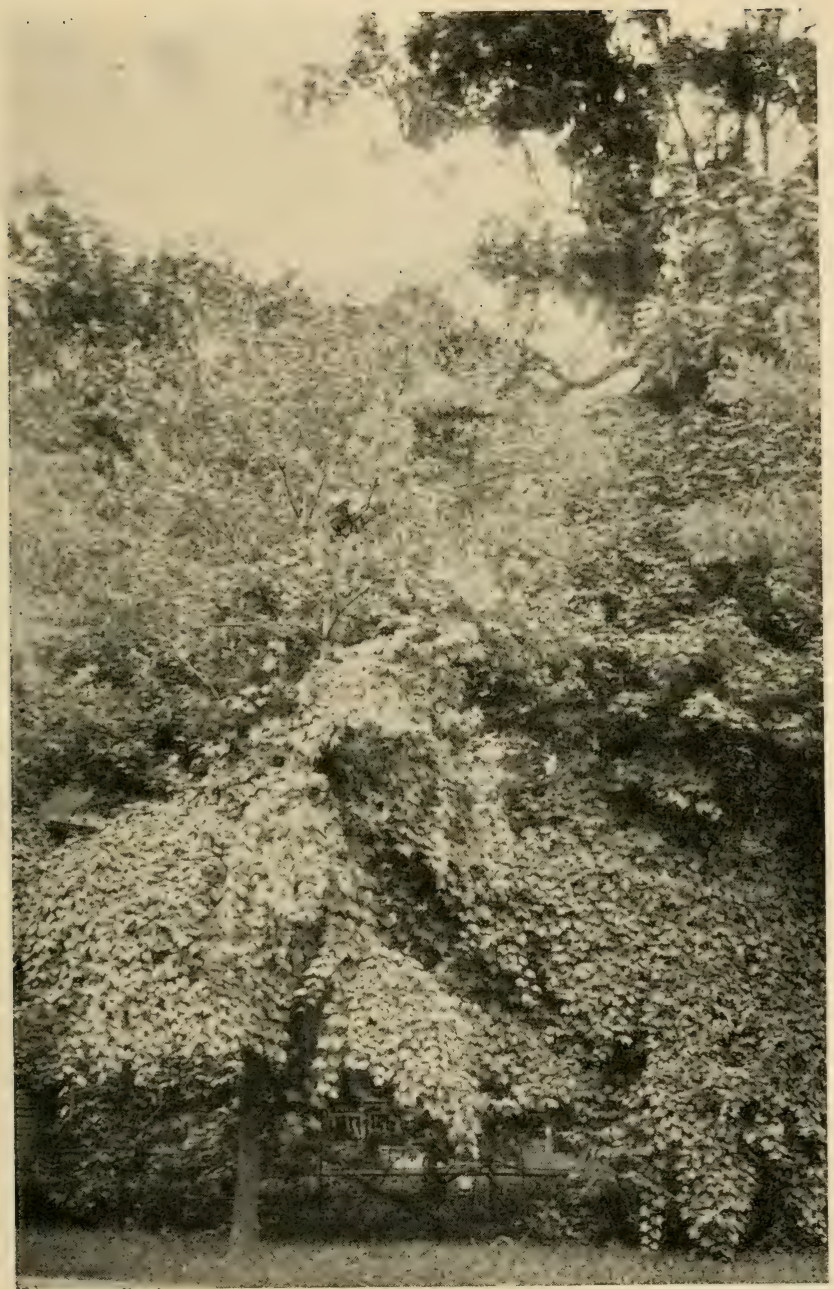

Wild Grape From Woods in City Yard 
als and peremnials-those which spring from seed and make their full growth and flower in a season's time, then perish with the first touch of frost, and those which persist year after year, either coming up from the root each spring or putting forth their leaves and flowers from the old stems.

In most instances where permanent effects are desired the hardy perennial vines should be selected. Many of these are known as shrubs by those who insist on an exact terminology, the body of the plant being woody and enduring year after year. Others are herbs dying to the ground each fall, the root alone subsisting from season to season. The chief value of these is their foliage, for of this the amateur can always feel assured, though there are, of course, many vines which bear flowers, but which, owing to the conditions un!cr which they are raised, frequently fail to produce blossoms.

The annuals are valuable as a rule for both their foliage and flowers. The morning-glory, which has already been used as an illustration, is an example. The annual vines are best adapted for quick concealment of unsightly objects and the most of them make rapid growth 
which soon rovers alleh, trellis, or support of whatever nature it may be.

\section{SOIL FOR VINES}

Thhile it has been suggested that the common peremial and annual vines are not exacting as to the conditions demanded for their health. still it is a fact that their requirements and culture are too often given but small consideration hy the planter. They are fresuently set out when preparation has been meager, established in poor soil sometimes made up largely of rubbish or of earth from which all the food has been extracted by other plants. Still, even under such conditions, vines struggle into leaf and occasionally into flower, but it should be remembered that it is futile to expect a free and luxuriant growth-which is a vine's chief charm-where the plants are neglected, or perhaps actually abused. It is common to observe a plant obtained from a florist or nurseryman turned out from a pot into a hole barely large enough to receive the ball of earth and dug in ground which has not been prepared by cultivation of any sort for the reception of the roots. Naturally such treatment will not lend encouragement to the hest and healthiest 
growth of the vine. It is far better to make too much preparation than to starve plants by too little. The ideal method to pursue, whether the vines be annuals or perennials, is to trench the ground thoroughly where they are to go, either working well-rotted manure into the old compost or filling in with a rich, fresh, friable loam.

Good sound loam is the best soil for the greatest number of climbing plants and, unless the amateur is experienced with varieties which are difficult to grow, he will find that this soil, with the addition of manure, will insure him excellent results. Where soils are stiff they can frequently be put into good condition by the addition of leaf mold, some sand and the manure, and where the soils are thin or sandy the addition of loam together with the manure will often prove effective.

\section{CULTIVATION}

If plants are ordered from a nursery and are received in pots, they may be planted out at almost any season between early spring and late autumn. In planting those that have been grown in pots, they should be turned out gently, disturbing as little as possible the root ball. 
Nake sure that the hole prepared for the reception of the plant is ample and that the roots when they begin to reach out into the new soil will not encounter obstacles in the form of. stones or unyielding clods to impede their progress and stunt the plant by starvation. It is usually best after planting to make the soil firm and solid. Then see to it at once that the plants have something upon which to lift themselves until they fasten by the natural means they employ to the permanent support upon which they are to climb upward. When vines require tying, the operation should begin immediately, even though the stem to be operated upon may be exceedingly short. It may perhaps be of some service to suggest that where vines are to be established in soil already crowded with the roots of trees or shrubs, a bottomless wooden cask or box may be sunk and this in turn filled with a suitable compost which will enable the climber to make sufficient root growth to support itself until it has gained strength and can hold its own with the other roots.

While it is important to give consideration to the proper preparation of the soil where the climber is to be planted, it must not be 
forgotten that it will respond generously to good treatment accorded after it has established itself. Only too frequently vigorous vines display signs of failure and decrepitude because their roots fail to find food enough to supply them with sustenance. Such plants

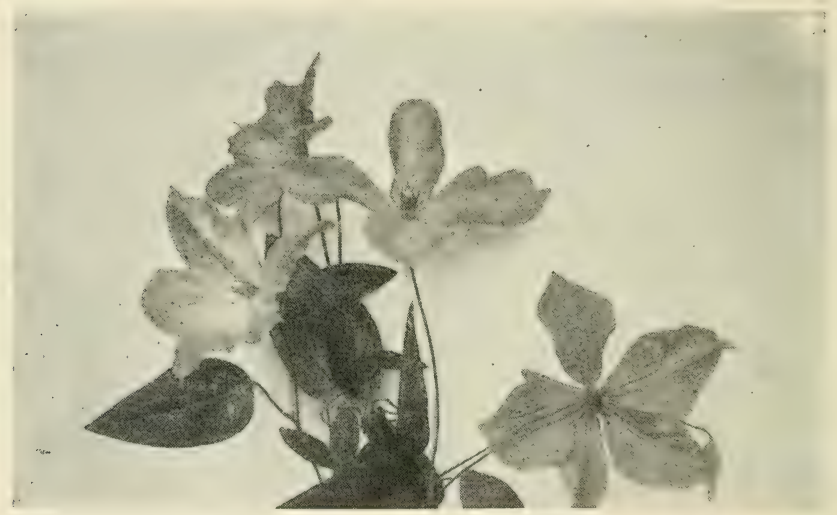

Flowers of the Clematis

(Clematis Jaclimani)

can be re-invigorated and maintained in healthy, thriving condition by annual applications of manure and an occasional top dressing with fresh soil and artificial fertilizers. Liquid manure, wherever it can be applied without offensive effects, will be found the most rapid agent in restoring a plant's strength and vigor. 
Then also it must be remembered that vines growing against walls where they are subjected to the direct and reflected rays of the sun require suitable quantities of water and, in dry weather, should be bountifully supplied with moisture. Apply the water by letting it soak into the soil until the ground is thoroughly saturated for a depth of half a dozen inches or more.

Another point in the cultivation of some vines is that a few of them thrive best when the lower part of the stems is shaded from the direct effects of the sun, even though the top portions may be in the direct line of the sun's rays. Such a vine is the clematis. Its requirement in this respect is easily satisfied by planting in front of it or near it some small plant which will supply the shade it desires.

\section{PRUNING}

The beginner is likely to hear much on the subject of the necessity for pruning permanent vines, and no doubt he will encounter many opposing opinions. It is practically impossible, however, to detail the various treatments which the different plants require. It must be remembered that some vines produce their 
flowers on the old wood matured the season before, and in such instances the strong growths should not be cut back, but the weak ones, however, should be sacrificed without hesitation and all decayed wood should be cut out immediately upon its discovery. Other vines produce their bloom on the young shoots of the current season and in such cases it is the old wood that should be eliminated and the fresh young shoots encouraged. Still others flower only on spurs that are sent out by the old wood and these climbers are best pruned by cutting out the weakly shoots and reducing the length of those remaining. But in every case a study of the particular species is essential. In some instances where the climbers have been set in position where they are not on parade, it is probably the wisest policy to limit the pruning to which they are submitted to the cutting out of the dead wood. This, however, is not to be taken as a general policy to follow for, wherever the best results are desired, pruning will be found to be essential. Even the freest rambling rose is materially benefited and improved by pruning which, to the novice, may appear to be extraordinarily and uselessly severe. Clematis, too, must be cut back if it is 


\section{VINES}

to produce the best results of which it is capable.

In decorating a yard the gardener will find that vines lend themselves to any plan he may devise. In fact, it is hardly possible that his yard can be artistically planted without the use of vines in numerous varieties. He should remember that they require but little room and lift themselves above the other plants, making it possible to set vines and shrubs in the same bed or border if desired, and thereby obtain an effect which, were flowers and shrubs alone relied upon, would be well nigh impossible. It requires, indeed, but little consideration to arrive at the conclusion that, however small the space to be planted, there may be vines in every desirable nook and corner, and still neither the lawn nor the flower-beds and borders will be encroached upon to any great extent.

\section{PERENNIAL VINES}

Although there are innumerable sorts ready for the planter's use still it is best to rely for the most part on the better-known varieties. A vine which will respond generously to the treatment accorded it by the average novice is the Virginia Creeper (Ampelopsis quinquefo- 
lia). Its good points are its quick growth, its absolute hardiness, its extraordinary beauty when it wear's its summer dress of green foliage and its gorgeous hues when it dons an autumn robe of red and adds a touch of purple with its dainty berries. The Virginia Creeper, or woodbine as it is sometimes called, is easily obtained and can be found in almost any wood, or growing along fences by country roads. It is available for use as a screen and with its rapid growth will hide a multitude of sins in a surprisingly short time. Its one bad feature, so far as small places are concerned, is its tendency to grow to the top, and as the top gains in strength and mass of spread, the vine ceases to show leaves near its roots. While this makes a plant desirable for growing up old trees or for hiding from view dead tops, it renders it of little use in sereening objects of less height, although in its younger years it answeirs this purpose very well. It tends also to exhaust the soil rapidly and its roots ramble subterraneously over a considerable territory. The familiar "Dutchman's Pipe," (Aristolochia macrophylla), however, a robust grower with enormous leaves, continues to throw out its foliage from the base and so 


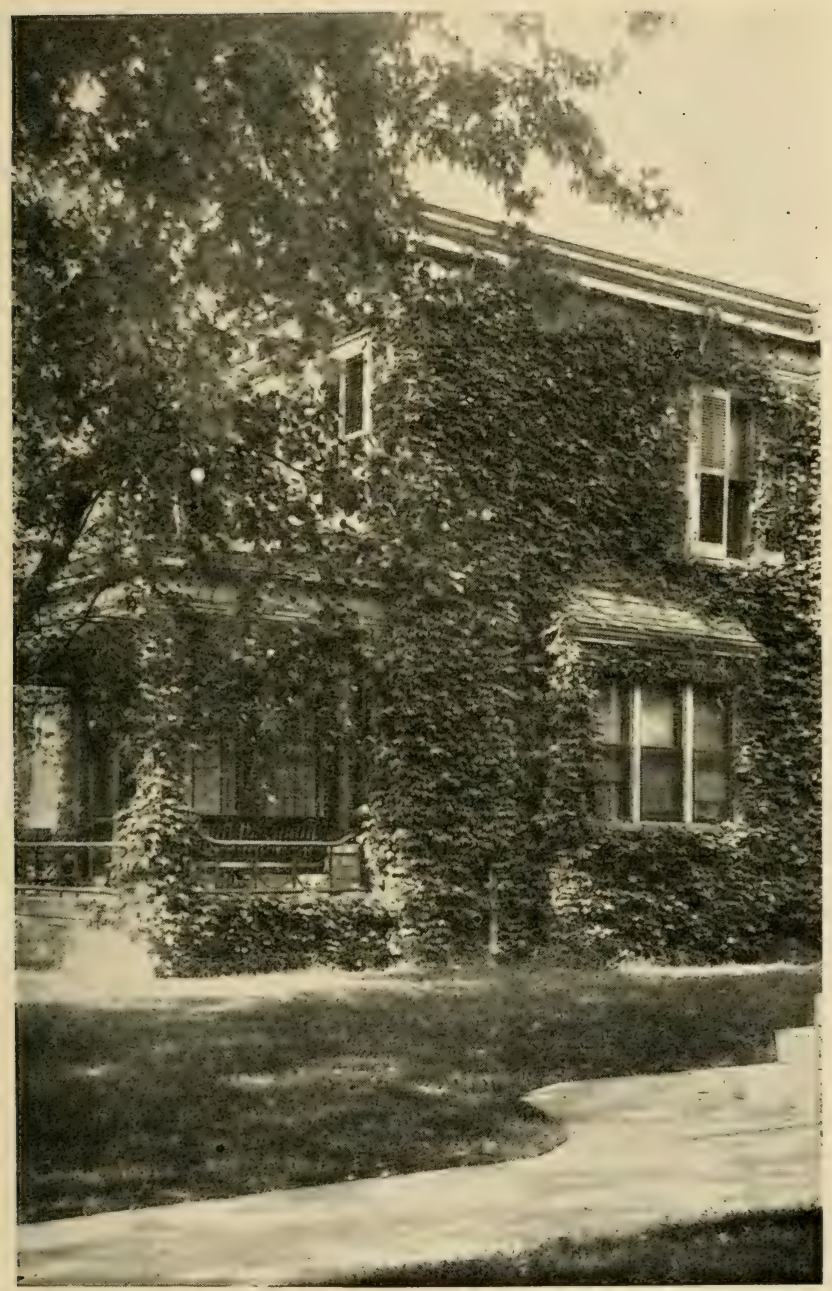

City Residence Covered with Woodbine (Ampelopsis quinquefolia) 
answers admirably for covering whatever it grows upon near the ground. It is also a climber but, growing with uniform density from the base up, it is suitable for arbor's or large fence spaces or for verandas and pergolas.

Considering the climbing roses as vines, the strongest growers and those producing under ordinary treatment the best results, are the Crimson Rambler with red blossoms and the Dorothy Perkins with pink. Both are entirely hardy and will thrive year after year, especially if pruning is attended to with any degree of regularity. The Wichuraiana rose is also desirable, its foliage being to a considerable extent evergreen, a feature which makes it of value in situations which are conspicuous in the winter. The Wichuraiana is also known as the Nemorial Rose, and though it lacks the brilliant color of the Crimson Rambler, in some respects it is better than the latter. As a climber for covering porches, trellises and arches or as a creeper for covering steep banks, it is probably unequalled so far as the roses are concerned. Another advantage it possesses is its apparent freedom from the attacks of insects or disease. One especial use to which it can be put to advantage is to plant it in the 
earth at the top of some high retaining wall or bank, letting its branches droop orer and hang toward the level helow. The Dorothy I'erkins has the same strong hahit of growth as the more familiar ('rimson Rambler and the flowers are borne in clusters of thirty or forty.

From time to time new varieties of climbing roses are introduced and almost all of them are well worth planting but the beginner will doubtless find that the red, pink and white blossoms of the Rambler, Dorothy Perkins and the Wichuraiana will answer his purposes. ('limbing roses should be planted no closer than four feet and the soil in which they are set should be more deeply cultivated than for other vines. In training them avoid taking their stems in a directly vertical course for this tends to take the sap to the top and to denude the lower part of the plant. Avoid this by bending the shoot in one direction or another then permitting it to take its upward trend if desired.

('lematises are familiar' vines in many places and because of their good qualities should be even more extensively grown than they are. They require a fairly rich soil of a light, loamy character and will be all the haprier if a little lime or old mortar is mixed with it. The soil 
in which they are planted should be well drained, and each year should be enriched by a top dressing of cow manure. They are used in many places to cover walls, mounds, trellises, arbors or porches. Unfortunately, clematises are subject to a disease which often results fatally. When planted close to buildings where the ground does not freeze to a great depth this disease is responsible for many disappointments. It is due to a parasite which it is believed is killed by hard freezing; indeed, no other remedy so far as is known exists. The vines should in all cases be fastened securely to the trellises upon which they are supported to prevent their being whipped about by the winds; training the vines upon strings or similar insecure devices is therefore to be avoided. Clematis flammula or sweet clematis blooms early in July; Clematis paniculata is a strong, vigorous grower and in late summer produces sheets of pure white flowers of the most pleasing fragrance. Both are perfectly hardy. The finest hybrids, including Clematis Jackmani and its varieties, are widely used and much admired. The plants bear large, intense violet-purple flowers remarkable for richness of color; they are free in growth and abundant and successive 


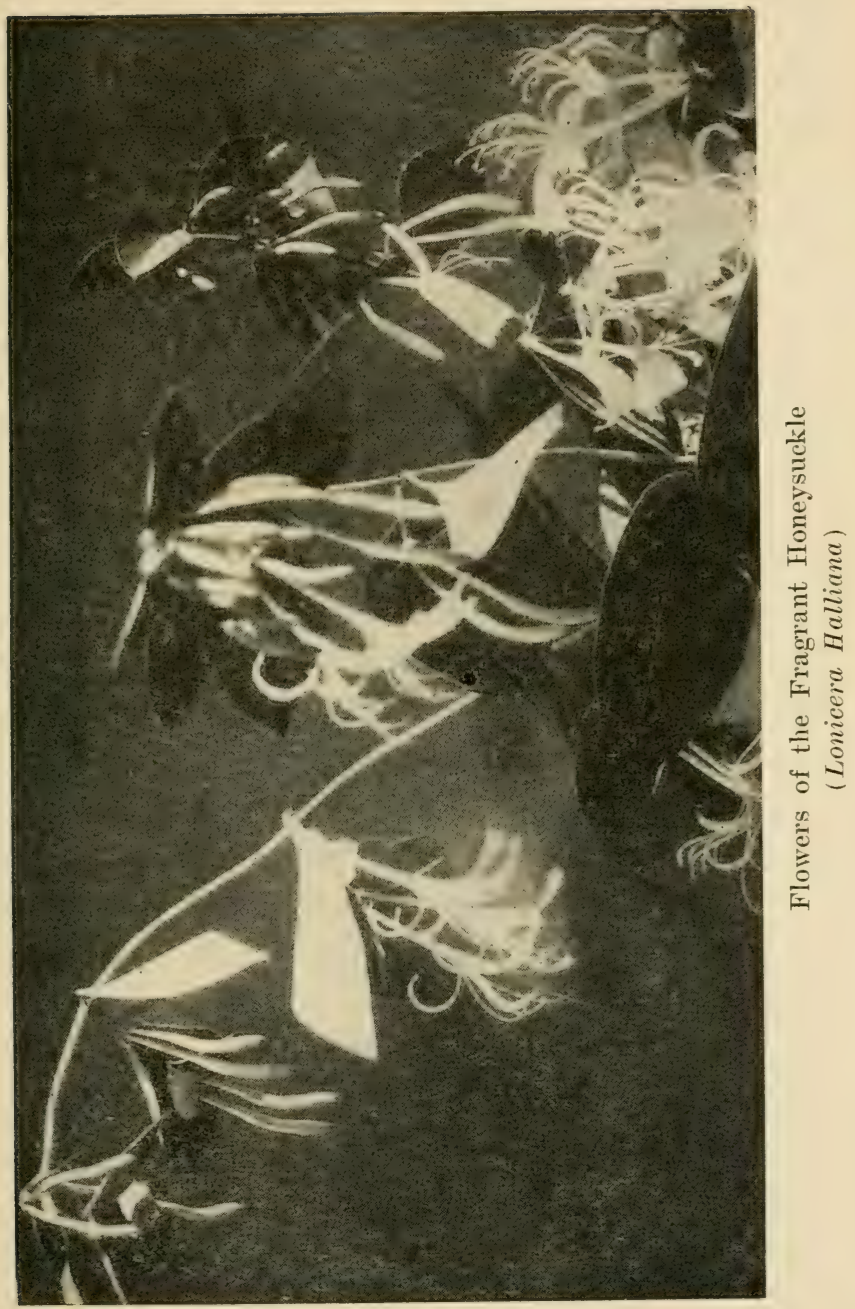


bloomers. Clematis Henryi is another good variety, a free grower and bloomer, bearing cream-white blossoms. A red variety of the large flowering Clematis can be had under various trade names.

The Honeysuckle is valuable for many purposes and particularly for its sweet-scented flowers. Lonicera sempervirens, L. Japonica and L. Halliana, which is half evergreen in the north, are the best for general uses.

A vine which is especially valuable for clinging to walls is Ampelopsis Veitchi, or Boston ivy, as it is popularly known. Its leaves are small and overlap one another, forming a sheet of green. It is somewhat tender in its early years and requires, for the first winter at least, ample protection; once established, however, there is small danger of its suffering from low temperature. It grows rapidly and its foliage is extraordinarily handsome in summer and assumes a crimson hue in autumn. It requires no support but clings to brick and stone structures readily and, while it encounters some difficulty in gaining a firm hold on wooden buildings, it seldom fails to succeed in supporting itself.

Other vines which will thrive in the city yard 
and which the planter should carefully consider when he is making his plans are the Trumpet Creeper (Tecoma radicans), Actinidia arguta, a strong-growing vine from Japan with large leaves and white purple-centered flowers; Akebia quinata, a rapid-growing vine bearing five-fingered leaves and sweet-scented flower's of a plum color, appearing near the end of April; Celastrus scandens, or the false bittersweet, with scarlet fruit pods that are highly ornamental; Wistaria multijuga, (known oftentimes as W. Chinensis), and W. speciosa. All these vines possess shrubby tops and do not die back in the fall. A list of vines which die back to the ground or nearly so in winter but whose roots persist from year to year will include many of the most decorative plants of the sort for general use. Among these is the cinnamon vine (Dioscorea divaricata). Another vine which should be more generally planted is Euonymus radicans; it is a splendid evergreen creeping plant with small pretty foliage and though it is rather slow growing, it is exceedingly useful for covering low stone walls or stumps. It has been said that it is not reliably hardy but in many situations it has endured a temperature as low as twenty de- 
grees below zero and this without any winter protection whatever.

\section{ANNUAL VINES}

Among the annuals are many easily grown plants of extraordinary value and beauty. The morning-glories and moon-vines come under this head, and one might of course consider the sweet-peas as belonging to the same division. Early-growing nasturtiums-always effective when trained on low wire trellises-yield luxuriant foliage and hundreds of flowers in the course of a season. All are readily grown from seed and, with the exception of the sweet-peas, which require elaborate treatment compared with the others, will reward the planter with quantities of blossom even when they are neglected and abused. Their rapid growth makes them especially useful as screens and frequently an unsightly spot in the yard where, for instance, a garbage can is kept, may be entirely hidden from view in a comparatively short time by the use of either nasturtiums or morningglories. The latter have the troublesome habit of seeding themselves and when a vine is permitted to produce seeds, it is not unlikely that the planter thereafter will have some diffieulty 
in ridding the spot where it grew of volunteer vines in subsequent seasons.

\section{TRELLISES}

Where the perennial vines are planted it is best to give them artificial supports that are of a permanent nature. Nothing is gained by erecting flimsy trellises which, as soon as the vines have taken hold upon them, begin to waver under their weight. Old gas-pipe is to be had very cheaply in most cities and this, when well set in the ground, affords a splendid and effective support which will last many years, and, once the vine is established upon it, will relieve the gardener of the necessity of marring the growth by tearing it down in order to strengthen the support. When vines are to be attached to frame houses which, of course, will require painting from season to season, it is hest to provide a support which is separate from the wall. This may be made of wire net or of wood lattice and, if constructed with some thought, may be removed, with the vine clinging to it, laid back until the painter has completed his work, and then, without disturbing the climber, replaced. Such devices are best made of a strong wood frame upon which the 
wire net is stretched. If desired, the bottom of the frame may he attached to the house by hinges and the top made secure by screws which can be readily removed. With these withdrawn, the trellis can he laid back on its hinges and, the painter's departed, quickly restored to its former position. 


\section{CHAPTER VI}

\section{ANNUALS}

It is with annual rather than with biennial or with perennial plants that most planters of small city gardens are familiar. The three groups are well marked and the characteristics of each well defined. Annuals, strictly speaking, are plants which normally survive but a single season, maturing from seed, producing seed and completing their cycle of life. Biennials live two years and the term, accurately applied, describes an exceedingly small group of plants which do not bear flowers or fruit until the second season following the planting of the seed. Of all the species of seed-bearing plants, it has been estimated that only one or two per cent. are true biennials. Perennials live from year to year and include, naturally, trees, shrubs and herbs, but, as the term is generally employed in relation to decorative gardening, it is applied to those non-woody plants more properly known as "hardy herbaceous

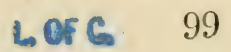


perennials., These include such well-known species as Peony and Phlox.

\section{GENERAL CLASSIFICATION OF ANNUALS}

Among the annuals are found some of the showiest plants in cultivation, and, inasmuch as they are, generally speaking, easily grown,

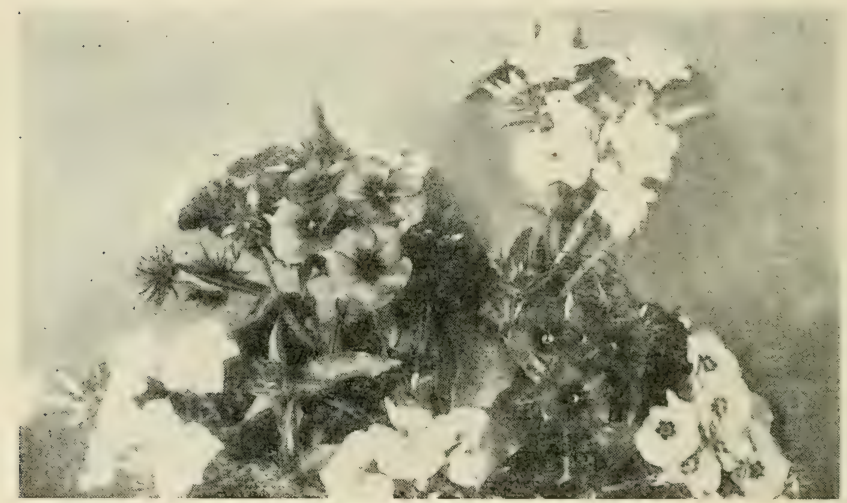

Annual Phlox (P.Drummondii)

additional merit on this account must be accorded the group. They afford a variety of brilliant colors and delicate fragrance, produce quick results, bloom at various seasons and attain varying heights. They are valuable in beds by themselves, as edgings for other beds or for walks, as trailers or vines, or in con- 
junction with borders of hardy shrubs or herbaceous plants. In the latter employment they serve to replace perennials that failed to survive the winter or to cover bare spots which frequently occur in the hardy borders.

Annuals are usually divided into three classes:

(1) Hardy annuals, or those sown directly in the open ground where they are to bloom. Many of these resent transplanting and, when the seeds have germinated, demand only thinning. Hardy annuals are the earliest to be sown outdoors.

(2) Half-hardy annuals, or those which are usually sown indoors under glass and later transplanted to the blooming beds. Sown outdoors, weather conditions must be such as to indicate that all danger of frost is past.

(3) Tender annuals, or those which require more heat than the half-hardy varieties, and which can not be safely transplanted outdoors until there is an assured temperature of not less than fifty-five or sixty degrees. These also are started indoors.

Catalogues usually make these divisions, and when once the meaning of the term is thoroughly understood there is less danger of fail- 
ure on the part of the amateur in dealing with them.

\section{EARLY PLANTING}

To obtain early flowers from annuals, in the North, seed must be sown in flats or pans or boxes and set in sunny windows until the seedlings grow strong enough to bear transplanting. Often this is begun entirely too early.

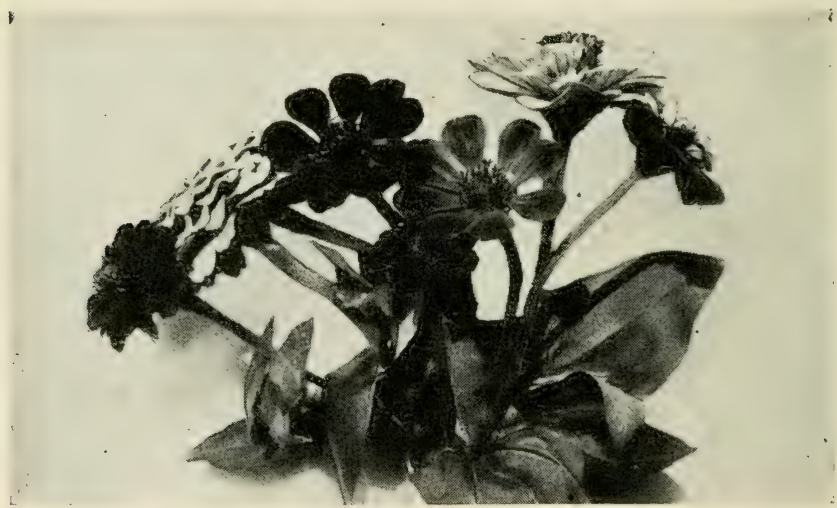

Single and Double Zinnias

Dwelling houses, as a rule, are altogether unsuitable for raising plants successfully from seed, and especially for "growing them on," as the florists call it, until it is time to set them out in outdoor beds. The seed, in most instances, will germinate, and, given the right 
conditions, the seedlings will thrive, but most beginners find it impossible to give the little plants these "right conditions." It is, therefore, best to give them as short a period in the house as possible and, at the same time, effect a gain in point of early flowering. So, instead of attempting to gain too much time, which in seven cases out of ten results in absolute failure, it is better to gain, say only three weeks, and have the effort crowned with success. To do this, sow the seeds in the house in the first week of April. There is much expert advice, of course, to the effect that March sowing is none too early, but there are, so far as the experiences of beginners are concerned, comparatively few cases where results from March sowing in the long run equal those of April planting.

\section{INDOOR SOWING}

The best plan to follow is to adopt the method employed by the florist-sow the seeds in flats. "Flats" are more convenient than mysterious; they are easily made, cheap and admirably adapted to the purpose. They are nothing more than boxes, trelve or eighteen inches wide and twice as long and three or four inches deep. 
The width and length may vary to suit the planter, although a box a foot and a half wide and two and a half or three feet long is more easily handled, but the depth must not be greater than four inches. Three, probably, for the average amateur is better. Empty cigar boxes are often used, and do very well indeed. Bore half a dozen holes in the bottom and over these place bits of crock, concave enough in form to permit surplus water to escape under them easily and quickly. Next put in a layer of coarse earth-unsifted loam-and, on top of this, place the finer soil. This must be sifted, made rich with old manure, with sand enough added to render it thoroughly porous. Press the soil down firmly, especially along the ends and sides and in the corners, dampen slightly, and sow the seed.

Sow very fine seed broadcast, scattering it thinly over the surface and pressing it in the soil with a block of wood. For larger seeds, sprinkle a little dirt on top-barely enough to cover them-and for seeds large enough to handle separately supply a heavier covering of soil. A safe rule to apply is to plant the big seeds at a depth three times their diameter. If, after the seed is planted, it appears that the 
soil is too dry, sprinkle lightly with water, taking care not to wash the seed out. Then cover the box or flat with a glass and sheet of white paper and place it in a warm place. A shelf above a radiator or stove is a fairly good situation, provided the heat is not too intense. Little light is needed until the seeds germinate,

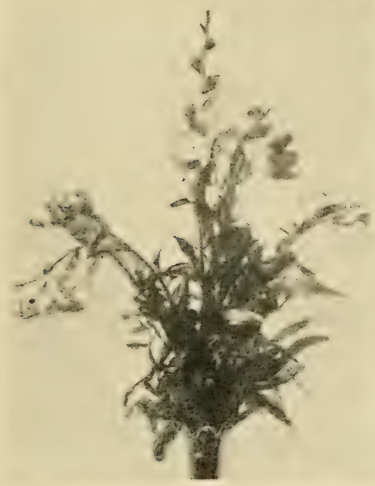

Snapdragon

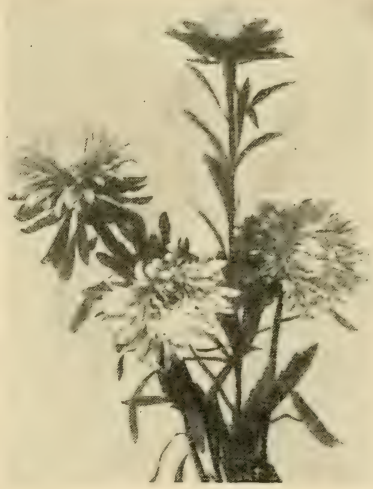

China Aster

when, of course, they must be moved to lighter quarter's. Watch the glass closely, for it will act, in a sense, as a barometer. When there is too much moisture in the soil, drops will form on the glass. Raise it and wipe off the surplus moisture, and let it remain elevated so that the dry air can strike the earth and rid it of the 
excess dampness. Careful attention to this detail will prevent the "damping off" of the seedlings, which so often discourages the beginner. If, on the other hand, the soil threatens to become too dry, sprinkle lightly with water, or, if the flat be small enough, set it in a pan of luke-warm water and let it absorb the water through the drainage holes in the bottom.

As the plants make growth, give more air, removing the white paper entirely and slightly elevating the glass. As growth continues, supply more air, and when the seedlings put out their second leaves place the flat in a light, warm window, making sure to screen the boxes from the sun. White paper is also excellent for this. When the first true leaves appear, dispense with the glass and gradually expose the plants to more sun.

\section{TRANSPLANTING SEEDLINGS}

By the time conditions outdoors permit transplanting, the seedlings should be strong enough and at the same time enough hardened to endure the shock without any marked set-back. But in some instances it may be necessary to transplant hefore the outside conditions will permit a transfer immediately to the blooming 


\section{ANNUALS}

bed. In such case transplant either to other flats-constructed in the same way-or else to what are called "thumb pots," miniature flower pots easily obtained of any florist at very small cost. These, however, are not necessary, any sort of receptacle serving very well for the seedlings. In transplanting thus to other

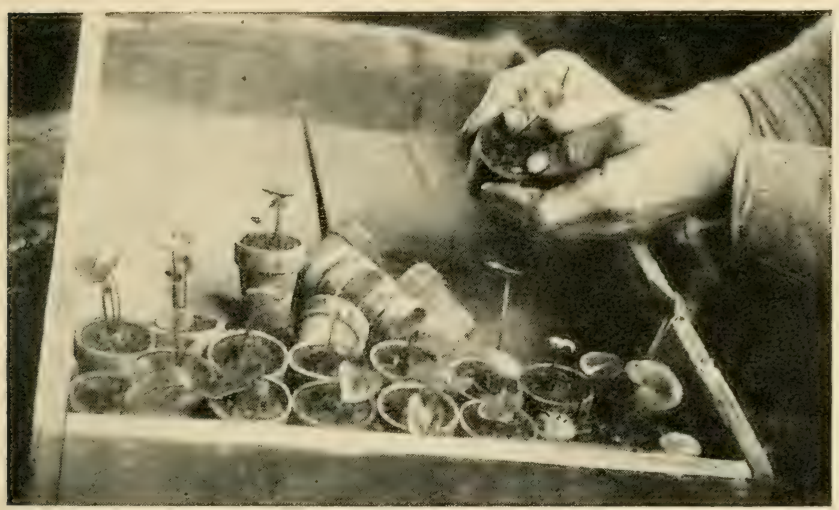

Transplanting Seedlings to "Thumb-Pots."

boxes, allow the young plants all the space you can afford; if set too close together their roots will intertwine and it will be difficult later on, when you come to set them in their permanent beds, to separate them without damaging them severely.

In any case, it is very important that the 
seedlings do not become spindly. To prevent this, increase the light and turn the boxes occasionally, so that one side is not always next to the window.

Select seeds for planting indoors with some care. Earliness alone is hardly worth striving for. The plant so treated blooms for only a definite period, say four weeks. In such a case, of comrse, what you would gain at one end you would lose at the other. But in many instances, especially in the case of verbenas and petunias, a month's start means a clear gain, for the plants, once they begin to bloom, will continue to bloom until frost.

\section{IMPORTANCE OF GOOD BEDS}

It is strange, to say the least, that many persons observe carefully all the little points necessary to insure success with seeds planted indoors, but prepare the outdoor beds in a manner at once indifferent and careless. Threefourths of the failures are due to this lack of thoroughness. In spring, the most of us, whether flower-raising is our hobby or not, want to plant. We rush into it, hastily and incompletely preparing the beds, sow the seeds, watch with increasing interest the germination, 
and then feel not only regret but wonder when the seedlings droop, wither and die. We attribute the trouble to the seeds. But the simple truth is, the fault is our own. We deliberately precipitate a floral tragedy; we deceive the plants; lead them to believe that the alluring surface conditions with which we provide them extend to sufficient depth to accommodate their roots, but when they reach out and down, hopefully and trustfully, they encounter stones and clods and soil as hard as cement. Not even the spade could penetrate it easily. The hot sun bakes the surface soil, blister's the fine roots, and, in the end, instead of bloom and fragrance, we have a dismal bed of dead and dying plants.

The careful gardener provides against any such catastrophe with his annuals by preparing his beds with that thoroughness which alone insures success. He realizes that it is better to spend time and labor in the beginning and to begin right than to exhaust patience later and suffer disappointment as well. A poorly made bed never produced a good flower, and annuals, although quick in their growth, demand proper rooting conditions if they are to do their best. 


\section{THE MOST SUITABLE SOIL}

The ideal annual flower-bed is within the reach of every person who has any flower-bed at all. First of all, it means suitable soil, and, in the second place, it means thorough treatment of this soil. If your ground is heavyclayish in quality-or light-due to too much

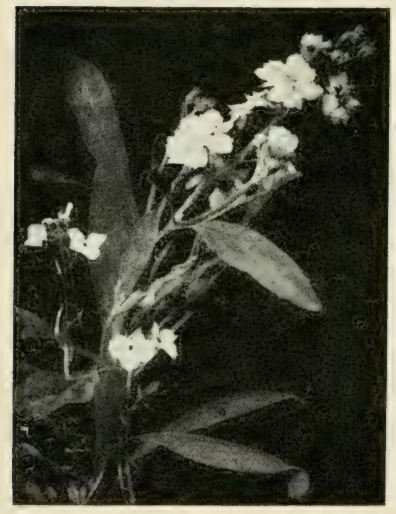

Stocks

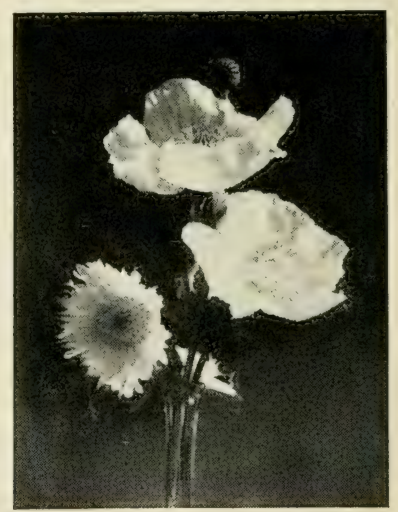

Shirley Poppies

sand-it is often best to get rid of it entirely. Outline the size of the bed, making sure not to make it too wide to permit easy access to every part of it, and excavate the poor soil to a depth of two feet. Cart it away. Level off the bottom and place a five- or six-inch layer of drain- 
age material on it. Sand or gravel or cinders will answer the purpose. Then on top of this put in the new soil, which should consist of rich, fine loam, leaf-mold and well-rotted cow manure in approximately equal parts. In filling, bring the surface of the bed three or four inches higher than the surface of the surrounding ground, to allow for settling, and do not attempt to sow seeds or set out plants in it until this settling has occurred.

But if the soil where the bed is to be made is satisfactory, such trouble, of course, is avoided. Remember, however, that where no bed has ever been made before, the earth must be spaded to a depth of eighteen inches at least -two feet is even better. All roots and stones must be removed and the clods thoroughiy pulverized. Begin by removing the surface soil to a depth of six inches, casting it to one side. Then spade the sub-soil to the required depth, incorporating with it well-rotted manure, and, when this is done, return the surface soil, making it as fine as possible-so fine, indeed, that it will readily pass through a sieve with a quarter-inch mesh. The surface soil is laid aside and finally returned to the top because it is always rich in humus, which furnishes the most 
arailable food for the young plants and tender rootlets. Nature herself, it will be observed, never turns the soil upside down. But in spading up old beds, where it is only necessary to break the ground and pulverize the soil, it may seem impractical to keep the surface soil on the

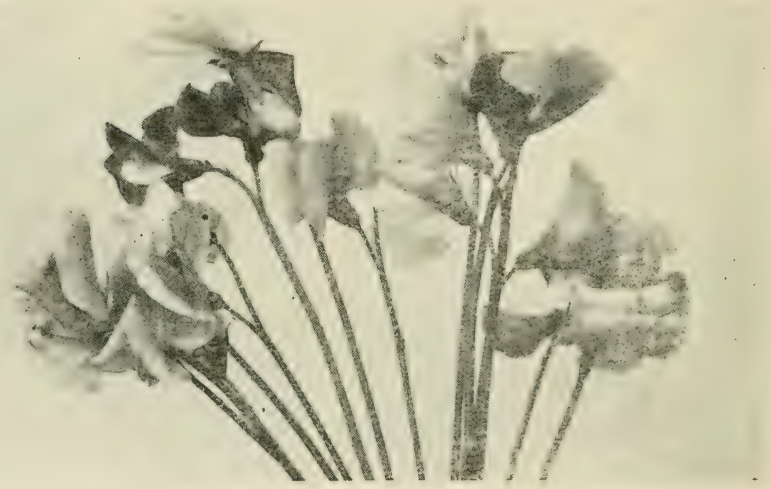

Sweet Peas

surface. It is easily enough accomplished, however, if the old bed was properly prepared in the beginning. Simply insert the spade to the required depth and twist it from side to side, loosening the soil without turning it under.

But no matter what particular process you 
may elect to follow in making your hed, remember these points:

Provide depth, and in the sub-soil incorporate manure.

Never turn the surface soil under.

Thoroughly pulverize the surface-it can not be made too fine.

By following these suggestions the foundation for success is laid. Enriching the sub-soil and giving depth are essential because the two processes combine to draw the roots of the plants downward and away from the surface, where the sun's heat will bake them. Pulverizing the surface soil makes it possible to sow the finest seed with satisfactory results.

\section{THE TIME FOR PLANTING}

In sowing seeds it is well to remember that April in the North is a month of many moods. The warmth of one day, which seems to presage the end of spring frosts, may be nothing more than a "weather-breeder." It may end in a cold night and a succession of cold days, when whatever has been planted in the way of tender annuals succumbs, and the gardener's work has been for nothing. Therefore, do not be im- 
patient to plant. It is better to wait until the ground is warm and all danger of frost is past than to be too early; give your impatience outlet by working the soil in the beds.

But by the fifteenth of April it is ordinarily safe to plant such of the hardier annuals as the Cornflower, Sweet Sultan, Calendula, Calli-

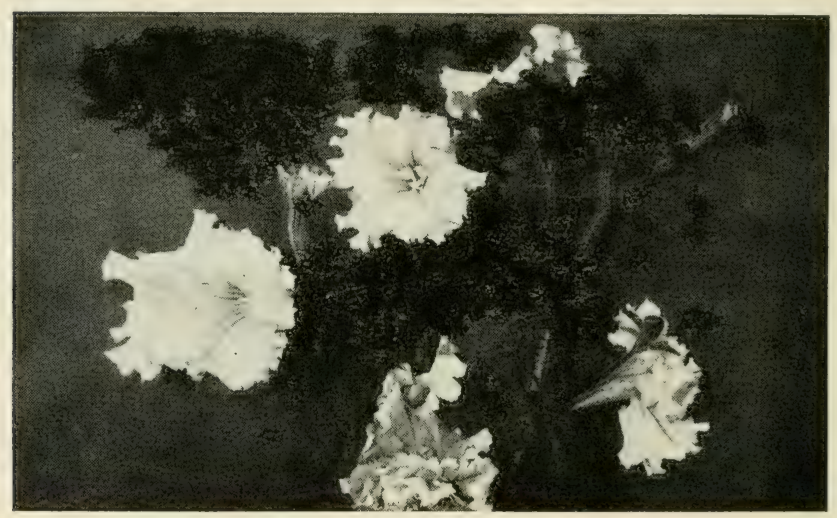

Petunias

opsis, Petunia, Sunflower, Morning-glory, Sweet Alyssum, Poppy, Candytuft, Mignonette. The last three, it must be borne in mind, will not bear transplanting, and must be sown where they are to bloom.

The gardener who has a choice of location for his beds of annuals should remember that 
most of them prefer open, sunny situations, but some of them, such, for example, as pansies and forget-me-nots, thrive where they get the full sunshine for only half a day.

\section{OUTDOORS SOWING}

It is in sowing the seeds of annuals outdoors that inexperienced amateurs make the most blunders. After the seed beds have been prepared as already directed, mark off rows on the surface from six to twenty-four inches apart. Be sure to make the rows straight. If, however, the planter desires, the planting may be done in circles, keeping the circles the same distance apart. In every instance the space between the rows or circles is determined by the height or size of the plant at maturity. Allow plenty of room for growth and do not crowd. Sow fine seed in the rows as thinly as possible, and, after the true leaves form, thin, permitting such to remain as stand as far apart in the rows as the rows themselves are far apart. Sow heavier and larger seeds one at a time and a little thicker than they are to stand when they begin growth; this allows for failures. When the seed is sown, sift a light covering of soil over the finer seeds-barely 
enough to assist in firming them in the ground, and then, with a smooth board or block of wood, gently pat down the surface, making the entire bed smooth. Be sure to label the rows if different varieties are planted, and it is best, usually, to mark on the labels the date of planting.

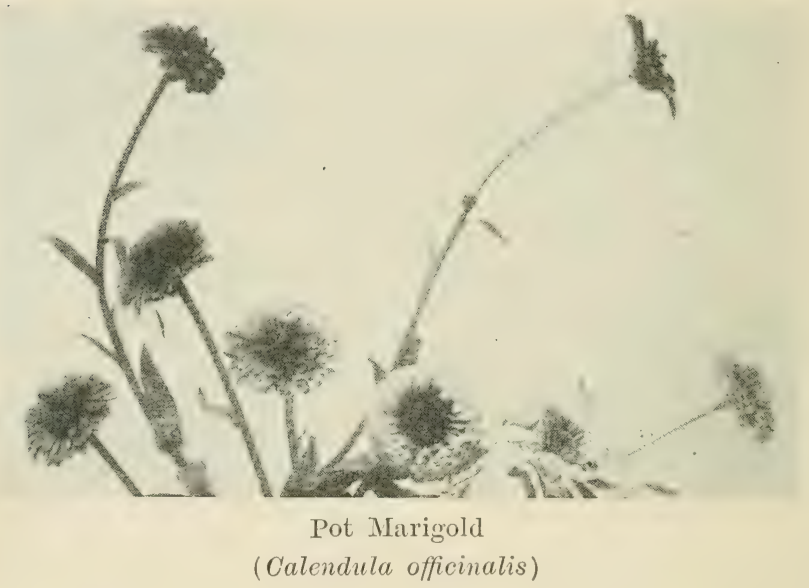

As soon as the seedlings have made enough growth, be on the lookout for weeds, and as fast as they appear rid the heds of them. Weeds quickly overcome the tender flowers, and either kill them entirely or cause such a set-back that the plants do not readily recover. Prepare also to afford such support as some annuals 


\section{ANNUALS}

may require, supplying twig's or stakes for them to depend upon, or, in some instances, wire netting or something similar-as in the case of sweet-peas-for them to climb over.

Good flowers, it must be remembered, do not grow in neglected beds. C'ultivation alone will bring out the best that there is in plants of any sort. And cultivation means a little more than the daily sprinkle of water over the beds. It means a little more than reeding. Still the work it embraces is neither arduous nor exhausting and, if a little be done each day, will scarcely occupy any time at all. It is possible, for instance, to keep in perfect state of cultivation a garden of annuals fifty feet wide and fifty feet deep by deroting twenty minutes a day to the work it demands.

\section{WATERING}

Many amateurs fail because, after their garden is well started, they water, as the florists say, "injudiciously.", It is difficult to understand what is meant hy the term, but not at all difficult to interpret it by the light of some unfortunate experience. In the first place, some plants demand more water than others, and this, of course, should be taken into con- 
sideration. It should he taken into consideration when the plan of the garden is being laid out; group those flowers demanding much moisture together as nearly as possible and those demanding less moisture in groups distinct from the others. Then apply the water accordingly, abundantly or scantily as the case may

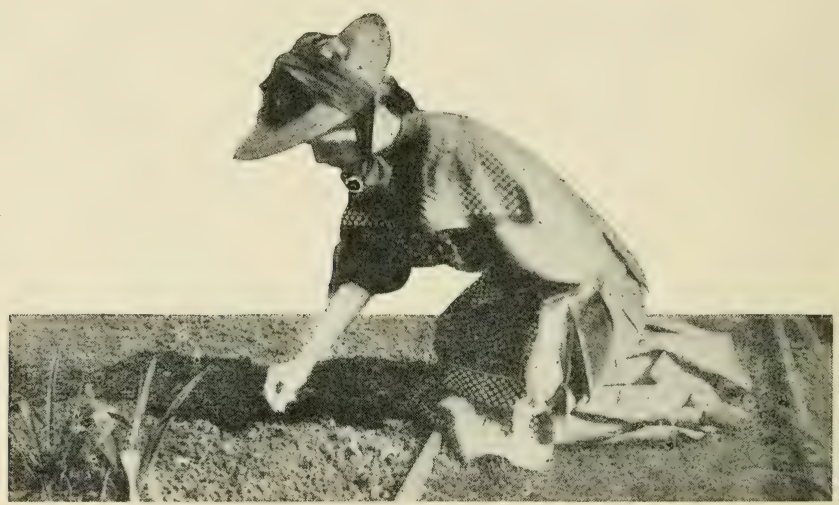

Sowing Seeds of Annuals

be, and at night. There is contrary advice, to be sure, but if the rule of applying the water at night is followed the flowers will all be benefited, and, at least, none will be harmed. But to water the beds in the late morning or early afternoon is dangerous, if not altogether fatal. Moreover, when water is applied, let the appli- 
cation he thorongh. It does very little good to sprinkle the heds with a light mist from the hose or watering-can; this may often freshen the foliage after a hot, burning day, but it gives no water to the roots, where the moisture is necessary. It is, in fact, better to water infrecuently, provided the watering then is done thoroughly, than to water often and only lightly.

Keep the surface soil of the beds well stirred, and ro not permit a hard crust to form. The process of weeding naturally tends to give the soil such cultivation as it reguires in this respect, but often, when weeding is thoroughly done, some weeks may pass before it appears necessary to repeat the work. It is in such intervals that the surface soil hardens and becomes almost as impervious to moisture as concrete, and at the same time, is quickly heated by the sun's rays.

In selecting annuals for spring planting, be wary of "novelties." Obtain the standards, which have been often tried and seldom found wanting. Only a few of the uncommon sorts, or those that are little known, are of value-if they were, they would very quickly cease to be uncommon. The old-time flowers are not easily 
displaced and the beginner will do well to rely in the main on pot marigolds or calendulas, clarkias, zinnias, balsams, candytufts, scabiosas, nasturtiums, poppies, calliopsis or coreopsis, phloxes, pinks, portulacas, China asters, stocks, sweet alyssum, cockscombs, silenes, petunias, sweet-peas and sunfiowers. For climbers none is better than the morning-glory or the nasturtium.

\section{PORCH AND WINDOW BOXES}

In connection with the discussion of annuals, it is fitting that there should be something said of porch and window boxes. Often the earth inclosed in these is the only ground some unfortunate city resident possesses; it must become his garden and his domain and therein he must raise the flowers with which to grace his residence in summer. Porch and window boxes may be filled with foliage or flowering plants, which, once they are established, will add immeasurably to the appearance of the residence and contribute generously toward redeeming the big city of its barren ugliness. These little box gardens, whether they are simple or elaborate, are always effective, and the effectiveness is invariably out of all proportion to the 


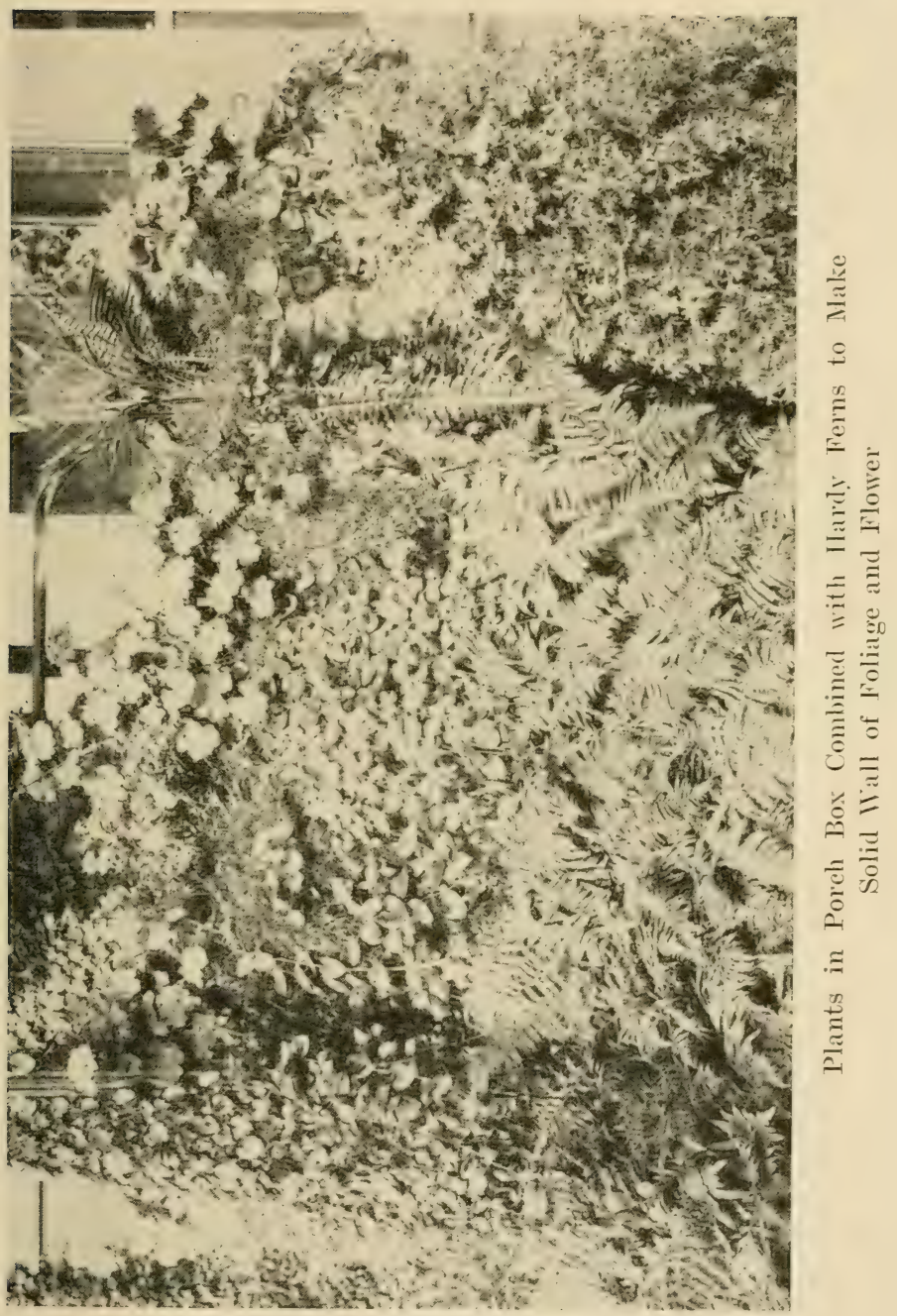


cost involved. There is nothing in the way of planting, especially in large towns and cities, that will give a surer, quicker touch of individuality and distinction to a residence at small cost and with little trouble than porch and window boxes.

Where there is a lawn, however small it may be, the boxes, with their green foliage and hanging vines, render less abrupt the line between lawn and foundation wall. Even where there is yard space enough to.permit the use of small shrubs or flowering plants, annuals or perennials, for the concealment of such walls, or the use of climbing vines to relieve the walls of any suggestion of obtrusiveness, the transition between lawn and architecture is less marked when box gardens are employed.

In recent years this fact has come to be more generally recognized, and, as a result, professional florists each spring prepare thousands of plants for use in this manner. Moreover, it is possible nowadays to have them in generous quantities at comparatively small cost. At the same time, the varieties offered for this purpose are increasing in number, and the range of choice now includes a score of plants which only a few seasons ago were sold at 
prices practically prohibitive so far as the purse of the average person is concerned.

\section{PRACTICAL USES OF BOX GARDENS}

When cost is considered, however, there should be some thought given to the usefulness of the boxes. In a modest way such gardens have a practical value. Not only do they add beauty to a house and in this respect prove their esthetic or ornamental value, but they frequently serve as effective screens, as when, on a porch without a railing, the boxes are used as a substitute. Wherever they are so employed it is seldom that the owner feels willing to abandon them for the usual balustrade. Again, when set before windows, they satisfactorily obstruct the view from the outside, though not materially interfering with the view from within. It might be mentioned, too, that by their use rooms may be rendered cooler in the hot days of summer, for the foliage of the plants will break the direct rays of the sun, and the evaporation of the water appiied to the boxes will in some degree reduce the heat of the atmosphere.

There is still another practical value which should not be overlooked. Persons who do not 
124 YARD AND GARDEN

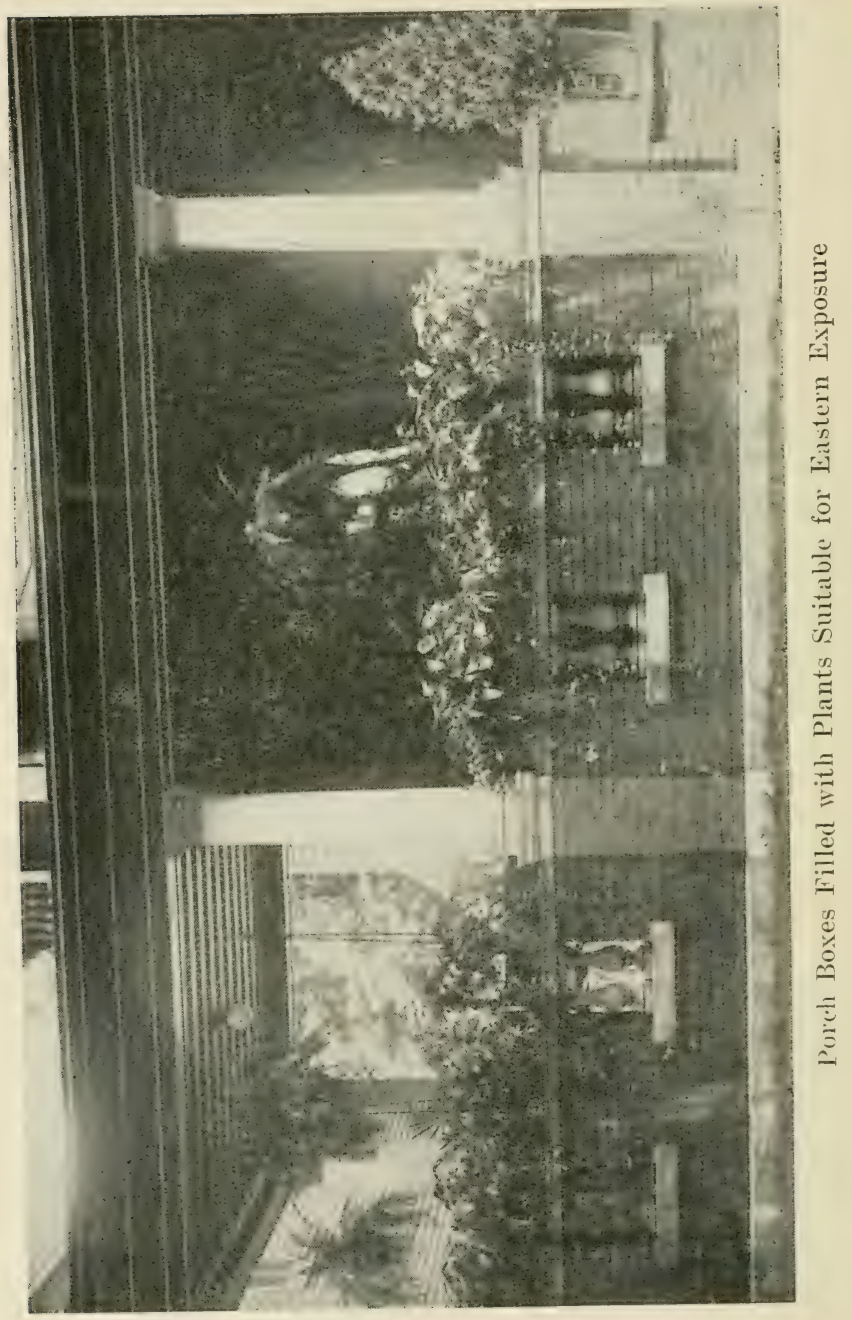


own their homes, but, on account of preference or for other reasons, rent them, may feel reluctant to expend even a comparatively small sum in the ornamentation of a place which is not their own. While such an excuse, in view of the small cost of the seed of quick-growing annuals, is extremely weak, still porch and window boxes present an immediate and happy solution. Easily moved from place to place, even when filled, they need never be abandoned, but can be carried away by the renter along with his furniture, and, though they may not appear to fit the new porch or the new windows, in all cases some use can be made of them, and usually they will be found to do as well in the new home as in the old. If one has window or porch boxes, therefore, he may move in midsummer if he desires, and, by carrying the box gardens with him, he can impart to his new residence an atmosphere of permanency which he could not attain in any other way.

But if these miniature gardens possess numerous advantages, it must be remembered that all of them disappear immediately if the boxes are neglected. When they are allowed to languish for want of care and attention, instead of adding beauty to a place, they be- 
conie shably and fade or wither, and remain a constant reflection on the planter, who was either careless or indifferent enough to permit their decline.

As in all gardening operations, the way to prevent such unhappy results is to begin properly. Time and labor spent in the beginning

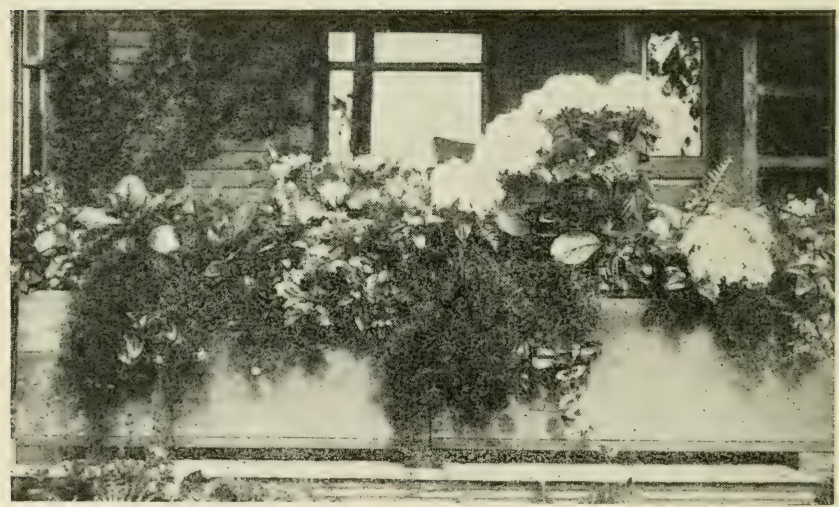

Porch Box Newly Started but with Plants in Bloom

means time and labor saved in the end. Give the flowers or plants the most congenial conditions possible, and, with ordinary attention, they will thrive and amply reward the planter for his pains. Remember in the first place that growing plants in boxes is vastly different from growing them in beds in the ground. In boxes 
they are generally exposed on three or four sides, and moisture taken up by the soil quickly evaporates, leaving the plants dry and thirsty. Then remember, too, that the smaller the box the more rapid is the evaporation, the more cramped are the roots, and the more quickly is the plant food in the soil exhausted when overcrowded.

\section{THE PROPER BOX}

In a word, begin properly by constructing the proper sort of box. Do not be niggardly with the lumber, and do not be fearful of getting the box too deep or too wide. Of course, in most instances, the planter-especially if he be the owner of his own home-must be governed largely by conditions; he must construct his boxes to fit these conditions. But before he begins let him examine carefully the conditions, with a view to making the most of them. Often what seems to be impossible, on reflection becomes possible, and where it appears at first that only a small box could be employed it becomes apparent that by some other arrangement than the first contemplated, a larger box can be used.

Boxes one foot deep and one foot wide, inside dimensions, are not too large. As for 
length, use a number of boxes of less length rather than one or two boxes of longer size. This, however, is merely a matter of convenience; the shorter the boxes the more easily are they handled, and if one makes them both wide and deep, much of the weight occasioned by these generous dimensions is overcome by reducing the length. Obtain boards fourteen inches wide, other boards twelve inches wide, and all of them of inch stuff. The fourteeninch boards are used as bottoms, and the twelve-inch boards are used for the sides and ends. It requires no mathematician to figure that, by employing such lumber, the task resolves itself into sawing the boards to proper lengths and nailing them together. By securing the sides and ends on top of the bottom boards, it will readily be seen that the inside dimensions are a foot wide and a foot deep. In order to secure the boxes and prevent their pulling apart-for nails soon work loose-make liberal use of small angle-irons. These are fastened on the outside, for, when round-headed screws are used, they prove ornamental as well as useful. Occasionally one may use thin iron bands instead, but these, while more difficult to adjust, seldom prove as satisfactory as the 


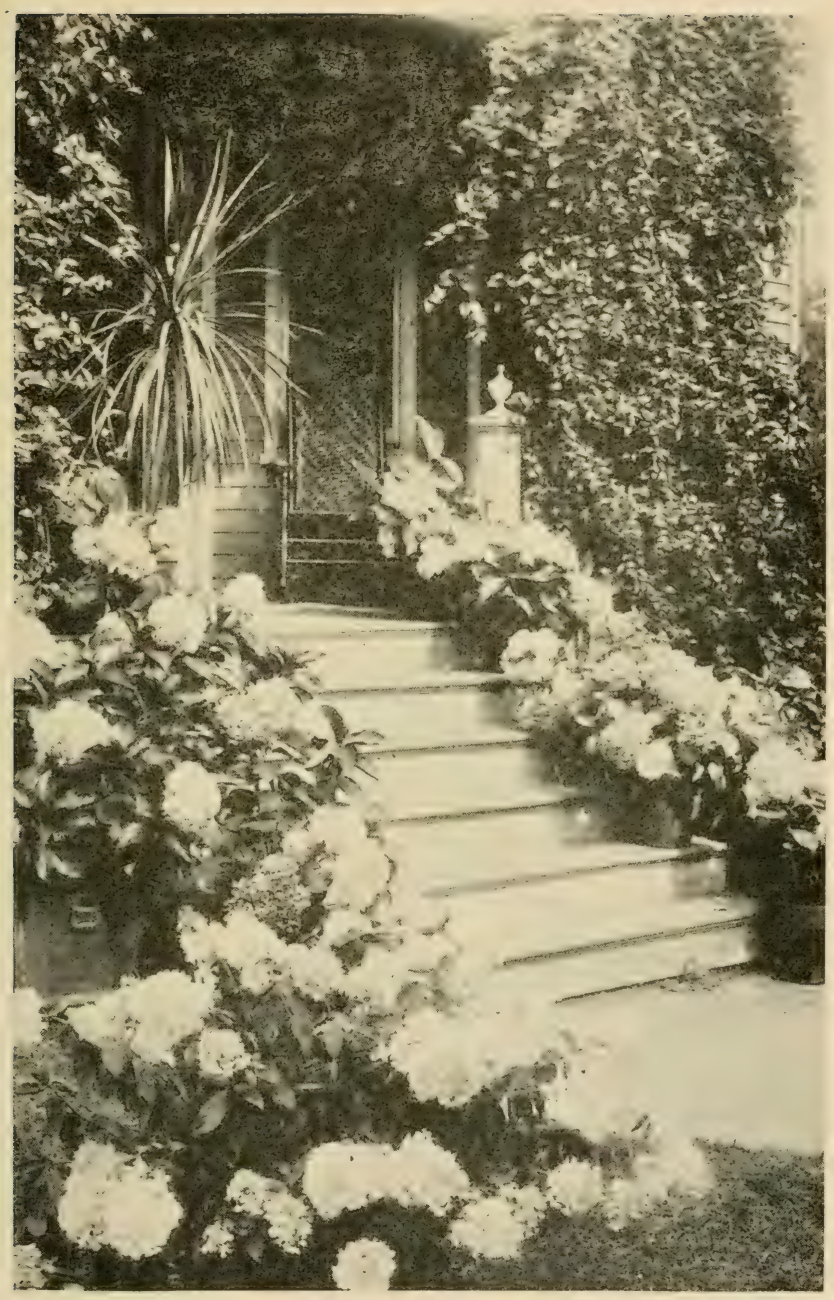

Effective Grouping of Single Plants 
angle-irons. The boxes should never be set flat upon the floor of the porch, but should be supported by pieces of "two-by-four." Stout iron brackets firmly secured may be used to support the window boxes. In the bottoms of all bore quarter-inch holes at intervals of six or eight inches to insure drainage.

\section{SOIL FOR BOX GARDENS}

For the best results, only the best soil must be used. Obtain good rich loam-such, for instance, as is found directly under the roots of the grass in a fertile pasture-and with this mix well-rotted manure and sand. The best compost is one-third loam, one-third manure and at least one-fifth sharp, clean sand. This, however, is a general mixture; for some plants it is not by any means the best. Ferns, begonias and caladiums, for instance, demand well-rotted leaf mold instead of the manure. But, even though rich soil is generously provided, thrifty plants soon exhaust it, and the successful box gardener will not overlook this fact. During the summer, from time to time, he will supply additional plant food in the form of fertilizer. Liquid manure is always best and safest; use, if it can be obtained, dried sheep 


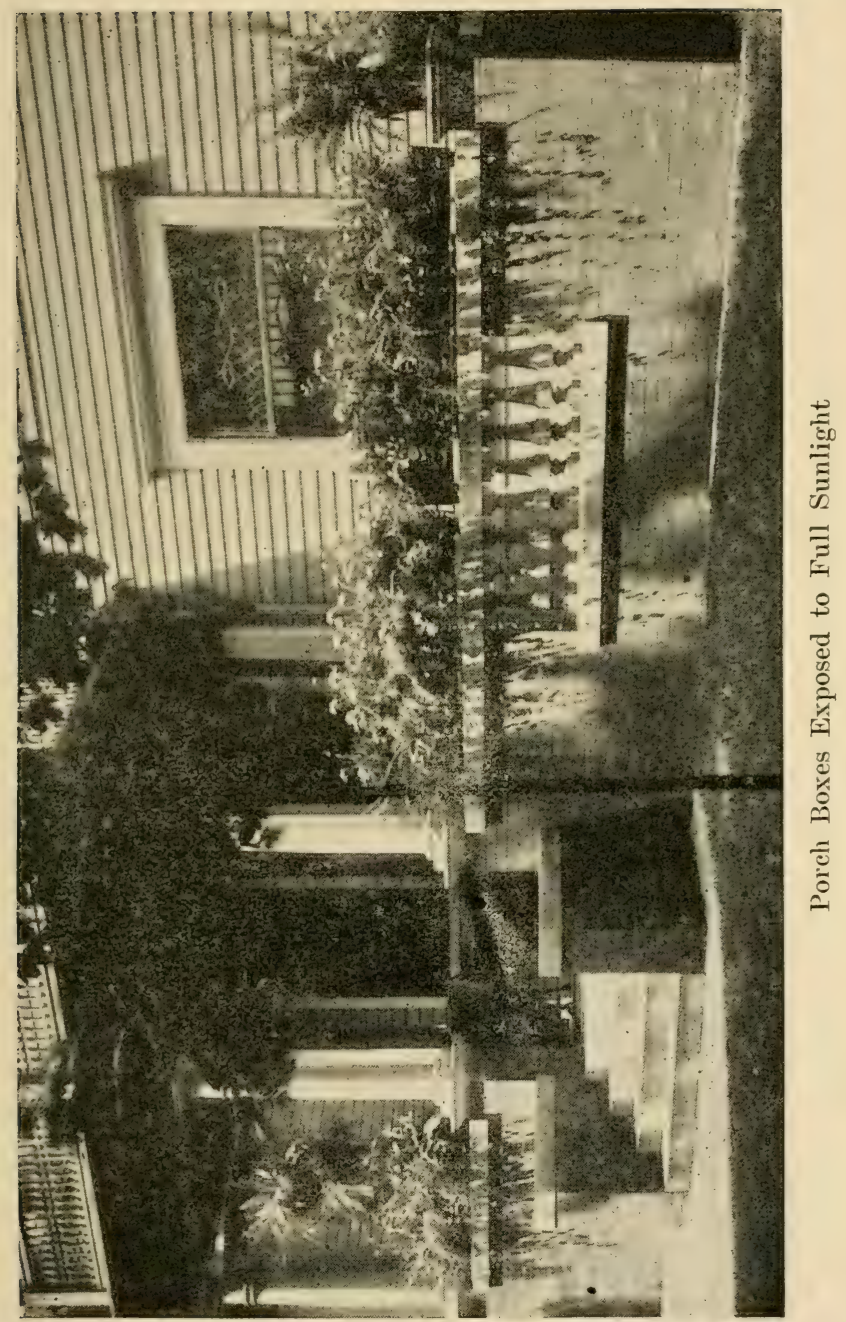


manure. Set a pound of this, held in a cloth bag, in five gallons of water and let it remain until the solution takes upon itself the color of weak tea. 'Then apply it at the roots of the plants once a week. Weak solutions frequently applied are better than strong solutions applied less often. Bone meal may be used by sprinkling it lightly on the surface of the soil, but it is never as satisfactory as the liquid fertilizer.

\section{CULTIVATION}

Window boxes, even where their proportions are generous, require much water. As a matter of fact they should he thoroughly watered every day if they are exposed to the sun, and in other situations often enough to prevent the soil from becoming dry. There is little danger of souring the soil if drainage has been properly provided. It is also necessary to keep the surface soil loose; never permit it to harden and cake. Aroid, too, the planting of flowers that demand sum in situations where only shade is to he had, and, on the other hand, do not waste time and effort hy setting shade-loving plants in positions exposed to the full glare of the sun. Neither will thrive.

Usually the most perplexing problem is to 
select plants for the north side of the porch or for the north windows. Trailing fuchsias, ivy geraniums, fancy caladiums, vineas, asparagus, Japanese morning-glories, glechoma and begonias are all suitable, to say nothing of the numerous ferns. The common "umbrella plant' also does well in such situations, but requires more water than the others.

For boxes on the south, geraniums, antirrhinums ("snap-dragons"), heliotrope, maurandya, Phlox Drummondii, nasturtiums, ageratum, weeping lantana, crotons, abutilons, coleus, are all excellent, while on the east use tuberous begonias, nasturtiums, thunbergias, vincas, ivy geraniums, heliotrope, manettias, maurandya, antirrhinums and ferns. 


\section{CHAPTER VII}

\section{HARDY PERENNIALS}

No class of plants is better adapted for the ornamentation of city yards than the hardy herbaceous perennials. Once established, they require comparatively little care and, provided they are properly planted, they will thrive from year to year, multiply and at the end of three ol four seasons, reward the planter with dozens if not scores of new plants with which to adorn additional space. Unlike annuals, they survive the winters, oftentimes with no protection whatever, and may be planted either in the spring or autumn, may be obtained as young plants or may be raised from seed.

\section{CLASSIFICATION OF PERENNIALS}

While it is hardly possible to give a clear definition of the herbaceous perennial and to distinguish between this and the biennial and annual, still it is understood that the herbaceous perennial is a plant provided with per- 


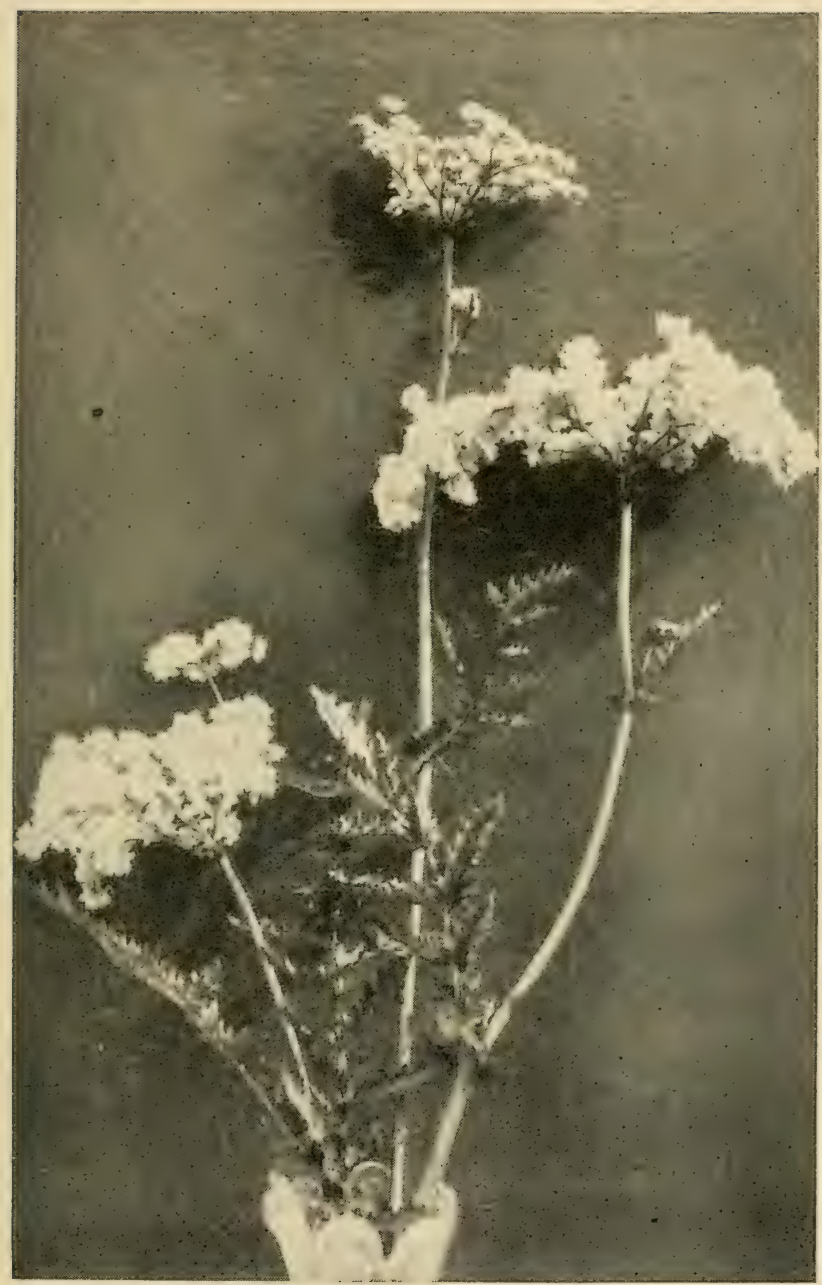

Meadow Sweet (Ulmaria Filipendula, known to the trade as Spircea Filipendula) 
ennial roots and a top that dies to the ground in the fall, such, for instance, as the peony, the columbine, the larkspur and the various forms of hardy ferns. Nurserymen, however, include in the list a number of closely allied species which possess evergreen foliage, such as the statice and the yucea and the evergreen creeping phlox and a number of Alpine plants.

American nurserymen now offer nearly three thousand species and varieties. Many of these, of course, are hardier than others and some require more generous treatment than others; and all vary in height and size, color of flower and period of bloom. It is only necessary to bear in mind that with such a list from which to select it is possible to have flowers in bloom from frost to frost. Indeed, with a judicious planting of spring-flowering bulbs and a liberal planting of herbaceous perennials not even the smallest city yard need be bloomless for more than four months in the year.

The perennials may be divided into three groups. The first will include those plants which are to be adapted for the garden of neat habit and form, requiring favorable conditions which a state of cultivation provides and which, with only a little more than ordinary attention, 
will attain perfection, persist from year to year and increase in size and vigor. The second group includes the perennial plants which are possessed of such aggressive hahits that they are not well suited to the garden but are adapted rather to planting in situations where they may remain undisturbed,

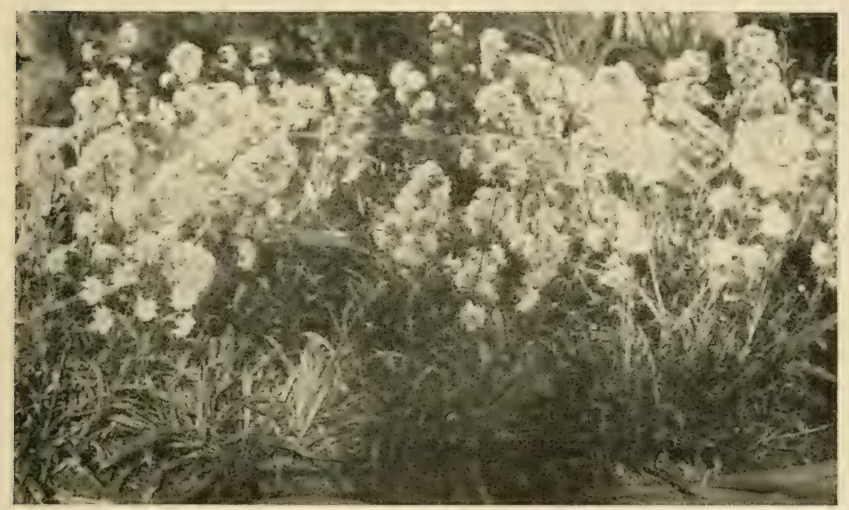

Catchfly (Lychnis Tiscaria, var. splendens)

and where their crowding and their irregular, sometimes ragged, growth will not prove a disadvantage. The third division will include plants that are best adapted to planting in the wild garden or which, if established among trees or in remote corners of the large rard or grounds, will be in the midst of condi- 
tions that suit them best and under which they will meet with that natural restraint necessary to curb rampant growth and prevent encroachment on grounds set aside for other purposes. This class of hardy perennials is more frequently employed by the landscape gardener who has an area of considerable extent to plant than by the owner of a city lot.

The latter, however, will find that in the various species and varieties of the herbaceous perennials nearly every sort of plant is to be obtained which he may desire. The group affords plants for almost every situation, every soil condition, and for almost every purpose. Varying in height from the lowly growth of a creeper to eight or ten and sometimes even twelve or fourteen feet, affording foliage that in itself is decorative, providing flowers for every month from early spring until late autumn, and including almost every shade in their range of color, the perennials are by all odds the best plants to establish in the space of the small garden.

While they are easily raised from seed very few of them bloom the first season when so planted. To obtain immediate results, therefore, it is best to obtain plants a year or more 
old. This involves greater expense but it is far more effective. Such plants set out in the spring will bloom the following summer, or, if set out in the autumn, will endure the winter and, as the frost leaves the ground in the ensuing spring, will send up their tender foliage

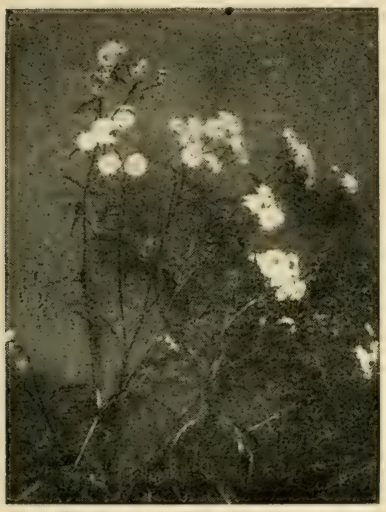

Achillea

(Achillea Ptarmica, var. "The Pearl")

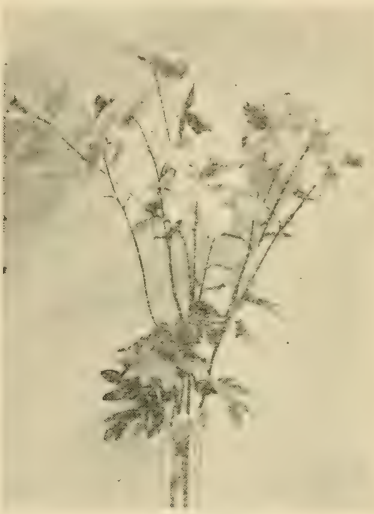

Columbine

(Aquilegia chrysantha)

and bloom-stalks and, long before it is seasonable for the planting of the seeds of annuals, they will be in vigorous growth. The gardener who has such plants to observe finds the early spring one of the most interesting periods of the whole year. He goes from bed to hed or border to border removing a bit of the win- 
ter cover here and a bit there, and finds beneath the litter the green shoots of the peremnials showing above the ground. For him there is no impatient waiting until the last danger of frost is past before gardening operations may be begun, but, with the first pleasant days of sunshine, life stirs in his garden. From this time on he has only to take care that a sudden frost does not catch him unawares and nip the tender shoots.

\section{WINTER PROTECTION}

In the fail, when the frost has cut down the foliage and withered everything in the yard and when the trees have shed their leaves, the gardener has only to place a light cover on his beds or border's to prepare for another season of bloom. This winter protection is heavy or light according to the location; in the northern section of the country a heavier covering of leaves or litter is required than in the southern yortion; in many sections of the latter the hardy perennials require no winter protection whatever. The protertion itself should be applied as soon as the ground has frozen to the depth of an inch. If it is applied earlier there is often danger of mice nesting under the litter and, in 


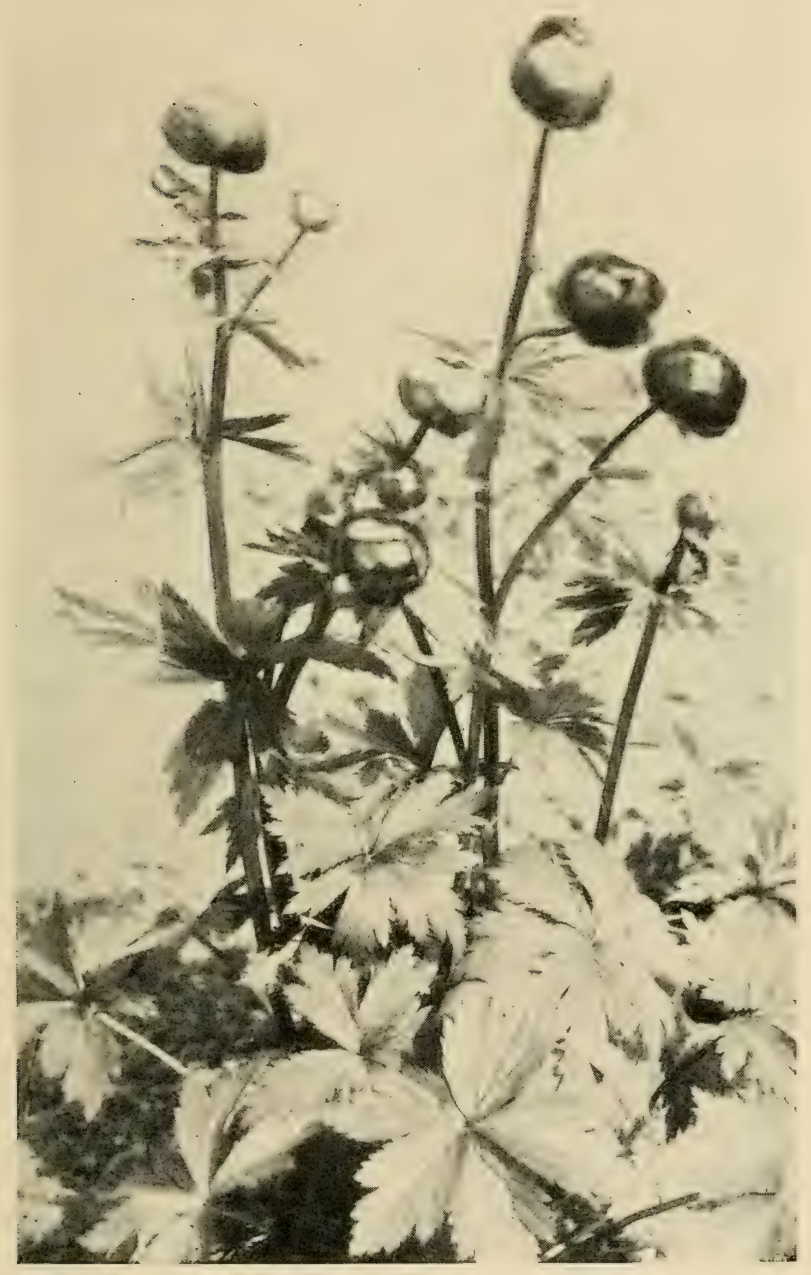

Globe Flower

(Trollius Europaus) 
the spring, nipping the shoots as they appear above the ground, or in the winter making their way through the soft unfrozen earth to the roots and so damaging these that the plants perish. It is best in applying the litter, which should consist of leaves-preferably the leaves of hard-wooded trees-or clean straw, to lay on at first a light covering and to add to this later as the season advances and the severity of the weather may suggest.

The purpose of the covering is not so much to keep the ground from freezing as to protect the plants from the rending, tearing and upheaving effects of the alternate freezing and thawing. It is this, rather than extreme or prolonged cold, that damages hardy perennials and the spring-flowering bulbs. The covering, therefore, should be only heavy enough to protect the beds or borders from this danger. And it should be of such a nature that it will not pack or settle heavily on the surface of the soil and smother the plants by excluding the air.

\section{PLANTING SEASON}

Thile the perennials may be planted in the fall as well as in the spring, unless the plants can be obtained early in the fall it is better 
as a rule to plant in the spring. The contention that fall planting is as safe as spring planting is due largely to the desire of various nurserymen to relieve themselves of a portion of the spring rush. In the spring they have thousands of orders for seeds, and for summerblooming or bedding plants to fill, and it is to

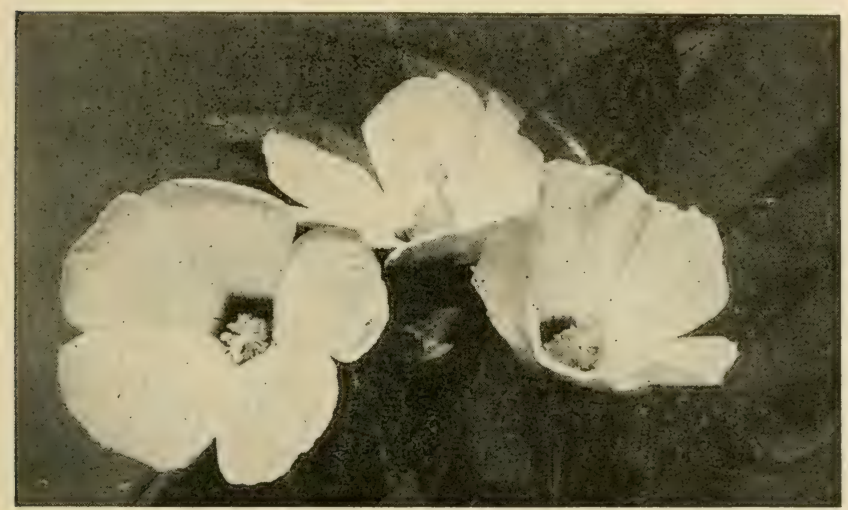

Swamp Rose (Hibiscus Moscheutos, var. "Crimson Eye")

their advantage usually to urge autumn planting of such plants as can with any safety be set out at that season of the year.

As a rule, however, in the fall nurserymen will not disturb their plants until the season's growth is matured-which is only proper-but in many instances this is so late in the autumn 
that in sections of the north plants thus obtained can not establish themselves before the deep hard freezes of winter set in. The plants are not well prepared as a result to resist the cold, and, in the following spring, the gardener is likely to find that many of the plants have perished. He rushes to the conclusion, then, that perennials are anything but hardy and makes up his mind that hereafter he will content himself with the usual spring planting of annuals. But where it is possible to obtain perennials early enough in the fall to insure some root growth in their new quarters before winter, the fall is quite as good a season for planting as the spring. Many gardeners have found that they are not able to obtain nurserygrown plants before October. In some sections October is early enough but in other sections it is too late and where this is obviously the case or, in other words, where the winter sets in early, fall planting is not at all advisable and the perennials should not be set out until spring.

\section{- PREPARATION OF BEDS}

Beds or borders wherein the herbaceous perennials are to be planted should be extraor- 


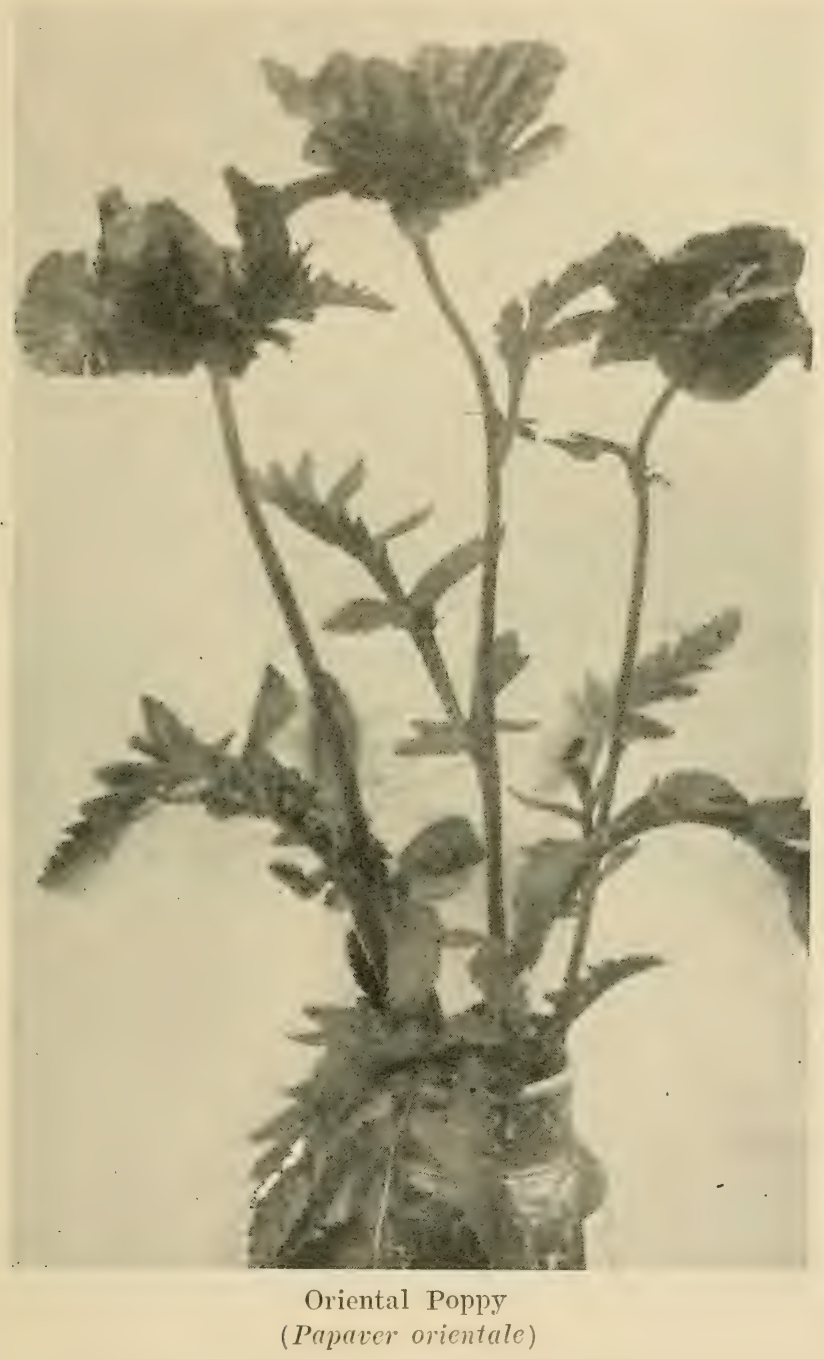


dinarily well prepared for it must be borne in mind that the plants are not anmuals and that they are to remain undisturbed where they are set for three or four seasons. The most of them, moreover, are gross feeders and require more plant food than the annuals. All the beds should be worked to a depth of two feet, though in some instances eighteen inches is sufficient. It is safer, however, to cultivate the soil to the greater depth-in by far the majority of instances this is required. In a word, every effort should be made by the gardener to provide ample depth for the growth of the roots, as it is only from vigorous root growth that the perennials can reach a state of perfection. The depth also is necessary to insure the plant against drought.

Underground drainage should be carefully looked to, especially in the borders where it is not intended to give the plants much attention until they have attained sufficient growth to demand lifting and dividing. Also it must be remembered that unless the drainage is good, plants will be in danger in winter when the frost penetrates to a sufficient depth to reach any water which may remain about their roots. In spading up the bed the sub-soil should be 
mixed with a portion of the surface soil. It is not necessary to supply the former with any great amount of plant food, but in the spit abore it there should be plenty of fertilizer, and the best for this purpose is well-rotted cow manure. In the fall a late top dressing of manure will assist in maintaining the fertility of the soil

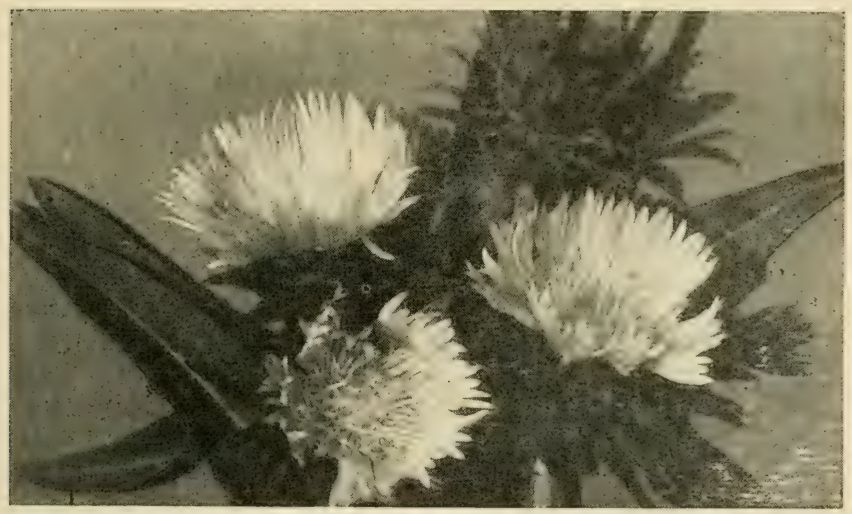

Stoke's Aster (Cyanea Stoliesia)

and likewise afford winter protection. It is essential, however, not only to see that the soil is not impoverished but that it is not over enriched; a surplus of food tends to weaken the plants and to render them liable to damage from the frost. In this connection it is well to emphasize once more the necessity for deep 


\section{YARD AND GARDEN}

cultivation. Plants afforded a suitable rooting depth are less likely to be injured by a surplus of fertilizer than those which find it impossible to obtain a deep root-hold.

\section{CULTIVATION FROM SEED}

The middle of July is a good time to sow seeds of perennials. Good-sized plants may be

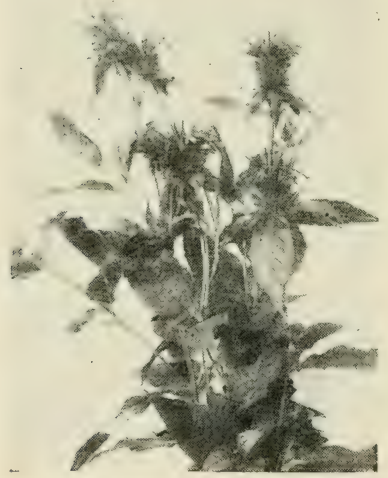

Bee Balm

(Monarda didyma)

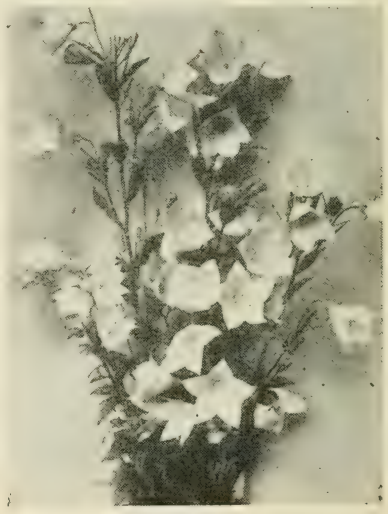

Balloon Flower (Platycodon grandiflorum)

obtained before cold weather sets in and these will make blooming plants in many instances the following summer. Prepare the seed bed carefully, providing a depth of a foot, and pulverize the soil even more finely than that prepared 
for the seeds of anmuals in the spring. Sow the perennials in shallow drills about four inches apart, thinning the seedlings as they begin to crowd or transplanting to other beds. It must be remembered that July sun is a good many degrees hotter than the sun of early May. Annuals planted at the latter time are not likely to suffer greatly from scorching, but perennials, submitted to mid-summer heat and drought, have a hard struggle unless some shade is provided. A covering of laths is good for the purpose and these may be employed by erecting a framework two feet above the seed bed and upon this distributing the strips so that intervals of two inches are left between them. A shade will then be cast over the bed, but enough sun also will fall upon the ground to keep the seedlings in good health and the soil sweet. Water carefully, using a spray, and applying the moisture so gently that the plantlets will not be washed from their hold on the soil.

In the autumn, if the seedlings have attained a fair size and are healthy and vigorous, they may be transplanted to their permanent places in the border. Here they will come through the winter unscathed if the usual protection is af- 


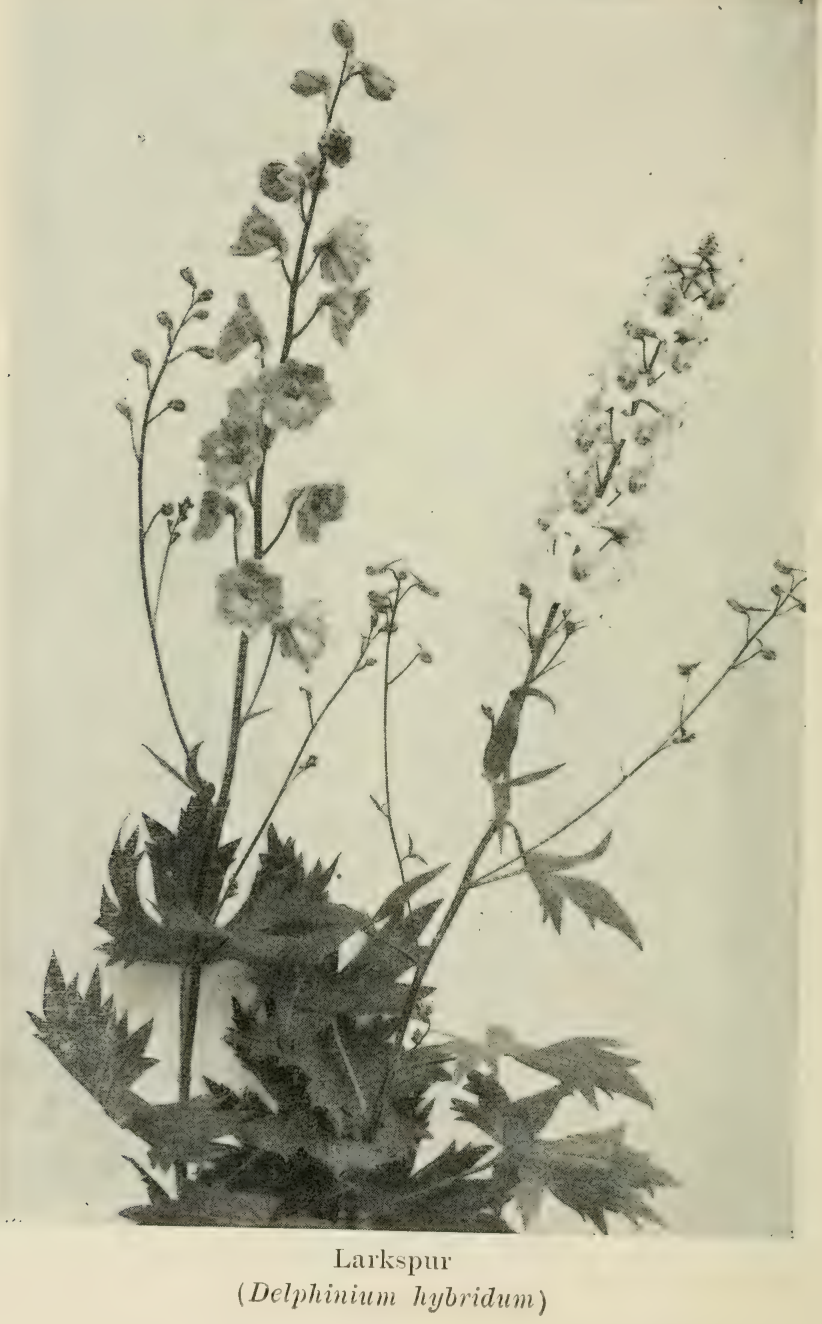


forded them and they are transplanted early enough to insure their reesstablishing themselres before winter freezing puts an end to their efforts in this direction. Seedlings so grown are very often healthier than those obtained from nurseries. They transplant better, too, for their roots are exposed but a comparatively short time and they suffer nothing through transit.

\section{SHORT-LIVED PERENNIALS}

Many of the perennials are best when treated as biennials. The lives of such are not long and the yearly renewal insures sturdy, vigorous, flowering plants. Among these short-lived perennials are the chimney bellflower (Campanula pyramidalis), Rocky Mountain columbine (Aquilegia corulea), Iceland poppy (Papaver nudic(rule), etc. On the other hand, to attempt to raise some varieties from seed is to invite failure. Some species have been greatly improved and, in many such instances, propagation by means of seed is almost sure to result in seedlings of altogether inferior description. The better means of propagating such varieties is by division of the roots either in early spring or in the autumn. To this class many of the 
peremnial phloxes belong and the hardy chrysanthemums, the Japanese iris and the peonies.

\section{ROOT DIVISION}

Propagation by root division is not difficult to effect. Either the early spring or autumn may be chosen for the work. The old plant

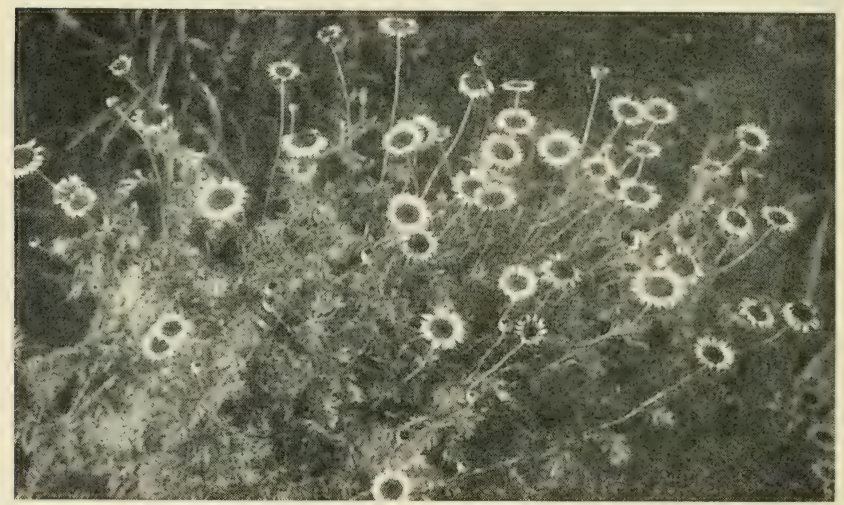

Golden Marguerite (Anthemis tinctoria)

should be carefully lifted, avoiding as much as possible damage to the root system, and the earth adhering to the roots should be shaken off or washed away by immersion in water. The root-stock and the tender rootlets leading from it are then fully exposed and the propagator can see clearly where and how to cut. No 
general rule for the cutting operation can be set down-different plants require different treatment. Some separate readily, the gardener finding himself in possession of half a dozen small plants almost as soon as the soil is cleared away, and with comparatively little cutting; others require the use of a knife or a similar instrument in order to effect the division. In the main, propagation by this method is simply the separation of a large clump of roots and crowns into smaller plants. In the case of plants possessing root stubs with buds or "eyes"-as the peony-the division, if desired, may be carried to the extreme where only a single bud to a piece of root is retained. It is well in all propagation by division to divide those species in the autumn that bloom before July and those in the spring that bloom later in the year.

The separation of hardy perennials, however, is more often practised in small yards and gardens to avoid over-crowding of roots and crowns. An iris, for instance, if allowed to remain undisturbed in a bed or border for half a dozen years, forms a circular mass of hard root-stock from the center of which no leaf or flower stalks appear. Overcrowding is the 
cause of this "rim" blooming and the symptom itself should be indication enough that the time for division is at hand. All the perennials benefit naturally when lifted and divided; some, indeed, actually crowd or grow themselves out

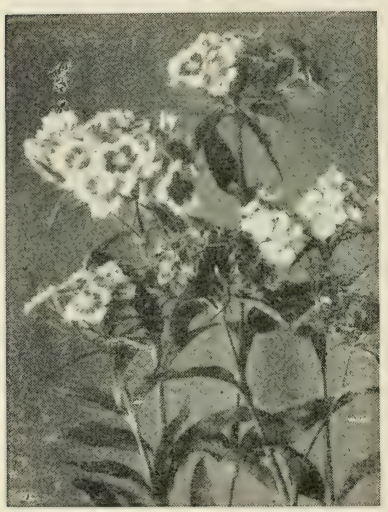

Sweet William

(Dianthus barbatus)

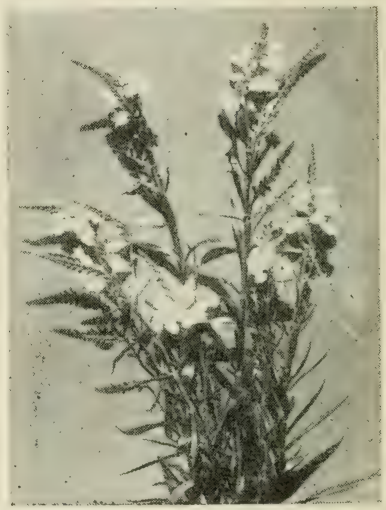

False Dragon-Head (Physostegia Virginiana)

of existence. But it is scarcely possible to establish any rule for the practice-some plants will do best when allowed to remain four or five years without disturbance, while others will thrive only when divided every two seasons. The peony is an example of the former class and Phlox maculata of the latter. 


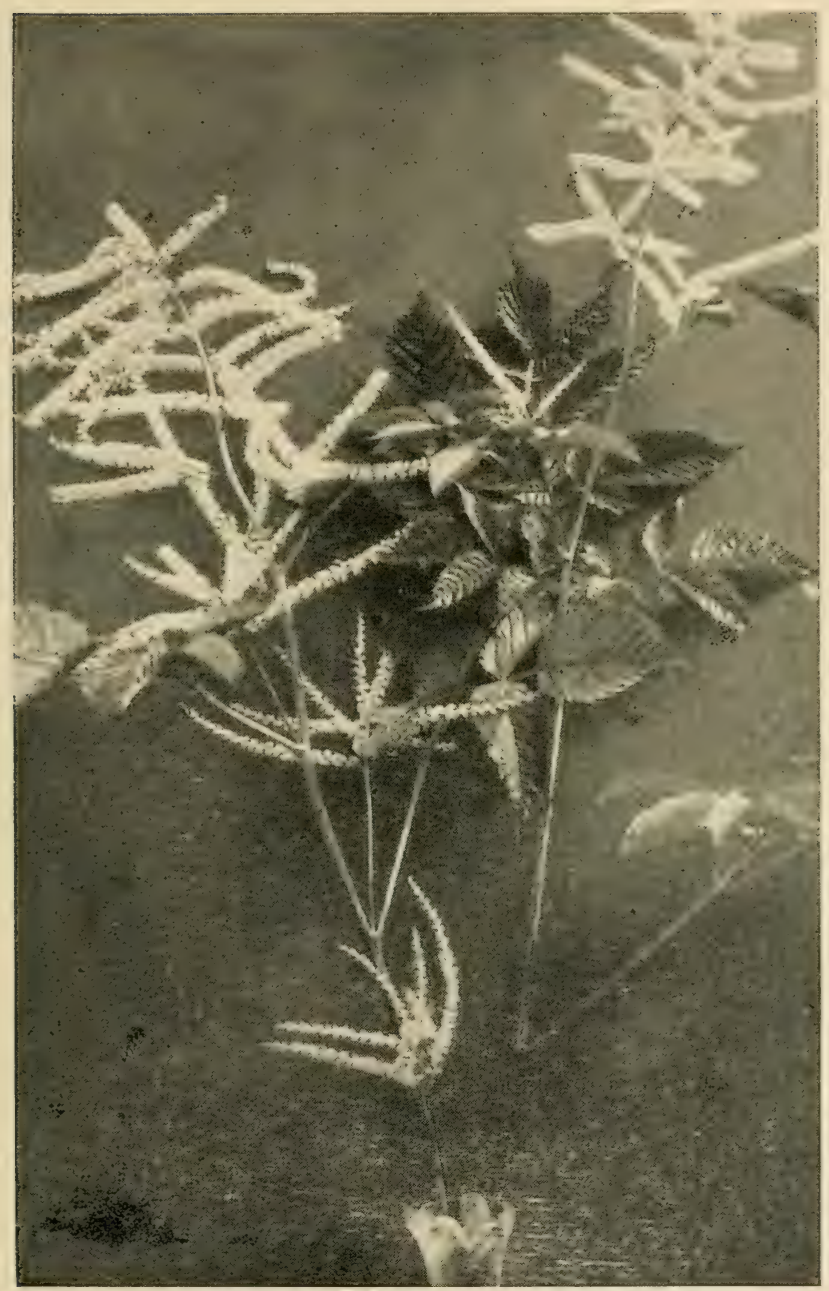

Spiræa

(Aruncus astilboides, known to the trade as Spirca aruncus) 


\section{PROPAGATION BY CUTTINGS}

Another method of propagation is by cuttings, but it rarely proves successful in the hands of the amateur. If he will provide himself, however, with a box of clean, sharp sand, and is prepared to give the cuttings the attention they require, failure need not by any means be the result of his efforts in this direction. Select a short piece of a foliage stem where the growth possesses a bud, lateral or terminal, and, making a clean cut with a sharp knife, insert the lower end of the cutting thus obtained in the moist sand. It is always best to have the lower end of the slip a node of the stem. Remove a part of the foliage of the cutting before insertion and cover the sand with glass in order to maintain the rooting medium at a slightly higher temperature than the ordinary atmosphere. Propagation by this method has the advantage of insuring quick results and the perpetuation of the parent variety-not always certain, as already said, when seed is the only reliance. 


\section{CHAPTER VIII}

SOME OF THE POPULAR PERENNIALS

It is doubtful whether a really comprehensive list of the most popular species of perennials could be prepared without doing some member of the large plant family an injustice. However, a consensus of opinion seems to indicate that the following sorts belong in such a list: iris, peony, larkspur, hollyhock, phlox, anemone, columbine, hemerocallis, funkia, and rudbeckia. To these also might be added bleeding heart, lily-of-the-valley, helianthus, chrysanthemum, coreopsis, dianthus, campanula and poppy, and still the list would be by no means complete. Nuch, of course, depends on the tastes and desires of the individual and also upon the purpose for which the plants are to be employed.

This brings us once more to the fact that perennials afford material for almost every requirement. We have them for sunny and for shady situations; for rich soil, clay soil and 
sandy soil; for quiet and for bold effect; for purely decorative value and for cut-flower purposes; for forbidding, cold and windy stretches and for sheltered positions; for naturalizing and for more formal planting; for bloom in spring, in summer and in autumn, and in al-

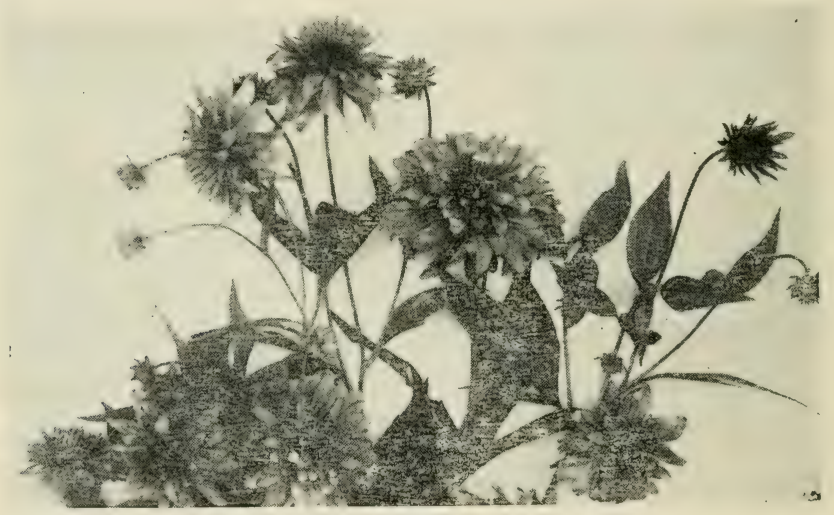

Golden Glow (Rudbeclia laciniata)

most every variety of color and in varying heights.

Take for example the succession of bloom possible to be obtained by the use of herbaceous perennials alone. The following list suggests the possibilities but by no means exhausts the varieties $^{*}$ :

* The common trade or catalogue names are used in this list. 


\section{POPULAR PERENNIALS}

APIIL

Name

Adonis vernalis

Aquilegia Canadensis

Arabis albida

Aubrietia deltoidea

Dicentra spectabilis

Helleborus niger

Helleborus orientalis, var. atrorubens

Hepatica triloba

Iris verna

Sanguinaria Canadensis

Trillium erectum
Height

Color

$1 \mathrm{ft}$. Yellow

1 to $2 \mathrm{ft}$. Scarlet

6 to 8 in. White

3 to 8 in. Dark violet

$11 / 2$ to $2 \mathrm{ft}$. Pink

9 in. White

9 to 12 in. Purple

6 in. Light blue

6 in. Blue

8 in. White

12 in. Brownish red

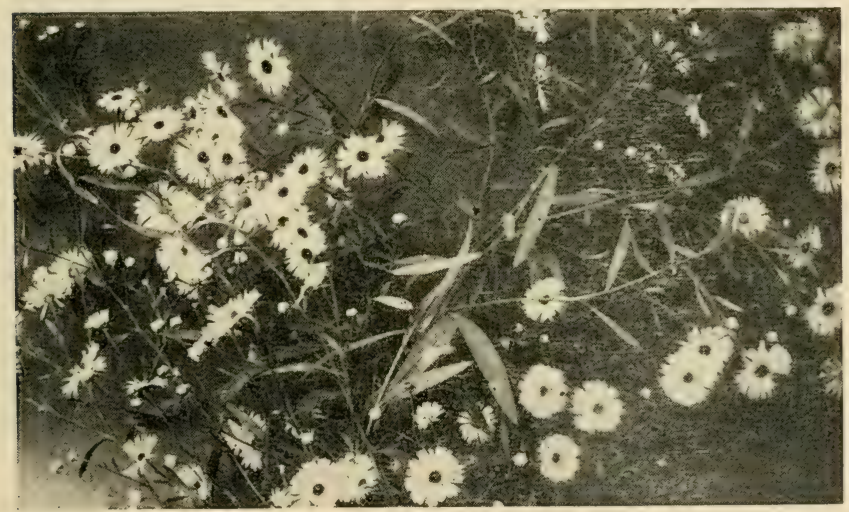

Boltonia (Boltonia asteroides)

MAY

Aquilegia, in variety Alyssum saxatile Anemone Pennsylvanica Bellis perennis

Convallaria majalis

Doronicum plantagineum, var. excelsum

$1 \frac{1}{2}$ to $2 \frac{1}{2} \mathrm{ft}$. White to blue

$1 \mathrm{ft}$. Yellow

1 to $2 \mathrm{ft}$. White

6 in. White and pink

9 in. White

$11 / 2$ to $3 \mathrm{ft}$. Yellow 


\section{Name \\ MAY - Continucd \\ Height \\ Color}

Geum montanum

Iberis sempervirens

Iris Germanica, in variety $11 / 2$ to

Iris pumila

Myosotis palustris, var. semperflorens

Pæonia officinalis and vars.

Pæonia tenuifolia

Phlox divaricata

Phlox subulata

Polemonium cæruleum

Primula in var.

Trollius Europæus

12 in. Yellow

8 in. White

$3 \mathrm{ft}$. Purple and lavender

8 in. Violet

8 in. Light blue

$11 / 2$ to $3 \mathrm{ft}$. Various

12 to $18 \mathrm{in.}$ Crimson

10 to $18 \mathrm{in.} \mathrm{Lilac-blue}$

Creeping Pink, blue, white

1 to $3 \mathrm{ft}$. Blue

$11 / 2$ to $2 \mathrm{ft}$. Yellow, pink, pur-

$11 / 2$ to $2 \mathrm{ft}$. ple

JUNE

Aquilegia, in variety

Armeria maritima

Astilbe Japonica

Baptisia australis

Callirhoe involucrata

Campanula Carpatica

Campanula persicifolia

Chrysogonum Virginianum

Clematis recta

Coreopsis lanceolata

Coronilla varia

Delphinium formosum

Dianthus barbatus

Dianthus plumarius, in variety

Dicentra eximia

Dictamnus albus

Digitalis purpurea

Erigeron speciosus

Gaillardia aristata

Geranium sanguineum

Geum coccineum

Helenium Hoopesii

Hemerocallis Dumortierii

$11 / 2$ to $2 \frac{1}{2} \mathrm{ft}$. White to blue

6 to 9 in. Pink

1 to $3 \mathrm{ft}$. White

$3 \mathrm{ft}$. Blue

9 to 12 in. Violet crimson

10 in. Blue and white

$11 / 2$ to $3 \mathrm{ft}$. Violet

$10 \mathrm{in.}$ Yellow

2 to $3 \mathrm{ft}$. White

$11 / 2$ to $2 \mathrm{ft}$. Yellow

$11 / 2$ to $2 \mathrm{ft}$. Bright pink

$\tilde{3}$ to $4 \mathrm{ft}$. Deep blue

$11 / 2$ to $2 \mathrm{ft}$. Mixed colors

9 to 12 in. White to pink

1 to $2 \mathrm{ft}$. Rose

2 to $3 \mathrm{ft}$. White

3 to $4 \mathrm{ft}$. White and purple-

$1 \frac{1}{2} \mathrm{ft}$. Lilac spotted

$11 / 2 \mathrm{ft}$. Yellow and maroon

12 to $18 \mathrm{in}$. Crimson

12 to 18 in. Scarlet

2 to $3 \mathrm{ft}$. Orange-yellow

$11 / 2$ to $2 \mathrm{ft}$. Orange 


\section{JUNE-Continucl}

Name

Iris Germanica, in var.

Iris lævigata

Iris pallida

Iris Pseudacorus

Iris Sibirica

Lychnis Coronaria

Lyehnis Haageana

Lychnis Viscaria, var. splendens

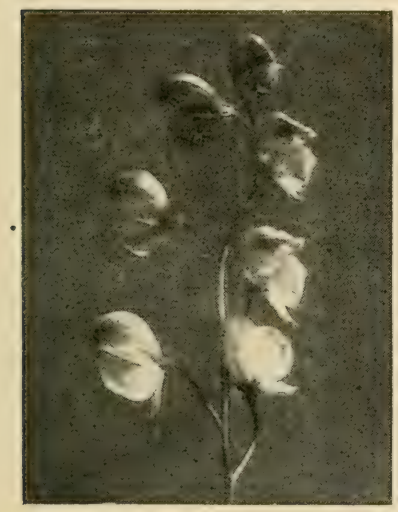

Monkshood

(Aconitum Napellus)

\section{Height}

$2 \mathrm{ft}$. Purple and lavender

3 to $31 / 2 \mathrm{ft}$. Various

2 to $3 \mathrm{ft}$. Indigo-blue

$2 \mathrm{ft}$. Yellow

$2 \mathrm{ft}$. Violet

$11 / 2$ to $2 \mathrm{ft}$. Crimson

12 in. Red

18 in. Blood-red

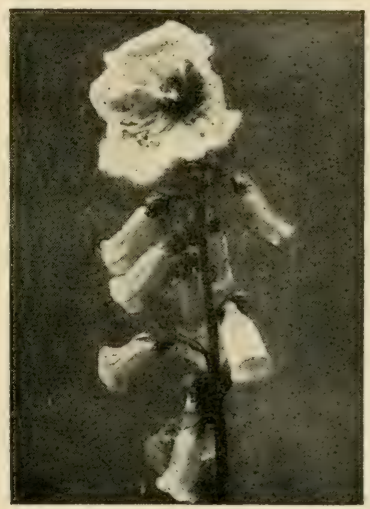

Foxglove

(Digitalis monstrosa)

Lysimachia nummulari

Lysimachia punctata

Enothera fruticosa

Papaver nudicaule

Papaver orientale

Pentstemon lævigatus, var.

Digitalis

Pyrethrum roseum

Seabiosa Caucasica

Spiræa Aruncus \begin{aligned} & Creeping Yellow \\ & 1 to $3 \mathrm{ft}$. Yellow \\ & $1 / 2$ to $3 \mathrm{ft}$. Yellow \\ & 12 to $15 \mathrm{in}$. White, yellow and \\ & \multicolumn{3}{c}{ orange }\end{aligned}

2 to $21 / 2 \mathrm{ft}$. Orange, scarlet

2 to $3 \mathrm{ft}$. White

$11 / 2$ to $2 \mathrm{ft}$. Pink and red

15 to $18 \mathrm{in}$. White and blue

4 to $5 \mathrm{ft}$. White 


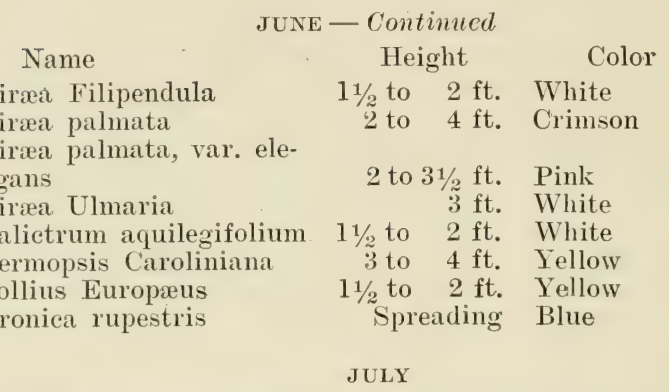

Achillea Millefolium, var. rubrum

Achillea Ptarmica, var.

"The Pearl"

Althæa rosea, in variety

Anthemis tinctoria

Belemeanda Chinensis

Calimeris incisa

Campanula alliariæfolia

Campanula glomerata, var. Dahurica

Campanula Trachelium

Centaurea montana

Chrysanthemum maximum, var. Triumph

Chrysanthemum Leueanthemum hybridum

Cimicifuga racemosa

Delphinium grandiflorum, var. Chinense

Digitalis ambigua

Echinacea purpurea

Eryngium amethystinum

Euphorbia corollata

Funkia Fortunei

Funkia lancifolia

Funkia ovata

Gypsophila paniculata

Heliopsis lævis, var.

Pitcheriana

Hemerocallis, in variety

Heuchera sanguinea

Inula ensifolia

1 to $3 \mathrm{ft}$. Red

$11 / 2$ to $2 \mathrm{ft}$. White

4 to $5 \mathrm{ft}$. White to crimson

$11 / 2$ to $2 \mathrm{ft}$. Yellow

3 to $4 \mathrm{ft}$. Orange, spotted red

$11 / 2$ to $2 \mathrm{ft}$. Lavender-blue

$2 \mathrm{ft}$. White

$11 / 3$ to $2 \mathrm{ft}$. White

2 to $3 \mathrm{ft}$. Light purple

15 to 18 in. Purple

$11 \frac{12}{2}$ to $2 \mathrm{ft}$. White

$11 / 2$ to $2 \mathrm{ft}$. White

3 to $8 \mathrm{ft}$. White

2 to $3 \mathrm{ft}$. Blue

2 to $3 \mathrm{ft}$. Yellow

$2 \frac{1}{2}$ to $3 \mathrm{ft}$. Purple

$11 / 2$ to $2 \mathrm{ft}$. Amethyst-blue

1 to $3 \mathrm{ft}$. White

$2 \mathrm{ft}$. Pale lilac

$2 \mathrm{ft}$. Pale lilac

$2 \mathrm{ft}$. Lavender

2 to $3 \mathrm{ft}$. White

3 to $4 \mathrm{ft}$. Yellow

$21 \%$ to $3 \mathrm{ft}$. Yellow and orange

12 to 18 in. Coral-red

8 in. Yellow 


\section{POPULAR PERENNTALS}

\section{JULY - Continued}

Name

Lavandula vera

Lychnis Chalcedonica

Lychnis respertina, var. flore-pleno

Lysimachia clethroides

Nonarda didyma

Enothera Missouriensis

Cnothera fruticosa, var. major

Enothera speciosa

Pentstemon barbatus

\section{Height}

1 to $3 \mathrm{ft}$. Lavender-blue $21 / 2$ to $31 / 2 \mathrm{ft}$. Searlet

1 to $2 \mathrm{ft}$. White

2 io :3 it. White

2 to $3 \mathrm{ft}$. Searlet

10 in. Yellow

15 to 18 in. Yellow

l.2 to ls in. White

2 to $3 \mathrm{ft}$. Scarlet

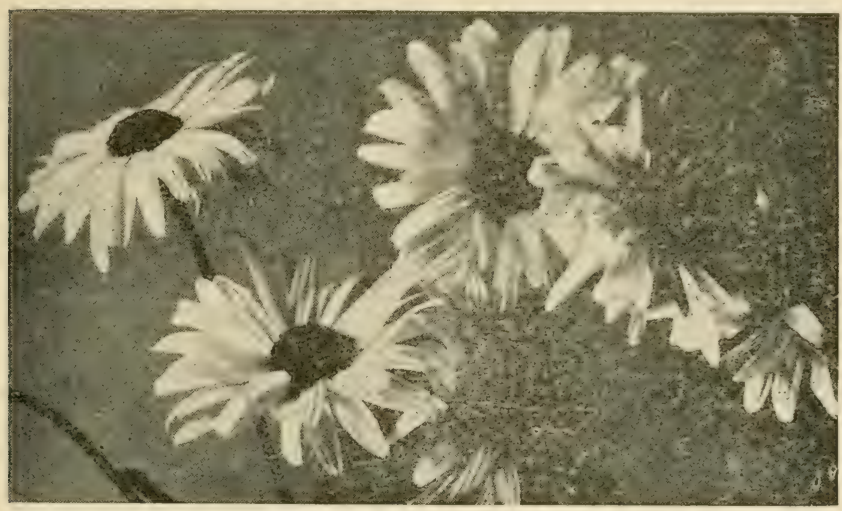

Chrysanthemum, "Shasta Daisy"

Pentstemon ovatus

Phlox paniculata, in variety

Platycodon grandiflorum

Spiræa lobata

Stachys Betonica

Statice Tatarica

Stokesia cyanea

Tradescantia Virginiana

Veronica longifolia, var.

$$
\text { rosea }
$$

Veronica Virginica
2 to $3 \mathrm{ft}$. Rosy purple

$11 / 2$ to 5 ft. Various

$1 \tilde{5}$ to $1 \mathrm{sin}$. Blue and white

3 to $4 \mathrm{ft}$. Pink

12 to 18 in. Rosy pink

12 to $15 \mathrm{in}$. Red

15 to $18 \mathrm{in.}$ Lavender-blue

$11 / 2$ to $2 \mathrm{ft}$. Purple

2 to $3 \mathrm{ft}$. Rose

3 to $4 \mathrm{ft}$. White 
Name

Asclepias tuberosa

Aster Novæ-Angliæ, var. roseus

Bocconia cordata

Boltonia asteroides

Boltonia latisquama

Clematis Davidiana

Funkia subcordata, var. grandiflora

Helenium in var.

Helianthus in var.

Hibiscus Moscheutos, var. Crimson Eye

Liatris graminifolia

Liatris spicata

Phlox paniculata in var.

Physostegia Virginiana

liudbeckia laciniata, var. Golden Glow

Rudbeckia triloba

Vernonia Arkansana

Veronica longifolia, var. subsessilis

\section{SEPTEMBER}

Aconitum Fischeri

Aster Amellus, var. elegans

Campanula pyramidalis

Ceratostigma plumbaginoides

Chelone Lyoni

Chelone obliqua, var. alba

Chrysanthemum in var.

Conoclinium cœlestinum

Eupatorium ageratoides

Helenium in var.

Helianthus in var.

Lobelia cardinalis

Lobelia syphilitica

Phlox paniculata, in variety

\section{ALGUST}

Height

$1 \frac{1}{2}$ to $2 \mathrm{ft}$. Orange

4 to $7 \mathrm{ft}$. Bright rose

4 to $6 \mathrm{ft}$. White

4 to $6 \mathrm{ft}$. White

$4 \mathrm{ft}$. Light lilac

2 to $3 \mathrm{ft}$. Lavender-blue

$2 \mathrm{ft}$. White

$11 / 2$ to $6 \mathrm{ft}$. Yellow

2 to $10 \mathrm{ft}$. Yellow

4 to $5 \mathrm{ft}$. White, crimson center

$1 \frac{1}{2}$ to $2 \mathrm{ft}$. Rosy purple

3 to $4 \mathrm{ft}$. Deep purple

$11 / 2$ to $5 \mathrm{ft}$. Various

3 to $4 \mathrm{ft}$. Deep rose

6 to $8 \mathrm{ft}$. Double yellow

3 to $4 \mathrm{ft}$. Yellow, black cone

5 to $6 \mathrm{ft}$. Purple

$11 / 2$ to $3 \mathrm{ft}$. Deep blue

2 to $3 \mathrm{ft}$. Blue

$11 / 2$ to $2 \mathrm{ft}$. Purple

2 to $4 \mathrm{ft}$. Blue

6 in. Blue

$11 / 2$ to $2 \mathrm{ft}$. Rose-purple

$11 \%$ to $2 \mathrm{ft}$. White

2 to $4 \mathrm{ft}$. Various

$11 \%$ to $2 \mathrm{ft}$. Blue

3 to $4 \mathrm{ft}$. Scarlet

$11 / 2$ to $6 \mathrm{ft}$. Yellow

2 to $10 \mathrm{ft}$. Yellow

$11 / 2$ to $3 \mathrm{ft}$. Scarlet

$1 \frac{1}{2}$ to $2 \mathrm{ft}$. Blue

$1 \frac{1}{2}$ to $5 \mathrm{ft}$. Various 


\section{POPTLAR PERENNTIIS}

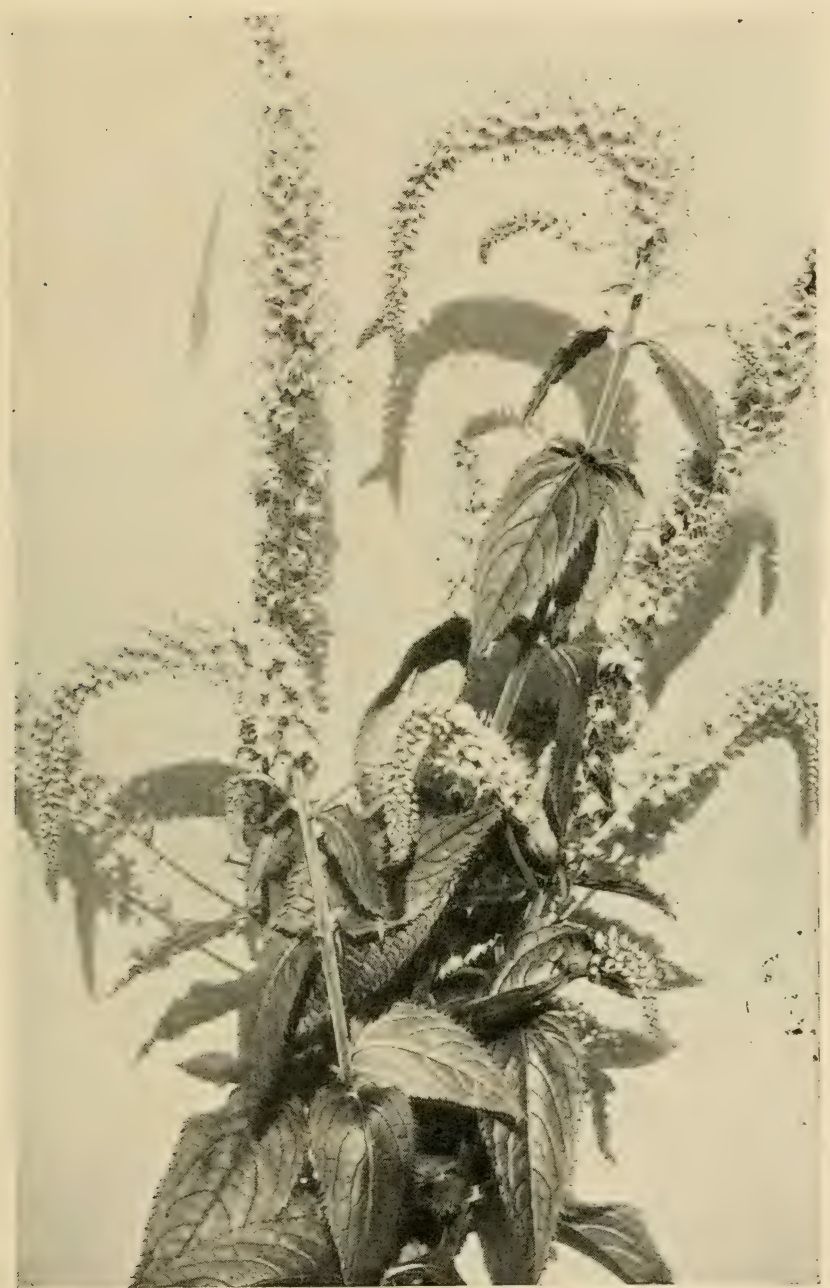

Veronica

(Veronica longifolia, var, subsessilis) 
Name

Rudbeckia in var.

Sedum spectabilie

Senecio pulcher

Aconitum autumnale

Anemone Japonica, in variety

Aster Tataricus

Chrysanthemum in var.

Solidago, in variety

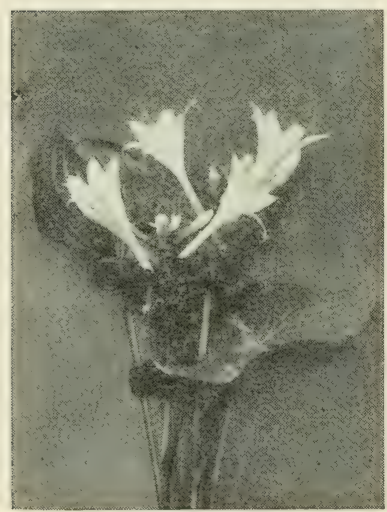

Plantain Lily

(Funkia subcordata var. grandiflora)
SEPTEMBER - Continued

Height

1 to $8 \mathrm{ft}$. Yellow

12 to $15 \mathrm{in}$. Rose

$11 / 2$ to $3 \mathrm{ft}$. Rosy purple

\section{OCTOBER}

4 to $6 \mathrm{ft}$. Blue

2 to $3 \mathrm{ft}$. White to carmine

4 to $7 \mathrm{ft}$. Purple

2 to $4 \mathrm{ft}$. Various

2 to $5 \mathrm{ft}$. Yellow

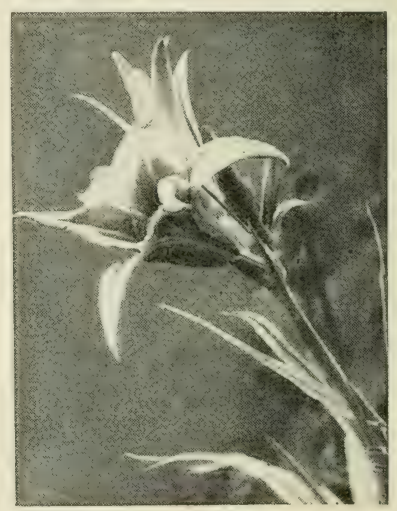

Yellow Day Lily

(Hemerocallis aurantiaca, var. major)

[This list is based on an average season in the latitude of Philadelphia; a rough and ready calculation allows six days' difference, either earlier or later, to every degree of latitude south or north.] 


\section{CARE AND ARRANGEMENT OF PERENNIALS}

Trhile perennials, once estahlished, demand little attention compared to ammuls, this does not mean that they will continue healthful and

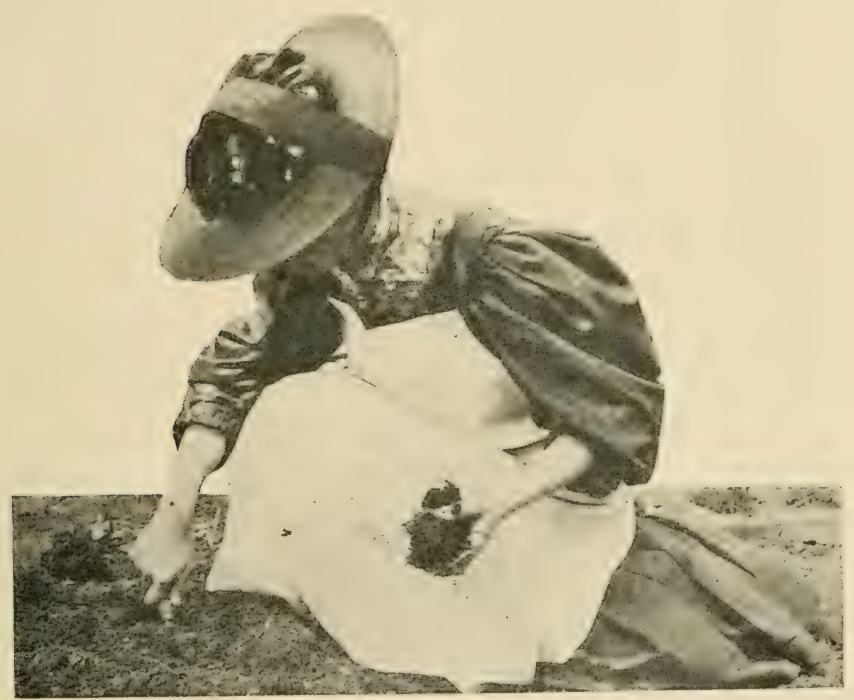

Transplanting hardy perennials

vigorous if neglected. On the contrary, they demand care and cultivation. In addition to the division, which must not be neglected where the plants show plainly-as they will-that they need it, reeds must be suppressed and 
the surface soil must be kept open and loose. For this latter purpose, as well as for weeding, no tool is better than a digging fork with prongs three inches long and an inch apart. In pulverizing the surface soil with this, be careful not to injure surface roots and avoid working the ground when it is wet. Watering, also, must be looked after wherever water for such purposes is available-few city yards are without such supply-and the moisture should be applied liberally. Soak the ground thoroughly, not merely sprinkling the surface and the foliage of the plants, and make sure that the supply reaches the roots.

It can be readily understood that no arrangement of perennials in beds or borders that does not take into consideration the heights, colors and blooming periods of the plants can prove satisfactory. It is necessary to know the heights of the various species employed in order to avoid planting the taller-growing varieties in front of the dwarf sorts; it is necessary to know the colors of the bloom in order to avoid a clash of tints and shades which, if grown in juxtaposition, would prove anything but harmonious; and it is necessary to know the blooming seasons of the plants in order to 
insure a succession of flowers. When these few points are mastered-surely not much to know about plants which are to be introduced in our yards or gardens as our companions for sereral year's to come-effective grouping's can be arranged without difficulty. For instance, where peonies are planted, phloxes could also be used; the bed or border then would not be barren of bloom when the peonies have departed in early summer. As another instance, oriental poppies would not he planted by themselves if the situation selected were a conspicuous one, for the planner and planter would know that, by the end of June, when the poppies have bloomed, the foliage of the plants becomes ragged and, a little later, disappears entirely. To aroid learing a gap in the border or a barren hed in the yard, other perennials, later in their period of blooming, would be planted with the poppies to follow with flower and foliage when the latter have ceased to be decorative.

Perennials serve another exceedingly useful purpose when planted with shrubs. When the blossom of the latter has passed, the herbaceous plants will throw their flower spikes to add a touch of color here, another there, to groups which otherwise would be without flower. 


\section{CHAPTER IX}

BULBOUS- AND TUBEROUS-ROOTED PLANTS

No class of plants presents more commendable features for planting on the small city lot than the bulbous- and tuberous-rooted section and none will more richly reward the amateur for the labor and time he may expend in establishing them. They are almost certain to prosper uncler his treatment, provicled a few simple and easily mastered rules are followed. Much of the spring charm of well-planted yards can be attributed almost exclusively to the free use of plants of this order and so far as later months are concerned, we have only to reflect upon the many flower's of this character, blooming until autumn frosts cut them down, to recognize and appreciate their extraordinary claims upon our attention.

Frery year hundreds of thousands and probably millions of hyacinths, tulips, crocuses, narcissi and other hulhs are planted and, considering the immense numbers set out, it is 


\section{BULBS}

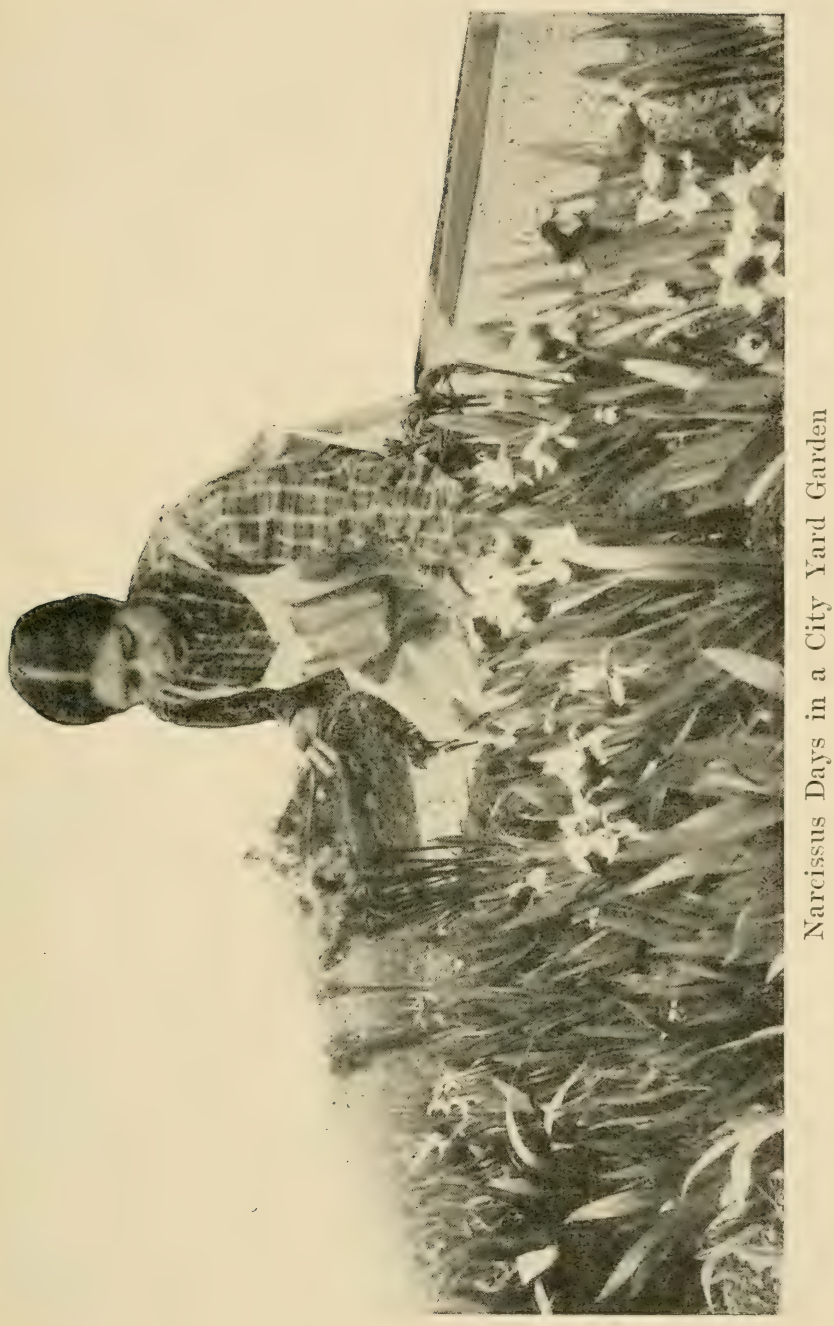


safe to say that no other class of plants brings so few disappointments to the cultivator. This is accounted for, of course, by the great ease with which they may be brought into bloom and by the readiness with which they seem to be able to adapt themselves rapidly to various conditions of soil and situation. Only occasionally do they fail, but even in such instances, provided the bulbs have been properly planted, the fault can not always be laid at the door of the amateur. It may be traceable to the bulb beds of Holland where the plants were brought forward to the flowering stage before they were offered to purchasers.

\section{VARIETY OF TUBEROUS PLANTS}

In speaking of bulbs, botanical definitions are not generally observed. Commercially the ter'm applies to a considerable class of flowering and ornamental plants which, were it strictly employed, would be excluded from the list. Nurserymen and dealers in seeds and bulbs, however, include in this class in addition to true bulbs many that are known by botanists as corms, such as the Crocus and Gladiolus; succulent tubers, as the Dahlia; fleshy, creeping rhizomatous roots, such as are possessed by 
some varieties of iris; pips, such, for example, as the flowering crowns of the lily-of-the-valley and other fasciculated fleshy roots, such as those of the ranunculus or peony.

Very few present any difficult problems so far as cultivation is concerned and the commoner sorts especially are easily raised. As a rule, all of them produce flowers of extraordinary beauty which not infrequently are deliciously fragrant. They comprise, moreover, endless variety in color, form, size and habit, and are adaptable on this account for many purposes. An advantage, often overlooked, is the fact that, following their season of bloom, their foliage matures and falls and no part of the plant shows above the ground to present an unsightly, faded appearance. When this transition has occurred and the period of rest is entered they can in most instances be lifted and stored away for future use, and in the beds they occupied new plants may be set to continue the succession of bloom throughout the season.

Although this class embraces almost numberless varieties, nurserymen divide the group into two divisions-hardy varieties, which withstand freezing, and the tender varieties 


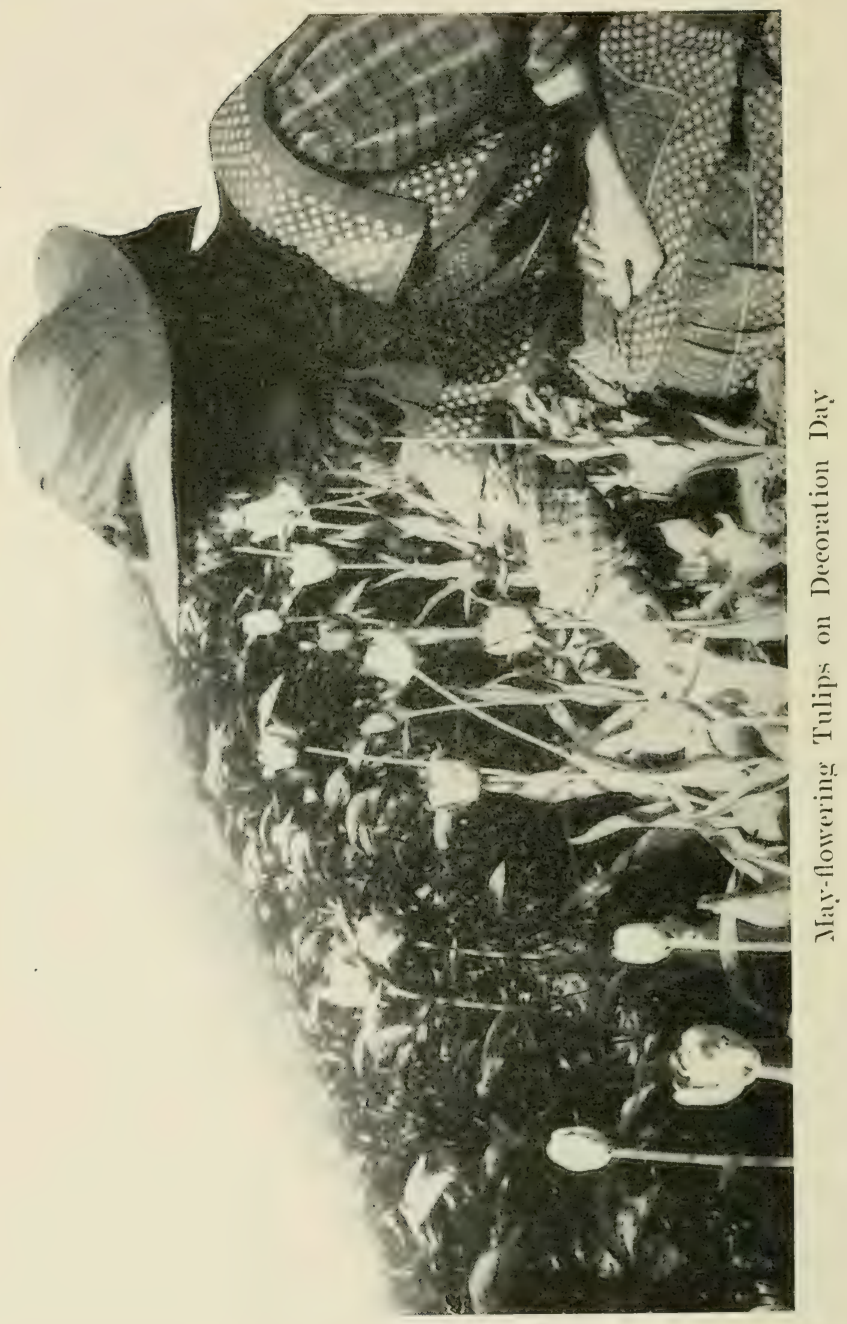




\section{BULBS}

which do not. The first is more popular although in the latter division there are a number of plants whose beauty and ease of culture should commend them for more liberal use. To the first belong hyacinths, tulips, narcissi, crocuses and similar bulbs, and to the second belong crinums, the tuberous begonias, ('ooperias, montbretias, callas (Richardias), tuberoses, tigridias and other garden bulbs usually planted in the spring.

By judicious selection of varieties from both divisions it is possible to have bulbous- and tuberous-rooted plants in bloom from frost to frost, and, if the city resident be the happy possessor of a small greenhouse or conservatory, there need be no month in the year without its wealth of bloom from this order of plants alone. In March, in the northern states, and earlier in the more southern portion of the country, snowdrops, scillas, crocuses, winter aconites and chionodoxas usher in the first days of spring with a glory of bloom all the more beautiful because of its earliness. In April come the hyacinths, tulips, narcissi, in all their numerous varieties, followed later in the month and in May by the late tulips, the poets' daffodils, and as the season progresses, hy irises, 
peonies, lilies, gladioli, montbretias, tuberoses and other similar flowering bulbs.

It is probably with the hyacinths, tulips and narcissi that we are most familiar. These are used for many purposes, appear in many situa-

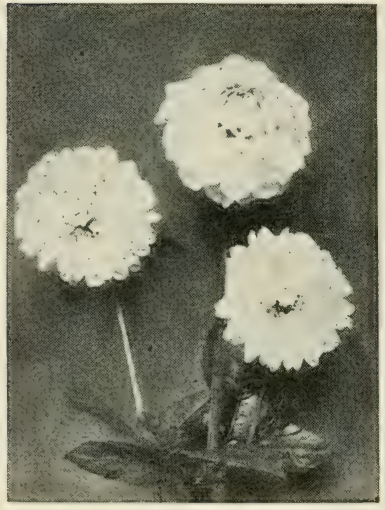

Dahlia

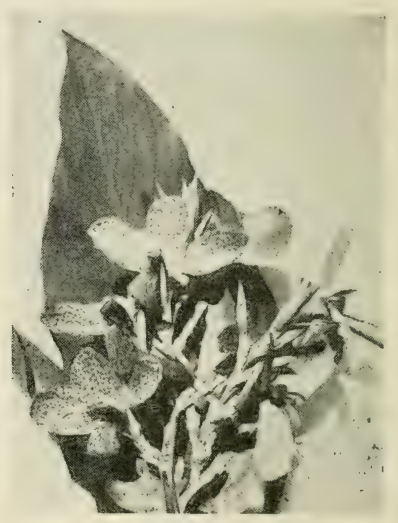

Canna

tions and, wherever and whenever they are grown, add beauty, life and color to the early months of spring.

\section{PREPARATION OF THE BED}

In the cultivation of all varieties two things are of commanding importance: first the preparation of the ground, and second the season of planting. So far as the first is concerned, 
it may be taken as a general rule that bulbs prefer a light, well-drained, moderately rich soil. Prepare the bed in which they are to grow by digging it at least fourteen inches deep. If the soil encountered is heavy and it appears that but little can be done with it by the addition of materials calculated to lighten it, throw it out and substitute good soil. In every case it is always best, if possible, to put a layer of small stones at the bottom for drainage. It is best in the long run to prepare the bulb bed carefully and, even where the soil is of proper texture, for best results it would be advisable for the cultivator to excavate it to the depth already mentioned, place the drainage on the bottom and upon this throw in the soil until it reaches a level upon which it is desired to set the bulbs. Prepare this surface, which may be anywhere from one to eight inches below the surrounding surface, by covering it with a thin layer of clean, sharp, grit sand. Place the builbs upon this blanket and then add the remaining earth until the surface of the bed stands slightly higher than the ground surrounding it. This elevation allows for settling.

While this is the best and surest process for planting the bulbs, where it is not convenient to 
follow it the beginner need not feel that failure will he the result of his efforts. On the contrary, bulbs respond generously where even indifferent treatment is given them. It will not be indifferent treatment, however, to plant bulbs in carefully spaded ground by less arduous methods. You may, for instance, content your-

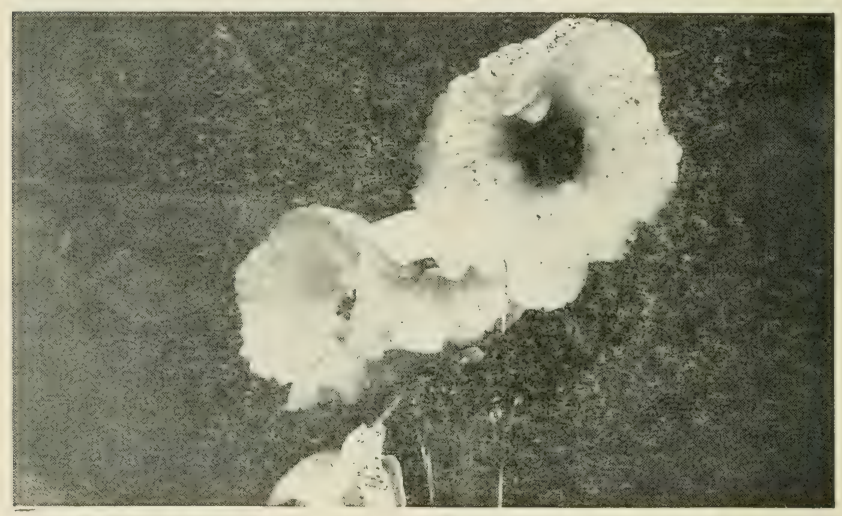

Flowers of Tuberous-Rooted Begonia

self with spading the ground to the required depth, pulverizing the surface soil, and then, by meams of a dibble, set out the bulbs. When the hole is made with this instrument it should be at a greater depth than is actually required, to permit of the addition of enough sand to form a cushion upon which the bulb may rest. 
After the bulh is inserted in the hole thus prepared, complete the process by filling the hole with earth.

\section{CULTIVATION}

Most bulbs resent the presence of fresh manure in the soil, and, though this does not mean that they do not resuire rich rooting material, they often disappoint the planter who has too generously applied his fertilizer. It has frequently been said that under no circumstances should manure be added to the soil of the bulb bed, but this can not he accepted as a guide without amendment. It would be better and more to the point to say that manure is not to be added to the soil in such manner that it will be brought into direct contact with the bulbs. By all means add the manure, but see to it that it is well rotted, is below the bulbs and is thoroughly incorporated with the soil and that the bulbs themselves are well surrounded by the cushion of sand already mentioned. In no instance, howerer, eren where the sand is most generously employed, is it safe to plant bulbs in beds containing fresh manure.

In the planting of bulbs, consideration must be had for the kind of plant with which the gar- 
dener is dealing, for some require different soil and different situation or exposure, from other's. The liliums, for example, would not prosper in a situation that would be regarded as ideal for daffodils and these, loving the sun, would find the ideal for liliums not so much to their liking. Then, too, where the area to be planted is small -as it is in most city yards-some attention should be given to the soil requirements of the different bulbous- and tuberous-rooted plants. If one kind demands more food than another, it is not difficult to satisfy its appetite, and, on the other hand, if a bulb prefer's a soil of less food value its demand may be satisfied by supplying fertilizer or manure in lighter quantities.

It is often desirable to plant the bulbs in borders instead of in beds, or between shrubs or hardy perennials. In such situations, the only requirement in many cases will be the preparation of the hole for the reception of the bulb by use of the dibble and, after adding the sand, the insertion of the bulbs. Usually the soil in borders where shrubs or perennials thrive is rich enough for bulbs but, should there be any doubt on this point, it is not by any means a matter of great difficulty to remove the top soil for a depth of six or seren inches and to incor- 


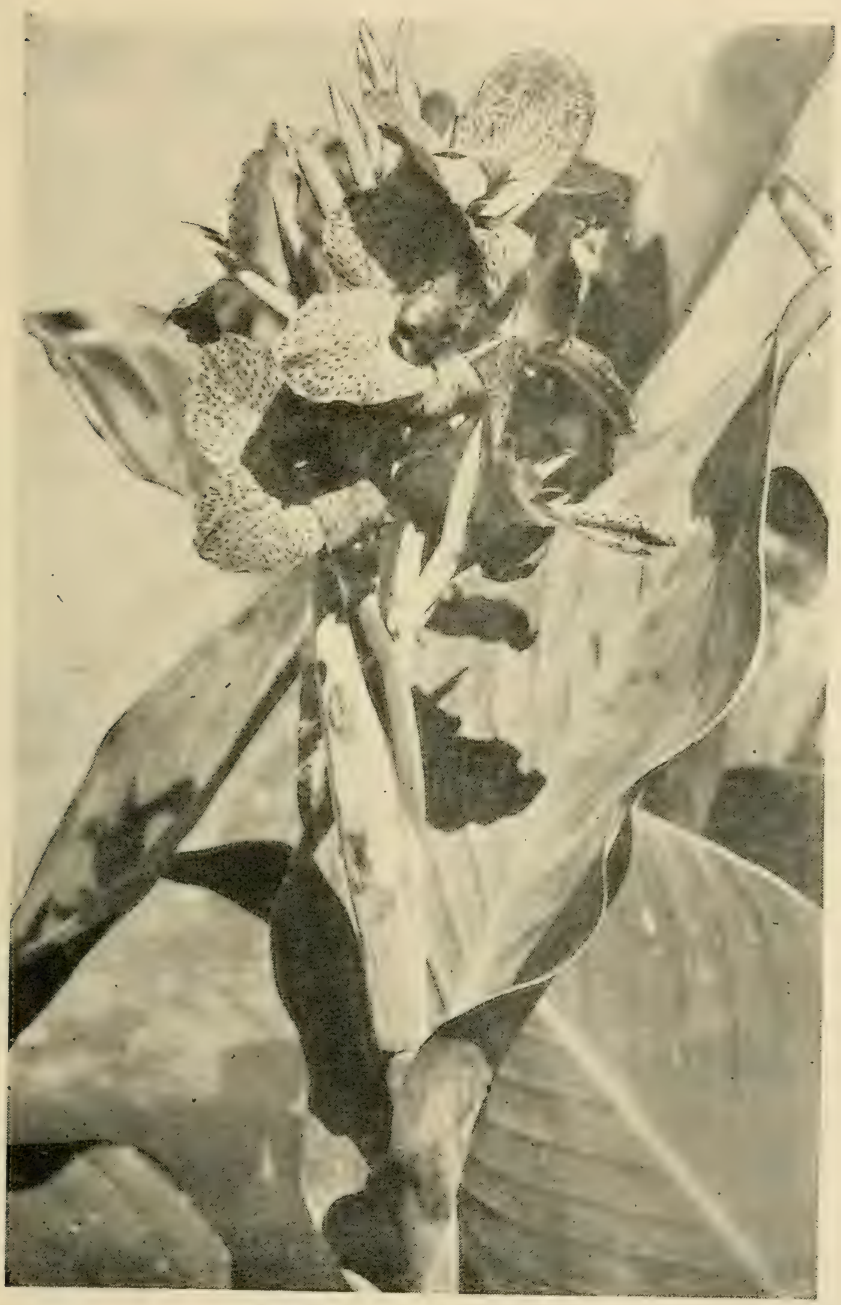

Flower of the Canma 
porate in the soil beneath enough decomposed manure to insure healthy and vigorous growth. The daffodils, of all the different kinds of bulbs that are grown in our gardens or yards, prefer the richest soil.

\section{SEASON FOR PLANTING BULBS}

Nowadays many nurserymen contend that hardy bulbs may be planted as late in the fall as the ground can be worked. Their catalogues, almost without exception, advise the purchaser that good, results are to be obtained from bulbs planted even as late as christmas and that they will flower as satisfactorily as those planted earlier in the fall. This is not only misleading, but absolutely incorrect. Bulbs planted late in the autumn are never as satisfactory as those planted earlier in the season. With daffodils, for instance, there is an absolute loss of strength and vigor when the planting is postponed later than October but when, on the other hand, the planting is done at an earlier date, even as early as the latter part of August, there is a material gain. Still, avoid too early planting, for cool weather is necessary to deter top growth, which is likely to make its appearance six weeks after the bulbs 


\section{BULBS}

are set unless winter is near enough at hand to put a stop to such a display of ambition. In short, plant the bulbs seven or eight weeks before frosty nights are likely to put in their appearance.

Many planters advise setting the bulbs from two to four times their depth beneath the surface but this must never be taken as a hard and fast rule. Lilies, for instance, require a greater depth, and in all cases the deeper the bulbs are set the later the flowers in the spring and, possibly, on this account the better the results.

\section{WINTER PROTECTION OF BULBS}

In the case of the spring-flowering varieties, winter protection should be afforded as soon as the ground freezes slightly in the autumn. Do not cover the beds with the idea in mind of preventing the light freezing, but rather with the idea of overcoming the heaving of the soil due to alternate freezing and thawing. Use leaves - preferably those from hard-rooded trees, for these mat down less than those from the softer-mooded varieties-or straw, and apply at least tro or three inches of such litter. $\mathrm{Hy}$ acinths should be more thoroughly protected than tulips and the latter should be provided 
with a four- or five-inch layer of leaves or litter.

One of the fine points in bulb culture is the removal of this winter mulch early enough in the spring to harden the young growths. If they are allowed to come up under the covering, penetrate through the mulch and become drawn and yellow they are in no condition to resist a suden freeze. It is best to remove the mulch by degrees beginning early in March by disposing of an inch of the litter and following this by the removal of subsequent layers until, by the time all danger of frost is past, no cover remains on the beds. Should the beginner believe, however, that the weather justifies his removing the litter all at once he will show his wisdom by having it close at hand so that a light cover may be hastily applied should the weather suddenly threaten a damaging cold spell.

\section{LIFTING AND DIVIDING}

It is always a question to determine how long bulbs should he allowed to remain without lifting and dividing them. This, however, is usually answered by attending circumstances. It may be desirable in some situations to set out bedding plants or to grow annuals or perennials in the beds which have been left bare by the 
blooming and passing of the flowers and foliage of the bulbs. In such cases allow the foliage to remain until it turns yellow and witherswhich generally requires six weeks-and then carefully lift the bulbs, dry them and store them away for use the next fall. But, where the beds are permanent, or colonies are established

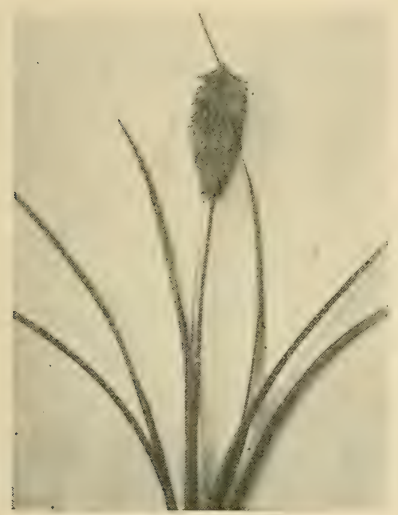

Torch Lily

(Kniphofia aloides)

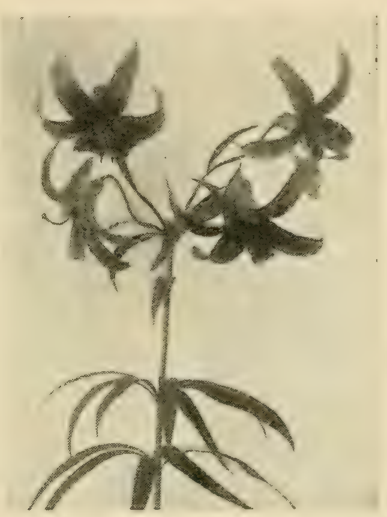

Canada Lily

(Lilium Canadense)

in herbaceous borders, the rule is to dig up only when the flowers show deterioration. If, after the first season or two, the blooms are neither so healthy nor so large as they were in the beginning, it is a fair indication that the cultural conditions are not congenial and the bulbs should be lifted as soon as the foliage dies 
and reset in soil better prepared and better adapted for their growth. If, however, the bulbs show no deterioration, let them remain undisturbed until, due to the natural processes of propagation, they become so crowded as to show by smaller flowers that they are too thickly set. Where the soil is not very rich, several seasons may pass before this sign of distress warns the gardener of the need of lifting and replanting. Daffodils, for example, may remain undisturbed, often for four or five years, and the peony, representative of the most permanent "bulbous", plant, may be allowed to remain undisturbed in rich soil, provided it has room to extend its growth, for ten or twenty years. Still, it must be remembered that, in what is called high-grade bedding where, as a general rule, only tulips and hyacinths and occasionally daffodils are used, bulbs planted in the fall, after blooming in the following spring, should be dug up and planted elsewhere, usually in the borders, and the next autumn new bulbs should be set out.

\section{HARDY BULBS}

One of the most delightful ways of growing bulbs is the cultivation of the hardy species in 
the lawn. This method of planting is especially suitable for suburban grounds where the area is more extensive than in cities. In cities occasionally it is employed but seldom satisfactorily, for the bulbs, after flowering, are not allowed to complete their process of growth before it is considered necessary to mow the

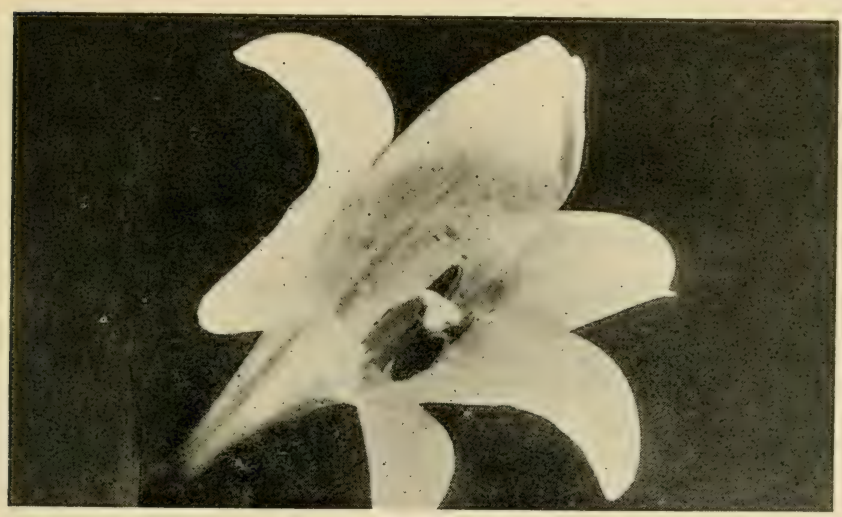

Kramer's Lily

(Lilium Japonicum, var. roseum, known to the trade as Lilium Krameri)

lawn. Where their leaves are thus sacrificed the bulbs deteriorate and lose their value. Practically all the hardy bulbs do well in the grass if the place is properly prepared for them by removing a portion of the turf, forking up the earth beneath, planting them and then re- 
placing the turf. But, wherever this method is followed, it must be borne in mind that on no occasion must the grass be cut until the plants ripen their leaves. This is always shown by the foliage turning yellow and withering. Neglect of this simple point has been the cause of disappointments in many instances where fall-planting by this method has been pursued on a large scale.

\section{DECORATIVE ARRANGEMENT}

When planting in the grass do not arrange the bulbs in regular lines or designs. Avoid the possibility of such arrangement resulting even accidentally by standing upright with the hands full of bulbs and allowing them to drop where they will and planting them where they fall. This method usually distributes the bulbs effectively and, at the same time, gives a center colony, or well-marked group, from which the bulbs appear to stray in all directions. The crocus, chionodoxas, snowdrop, Scilla amœna, and bulbocodium, winter aconite, and snow flakes are suitable for planting in the grass. All of these will grow, increase, bloom and ripen the foliage before it is really necessary to use the lawn-mower, but not before the 
grass, especially in cities, will require cutting, if the appearances of the lawn are to be considered.

While many persons seem to realize that purposeless planting of flowers, shrubs, vines or trees on the lawn is in poor taste, still there are not a few who seem to consider that an excep-

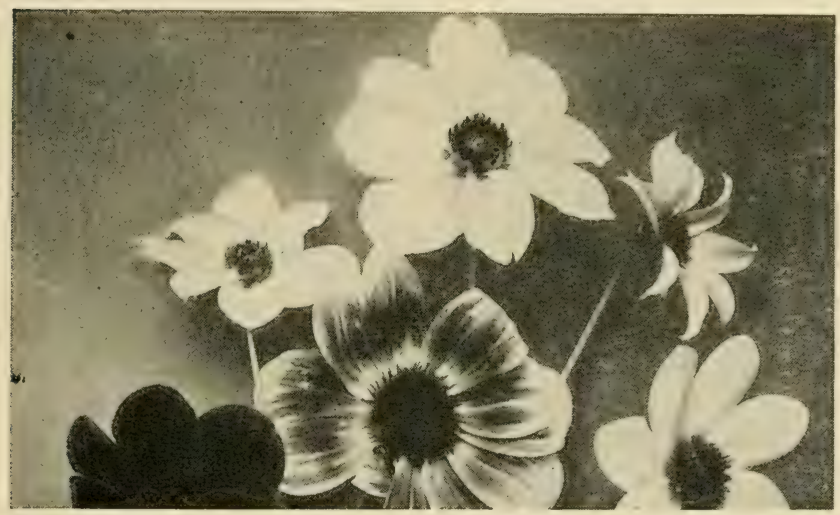

Single Dahlias

tion may be made of the bulbous plants. But as a matter of fact, the same rule holds with this class as with all other's. The star-shaped, square-shaped, round-shaped bed of tulips or lyacinths set down without reason or sense in the center of a lawn invariably discloses poor judgment. Moreover, it is as expensive as it 
is gaudy and vulgar. And in the city another objection to this method of planting is that the beds, being on display, usually attract the small boy or other marauder who, when he has helped himself to such bloom as he may desire, has absolutely ruined the appearance of the design and destroyed the only virtue possessed by the geometric horror, its symmetry.

Bulbs should not be planted with less purpose than other plants. Use them in corners, in borders, in shrubberies and between herbaceous plants wherever space permits. As an example of one use to which bulbs may legitimately be put in this connection, there is, along the south side of one city house, a border between the foundation and the walk three feet wide in which are planted plantain lilies, (Fun'kia subcordata, var. grandiflora), which, as they develop their foliage, conceal the foundation wall, and the well-known poet's narcissus $(N$. poeticus), and $N$. poeticus ornatus. The latter blooms earlier than the poet's narcissus and is set out in front of its companions. In this border, some forty feet long, these daffodils are planted three or four inches apart and in four rows. They are through blooming before the funkia has developed its foliage, and while 


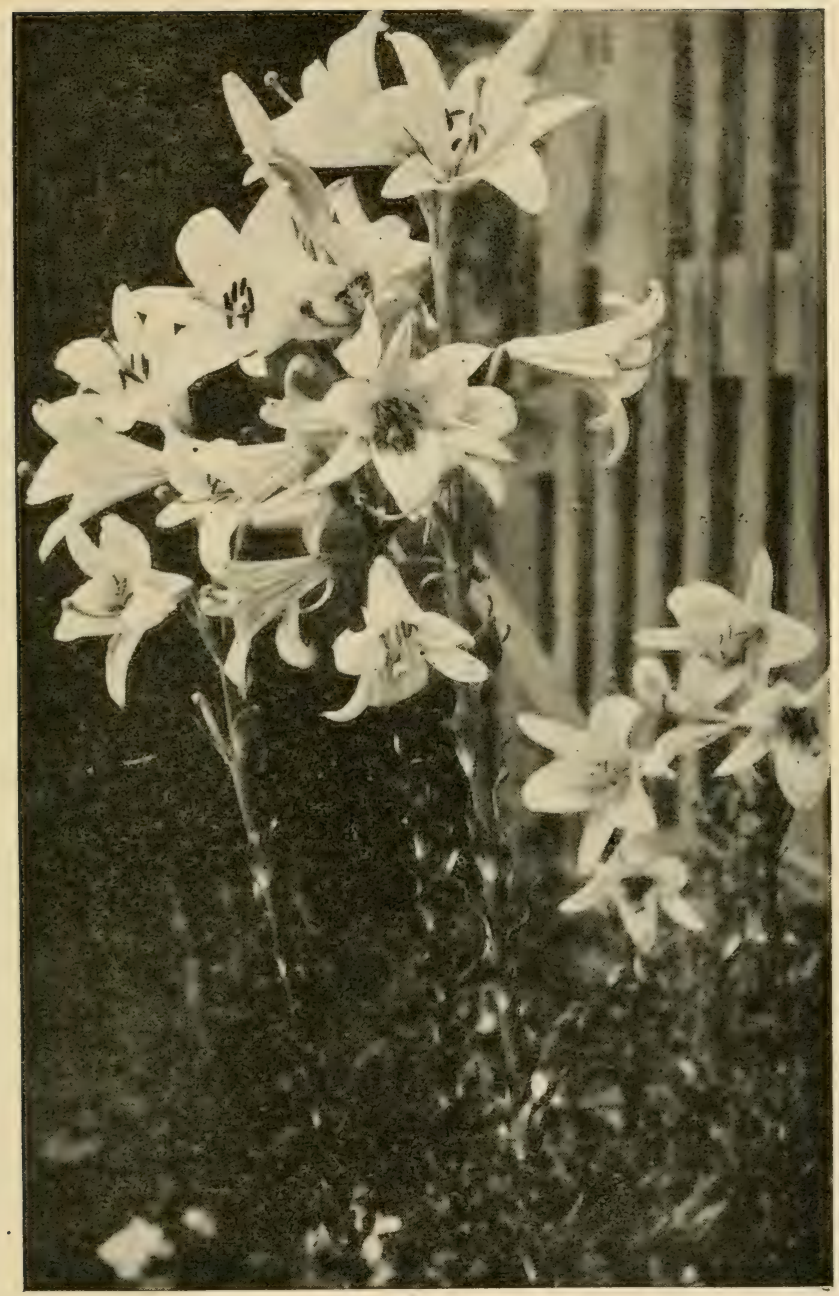

Madonna Lily (Lilium candidum) 
they are in bloom they not only perfume the air, but serve, to some extent at least, as a screen. Another effective composition is the use of tulips-especially the May-flowering varieties -with dwarf deciduous and evergreen shrubs. As the somber winter browns and the dull greens of the deciduous and evergreen plants give way before the magic touch of spring, they are suddenly converted into an ideal setting for an array of brilliantly colored flowers. Furthermore, blooms cut from such plantations of bulbs are not missed as they are when taken from formal beds where the removal of a single blossom mars the perfection of the whole design.

Hardy bulbous plants may be used effectively in borders by themselves and occasionally bold clumps of the taller plants of the sort may not be ineffective when given a somewhat isolated position. In almost every instance, however, they show to best advantage when supplied with a background of shrubbery or of tallergrowing plants.

In such situations, where the object desired is a brilliant mass of one color, which is all the more striking on account of the contrast with 


\section{BULBS}

the surroundings, hemerocallis may be used or such lilies as auratum, speciosum or tigrinum. The German and Japanese irises, tritomas, and montbretias also appear to adrantage. 


\section{CHAPTER X}

SOME POPULAR HARDY BULBS

Usually the hyacinth is given the place of first importance among hardy bulbs but this does not indicate by any means that the hyacinth is deserving of an honor so great. As a matter of fact, this sort of classification depends largely upon individual taste. Tulips are given second place and narcissi third. But there are a number of gardeners who would reverse this classification and give the narcissus the position of honor. And there is good reason for this. In the first place the varieties of this prime favorite are almost without number, they are easily cultivated and generally certain in results. They may remain in the ground undisturbed for a longer period than hyacinths or tulips and under such treatment will prosper. They are especially adapted for planting in mixed borders between shrubbery, along walks and drives and will thrive in almost any soil or situation. They 
attain sreater perlection, liowerer, when the treatment accorded them is liberal. But, given a thoroughly drained soil of a moderately rich, loamy character in which there is a generous amount of sharp sand, they will succeed very well when no further cultivation is accorded them.

\section{NARCISSI}

Narcissi lend themselves well to naturalizing. This method of planting, howerer, has little to recommend it to the owner of a small city yard, but where it is desired to have early flowers on the grounds of a large suburban home or country estate, this feature of the narcissi is well worth considering. Thousands of them may he planted along the hanks of a stream, in a bit of meadow or wood and in such situations will form a floral picture of surpassing loreliness. For this purpose the poet's narcissus ( $N$. poeticus), is probably the best, but nearly all daffodils may he naturalized to advantage.

While the colors of the narcissi are confined to a very narrow range of yellow and yellowish white, some are pure white and others, recently produced, have red trumpets. Still the coloring, though it might be considered by some monot- 
onous, is one of the chief charms of this group of hardy bulbs. The yellow, like rays of sunshine sifted through green foliage, is especially welcome in the early spring. For formal bedding, however, tulips and hyacinths should be relied upon and the daffodils omitted. The latter may be planted any time between August

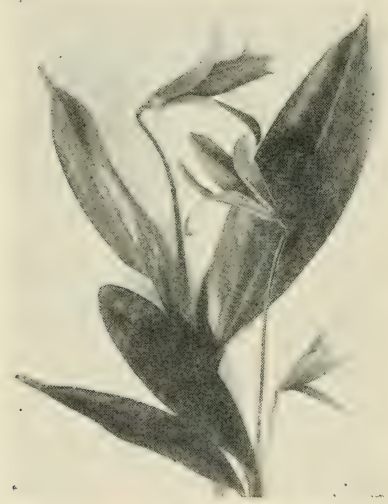

Erythronium

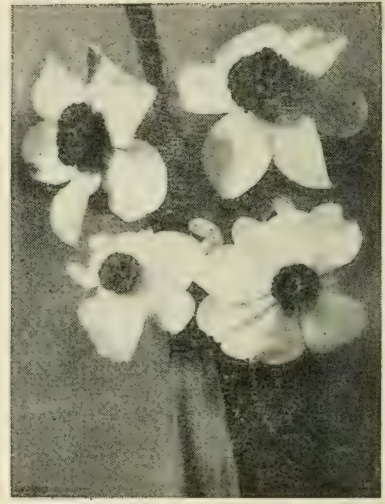

Poet's Narcissus

and November and the earlier they are set the better; they make roots earlier in the autumn than most of the other spring-blooming bulbs and on this account demand earlier planting. The poeticus types especially require early planting for they legin to throw out their new roots almost hefore the old have withered. 
These thrive in almost any gooul garden soil and only demand that the situation be well drained.

It is almost impossible to say which daffodils are the best for out of doors planting. But it is probably safe to designate the Golden Spur as one of the best yellow trumpets for the small garden. Other good trumpet sorts of an allyellow color are the Emperor and the Glory of Leiden. Among the bi-color's, Victoria, Empress and Horsefieldi are the hest. In the allwhite group, the best for general use are Mrs. Thompson, William Goldring and Madame de Graaff. It is not likely, howerer, that the Madame de Graaff will be rery extensively planted for years to come. It is expensive and, though beautiful, for ordinary purposes, it is hardly worth the high price which it now commands when other varieties of trumpet narcissi are to be had from twenty to sixty cents a dozen.

The Horsefieldi, with large flowers of pure white perianth and rich rellow trumpet always strikingly beautiful, is difficult to obtain in good condition; frequently it decars in the packages and reliable nurserymen will import it only at the purchaser's risk. The Empress, which is not 
ouly well adapted for planting in small yards, but is also happy when naturalized in orchards or meadows, is really an improved Horsefieldi and entirely free from disease; its flower possesses a pure white perianth with yellow trumpet. The Emperor is one of the largest daffodils in cultivation and breeds a superb flower of a golden yellow color. These two, both cheap, are among the best that can be planted. Other desirable varieties are the Bulbocodium, or the hoop-petticoat narcissus, with rich golden-yellow flowers, the Maximus, IIenry Irving and Major.

Among the incomparabilis varieties, Sir Watkin, with very large petals of a rich sulphuryellow color and large cup tinged with orange, is one of the best; the flowers are sometimes five inches in diameter and appear very early and are horne freely. Other's that are good are Stella Superba with a white perianth and yellow cup, the Figaro with yellow cup and perianth colored orange and the Cynosure with large creamy-white petals and eup of the same color stained with orange-scarlet. In the Barrii group, Conspicuus, with large yellow flowers and bright red-edged crown, is undoubtedly the best and at the same time the cheapest. In the 


\section{POPULAR HARDY BULBS 199}

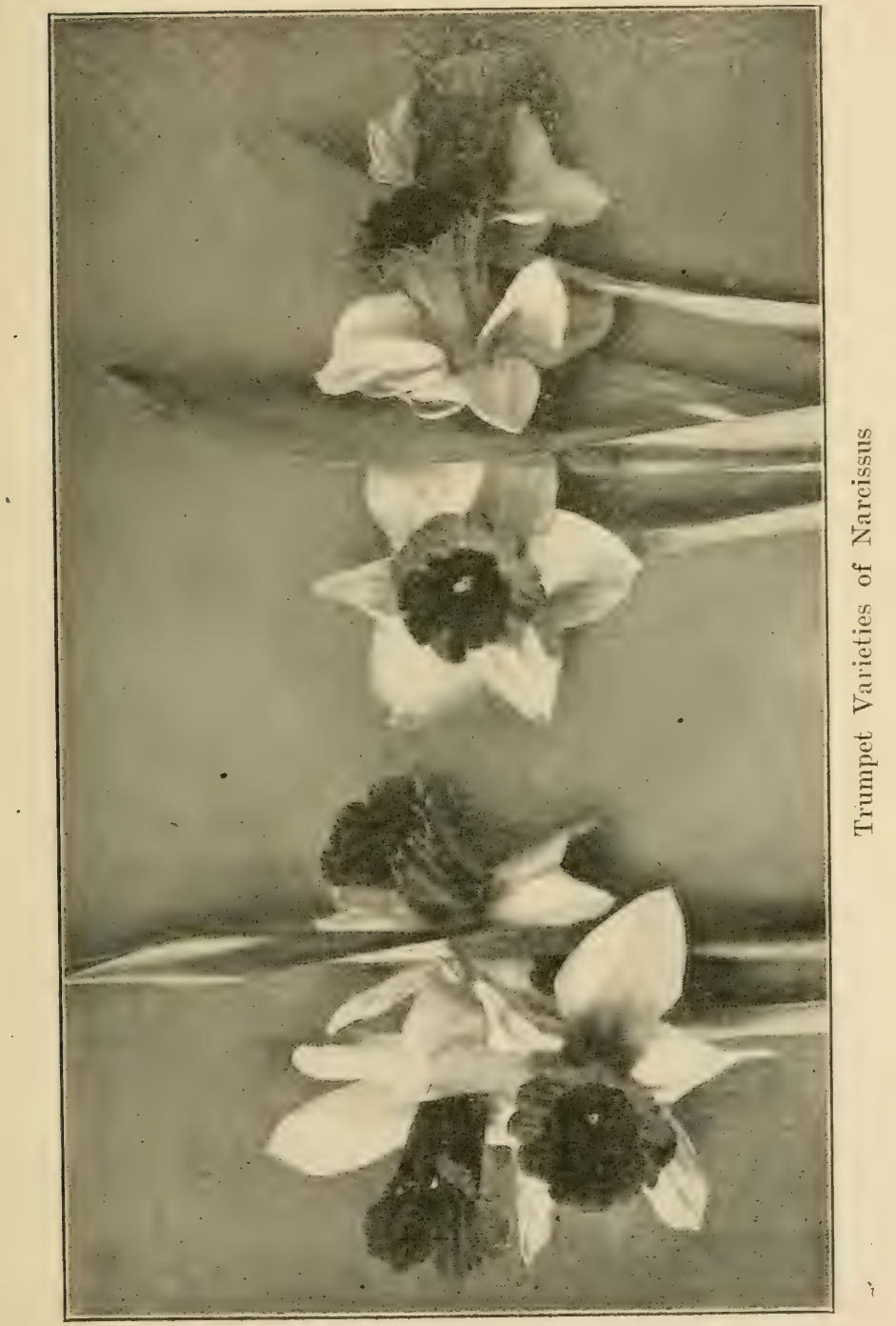


Leedsii, Mrs. Langtry, with flowers of a pale creamy yellow borne freely and excellent for cutting; is at the head. The two best varieties of the fragrant poet's narcissus are the wellknown poet's nar'cissus itself, sometimes called pheasant's-eye, and $N$. poeticus ornatus which blooms earlier. The most important of the douhle daffodils are the Van Sion and Sulphur Phœnix.

\section{HYACINTHS}

Hyacinths are not difficult to raise when good bulbs are obtained. They should be planted at least four inches deep and on a cushion of clean sand. They are more susceptible to injury from frost than other bulbs planted in the fall and should on this account be more heavily covered during the winter. Many planters purchase the bedding varieties, but if the largest spikes of bloom and most perfect flowers are desired it is better to obtain only " named" varieties which, though they are more expensive, produce a far more satisfactory display in the spring than the cheaper varieties. The planter must not expect from a hyacinth bulb the second season the same fine flowers it produced the first. The spikes are smaller and the bells are not so numerous. On this account many grow- 


\section{PUPULAR HARDY BULBS 201}

ers are disappointed and, after an experience of this sort, are inclined to consider hyacinths as difficult to grow, but it must be remembered that this is a peculiarity of the bulb itself and is not due to any lack of proper culture. The most satisfactory method of planting them is to remove five or six inches of the top soil

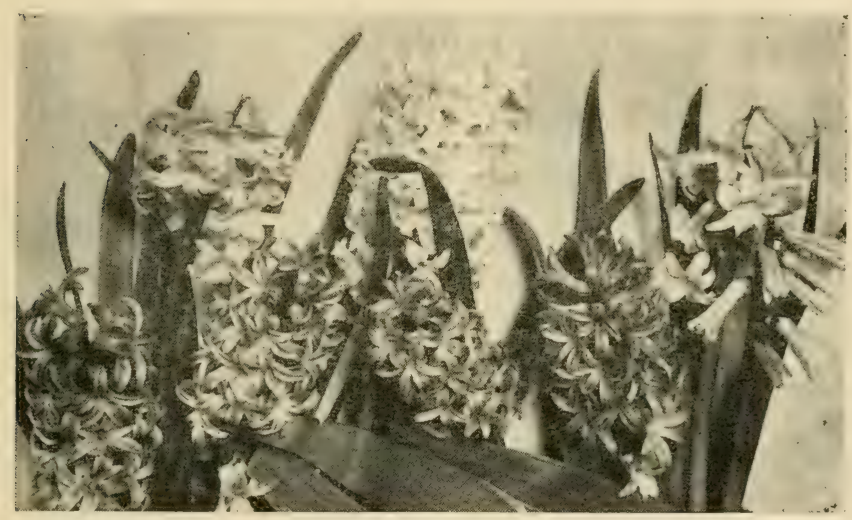

Hyacinths

in which they are to be set, carefully spade up the sub-soil to a depth of twelve inches or more and, making the surface of this fine, spread over it a half-inch layer of sand and on this set the bulbs. Hyacinths when thus planted are set at a uniform depth and consequently throw their bloom spikes at practi- 
cally the same time in the spring. This method of planting is also to be recommended because it enables the planter to place the different colors with precision-a point in display-bedding when either hyacinths or tulips are employed that is of considerable importance. It is never advisable to set the bulbs closer than six inches.

To obtain the shades of color which may be desired in formal beds the following varieties are to be recommended: Norma, pink; Robert Steiger, deep crimson; Nadame Vanderhoop, pure white; Leonidas, light blue; Baron van Thuyll, dark blue, and Ida, citron yellow. All these are single hyacinths. The double varieties of hracinths, although the flowers last longer than the single varieties, have a heavy appearance and lack the distinctive form of the single type.

While occasionally the practice is made of setting hyacinths and tulips in. the same bed it is seldom if ever advisable. The colors are not likely to prove pleasing as the various shades of the two classes usually clash harshly. But tulips by themselves are always effective especially when the best or named varieties are planted. Superior results can 


\section{POPULAR HARDY BULBS}

not be expected from inferior bulbs whether they are of tulips, hyacinths, narcissi or any of the other spring-blooming bulbs.

\section{TULIPS}

There is no reason why tulips should not be even more liberally planted than they are, for, considering the slight cost of good bulbs

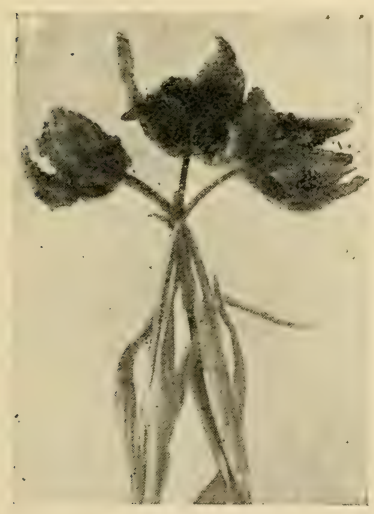

Pairot Tulips

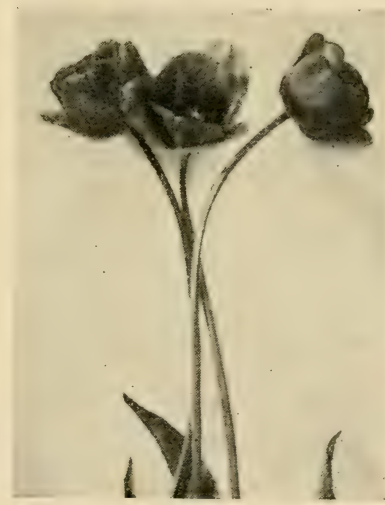

May-flowering Tulips

and the little trouble involved in their cultivation, the effects produced are amazingly striking. They should be planted preferably the last reek in October or the first week in November and it is always best to have the ground in good condition a fortnight in ad- 
vance of the planting. While it is sometimes thought that tulips may be planted as late as December, it is never advisable, except in the South, to postpone to so late a date the work of setting out the bulbs; they require time to develop their roots before winter sets in and puts a stop to the process. In preparing the bed, elevate it slightly and slope it from the center toward the edges so that good drainage will be insured. Tulips, like hyacinths, should be planted on a cushion of sand and should be set about five inches apart and covered with not less than four inches of good soil. After the beds are made, firm the earth to prevent its heaving by the action of the frost. When a slight freezing has hardened the surface soil to a depth of an inch or two, cover the beds with leaves or litter.

When tulip bulbs are planted in the borders -where they always appear to great advantage-they may be left in the ground undisturbed for several seasons, but when they are planted in beds which, after the tulips have bloomed, are to receive summer-flowering plants, the bulbs should be removed, dried, and stored away to be planted the following autumn. They should not be lifted, however, 
until the leaves have turned yellow and thus indicate that the bull) has completed its season's work in preparation for next year's flower. In lifting the bulbs it will be found that sets have been formed around the base; if it is desired, these may be planted separately in a sandy loam where, in the course of two or three years, they will develop into bulbs of a flowering' size.

Tulips are usual!y listed by dealer's under the heads of early single tulips, early double tulips, late double tulips, parrot tulips, late garden or May-flowering tulips and T)arwins. The best early singles for outdoor planting are the following: Artus, dark scarlet; Belle Alliance, bright scarlet; Brutus, scarlet; Rose Gris-de-lin, the best bright pink; ('hrysolora, the best early yellow; Canary Bird, yellow; Pottebakker, pure yellow; Pottebakker White, pure white; La Reine, rosy white. Of the double-flomering tulips, none of which is equal to the single but all of which are valued because the blooms are more lasting, the best are, La ('andeur', pure white; Couronne d'Or, yellow; Duke of York, carmine with white edge; Rex Rubrorum, bright scarlet; Couronne des Roses, deep pink. These are all early varieties of the double class; 
of the late-blooming double tulips, which usually come into bloom in May, the best are Yellow Rose, golden-yellow; Blue Flag, violet-blue; Peony Gold, red and yellow; Marriage de ma Fille, white, striped with carmine.

The parrot tulips form an odd and interesting section, but the flowers lack the neat pre-

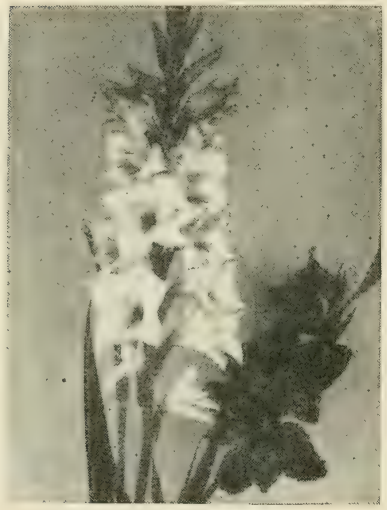

Gladiolus

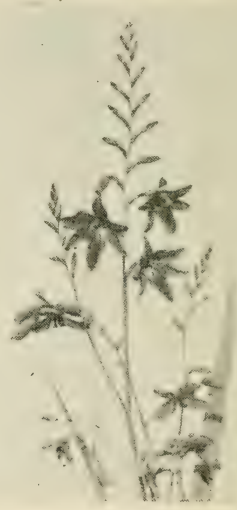

Montbretia

cision of outline which seems to be the tulip's chief characteristic, the petals being irregularly cut and fringed with a variety of colors. All the parrots are exceedingly effective and always striking when planted in borders where they thrive if left undisturbed. The best varieties of these are Admiral of Constantinople, 
orange-red and scarlet; ('ramoisie Brilliant, searlet; Lutea Major, golden yellow; Markgraaf van Baden, golden yellow inside, outside feathered scarlet, purple and green. All bloom in 'May and prefer a light sandy soil and a sunny location.

In the judgment of many, the best tulip for the average city yard is the May-flowering or cottage garden tulip. Flowers of this group come into bloom from two to four weeks later than the earlier varieties and usually at a time when the flowers are more appreciated. The blooms are superior as cut flowers and last a week or more in water. All varieties are of a free and graceful habit, attaining a height of from eighteen to twenty-four inches and bearing their exquisitely colored flowers on long, strong stems. These tulips can be planted to great advantage in both beds and borders and under either method of cultivation generally produce better results than the early type. Among the best of the section are: Bouton d'Or, deep golden yellow; Gesneriana spathulata, dazing scarlet; La Nigrette, almost black in color; Maiden Blush or Picotee, a beautiful blush white; Bridesmaid, cherry rose, pinkish white stripes; La Candeur, 
pure white; Firefly, hrilliant orange, and Retroflexa, a bright yellow tulip with recurved petals.

Late-flowering tulips are again divided and flowers of the sub-group are known as Show or Florists' tulips. In this division are the bizarres, byblomens, and roses. The bizarre has a yellow ground with red, brown, scarlet or crimson shades. The byblømen has a white ground upon which markings of black, brown, lilac, etc., show. The rose possesses a white ground upon which bright markings of pink, scarlet and crimson show. Breeder or "mother" tulips, or selfs, bear flowers without markings, but with yellow bases, the upper portion of the petals being self-colored white, rose, scarlet, red, brown or purple. The Darwins belong to the self-colored group and are improved "mother" tulips, as a matter of fact, surpassing in color and brilliancy all other tulips. The best of these-and no garden can have too many-are Onida, carmine-red; Nautica, purplish-rose; Kate Greenaway, white and lilac-rose; Faust, purple-black, and Buffon, rosy-lilac. These "show" tulips are the flowers which years ago caused the famous tulip "mania", in Europe. At that time tulips sold 
as high as one thousand dollars each, and entire communities became involved in the excited speculation-usually to financial disaster.

There are still other varieties of tulips which the amateur will find both interesting and valuable. Among these may be mentioned Greigi, one of the best, orange-scarlet, yellow and black center; Carinata rubra, crimson and green; Clusiana, white, with broad red stripe; Sylvestris, or Florentina odorata, fragrant, yellow; and Persica, dwarf, brown.

\section{OTHER SPRING-FLOWERING BULBS}

There are other bulbs for fall planting, some of which have already been mentioned, that will prove hardy all over the country. Many of them are especially valuable because of the early bloom they afford in the first days of spring. In fact, there are about a dozen that can generally be relied on for March flowers in the north. Their delicate grace and unconquerable hardiness are their chief charms ; Maeterlinck has said of them that they are "frail and chilly but bright as a hold idea." As a rule they have sacrificed both size and fragrance in order to press forward extraordinarily early in the season. Of all of them 
snowdrops are the earliest. They appear in Narch and seem eminently capable of taking good care of themselves. They require little or no attention at all and possess in addition the extraordinary virtue of being able to adapt themselves to situations where other bulbs could not be expected to prosper. The snowdrop, for instance, will do exceptionally well, compared, of course, to other flowers, on the north side of a house, or in a narrow and poorly lighted passageway where one would expect that ferns alone would thrive. Galanthus Elwesii is the giant of the genus and its large size of flower is not attained by any sacrifice of refinement. It is not so early, however, as the little snowdrop, following it some two weeks.

Occasionally the spring snowflake (Leucojum vernum) is mistaken for the snowdrop. It possesses a white flower and blooms in March. There is also an autumn snowflake, but it is not reliably hardy; and there is a summer flower of the same sort blooming about the first part of May.

Scilla Sibirica is another excellent flower appearing early in spring. Its blooms, while small and borne only one to three on a stem, are of a rich blue color especially desirable at 


\section{POPULAR HARDY BULBS}

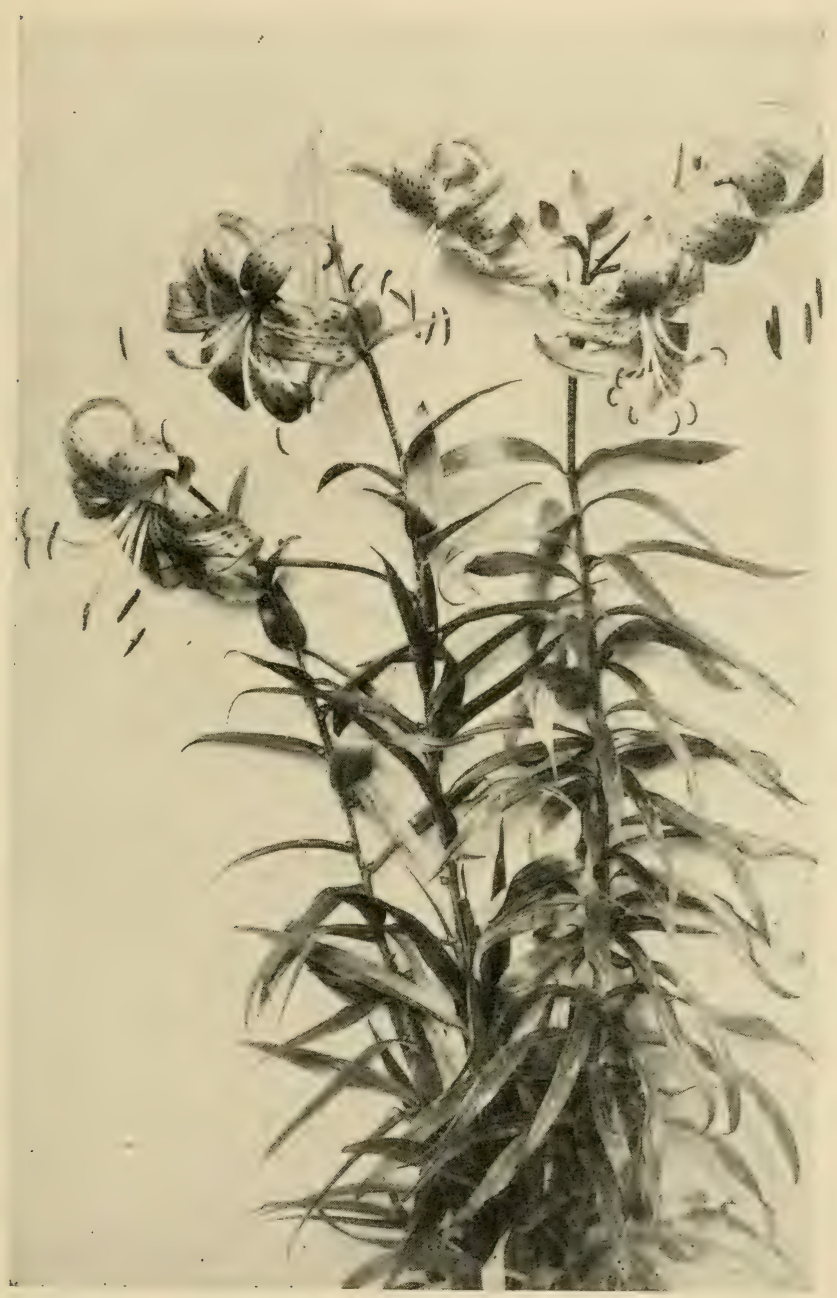

Tiger Lily (Lilium tigrinum) 
this season of the year. Other desirable bulbs are Chionodoxa grandiflora or $C$. gigantea, with single blooms an inch and a half across and of a slaty blue color; Chionodoxa Lucilice, with flower's somewhat smaller but of sky blue, except the lower part of the petals which is white, and Chionodoxa Sardensis, with flowers still smaller but appearing six or seven on a stalk, and of a darker blue.

The crocuses are other March bloomers and some of them frequently will open even earlier, according to the weather. Almost all of the named varieties are well worth planting, and if the prices charged for these, usually not more than seventy-five cents a hundred, appear to be somewhat high, the crocus can - be had in separate colors-purple, yellow, blue and striped-for prices a third cheaper. There is no reason why everybody, even if only a small strip of ground is available, should not plant generously of them. Once set out they are no further trouble and bloom year after year.

Crocuses, as well as the other early spring bulbs, should be set from one to two inches below the surface of the ground. When planted in the grass they are usually estab- 
lished hy lifting a portion of the sod and setting the bulbs under this, then replacing the turf. If, however, you prefer them for bed display, provide a deep rich sandy loam. In this they should be set three inches apart and allowed to remain until, through natural increase, they become so crowded as to show signs of deterioration. This is not likely to occur for four or five years. Avoid planting crocuses too deep, two inches being the best depth as a rule-when they are set deeper, they often fail to bloom.

Another hardy flower of March is the winter aconite (Eranthis hyemalis). Its flowers are yellow and larger than the crocuses and sometimes, if the weather is extraordinarily open, it will come into flower as early as the first of February. The winter aconite belongs to the buttercup family and has from five to eight golden sepals. It grows about six inches high. While it is a flower frequently mentioned by writers on English gardens it is seldom seen in America, probably because it is not as well adapted to our climate as to that of its European home. But where it is planted in partial shade it stands a fair chance of succeeding. 
The following planting table will be a safe guide for the setting of these smaller bulbs. All of them should be planted in the fall as soon as they can be obtained from the dealers.

Snowdrop (Galanthus)

Glory-of-the-Snow (Chionodoxa)

Squills (Scillas)

Winter aconite (Eranthis)

Crocuses

Spring snowflake (Leucojum vernum )

Depth
(Inches)

2

2
3
1
2

2
Distance apart (Inches)

2

3

4

4

5

4

\section{LILIES}

No plea should be required to induce a liberal planting of lilies. Their beauty and fragrance recommend them especially for use on small city lots where special attention may be given them, and their requirements, so far as soil and situation are concerned, easily satisfied. It is due, possibly, to the mistaken idea that they are difficult to cultivate that more of them are not planted. But as a matter of fact, the lily really makes no extraordinary demand. Of all the numerous varieties many will be found to flower well in ordinary garden soil and if planted in a sheltered spot, partially shaded and at a 
proper depth, they will hardly fail to prosper. Fully four-fifths of the important species of lilies are imported from Japan or the Far East and usually reach the United States about the first of November. In the northern states this is a little late for planting, for October is unquestionably the ideal month for setting out lilies. They succeed, however, when planted later and it is always better to plant the bulbs in November than in the spring, for the lily bulb is not safely stored and, even when given the best of care, loses much of its vitality and sometimes throws no bloom for a season.

Among the best varieties to plant are the longiflorum, whose funnel-shaped blooms are the longest of any hardy lily; Japonicum, with colors varying from a blush to a deep reddish pink; Brounii, with blossoms that are pure white inside but marked with a beautiful purplish brown on the outer part of the petal; Batmannice, bright orange; Henryi, dark reddish yellow, and auratum, the most gorgeous of lilies. The bulbs of the last, however, must be renewed every two to three years in this country. Its flowers are exquisitely beautiful, bearing on white petals gold, red and yellow 


\section{YARD AND GARDEN}

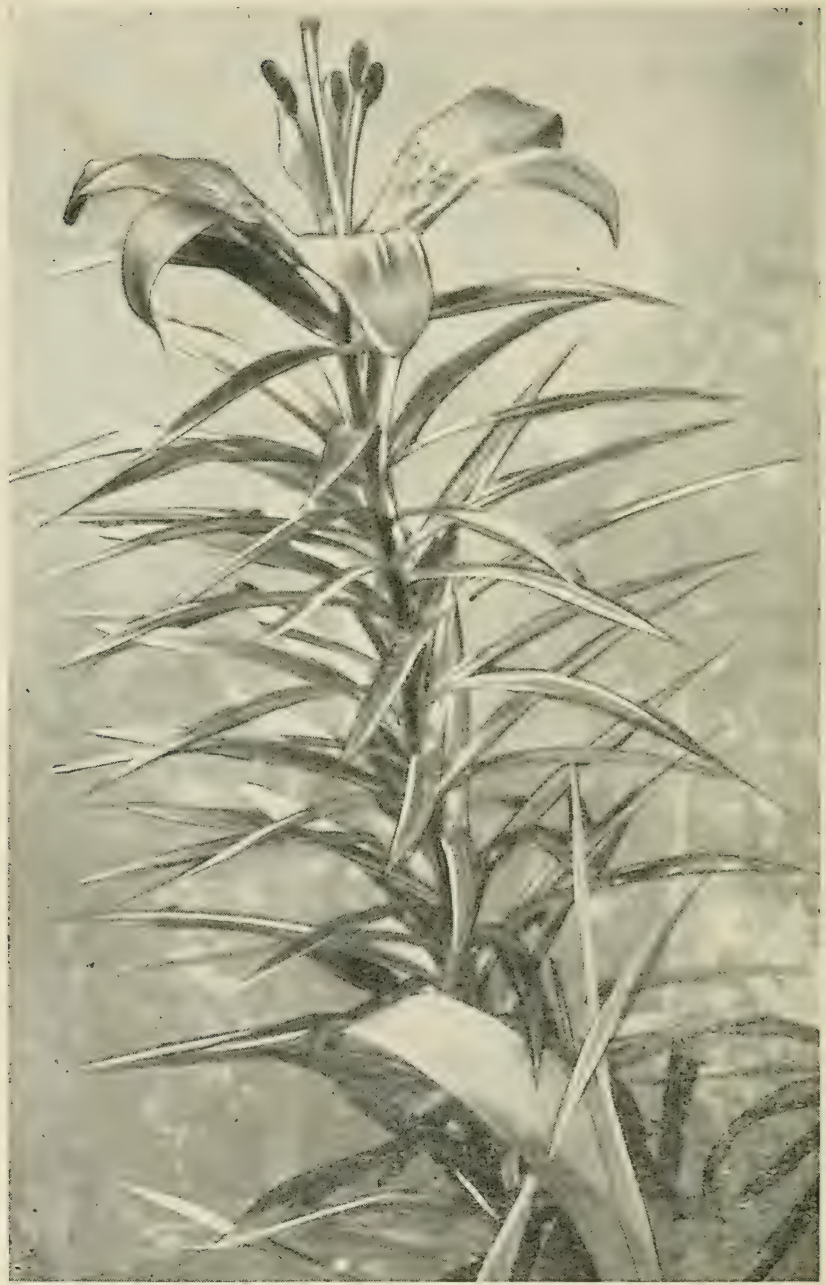

Thunbergian Lily (Lilium elegans, known to the trade as L. umbellatum, L. Thunbergianum, ete.) 


\section{POPULAR HARDY BULBS}

bands. The lily that every one knows and one which, unlike the auratum, persists for generations is Lilium tigrimum (tiger-lily). Though its flowers are large, the bulbs are so cheap and so easily grown that it is not accorded the merit it deserves. It bears red flowers with purplish spots. The list might be extended almost indefinitely, but the following should certainly receive consideration: superbum, Wallacei, candidum, croceum, umbellatum, speciosum, and Canadense.

An eminent authority on lilies has made the following list of soils most suitable for their cultivation :

First, any good garden soil of a fair depth well dug before planting is suitable for such kinds as Brownii, candidum, Chalcedonicum, croceum, excelsum, Hansoni, Henryi, Martagon (purple), Thumbergianum, tigrinum and umbellatum.

Secondly, lilies that prefer a strong soil, such as a good, rich, friable loam not too heavy : auratum, Batmannic, Martagon, album, speciosum and Washingtonianum.

Thirdly, those that require peat and moisture: Canadense, pardalinum, Philadelphicum and superbum. 
It might be added, too, that the above list represents those lilies which can be grown with the least trouble. Those of the first list will succeed in any ordinary border; those in the second list require a certain amount of partial shade and coolness at the root and are best planted in shrubbery beds. And those in the third group comprise the lilies that require a cool shady spot where they are not exposed to the direct rays of the sun.

The general rule when planting lily bulbs is that they should be put in the soil about three times their depth, but this is not always a safe guide, for some lilies possessing small bulbs require deeper planting than this calls for. Furthermore, whenever bulbs are placed among shrubs they should be planted two or three inches deeper than they would be set in other situations. The distance hetween the bulbs should be from twelve to eighteen inches. 


\section{CHAPTER XI}

\section{IRISES AND TENDER BULBS}

The Iris has been called "the poor man's orchid,' and a fitting name it is, for in bloom, in richness of coloring, in beauty and in delicacy it is of the "blue-blooded" nobility of the flower family, while, in point of culture, in its general adaptability to various conditions and various situations, it is as entirely democratic. Cultivate it, nurse it, coddle it, and it will respond eagerly and gladly to every effort, but neglect it, ignore it, trample on it and despise it, and, once planted, it will remain with you, bloom for you, and, if you have the least respect for floral beauty, shame you with its blossoms. It requires little and gives much, and, asking no more than it has received, prepares itself at the same time to give you more another season.

\section{VARIETIES OF IRIS}

This, of course, refers to the common iris of our gardens, a variety with which all planters 
have been familiar for years, even for generations. But there are other varieties with which we are not so familiar, but which are no more exacting or fastidious in their demands or their tastes. Then there are still others, veritable aristocrats in all their requirements as well as in the beauty of their bloom. These-the Oncocyclus group, with flowers delicately veined and reticulated, generally with a darker color on a light background, natives of Persia, Armenia and Afghanistan-require special culture and attention, and are as difficult to grow as the other's are easy. For the amateur they can not be recommended, though, now and then, one finds a gardener who is interested enough in the irises to attempt the cultivation of this difficult class. A representative of it is the mourning iris, or Iris Susiana, frequently offered in the American catalogues, and usually with the misleading announcement that it is easily grown.

It is not easily grown; indeed, the amateur seldom succeeds with it. Yet it is the easiest of the Oncocyclus group to grow. It, like other varieties of the same class, requires hard sun-baking after its short blooming sea- 


\section{IRISES AND TENDER BULBS 221}

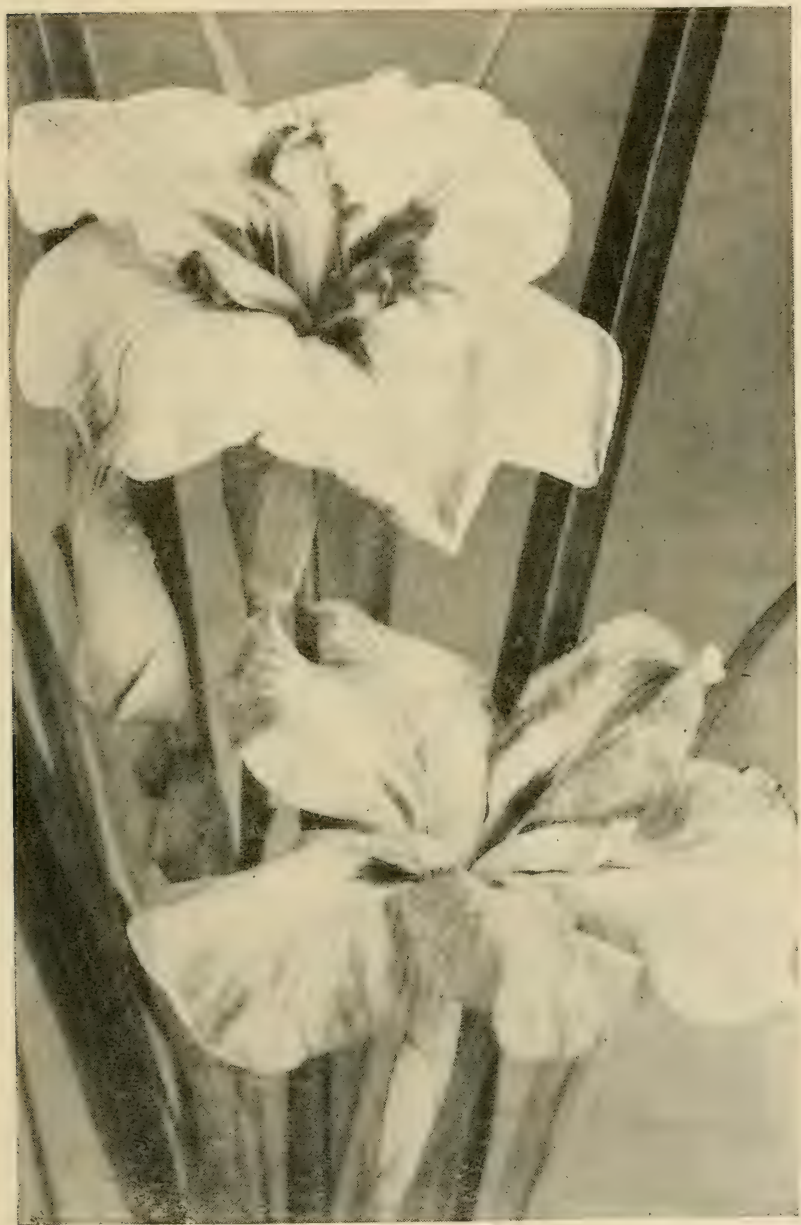

Japanese Iris

(Iris lavigata, known to the trade as $I$. Kampleri) 
son, and it can not be considered hardy. However, when brought into bloom, its large gray flowers closely veined with black, odd as well as beautiful, amply reward the cultivator for his trouble. Usually it is best to lift the plant in the fall and store it through the winter, as dahlias or cannas are stored. Still, in some few instances, it can be brought to bloom without this annual disturbance by plentifully covering it in winter, and in spring removing the litter gradually as the season advances. Success with it is ample reward, and, as it can be had for fifteen cents, failure would not be altogether a financial disaster.

But when the iris offers so many varieties, all of the easiest cultivation, why regret that the Oncocyclus group brings confusion to our efforts? Consider a moment the possibilities the iris presents. Usually, when we mention the name, we picture in our minds only the "German" iris; it is so common in our gardens, and it was so common in the gardens of our grandfather's and of their fathers, that we have lost sight of its value and its beauty, and, at the same time, have come to consider it as alone representative of the family. Nothing could be more absurd. One might, if one 
chose, plant a garden, large or small, with irises and nothing else, and have for his pains a wonderful procession of wonderful flowers from early spring to late summer, and then, if he cared to fill in the winter months, continue the succession indoors in window garden or conservatory. In fact, it is possible, with but the slightest effort and with but ordinary conditions-such as a sunny window-to have iris blooms every month in the year.

The Iris, or, as it is popularly known, the fleur-de-lis or rainbow flower, has more than one hundred and seventy species, of which as many as one hundred have been cultivated by American floriculturists. In England, where the flower is more appreciated, more than one hundred and fifty species are grown by iris fanciers. Of the number grown in America, seventy-five might safely be attempted by the skilled amateur, and this number itself is but a small fraction of the number of varieties which have been produced by cross-fertilization and selection to contribute generously to garden ornamentation.

When consideration is had of the possibilities these figures suggest, surely we will no longer look upon the "German" varieties as the 
limit of iris variations. In fact, the question, so far as planting is concerned, becomes one of selection-of selection for ornamental and color effect, for best varieties and those easiest grown, and for season of bloom, that a succession may be maintained. In this connection it is well to know that the irises which are grown and offered for sale by nurserymen are divided into two divisions: those of bulhous character and those with surface rhizomes-of which the common "German" is a type-and those with exceedingly narrow, inconspicuous, subterraneous rhizomes, with roots more conspicuous.

In the bulbous division the irises best known are those popularly called Spanish and English. The former (Iris Xiphium) and the latter (Iris xiphioides) deserve to be more widely planted than they are. They are of easy culture, thriving best in some sheltered corner of the garden, and preferring a loose, friable soil. Their flowers are excellent to cut for vase or table decoration, and in form, size and color are more dainty than the common variety. The Spanish group blooms first-the latter part of June-and its flowers are followed by those of the English iris. For best effects the bulbs 


\section{IRISES AND TENDER BULBS 225}

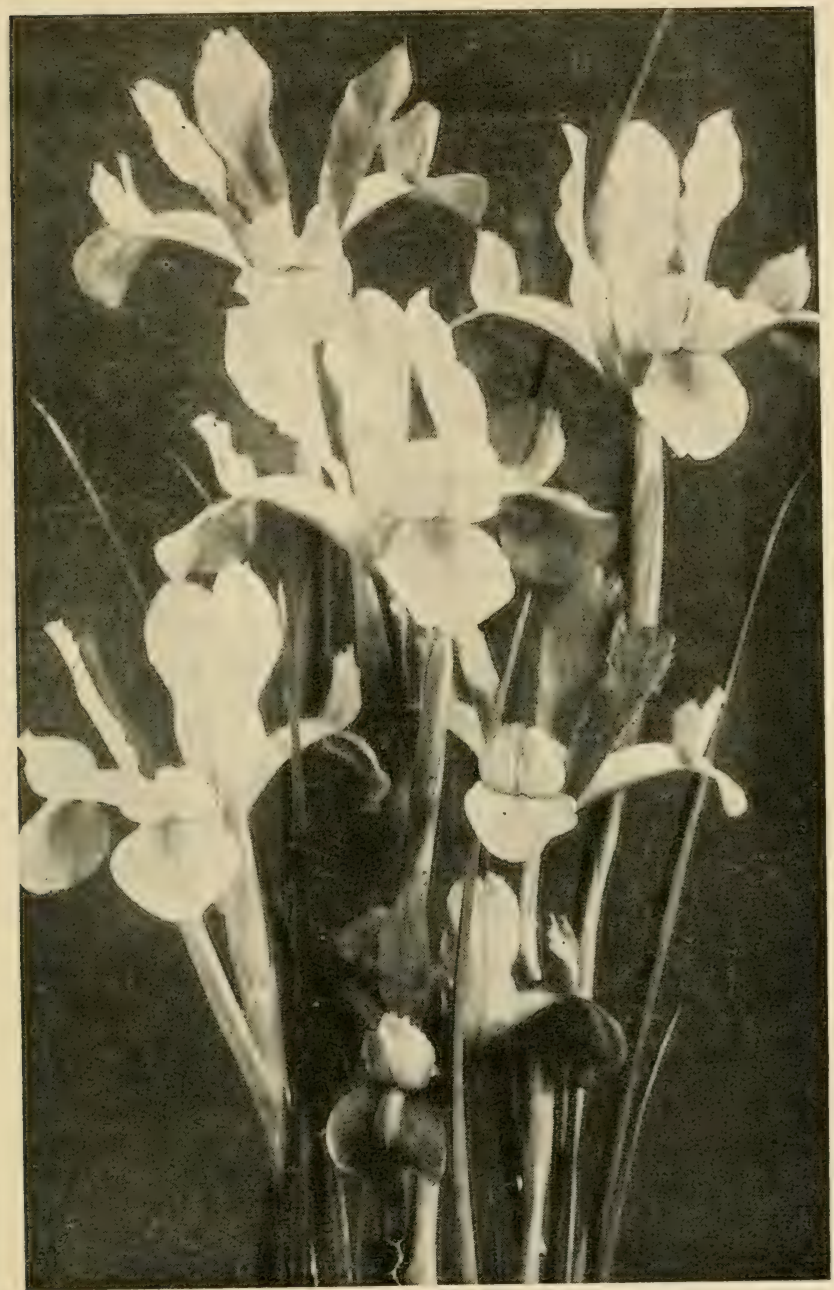

Spanish Iris

(Iris Tiphium) 
of both should be planted liberally. At least twenty-five should be set in a group; more would be better. The bulbs are inexpensive, costing from seventy-five cents to one dollar a hundred, the English being the more expensive of the two, and should be planted in the autumn three or four inches deep and five or six inches apart. They are entirely hardy, but should be planted early in order to enable them to make some growth in the fall before hard frost comes; and they will be all the better for a slight winter covering.

There are a few other species of the tallgrowing bulbous irises-though none grows higher than eighteen inches-which could be planted to advantage. One, for instance, is Iris juncea and another is the rare I. Boissieri, but these are seldom to be had from American nurserymen, except on special order. Still, even when imported, their cost is comparatively small. The first, however, is not hardy in the north, and the other requires heavy winter protection. A third variety which can be obtained in this country is Iris reticulata; it is a native of Palestine, and is one of the prettiest and sweetest of spring flowers, coming into bloom with the crocus. It is absolutely 


\section{IRISES AND TENDER BULBS 227}

hardy, and will thrive in almost any situation, throwing flowers gorgeous in coloring, with brilliant shades of purple and gold and a violet fragrance. Iris Bakeriana, an Armenian variety, is even earlier, but less showy. Their cultivation is identical with that of the Spanish and English varieties.

Of the rhizomatous division, the most difficult to grow is the Oncocyclus class, to which reference has already been made. But, again, why lament the fact that these plants, even granting that they are splendid, resist our best efforts? Have we not the Japanese as well as the German irises? And, have you ever seen a hundred plants of the Japanese in bloom? It is a sight worth traveling far to see. In Japan they are grown by the million, and during their season of bloom the little empire is a paradise of color-marvelous and exquisite color. The Japanese have heen cultivating the iris for generations, and they have brought to bear upon its flowers all the wonderful skill for which they are noted. Traveler's have remarked the iris gardens ever since the tourists began to journey to Japan, but, strange to say, these irises, known as I. levigata, or I. Kcempferi, as they are called by the trade, as easily 
grown as a potato, perfectly hardy, demanding but little attention, were until recent years but little known in America. Yet importations were made among the first products brought from the land of the Mikado. We have been dilatory in planting them, but now, however, they are planted by the thousand every season in America, and each season the demand increases.

We are always advised that they are "excellent for naturalizing in the water garden," and that here they thrive best and their flowers attain greatest size. This is true, but not exclusively true. We do not need a water garden to have Japanese irises; we do not need even a "swampy" situation. Hundreds of them have been grown without either. Some employ a sunken hed. To prepare this, dig a trench two feet wide for a single row, or wider, according to the width of the bed projected. Remove all the dirt to a depth of two feet. The soil in the bottom of the trench is then loosened to a further depth of twelve inches, well-rotted manure is liberally spaded in, and the earth first removed from the trench, mixed with manure, is returned until the surface of the bed thus prepared stands some three or 
four inches below the surpounding surface of the garden or lawn. Irsually it is best to board in this sort of a hed, to prevent the edges from being hroken or marred. Then the plants are set out, two feet apart, and in winter a covering: of leaves, straw or other litter, to which is added a generous amount of old manure, is applied. In the spring this is remored, and when the leaf growth has attained a height of ten or twelve inches, water liberally, letting the stream from a hose flow over the sunken bed when possible.

This method of planting and cultivation has never failed to give the maximum of bloom and a bloom of maximum size. The flowers sometimes measure twelve inches in diameter. The colors range from silvery white through pale blue, lilac, plum and purple, and the flowers are marked with exquisite reinings and starlike centers of contrasting shades, frequently of gold. They bloom luxuriantly in late June and early July.

But what of the "German irises"? They are truly the democrats of our gardens, yet, as already said, they are of the nobility of the flower kingdom. Their flowers are not so fine. perhaps, as those of their Japanese cousins, 
but they are different in form rather than different in value. They have shorter, broader leaves than the Iris lavigata, and flowers whose petals do not lie flat. They have three strongly recurved and handsomely marked petals or "falls", and three upright standards.

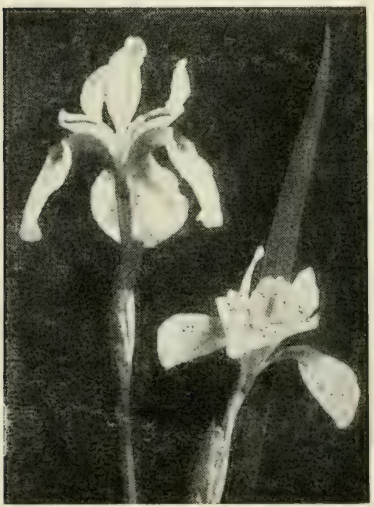

White Siberian Iris (Iris Sibirica, var. alba)

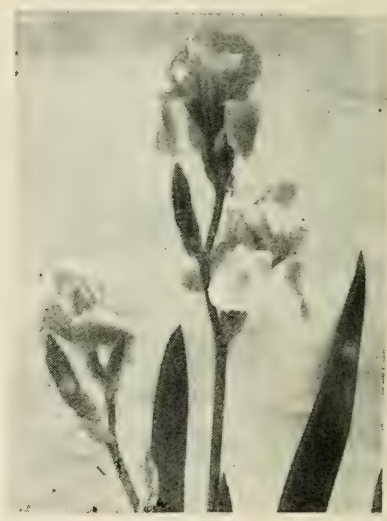

German Iris (Iris Germanica)

Their colorings include white, yellow, lilac and purple, and some curious browns, rich maroons and dark yellows. No plants are of easier culture; unlike the Japanese they prefer a dry soil, but are gross feeders, spreading rapidly, and thriving best in a sunny situation. However, they insist upon none of these conditions, 


\section{IRISES ANI) TENDER BULBS 231}

and are seen growing where all are lacking. But feed them once a year, and, just as springflowering bulbs are passing with their pageant of bloom, these German irises will reward the planter with a lavish display of beautiful flowers.

And still the list is not ended. There are other varieties, all hardy, all easy of cultivation, making no more demands as far as treatment is concerned than their accommodating German relatives, blooming at different seasons, and ranging in height from a few inches to three feet. Indeed, this range of height offered by the iris family is almost as important to the iris fancier as the range of color and the varying seasons of bloom, for, through the advantages this affords, effective groupings can be arranged, the dwarf sorts in front and the taller-growing varieties in the rear.

There are a number of the dwarf varieties from which the amateur may select to suit himself. These have been, for some unknown reason, much neglected, but fortunately, in recent years their value has been more appreciated, and the great merit they possess has brought them into prominence. There is, for instance, the little Iris pumila, which is, per- 
haps, better known than the other species, and which grows nine inches high and bears in April showy flowers of deep purple. It is, moreover, a profuse bloomer, and as an edging plant possesses extraordinary value. Its green leaves appear in March, and it is always in trim, neat form, even throughout the hot days of midsummer. It can be had in various colors, ranging from pearly white through clear blues to the deeper-colored typical tint. Iris verna is another dwarf species, quite prolific in bloom, producing its purple flowers also in April. Another gem among dwarf irises is Iris cristata. It grows only six inches high, has foliage of a light green color, forming a carpet of verdure, and bears freely pale lilac flowers beautifully blotched with golden yellow. Iris Chamceiris is a variety sometimes mistaken for 1 . pumila, but its yellow flowers, with falls veined with purple, disclose its identity. It also is of value, and of value, too, is the dwarf form, Iris flavissima, or I. Bloudovii, as it is sometimes catalogued, which bears showy flowers of a pure yellow color.

Taller-g'rowing species which are of easy culture and which are effective in the garden wherever planted are also numerous. Promi- 


\section{IRISES AND TENDER BULBS 233}

nent among those which are to be recommended for the average amateur is Iris Florentina, the orris-root of commerce, deservedly popular, and for over one hundred years a familiar flower in the old-fashioned New England gardens. It is free-blooming, producing flowers of pearly whiteness, deliciously fragrant, delicate and effective. Iris pullida, whose blood flows through the veins of all the better hybrid German irises, is a plant with broad leaves and sword-like foliage which often attains a height of two and a half feet, the blades measuring an inch and a half across. It bears its flowers on long stems, raising them high above the foliage, and the result is most effective. Then there is Iris Pseudacorus, Jacob's sword, as it is sometimes called, which possesses ample green foliage and forms quickly a vigorous clump. It bears flowers of a rich golden yellow color, and produces them in profusion.

The much-admired Siberian iris (I. Sibirica), has a number of forms of which the most common type is a tall-growing variety, attaining a height of two and a half or three feet, and bearing many flower stems, which are topped with blooms of a dark blue color marked with white 
pencilings. The best sorts are the pure white, growing about two feet high, and the variety orientalis, twenty inches high, the latter bearing in profusion rich blue flowers of charming form. It has the valuable quality of reproducing itself rapidly, and from a few plants

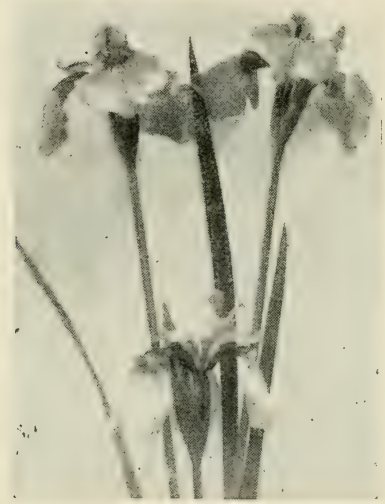

Siberian Iris

(Iris Sibirica)

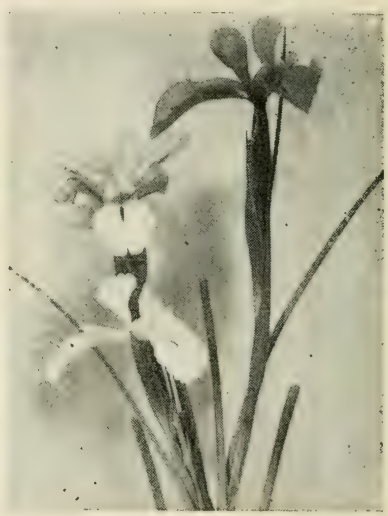

English Iris (Iris xiphioides)

enough can be obtained in two or three seasons to plant a considerable area.

All of the irises with surface rhizomes thrive in ordinary garden soils, requiring division and replanting as their clumps increase in size. This should be done as soon as the foliage shows signs of ripening, and should be accom- 


\section{IRISES AND TENDER BULBS 235}

plished early enough in the autumn to permit the newly planted roots to become thoroughly established before winter sets in. The rhizomes should never be planted deeper than an inch below the surface, unless the situation is unusually dry. As the clumps increase in size, divide them by cutting the rhizomes sharply with a spade or similar implement, transplanting the portion detached and allowing the parent plant to remain in its position undisturbed.

\section{TENDER BULBS}

There is another class of bulbous, tuberousrooted plants which is worth considering and which, like those requiring planting in the fall, are easily grown. These are the bulbs which bloom in summer and autumn and are planted in spring. They are known as tender bulbs because they will not endure the winters, but, after blooming and ripening, are dug up and stored away to be replanted the following spring. Among the most important species of this class of bulbs are the agapanthus, alstrœmeria, tuberous begonia, bessera, canna, caladium, cooperia, crinum, dahlia, gladiolus, madeira vine, montbretia, oxalis, calla, tigridia, tuberose, and zephyranthes. 
No flower is easier of culture or less doubtful so far as success is concerned than the dahlia. We have the single and pompon, the show, the quilled and fancy, the decorative and the cactus varieties. The hundreds of shades and colors and the beautiful forms as well as the grace of the plant and its value for cutting give this flower an exalted position which it well deserves. The roots should not be planted in the northern states before the middle of May and, when the growth appears above the surface six inches or so, it is generally well to pinch the tops, a process which produces a bushy, compact, dwarf growth.

Following the dahlia in popularity and praise are the gladioli. They may be planted either in separate beds or among perennials where they will add gay colors to borders which might otherwise be hare. Gladioli should be planted as early in the season as the ground can be worked and every two weeks thereafter until July first for a succession of bloom. They prefer a sunny situation, a rich soil and plenty of moisture and should be planted six inches deep, seven or eight inches apart.

The tuberous-ronted begonia is raluable be- 


\section{IRISES AND TENDER BULBS 237}

cause it will flower in shady situations. In a spot where other flowers have persistently refused to grow, the tuberous-rooted begonia will frequently be found at its best. They are best started in the house during March and April in pots and then planted out of doors the latter part of May. If started early enough indoors, they will be in bloom by the middle of June and will continue to flower until frost. They thrive best in a rich, loose, moisture-retaining soil and prefer a considerable quantity of leaf-mold to which has been added a liberal amount of sharp sand. The bulbs should be planted three inches deep and ten or twelve inches apart.

Montbretias are desirable when planted in groups of fifty or a hundred bulbs. The bulbs are planted in the spring about four inches deep and will prove hardy when afforded a winter protection of litter four. or five inches deep.

The summer hyacinth, (Hyacinthus candicans), bears large, white, bell-shaped flowers on stout stalks two or three feet high. For best effects this must be planted in clumps and, like the Montbretia, proves hardỵ when given protection during the winter. Tuberoses and 
caladiums are well-known popular bulbs which are extensively planted.

\section{BULBOUS VINES}

Among the summer-flowering bulbous- and tuberous-rooted plants are several vines which prove exceedingly valuable. Most city yards possess some objectionable spot or object which it is desirable to conceal from sight; this may be accomplished by the use of annual or perennial vines. But annuals, while they are quick growing, are objectionable owing to the fact that they must be replanted each year; perennials, on the other hand, frequently require from two to three seasons to establish themselves. Between these two come the bulbous vines. They are quick growing and, when once planted, require no further attention, thus combining the advantages of both annual and perennial. Moreover, they are inexpensive. Foremost among these is the Madeira vine which attains a considerable height in a very short space of time. The foliage is dense and the flower small and white. The Cinnamon vine, with glossy, green, heart-shaped leaves and very fragrant racemes of white flowers, grows to a greater height and blooms in $\mathrm{Au}$ - 


\section{IRISES AND TENDER BULBS 239}

gust. Another fine climbing plant is the Kudzu vine, which possesses magnificent foliage, deep and dense, and makes a wonderfully rapid growth the first season. It comes from Japan and is very extensively planted. A native vine is Apios tuberosa which seems to be more appreciated in England than at home; its special features are its adaptability to situations in absolute shade and its beautiful flowers of pleasing fragrance. It grows rapidly and blooms in July. 


\section{CHAPTER XII}

\section{SHRUBS}

In planting as it is usually done on the city or town lot of average size, in most cases a shrub would be preferable to the tree which is ordinarily set out. Too often trees are crowded into situations far too small for them, which is neither good for the tree nor of value to the site. Due allowance is seldom made for the tree's growth and spread and, planted in close proximity to some building on one side and subject to exposure on another, a straggling, unbalanced specimen is produced that lacks beauty, strength and vigor. This does not mean, of course, that trees have no place in the small rard; when properly selected and properly located, they add immeasurably to the appearance of the home. But, before a tree is set out, careful thought should be given to its fitness for the place where it is proposed to establish it. 


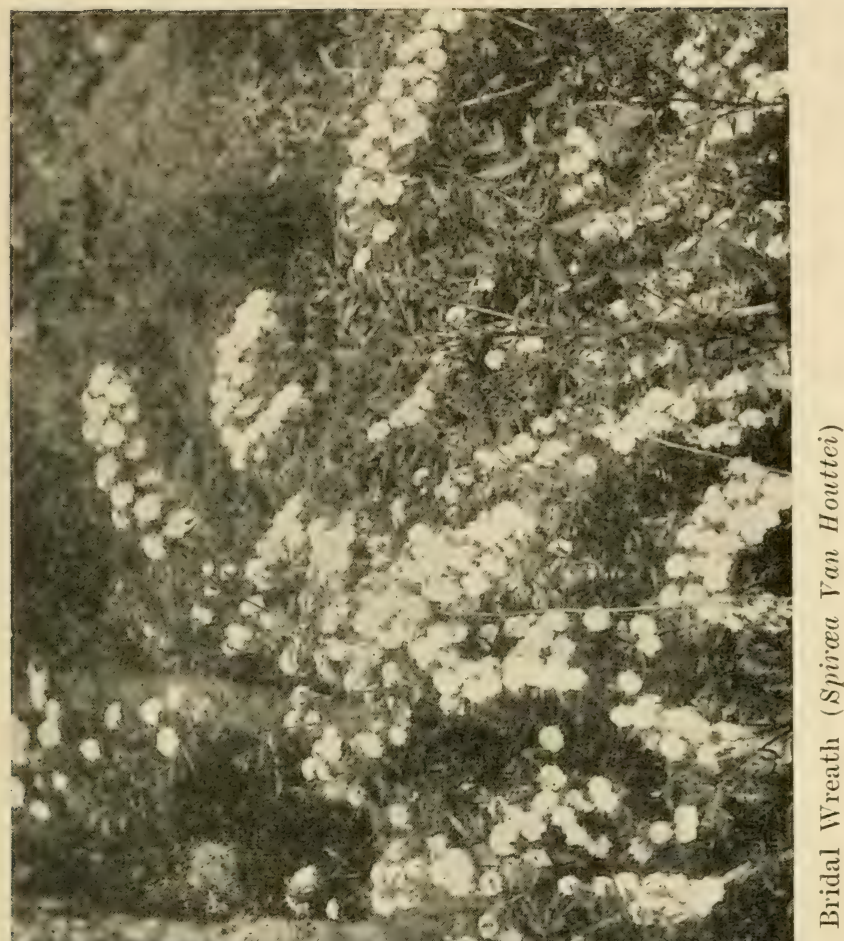




\section{DISADVANTAGES OF TREE-PLANTING}

The tree should be considered as a mature plant. It must not be forgotten, that, as the years go by, the tree will continue to grow. It will not long remain the small specimen received from the nursery which, when first planted, may appear to be entirely suitable for the location selected. Each year will add to its height and increase the spread of its branches, so that, in ten years, perhaps, it may have attained a size that unfits it for the effect desired. Even then it may be only in its infancy, requiring, for its fullest development, twentyfive or fifty years more.

This fact suggests the permanency of the tree and is converted at once by the incautious planter into a recommendation which more than offsets any objection which may be found against its use. However, a second thought may lead to the conclusion that this is not the advantage it may at first sight appear to be. If one is planting for future effect, if one is planting the home grounds for the enjoyment of one's children and one's children's children, well and good, the tree's the thing. Its leafy branches will cast grateful shade for them and 
the massive trunks will stand as monuments to the forethought of the ancestor who felt so tender an interest in the comfort of his descendants. But if one is planting for oneself, for to-day, for this generation, for immediate effect, the tree is not the thing. The shrub must displace it.

We have come to a fuller realization of this in the last few years than erer before. And; as we have gained in this direction, we have come to understand and to appreciate the value and the uses of trees. Te no longer plant them in such proximity to our residences that both tree and house suffer as a consequence, and we no longer fancy that a tree is as essential to a lot as a roof to the house. Planting experts are now practically unanimous in declaring that a tree which attains average height and spread should not be planted within trrenty feet of the house. The reason for this dictum is not difficult to discover. Trees set at closer distance can not attain the full development they require as they grow older and, so far as the residence is concerned, if planted nearer than the twenty feet limit, too much shade is likely to result, with dampness and ill health as the immediate consequence. 
Moreover, where trees overspread the lawn, grass of that "velvety" texture so desirable is almost impossible. Then, too, not only is a free circulation of air shut off from the residence and the sunlight excluded, but the planter who has thus elected to proceed will find that he has made flower-growing exceed-

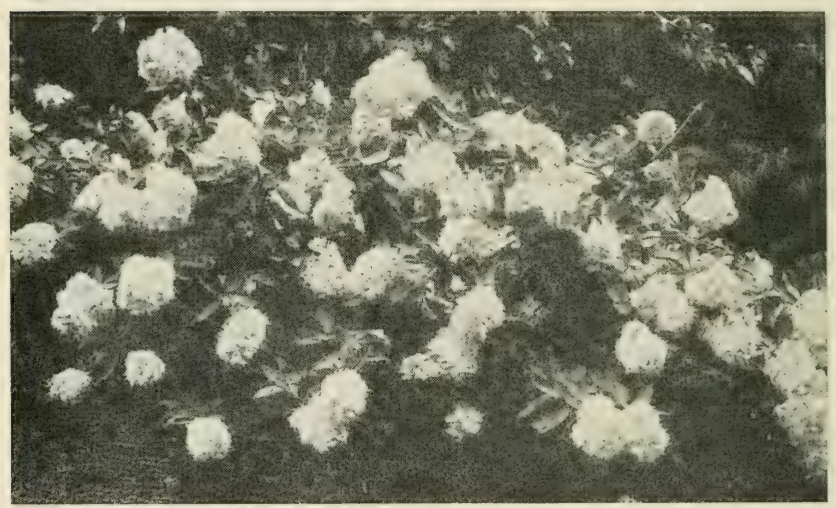

Hydrangea Laden with Flowers

ingly difficult. In a word, the owner of the small city lot sacrifices too much in planting trees for what he gains. If his yard is large enough, trees have a place in the planting scheme. But if the yard is small, confine treeplanting to the park bordering the street or 
highway and make use of shrubs for lawn planting.

\section{EFFECTIVENESS OF SHRUBS}

Too often the advantages of shrubs are overlooked or ignored. Tall-growing and dwarf, deciduous and evergreen, there are few places where they will not succeed and, thriving, add materially to the beauty of the home. They have in the first place two distinct values: they are serviceable when employed as individual specimens, planted in isolated situations for formal effect, and valuable when grown in masses forming what are commonly termed shrubberies. Both methods of planting have their particular uses and advantages but, although the inclination as a rule is in the direction of individual or specimen planting rather than mass planting, the latter and not the former is to be recommended. The amateur, however, is far more likely to adopt the course proscribed than that which is advised, for it appears to him that shrubs scattered about the lawn add more to the yard's general appearance than when they are grouped. But, as a matter of fact, mass planting and not specimen planting 
contributes more toward harmonious and satisfactory effect.

Frequently a yard presents a "patchy" appearance for which the planter is unable to account. In such instances, were it possible to shift specimen shrubs temporarily from their isolated positions to shrubbery groups and observe the increased effectiveness resulting from the change, the perplexed gardener would at once detect the cause of the trouble and, it is safe to conclude, would make the temporary arrangement permanent. Shrubs, or plants of any sort, for that matter, scattered indiscriminately and without apparent purpose over a lawn destroy all suggestion of unity and conspire to obscure the motive of the planter; his cultivated area, consequently, whether it be large or small, loses all meaning to the observer and lacks at the same time that individuality which is one of the most desirable features in a properly planned and planted yard. On the other hand the mass planting of shrubs adds harmony to a place, contributes to its unity, assists in defining the motive and, in most instances, supplies a touch of strength which is as essential to a well and tastefully beautified yard as a suggestion of delicacy. 


\section{SHRUBS}

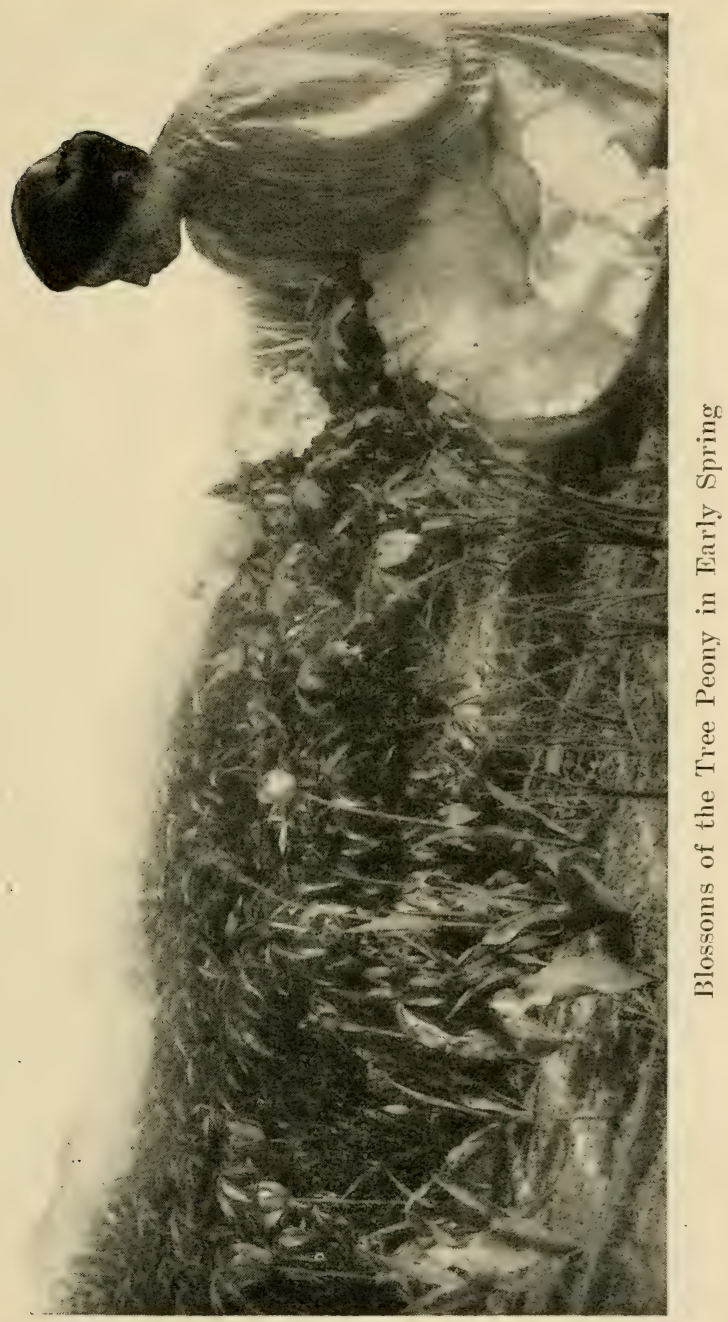


Some beginners probably will find it difficult to distinguish between shrubs and small trees. But this need not discourage them; experienced planters are similarly perplexed. What one calls a small tree another may call a shrub, the distinction being often difficult. Shrubs, as a rule, have a number of stems springing from the ground whereas a tree possesses but a single trunk. Still this is not true in all cases.

The wide variety in habit of growth, foliage, fruit and flower makes the worth of shrubs. They can be had for every situation, of varying height, and of varying seasons of bloom. As the leaves differ, so the flowers differ, or the berries in cases where the shrub's chief value is determined by its fruit rather than by its bloom, but if in any of these respects the variation is wide it is no wider than the variation in the uses to which shrubs may be profitably put. They serve to conceal foundation walls; they form backgrounds for plants; they act as harmonizing agents between lawn and tall-growing trees; they can be used as a covering for ground which on account of its slope, exposure or other adverse conditions will not support grass, and they are valuable as mate- 


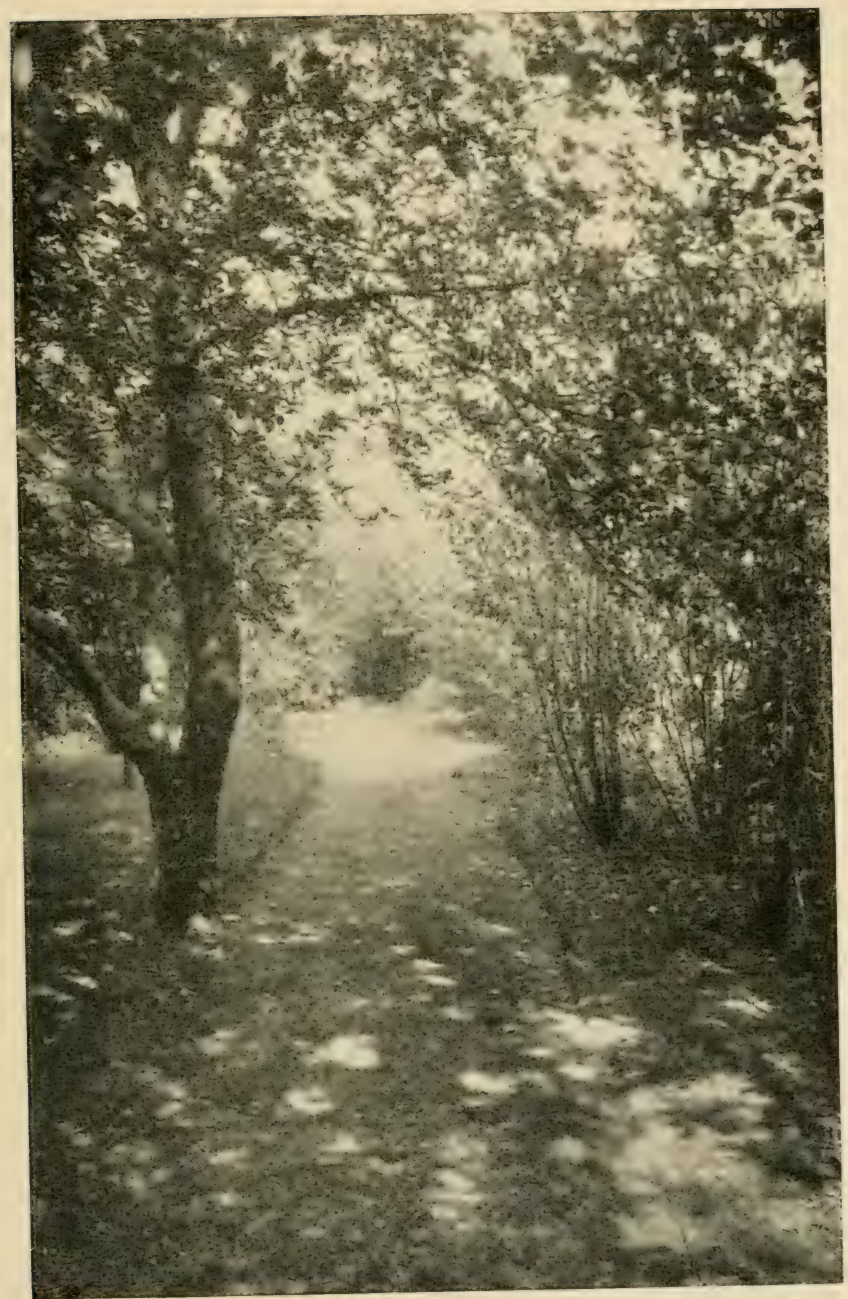

Shrubbery Walk in Small City Yard 
rial for breaking dead levels and hiding and obscuring unpleasant views.

They may be used also to supply motive for a sudden or abrupt turn or termination of a walk. Very frequently a walk is given a slight or even pronounced turn without apparent cause; instead of being what it should be, the most direct means of getting from one point to another, the walk twists until it follows a rambling course which is utterly purposeless and inexcusable. But, where the turn is projected, plant a clump of shrubs and there is at once established a sensible and logical reason for the turn. The walk then seems to curve in order to avoid the shrubs planted in its more direct course.

Another considerable advantage shrubs possess is that, once established, they require comparatively little attention. This does not mean, of course, that they should be heedlessly planted or grossly neglected. Though very frequently they will grow when conditions are both unpleasant and unfit for them, still if the best results are to be obtained some consideration must be had for the demands of the plants. They will reward the gardener royally for the care he bestows on them. 


\section{PLANTING AND ARRANGING SHRUBS}

In preparing beds for shrublery, spade the ground to a depth of at least two feet, work into the soil well-rotted manure, make it fine and soft, and see to it that it will not suffer from want of proper drainage. In planting first examine the roots and, where these have been broken or twisted in transit, cut off the broken or injured portions with a shar p knife, then, having prepared a hole amply large for the reception of the bush, set it in at a slightly lower level than that at which it stood before it was lifted. This depth can readily be ascertained by observing the marks left by the soil on the stem or stems. Allow sufficient room for the development of the shrubs, bearing in mind the fact that they increase their spread as they grow older, avoid crowding, and avoid also setting them too far apart. Group them by planting the taller-growing varieties in the rear and the dwarfs in the front, but do not aim at too uniform an effect. Occasionally it may he desirable to establish a round bed, although there can be but little need for such an arrangement, but if this method of planting is considered desirable, place the taller-growing varieties in 
the center and group the dwarf sorts around them. This arrangement is suggested not only because it presents a better appearance but because if it were not followed it is obvious that the low-growing shrubs would be entirely hidden by the taller varieties and at the same time so densely shaded by the foliage that they would soon perish.

In any event avoid monotony. Shrubs in this respect are easily abused and often, through lack of judgment in planting, monotony occurs where the purpose was the contrary. But in avoiding any suggestion of regularity the planter must also avoid any appearance of studied irregularity. Do not plant in straight lines and do not plant in mechanical zigzags. Group the shrubs.

\section{CULTIVATION}

Though hardy shrubs require little protection in winter, still it is always best to leave on the ground the leaves they drop at the first touch of frost and to add to these additional small quantities as the winter advances. Very little trimming or pruning should be practised. Keep the dead wood well cut out but be exceedingly cautious in applying the pruning 
shears in any other manner. Occasionally, where a shrub assumes a tall, spindling growth, it may be advantageous to cut it back to induce a broader and more spreading growth. Wherever this is necessary cut back boldly or the purpose of the pruning will not be accomplished. But, for the most part, let the shrub have its own way, especially when it is healthy and vigorous, and apply the shears only when it is absolutely necessary. Shrubs sheared into unnatural forms seldom possess any value as ornaments unless the effect aimed at is altogether formal.

\section{VARIETIES}

On the smaller grounds in town or city the greatest value of shrubs is in the grouping of many flowering varieties in one mass so that a succession of bloom is insured from April to November. If only seven shrubs were planted it would be possible to maintain such a succession, the bloom first appearing immediately after the last frost in spring and continuing until autumn frosts blight the bushes. This list would include:

Forsythia ............................

Syringa (lilae) .................... May

Spiræa ......................June

Deutzia 
Rhus (smoke-i)ush) . . . . . . . . . August Hydrangea . . . . . . . . . . . September Hamamclis (witch-hazel) ............. October

All these shrubs are perfectly hardy and will respond graciously to ordinary treatment in any good garden soil. Moreover, good plants of large size may be obtained at small expenditure, the whole collection costing from one to two dollars, according to their age.

It would hardly be possible to prepare a list of the essential qualities which should be demanded of shrubs for the home embellishment - the preparation of such a list would require consideration of the individual places to be planted. Still, whether grounds are large or small, whether many plants are required or few, and whether shrubs are desired for bloom or foliage value, to obtain the best effects from their use, plant them as a general rule in masses. Use them liberally, for they possess more actual value than perennials in that they are more permanent and, compared with annuals, they demand but little attention. In a word, you may plant annuals for a season, perennials for a few rears, trees for posterity, but shrubs you plant for yourself for immediate effect and for practically the whole of your own lifetime. 
It must also be borne in mind that there are evergreen as well as deciduous shrubs and that a judicious selection of the former will give a touch of life to the yard or grounds in winter which could not be obtained otherwise except through the use of evergreen trees. As long as we have these-both trees and

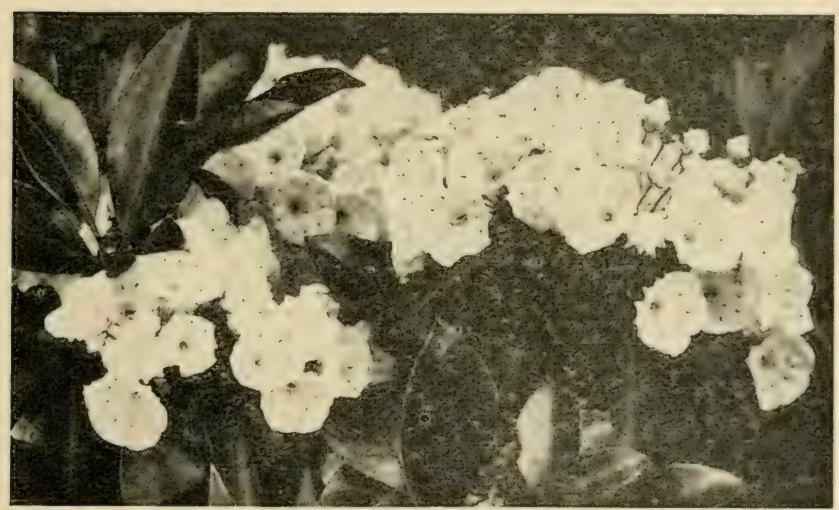

Flowers of the Mountain Laurel (Kalmia latifolia)

shrubs-there is small excuse for any place either in the city or the country assuming a dead and desolate appearance in winter. Any one who has observed a group of rhododendrons in winter with their great glossy leaves can not fail to be impressed by the life they lend to the landscape. Rhododendrons, how- 
ever, are not the only shrubs that lend themselves to this particular use, for here again a variety is presented which affords the planter a wide field from which to select. There is, for instance, the Mountain Laurel (Kalmia latifolia), which is without doubt one of the choicest of American broad-leaved evergreens. The leaves are particularly conspicuous in winter and as the Kalmia is perfectly hardy as far north as Maine and is neither difficult to establish nor difficult to maintain, it forms one of the most valuable shrubs in the list. In the spring its sheets of bright rosy-pink flowers, delicately adorned with carmine dots, add to its value for decorative purposes.

Then again, among the most useful of our early spring-flowering shrubs are the hardy azaleas, many varieties of which have persistent evergreen foliage. A low-growing shrub with evergreen foliage and of compact habit, bearing white flowers in great abundance in spring is the Andromeda floribunda or Pieris floribunda. Mahonia Aquifolium, or Berberis Aquifolium, as it is more properly known, is another dwarf species with purplish shining prickly leaves retained throughout the winter, and with showy bright yellow flowers in dense 
cluster's in May succeeded by bluish-black berries. Its handsome deep green glossy foliage, which assumes a bronze or coffee hue in winter, and its neat habit render it especially valuable for decorative planting. Another evergreen shrub of value is Euonymus Japonicus, or Japanese euonymus.

\section{SHRUBS SUITED TO THE CITY YARD}

In the selection of evergreen varieties for planting in cities, we are to some extent limited by soil conditions and by the injury inflicted by the smoke-filled atmosphere. Only such evergreens as will most sturdily withstand these blasts of coal smoke and which, at the same time, will not make too many demands for special soils should be planted. In the list of deciduous shrubs, however, we find less delicacy displayed; they submit more happily to adverse conditions which the evergreens could scarcely withstand, and apparently thrive despite them. While the deciduous varieties that bloom in late summer are few, there is apparently no end to the varieties that flower in spring or early summer. In the list of these not only is almost every color of flower to be had and every height from one to twelve feet 
as well as numerous varieties of foliage, but there will be found shrubs for almost every conceivable situation and purpose. Indeed, with so many varieties at hand the amateur will experience no difficulty in obtaining what he may require but, on the contrary, will doubtless be embarrassed by the quantities from

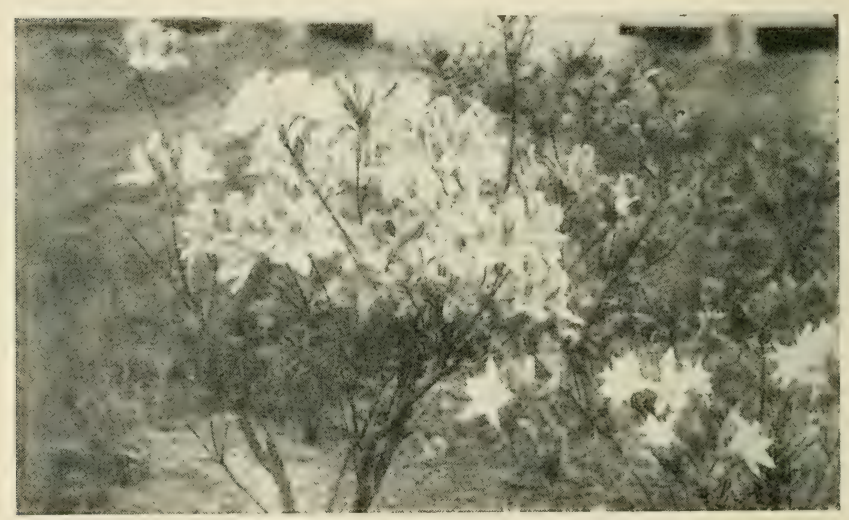

Hardy Azalea in Bloom

which to select. As he reads descriptions it will seem to him that first this shrub and then that is absolutely indispensable, but he will do best if he limits the varieties he selects to those which are most commonly employed. Experience has proved the value of these and they are, generally speaking, quite as effective and 
quite as adaptable to his purpose as any of the rarer shrubs which nurserymen may offer in their catalogues.

A showy shrub is the lilac (Syringa) with pink, white or lilac blossoms. It is best, however, not to mix the three colors but to mass each variety separately, thereby obtaining a stronger and at the same time a more restful effect. In planting lilacs obtain good shrubs. Do not plant a bush because it is to be had for nothing; it seldom proves worth the trouble. Avoid also the double-flowered varieties, for their flowers are heavier and less graceful and give no suggestion of the freedom and unconventionality of the single variety. The Mock Orange, or syringa as it is sometimes called, (Philadelphus), is a hardy, free-flowering shrub with showy flowers appearing in late spring. If the most fragrant variety is desired, obtain Philadelphus coronarius. The Snow Ball (Tiburnum) should not be forgotten. Aroid the old-fashioned kind which is invariably a prey to aphids or plant-lice whose ravages cause the leares to curl and the flowers to lose their beauty, and select instead Japanese Snow Ball which, though it has smaller flowers, possesses better foliage and habit. This is known 
to nurserymen as Tiburnum plicatum, although its proper designation would be Viburmum tomentosum, var. plicatum. It attains a height of eight feet-some four feet less than the common snow ball-and has especially attractive foliage while its globose flower clusters are three to four inches across.

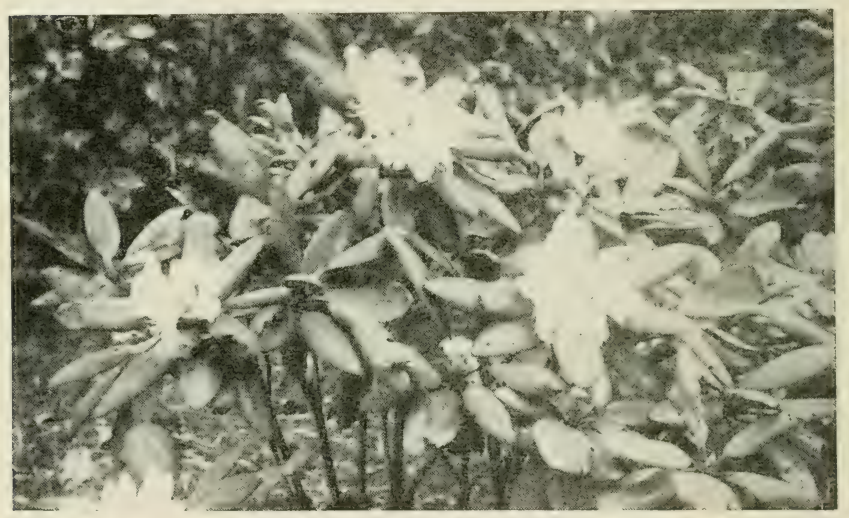

Rhododendron in Bloom

The Spirac forms another group of shrubs excellent for a small city yard. The most popular species probably are S. Tan Houttei, S. Thunbergii and S. prunifolia. The blossoms of these are white and are borne in May and June. The common Briclal Wreath is S. Van Houttei. The Thunberg Spiræa (snow gar- 
land) comes into bloom earlier and of this variety there is a hybrid known as Sprirca argutu which is considered by many to be the showiest of all the earlier blooming spiræas.

\section{SEASON FOR PLANTING}

In the matter of determining the season for planting, whether it shall be spring or fall, no fixed rule can be given. In any event plant early enough, if the spring be selected, to insure the plant's establishing itself before the hot suns of summer scorch it, and if the fall season be chosen, set the plants early enough in autumn to insure their becoming established before hard freezing begins. Evergreens should be planted very early in spring or in August. After the shrubs are once established most of them, save for an occasional pruning, will take care of themselves, but it is always well to have on hand a little ammoniacal carbonate of copper ready to be diluted and to be applied to the shrubs in the form of a spray for all fungus attacks, and a little hellehore and similar poison to preserve them from the onslaught of destructive insects.

Whether deciduous or evergreen shrubs are used their value as ornaments for the small city 
yard is (quickly apparent if we will only observe our own haliit of vision as we pass along the streets. While it is seldom that our line of vision takes in the foliage of trees, our sight as a general rule rests upon those objects which are on a line with our eyes. In other words, while we infrequently turn our gaze upward

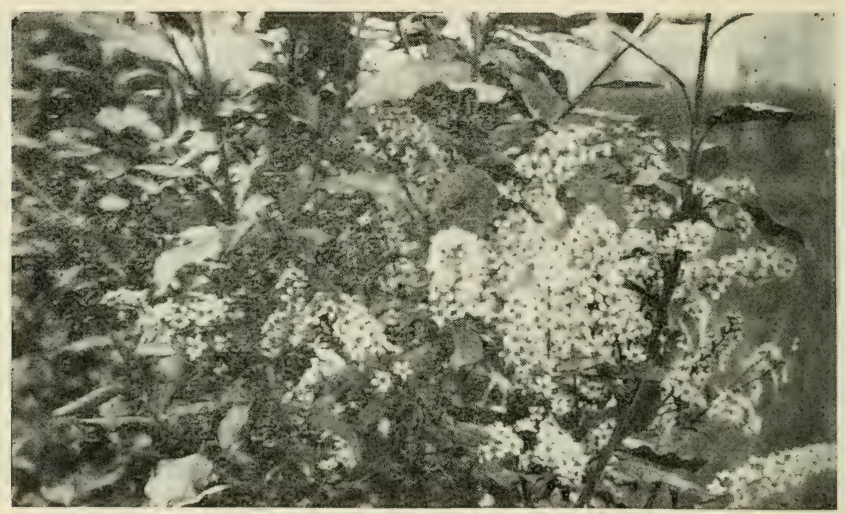

Flowers of the Tall-growing Bird Cherry

toward the tree-tops, almost constantly our vision is directed to those objects which are on a level or below the level of our sight. We may fail to observe the form or character of the foliage of a tree but it is not likely that we shall fail to observe the low-growing shrub, especially when our gaze is attracted by the 
mass of bloom put forth in spring and summer. If this fact were more frequently taken into consideration shrubs undoubtedly would be more plentifully planted. Because of this fact, they add to a city yard a means of contrast which on a large estate could be obtained only by the judicious planting of tall-growing trees. By the use of shrubs, therefore, we are provided with the finishing touches which are necessary to the completion of the picture we desire to produce with nature's materials.

The following list will assist the amatenr in selecting shrubs for various situations and purposes:

THE BEST HARDY SHRUBS

FOR SHADY SITUATIONS

Mountain Laurel, Kalmia latifolia

Mountain Fetter Bush, Pieris (Andromeda) floribundu

Mahonia, Berberis Aquifolium

St. John's Wort, Hypericum aureum

Barberry, in variety, Berberis

Privet in variety, Ligustrum

Dogwood in variety, Cormus

Sweet Pepper, Clethra alnifolia

Wolfberry or Snowberry in variety, Symphoricarpos

Sweet-scented shrub, Calycanthus floridus

Wild Black currant, Ribes floridum

Slender deutzia, Deutzia gracilis

Rough-Leaved deutzia, Deutzia scabra

Japanese quince, Cydonia Japonicu

SHRUBS THAT BLOOM TWO MONTHS

Japanese rose, Kerria Japonica

Shrubby cinquefoil, Potentilla fruticosa

Sweet pepper, Clethra alnifolia 
St. John's Wort, Hypericum prolificum

Red root, Ceanothus Americanus

Stagger-bush, Pieris Mariana

\section{EVERGREEN SHRUBS}

Mahonia, Berberis Aquifolium

Evergreen azalea, Azalea amoena.

Mountain laurel, Kalmia latifolia

Mountain fetter-bush, Pieris (Andromeda) floribunda Rhododendron Cataubiense and hybrids

Dwarf pine, Pinus montana, var. Mughus

\section{SHRUBS WITH VARIEGATED FOLIAGE}

Purple-leaved barberry, Berberis vulgaris, var. atropurpurea Dogwood in variety, Cormus

Syringa, Philadelphus coronarius, var. aureus

Weigelia, Diervilla rosea, var. nana variegata

Shrubby Althea, Hibiscus Syriacus, var. fl. pl. fol. var.

Purple-leaved plum, Prumus Pissardi

Golden elder, Sambucus nigra, var. aurea

Filbert, Corylus maxima, var. purpurea

\section{SHRUBS THAT BLOOM FROM APRIL TO JUNE}

Goldenbell, Forsythia suspensa

Japanese Quince, Cydonia Japonica

Juneberry, Amelanchier

Lilac, Syringa vulgaris and varieties

Barberry, Berberis vulgaris

Azalea, in variety

Daphine

White Kerria, Rhodotypos kerrioides

spircea in variety

Tree peonies in variety, Pronia Moutan

Bush honeysuckle, Lonicera Tatarica

Deutzia.

Snowball, Viburnum

SIIRUBS THAT BLOOM IN JULY, AUGUST AND SEPTEMBER

Buttonbush, Cephalanthus occidentalis

Spircea

Sweet pepper, Clethra alnifolia

St. John's Wort, Hypericum prolificum

Deutzia

Hydrangea paniculata var. grandifore

Shrubby Althea in variety, Hibiscus Syriacus 


\section{SHRUBS}

SIILLBS WITIL ORNAMENTAL FIRTT

Barbery, Berberis, searlet and violet in September

lied Osier, Cornus sanguinea, white berries in September

Oleaster, Elcogmus longipes, red fruit

Strawberry bush, Euonymus, red and white fruit

Cornelian cherry, Cormus mascula, fruit red fruit

Bush honeysuckle, Lonicera, in variety, showy red and yellow

Brambles, Rubus, in variety, red fruit

Elder, sumbucus, purple fruit, changing to black in August and September

Snowbery, Symphoricarpos raccmosus, white berries all winter

Wayfaring tree, Tibumum Lantana, bright red, nearly black in September

High cranberry, Tiburmum Opulus, red fruit, very ornamental

Mahonia, Berberis Aquifolium, bluish berries in July

Buckthorn, Rhammus, black fruit 


\section{CHAPTER XIII}

\section{TREES}

If it is well understood-as it should bethat the lawn surrounding the house is the canvas upon which a picture is to be made, we shall appreciate the fact that the extent to which trees are planted will depend entirely upon the size of the lawn. Naturally, where the area is small and the plot of grass is limited, more dependence must be placed on shrubs than on trees. In a yard of generous dimensions, the trees have a place; and, in such situations, they are the legitimate materials with which the landscape gardener obtains many of his most effective results.

\section{PROPER SETTING FOR TREES}

In the city yard of small size, trees, especially those which attain a great height, can not be employed effectively. Here, if trees are planted, very often the desired picture is marred. It is, for instance, little less than ab- 


\section{PLANTING A TREE}

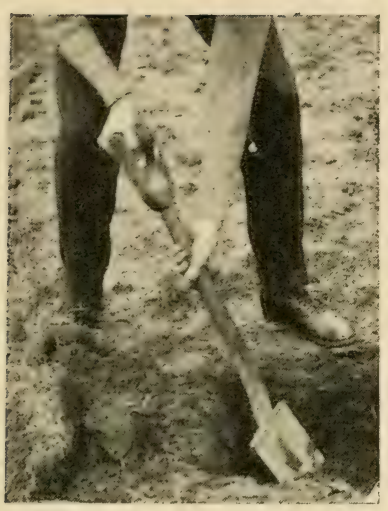

-1 -

Dig the hole large and deep, laying surface soil to one side. Loosen earth in bottom of hole.

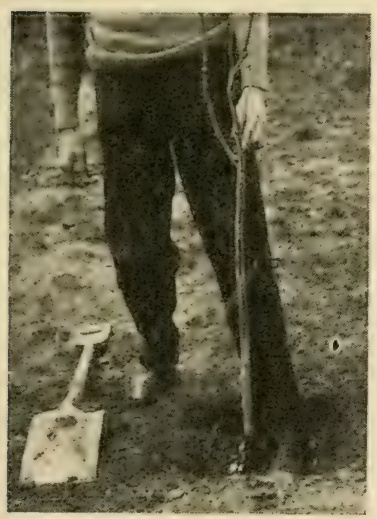

Throw in more soil, steadying the tree, and tramp into place. Be careful not to injure the roots.

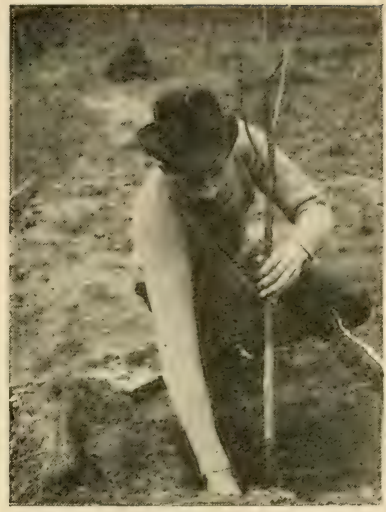

\section{- 2 -}

Set the tree straight and throw surface soil around the roots. Leave no air spaces; firm with the hand.

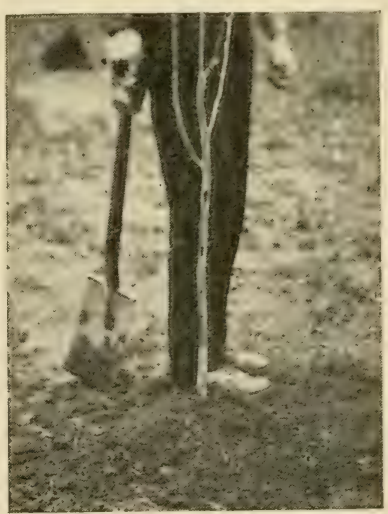

\section{$-4-$}

Do not firm the top layer of soil; let it remain loose and sulverized. Slightly mound the soil, 
surd, as was said in the chapter on shrubs, to set one or more of the tall-growing varieties in a front yard that is no more than ten or fifteen feet deep and forty feet wide; the space could be employed to far greater advantage. We want shade but not at the expense of sunlight, fresh air, good taste and health.

Still, trees have their value and it is only necessary to give them the proper setting in order to make apparent immediately how great this value is. To crowd them on a small area where they will not thrive, or to plant them where, owing to their size, they are entirely purposeless, is an error. Yet it is only too frequently made; indeed, it is rather the rule than the exception. It seems to be the disposition of most persons, as soon as they obtain a lot whereon they expect to build sooner or later, to begin immediately the planting of trees. Without due consideration of the future possibilities, of the health of the trees themselves or the appearance of the place, they order them to be set out and thereafter are reluctant to get rid of them even though they find subsequently that their planting was unwise. Irresponsible agents of nurseries are to a great degree respon- 
sible for this indiscriminate practice, for they no sooner learn that an unimproved lot has been purchased by a prospective home-builder than they besiege him. In glowing terms they describe the various sorts they offer and in the end usually triumph by closing a contract for enough stock of the kind to plant an entire acre.

The simple truth is that we buy trees and plant trees without giving due thought to either the purchase or the planting. We set them out because they are trees and not because they will lend beauty to the yard. While this statement is made deliberately, it is not to be understood as decrying in any sense the ornamental value of the tree. The intention, on the contrary, is to impress the planter with the idea that indiscriminate planting is to be avoided and that if the full value of the decorative quality of the tree is to be realized, it must be given not a haphazard setting but one in which it can show to best adrantage and in which it will harmonize most gracefully with all its surroundings. There is ample reason for objection to the planting of tall-growing trees on ordinary city lots where the valuable 
space is so small as to make a tree a ridiculous if not a pitiful sight.

Where the yard is narrow and shallow with a front lawn not more than fifteen feet deep and the area in the rear of the house not more than thirty feet deep, trees are out of place. Doubtless there are many who will take issue with this statement, but in support of the contention, it should be necessary only to point to small yards upon which are crowded large trees and small yards upon which shrubs, vines and flowers appear in their stead. The difference in appearance should prove convincing.

\section{PLACING TREES SUITABLY}

To begin with, trees require many years before they reach that stage of perfection where they cease to be mere nursery stock. Until that stage is attained they are usually lacking in decorative value for the reason that they have not perfected their growth. In the second place, when they have attained mature height and spread of branches, if they are even fair specimens of what they should be, in by far the majority of instances they have outgrown their surroundings and appear out of place. In the third place, it is difficult to grow 
healthy trees under conditions presented by the small city lot; usually there is a surplus of shade in one direction or a surplus of sun in another, protection from one side and lack of protection from the other, and all these things tend to make a tree more or less one-sided in its growth-a blemish which mars the appearance of the tree and discounts to a great degree its value as an ornament. If there be any doubt of the truth of this statement compare the tree grown in the city with the field-grown specimen where conditions are not unbalanced and where the growth is unhampered and unimpeded.

\section{BORDERING PARKS}

If provision were made on all city streets for bordering parks wide enough to accommodate trees, not only would it be unnecessary to plant them within the limits of yards, but the general effect obtained would be better. Sometime it will be more commonly recognized that in residence sections of our larger cities, width of roadway may be often reduced without loss to gain additional width to the street parks. In far too many instances, we fancy that we must have great width from curb to 
curh and no parks, whereas, it would profit us a great deal more, so far as appearances are concerned, to have less width between curbs and more width in the border between sidewalk and curb. If the latter policy were adopted, by the judicious selection and planting of trees

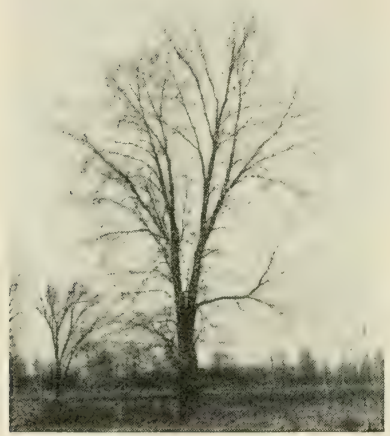

Tree that has never been pruned

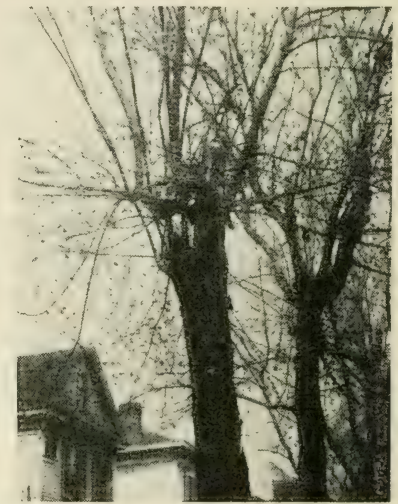

Trees ruined by ignorant pruner

(Photos. by Benjamin W. Douglass)

on these bordering spaces, the entire street would take moon itself an appearance impossible to oltain where everything is sacrificed to roadway width.

There is no prettier or more refreshing sight than city streets bordered on both sides by tall-growing and wide-spreading trees in 


\section{TREES}

healthy vigor, in mature strength, farr-reaching in spread of foliage and with leaves and limbs free from pest and disease. Residences are sufficiently shaded, the streets themselves become leafy archways and those who live thereon as well as those who use them as highways can not fail to mark the beautiful aspect they present.

If, on the other hand, we thrust our sidewalks against the curb, widening the roadway until the last arailahle inch has heen seized upon, and abolish the bordering park, we have converted a street into a mere thoroughfare for traffic and have rohbed it of all the ornamental possibilities it might otherwise possess. ()r, if we crowd the sidewalk out and the street curbing in until we have left a border only two or three feet in width, our only gain is something which is practically valueless. Under such conditions it is difficult to establish even a fair growth of grass. It would be better to carry the crowding process to its extreme and rid ourselves completely of this strip of grass. But, where it is possible to have street parks of fair width, either at the sides or in the middle of the street, trees should he planted and every effort should he made to 
insure their steady growth and healthful development.

\section{TREES ON LARGE CITY LOTS}

Of course, where a city lot measures as much as one hundred feet in width and one hundred and fifty feet in depth trees may be used to advantage, for some shade about the house is an absolute necessity if the hot days of our summer months are to be spent with comfort and if we are to be protected from the cold of our bleak and dreary winters. But this does not mean that they are as available as decorative material to the planter of such a yard as they are to the landscape gardener who is working on the extensive area of a country estate. On the latter, trees are used to hide unattractive views or to form backgrounds against which other ornamental materials are employed and here also they may stand for their own individual beauty. On such a place they have "purpose" ; there is motive for their planting. On the small city lot there is seldom the one or the other.

Frequently, however, city lots are purchased whereon already a tree of large size has established itself. Where such is the case every ef- 
fort should be made to save the tree; it should be protected from any possible damage at the hands of excavators, ditchers, or carpenters, and where one obtains such a prize one should make every effort to set the house so that the tree need not be sacrificed. Even if it is necessary to locate the dwelling three or four feet in one direction or another from the site originally selected it will usually pay to make the change; the builder can well afford to accomodate himself to the requirements of a stately and magnificent tree specimen which, no matter how he might plant or cultivate, could hardly be duplicated in the course of a lifetime.

\section{PRUNING}

Very often the fact that such trees are established on the lot purchased presents not a few problems for solution. The tree mar, for instance, interfere with the grading desired. This, howerer, is not difficult to overcome if a little ingenuity is exercised. Sometimes the trees will require pruning and wherever such is the case the work should be undertaken by a person of unquestioned knowledge and experience. Too often splendid specimens of trees have been ruined by "butchers", who 
possess no knowledge whatever of pruning requirements. 'They have "hacked" the tree out of all semblance of shape, destroyed its proportion and "headed" it back until, if it recovers from the process at all, it will never attain the perfect form it possessed before the inexperienced laborer began his work. Severe trimming and subsequent training in many instances may be necessary, but rather than prune too severely it would be better to err on the safe side, obtaining the effect desired by degrees rather than by submitting the tree to the tender mercies of a man without knowledge or experience. When a tree is old, long straggling branches are in many cases the cause of retarded growth; they are exposed to the heat of the sun and to the drying winds and the sap is impeded in its flow to such an extent that very little new growth can be made. If these branches be headed hack, not too severely, new growth will soon show and the trunk and limbs will subsequently be clothed and protected while the tree's form will be improved. But, in cutting off branches, if they be large, the wounds left should be painted with linseed oil paint. This prevents decay of the wood and serves to protect the tree from 
diseases which often follow the operation of pruning.

If the following principles are borne in mind pruning will cease to be a mystery to the novice and his trees thereafter need not be left at the mercy of the ignorant:

1. Pruning the top strengthens the limbs remaining-the root system is not altered.

2. Pruning the roots retards top growth because it reduces the supply of food.

3. Trimming away terminal growths causes forking which, obviously; increases or thickens the branch system. It likewise encourages fruit and flower production.

4. Winter pruning produces greater vigor in limbs permitted to remain; summer pruning produces more wood.

5. Light annual pruning is better than heavy pruning done at longer intervals.

6. Dead rood should be remored at once, no matter the season.

\section{TRANSPLANTING LARGE TREES}

Modern methods now in vogue permit the successful transplanting of trees of extraordinary height and with an extensive spread of roots. When, therefore, a lot is obtained upon 
which there are no old trees and upon which it is desired to have trees of large size for immediate effect, these may be employed. Of course, while the tree presents no exception to the rule that the younger a plant is the better it withstands transplanting, still if the operation is carefully carried forward trees will suffer few ill effects from the transplanting. The principles governing the operation are the same whether the tree is large or small; it is only in their execution that there is a difference. Small trees may he transplanted by hand, whereas various mechanical devices have been perfected for the safe transplanting of the larger trees. By these devices or machines an immense ball of earth is lifted with the roots and the roots themselves are but slightly damaged. Where these machines are not to be had they may be approximated by the use of the riggings commonly employed by . house movers.

Many persons believe that the moving of large trees, even when the operation is accomplished with apparent success and without evident damage to the root system, is invariably an ultimate failure. They are inclined to believe that smaller trees which have not been 
submitted to such violent disturbance quickly overtake the larger trees. This idea arises, no doubt, from the custom which still very generally prevails of moving trees with trunks six to twelve inches in diameter, with only a small ball of roots measuring, in some instances, only three or four feet in diameter. This ball, as small as it is, can not contain the larger roots and, as from sixty to ninety per cent. of the feeding roots are lost in the process, the tree naturally receives a set-hack from which it is not likely to recover. It sends out its leaves, using in this process the plant foods stored within its cells but, having nothing with which to replenish the supply, fails to support the foliage and, in successive seasons, the leaves are less plentiful, the branches die and the bark itself perishes.

In the transplanting of large trees it is most important to obtain all the roots possible. In order to do this the digging should be begun at a distance great enough from the trunk of the tree to permit all the excavation that may be necessary. As the ends of the roots are uncovered they should he carefully lifted and tied so as not to impede the progress of the workmen or suffer damage at their hands. As the 
earth is removed from beneath the tree the tree itself should be made secure by ropes which, by the employment of pulleys, can be so adjusted as to give the tree at all stages of the operation the necessary pitch to facilitate the excavating. Supports should be placed under the ball of earth remaining in contact with the roots so that the tree will not be in danger of falling into the hole made by the diggers. Then, with the root system uncovered and carefully tied so that no damage will result, by use of the "jacks" and other apparatus commonly employed by house movers, the tree may be lifted and brought to its final location.

\section{TRANSPLANTING SMALL TREES}

But, when a tree is small, we have no such difficulties to encounter in transplanting it. As already suggested, nursery-grown trees which have been transplanted once or twiceas most nursery trees are-prove the best. They have been cultivated with a view to transplanting and withstand the operation much more successfully. Such specimens, if sound, full of life and planted in a favorable soil, are almost sure to thrive. To make this surer, however, it is necessary to remember a few 
fundamental principles in the treatment and care of the stock that is being transplanted. As soon as the tree is received from the nursery, it should be pruned. First, eut out all the broken hranches; second, cut back all the side branches to within a few inches of the stem, leaving at least two sound buds; third, the leader should be cut back; and fourth, all the broken or bruised roots should be cut away just above the wound with a sharp knife, making the cut in such manner that, as the tree is set on the bottom of the hole, the cut surface of the remaining stub will come in direct contact with the soil. It is also advisable to shorten slightly any straggling roots which may appear.

These rules apply particularly to fruit trees that inay be set out on the home grounds, but in the planting of shade and ornamental trees the process is not very different. Of course, the owner does not relish the idea of buying a fifteen-foot Norway maple, for instance, only to cut off its top and half of its roots before he plants it. But it is always hest to eut back the tops of the trees to a considerable degree when they are transplanted, for the root system is almost invariably reduced and if the top 


\section{TREES}

is not shortened in similar proportions the balance between roots and top, which it is always wise to preserve, is destroyed.

\section{METHOD OF PLANTING}

Deciduous trees must be transplanted either very early in the spring, as soon as the ground can be worked, or late in the fall after the leaves have fallen. Possibly the best results follow spring planting under ordinary conditions. But, whicherer the season selected, the hole to receive the trees must be deeper and larger than the root mass and in the bottom there should be a liberal quantity of well-rotted manure stirred in the soil. On top of this in turn there should be a layer of three or four inches of good earth.

It is always best in setting the tree to have at hand a quantity of finely pulverized soil which may be thrown in as soon as the tree is placed in position. As the hole is gradually filled make sure that the dirt is pressed down frequently and that the roots come in close and intimate contact with the earth so that no air spaces are left. Also make sure that the roots are spread in a natural position and that no two of them touch each other. Do not hesitate 
to firm the soil thoroughly about the roots so that the new growth will be encouraged from the beginning. While it is possible, of course, to apply too much pressure to the soil about the roots, more often the trouble is due to a lack of pressure. Before the soil is made firm, see that there is sufficient earth underlying the roots to prevent any damage to them owing to the pressure from above. When the roots have been covered with earth and this has been "firmed," water should be applied liberally. After this the remaining dirt should be thrown in loosely and not tamped at all. Applied in this manner, it serves as a mulch and is far better than when the soil is rendered hard and compact from the surface down.

\section{CULTIVATION}

The planting does not represent the end of the work by any means. Trees require plant food and unless the soil is naturally very rich this food must be supplied from time to time. When the tree is planted on the lawn and liberal dressings of manure are supplied for the grass in the fall or spring, this usually will suffice for the trees. But trees are always grateful for plant food in any form, such as ground 
bone and potash or other good commercial fertilizers or barnyard manure. Watering also should not be neglected while the tree is recovering from the shock of transplanting, and the water should be so generously supplied that there will be no chance of the moisture failing to reach the roots. Nere dampening of the surface is of no benefit; the water must be given in such quantity that it will saturate the soil and penetrate to the roots. This takes much more water than is commonly supposed, for the diffusion of moisture through the soil when supplied to the surface is so slow that the beginner may imagine that, because a puddle has been formed on top, the roots have been plentifully supplied.

\section{EVERGREENS .}

In the transplanting of evergreens more care is necessary than with the deciduous trees. They should be planted a full month before the usual summer drought sets in or before the cold of winter is due. This advice is made reasonable at once when it is considered that the roots of evergreens must supply the foliage with moisture every day in the rear. Therefore, if established liefore natural conditions 
begin to tax all the energies and resources of the trees, they are more likely to succeed. In winter, for instance, a few days of sunshine will prove a severe trial for even an old-established tree; the leaves dry faster than the frozen roots can replace the sap lost. A newly planted tree, under such conditions, would suffer severel: for the roots, broken and bruised, would find the task too much for them in their enfeebled condition. So far as transplanting in summer is concerned, it must be remembered that evergreens are far more sensitive than decidnous trees to drying of the roots. The presence of the resinous sap is the explanation; this, when slightly dried, hardens. On this account, aroid exposing the roots of evergreens to the sun or wind; even when conveying the trees only a short distance, puddle the roots or wrap them in wet sackeloth. See to it also that all ragged ends of roots are neatly trimmed, cutting off the hroken end square and clean. But never prune the foliage. The leader may ha ent out if considered necessary, but, further th:m this, no trimming should be done. Not enough can he accomplished in the way of restoring the balance between root and top growth to make the pruning of value, while 


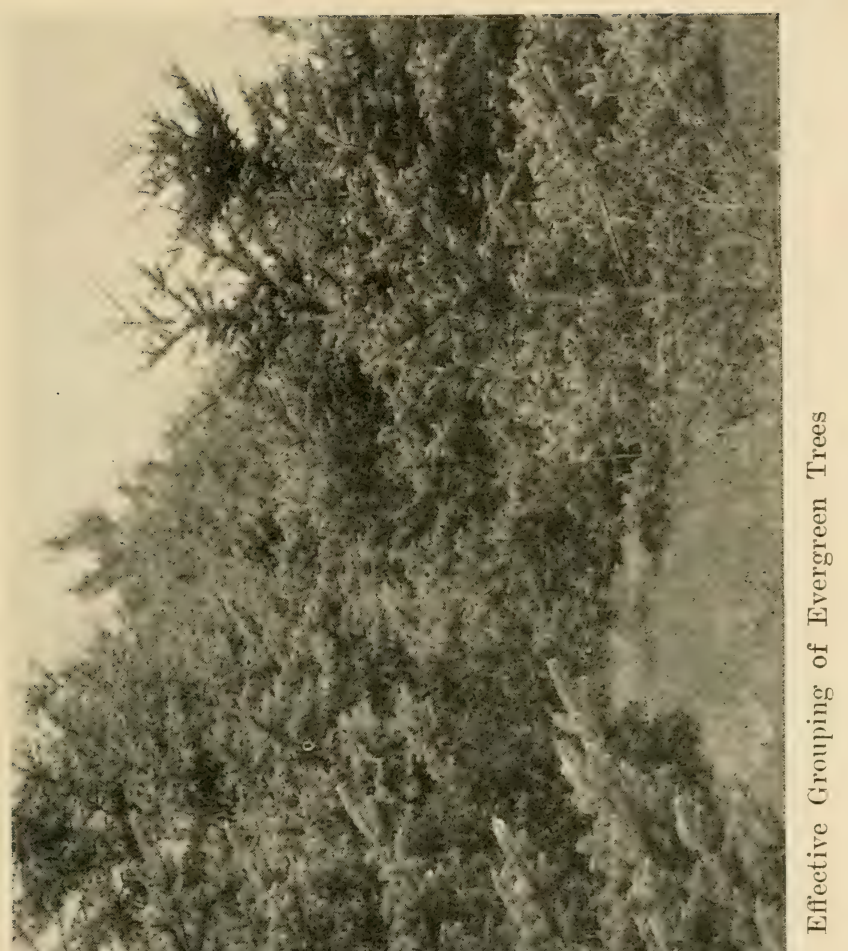


even a little pruning-in addition to cutting back the leader-will mar the symmetry and beauty of the specimen.

\section{SELECTING TREES}

American and European nurseries offer more than six hundred species of trees that are hardy in the northern and middle states of this country. Of this number nearly two hundred and fifty are natives of America; the others come from eastern, western and central Asia and Europe. From such a list, of course, it is possible to make selections almost without limit, but only such trees should be planted as are well adapted to the conditions under which they are to be grown. On this account native trees are always to be preferred, for these will be better suited to the climate and soil and accordingly will be more likely to succeed.

The selection of trees for street and avenue planting is a matter of much importance. No matter how imposing may be the architecture of a city, the foliage of trees will enhance its value; on the other hand, no matter how unpretentious, even ugly, the structures may be, the trees will lend them beauty. They provide grateful shade in summer for overheated man 
and beast and, from a pecuniary point of view, they are a good investment, attracting attention and inviting home-seekers. Fortunately the list from which we can select for this purpose is large and varied, but the following are undoubtedly the best, all considered: The American elm (Ulmus Americana); the English elm (Ulmus campestris); the horse chestnut (Esculus Hippocastanum); the silver maple (Acer saccharinum); the American ash (Fraximus Americana); the buttonwood or sycamore (Platanus orcidentalis); the maidenhair tree (Ginkgo biloba); the rock or sugar maple (Acer saccharum); the Norway maple (Acer platanoides); the American beech ( $F a$ gus ferruginea); the white poplar (Populus alba); the American linden ( Tilia Americana); the European linden (Tilia vulgaris); the tree of Heaven (Ailanthus glandulosa); the white willow (Salix alba); the tulip tree (Liriodendron tulipifera); the red oak (Quercus rubra); and the pin oak (Quercus palustris).

In the planting of street trees, sanitary and hygienic conditions must be considered. The streets should not be too shaded, nor should the trees themselves be crowded. The minimum distance apart for setting the trees fixed by 
experts is sixty feet, but in the case of the large growers, like the elms and soft maples, seventy-five feet would probably be better. It is usually found, however, that the distance is much less, each owner of a small lot planting two or three trees in the immediate front of his own home without regard to the proximity of neighboring trees. This is very likely to continue the case until municipal governments realize not only the advantages but the necessity of taking in hand the street planting as they have the control, the management and the ornamental planting of the public parks.

\section{TREE-DESTROYERS}

Trees planted in cities are established under artificial conditions and, in the care bestowed upon them, this fact must not be overlooked. A specimen growing in the open field, under normal conditions, will in most instances take care of itself; it requires no pruning-it prunes itself-and, in other respects, it thrives best, probahly, when left to its own devices. But the same tree transplanted to a city site is introduced to abnormal conditions; the atmosphere is smothery with smoke, buildings crowd it, electric light wires burn it, leaking gas suf- 
focates it, and careless excarators shatter its roots. It becomes an easy prey to insects and an easy victim of disease. It reguires attention, even some coddling, and unless attention is given it, its health is not likely to be remarkable. But it resents misdirected efforts in its behalf as much as it resents the infliction of damage due to less considerate motives. And probably the most persistent source of disaster is the ignorant laborer armed with pruning shears and saw to whom reference has already been made. Still he is not alone in the category of tree-destroyers. In every tree-top we can read the history of some great fight with impending disaster. Leaf, flower, fruit, twig and branch recite the story to those who know the language, while, undernround, other disclosures await the intelligent investigator. Some of the enemies are natural hut many of them can be traced to man and man's civilization.

Insects come first. After these the most destructive agent is fire. Winds, lightning, ice, drought and flood all cause damage; fungi attack the rood; wasteful lumbermen deplete the forests and bacterial and constitutional diseases lurk where least suspected. 
The insects may be combated with success if the battle is begun in time. Borers, infesting the solid wood, tunneling and cutting it into channels; sucking insects, puncturing the skin of leaves, fruit, twigs or roots and withdrawing the juices; chewing insects, devouring the substance of leaves and other parts of the tree -all these can be exterminated by the use of poisons, sprayed or fumigated, or by the employment of mechanical means. The borers must be dug out, but the chewing insects may be killed by spraying poison-Paris green or arsenic of lead, for instance-on their food. The sucking insects are killed by spraying with kerosene and water, made into an emulsion, with whale-oil soap or with a mixture of lime and sulphur in solution. These sprays choke or smother the insect or so injure the body wall that the tree enemy succumbs. 


\section{CHAPTER XIV}

SOIL AND FERTILIZERS

Science, with all its discoveries, has not yet solved the mystery of soil. It has learned much from practical experiment and laboratory investigation, but it has not yet unriddled the riddle of the soil's support of plant life. We are still in the dark as to the nature of many of the substances which contribute to the formation of soil and we know no more of the part they play in plant nutrition. We know, in fact, little more than that the soil, far from being a dead, inert mass, is teeming with living organisms that are constantly at work. It is, as it has been described, a laboratory in which wonderful chemical actions are taking place whereby food for vegetable life is supplied and means provided for its assimilation by plant roots.

But with the theory of all this, the gardener has little to do. Like the electrician who harnesses a power whose very nature is a mys- 


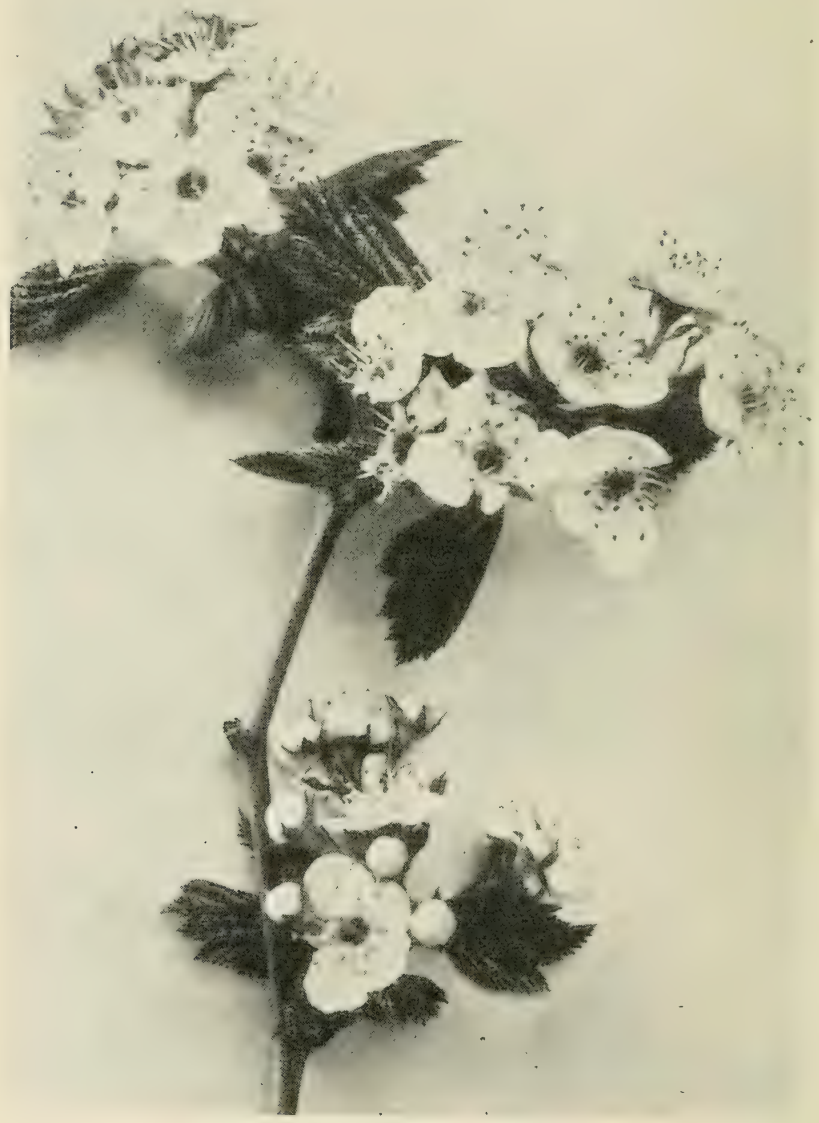

Decorative Value of the Haw 
tery, the cultivator may proceed to turn to practical use what Nature has provided even though he has no intimate knowledge of the purposes or the processes involved. Experience must be his teacher and, in this instance, at least, it is a good instructor.

\section{COMPOSITION OF SOIL}

Plants, we know, must feed and breathe if they are to live. We know further that some soils provide the plants with the necessities of life in plentiful quantity, others half starve them and still others feed them not at all. It is obvious that the gardener, if he is to have healthful, fully developed plants, must obtain, at first hand or by cultivation, soil conditions that will provide his plants with all they demand.

Soil, in a physical sense, is a substance composed chiefly of minute fragments of mineral matter with which is mixed decayed vegetable and animal matter. According to its composition it is one of three types - sand, clay or humus. Sandy soil contains 80 to 100 per cent. of sand, and, owing to the absence of vegetable or animal matter in any appreciable proportions, supplies but little nutriment to growing 
plants. It is valuable, however, as a medium in which to root cuttings, for fungus diseases seldom develop in such a soil, and, as the plantlets, until their roots have sprouted, require little nourishment, outside of what is obtained through the water applied, no soil is better adapted to the purpose than that which is sandy.

Clay soils contain only a small proportion of sand-from 0 to 20 per cent.-and, unless in some manner more sand is added, it is of little value for plant raising. It contains an abundance of plant food, but, owing to the fact that the food is unavailable, plant life can not thrive in such a rooting medium. The small particles of soil are tightly compressed in clay and, though these absorb moisture, they give it off reluctantly. Roots suffer not only on this account but also through their inability to penetrate into the compact mass.

Humus is decayed vegetable matter and may, in turn, be divided into two classes. The first is composed of vegetable matter which has come to decay in dry earth and is known as leaf-mold. The second is composed of vegetable matter which has decayed under the water of bogs or swamps and is known as peat. Both 
are important constituents of good garden soil, but neither is supplied with all the nutritive substances demanded by plants for their development. Both are light and porous and are used to mix with stiffer soils to impart to the latter the two qualities for which they are most noteworthy.

Soils, as they are found in yards, gardens and fields, are mixtures. They partake of the character of one or another of the types according to which contributes most to the composition. A sandy soil, for instance, is that in which sand predominates, while a stiff, heavy soil, or clay soil, contains a greater quantity of clay than a well-proportioned soil should contain. These mixtures have in their turn been named. First, there is loam, a soil in which there is from 40 to 60 per cent. of sand and the rest clay. This is the basis. If a loam contains more sand - from 60) to 80) per cent.-it is known as a "sandy loam"; if it contains less - 20) to 40 per cent. - it is known as a "clay loam." In most instances, some of the sand and clay is replaced by liumus and, if the quantity le large, the soil is designated as " black loam."

Plant food is of three kinds-water, chem- 
ical substances and gases. The first is essential not only as a source of food but as a food solvent and a distributing agency of many essential inorganic substances which plant life requires. The principal chemical substances demanded by plants are potash, phosphorus and lime; and the gases are nitrogen, oxygen, carbon dioxide and hydrogen. Most of these are present in the average soils of meadows, but if the soil lacks them, they must be supplied in greater or less quantities and in available form before sturdy plants of any sort can be raised. This we do by applying fertilizer's.

\section{GOOD GARDEN SOIL}

Fertilizers, however, will not put poor soil into good mechanical condition. TVe might apply hundreds of pounds of any or all of these fertilizers to clay and still the plants supported by the soil would not prosper. This would be due to the fact that the food so supplied is not available. The mechanical condition of the soil would prevent the proper assimilation of the food and the plants would perish. To get soil, therefore, into the best condition, we must first of all cultivate it, work it and see to it that, from the mechanical viewpoint, it does not pos- 
sess an injurious surplus of sand or clay or humus. If the soil of our yards is too heary, sand must be added; if too light, we must supply clay and humus.

The matter is simple, and the amateur must not permit himself to become confused by technical terms or to believe that the soil in his

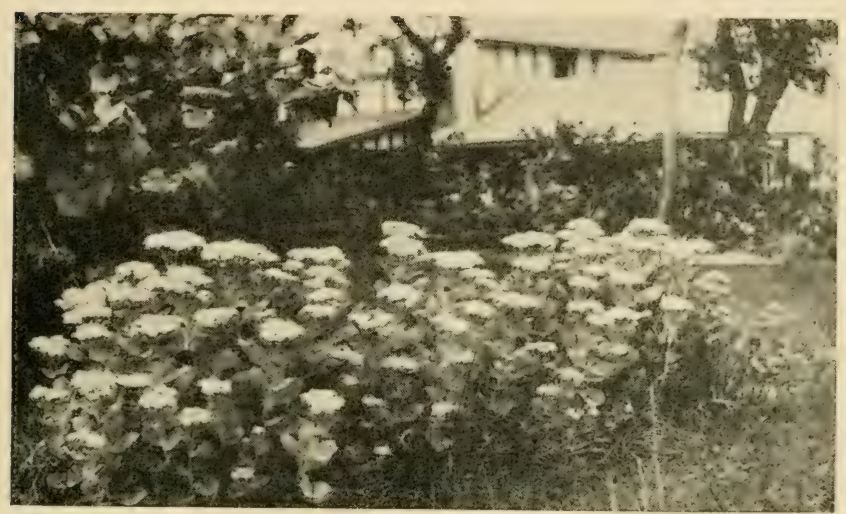

Colony of Sedum spectabile in Poor Soil

yard is "impossible." Soil can usually be put into very good condition by no other process than thorough cultivation. It is not wise, therefore, to be too hasty in deciding that the soil at your disposal is not good soil. In not a few instances, the amateur, bent upon supplying all the best conditions for plant growth, 
fancies that new soil is necessary. The old soil is removed and, in its place, new earth is deposited. The expense is great, but the real extravagance is only evident when it is learned subsequently that the work was altogether unnecessary. The author recalls one instance in which he was informed by an enthusiastic beginner that the soil in the yard where the latter expected to establish his garden was worthless. A visit to the place, however, disclosed the fact that a rank growth of weeds had sprung up and was thriving so luxuriantly that there could be no question of the value of the soil on hand. In another instance, over one hundred loads of soil were carted away from a back-yard and dumped upon a vacant lot. This was done, of course, to make a place for good soil. Two months later, the weeds upon the "poor", soil stood higher than a man's head and a colony of nasturtiums had established itself and was producing blooms finer than those the hasty beginner was coaxing in his new soil.

Sorauer, in his Physiology of Plants, says: "The ideal condition of a soil is one in which it resembles a sponge, and in which it will retain the greatest amount of nutritive substances 


\section{SOIL AND FERTILIZERS}

and water without losing its capacity for absorbing air."

No briefer or more practical definition could be made and if the amateur pays heed to it many gardening problems and disappointments will be avoided. Cultivation is obviously the first means to the end, for not only does it bring the soil to good condition, but it renders available such plant food as it contains, and prepares the earth for the reception of additional nutritive substances. At the same time, cultivation enables the gardener to provide, even in limited space, the soil most suitable for the plants he may desire to grow. For instance, if his soil be of a heavy nature, containing less sand than it should, it will need comparatively little modifying to make it fit for the growth of roses, plants that prefer such soil conditions. On the other hand, in the bed wherein he may desire to grow pansies, he will find that the addition of leaf-mold will insure him more vigorous plants and more profuse and larger blooms.

\section{CULTIVATION OF THE SOIL}

It follows, consequently, that if there be in the beginning a workable foundation, it is bet- 
ter to bring it to the fittest condition by careful cultivation than to remore it entirely and substitute a better soil, perhaps, but one which, after all, must be considerably modified to meet the demands of various plants. But, whether the soil is new or old, it must be well worked. Plow it or spade it and in either case make sure that the cultivation is deep and thorough.

There is no better method of preparing the soil than that which the English gardener terms "bastard trenching." It is effective and not difficult to execute. The top soil to the depth of one foot is removed, pulverized as it is thrown to one side, and the underlying soil is spaded to the depth of a foot. The surface earth is then replaced in its original position. It is at once apparent that this method of digging garden beds and borders permits not only a thorough tillage of the soil but the addition of fertilizer and its complete incorporation with the earth. It affords, too, a simple means for the preparation of the soil for plants which may require special rooting mediums; humus may be added while the operation is in progress or sand or heavy soil may replace that which is not of proper physical condition. The process, moreover, insures the 
removal of all stones and rubbish from the beds and borders so treated and discloses the necessity-should it exist-for providing drainage.

\section{DRAINAGE}

The subject of drainage should not be orerlooked by the gardener, for it often means success or failure. In cases where the garden is small, confined to a bed or border, drainage may not play an important part. Still, eren in such instances, a water-logged soil is obviously not desirable. It can be corrected l,y removing the earth entirely to a depth of thirty inches and, after setting a five-inch layer of gravel in the bottom, refilling, being careful to replace the surface soil on top. Where, however, larger areas are to be drained, tile pipe, set in runs, should be used.

\section{FERTILIZERS}

The use of fertilizers is a matter that prores difficult for the beginner to master. He is far more likely to surfeit his plants on too much than to starve them on too little, and, so far as this danger is concerned, he must depend upon his own judgment to avoid it. No rule can be laid down for the application of animal ma- 
nures or of those in chemical form, for soils differ materially and what might be right in one case would prove too much or too little in another. If, however, the amateur confines himself in the beginning to the use of animal manures, he will materially reduce the risk. Of these manures, produced by cow, horse, sheep and poultry, cow manure is the best and safest. In any event, it is most generally applied and the best for the greatest number of plants. Horse manure is more heating and, with hen manure, should be used on stiff, cold soils rather than upon a warm, sandy compost.

All animal manure should be well rotted before it is applied. Make use of it only after it has stood at least six months and, during this period, been forked over frequently. It should then assume much of the appearance of rich, black earth, should be fine and should retain very little, if, indeed, any of its original form. So far as the quantity to be applied is concerned, here, as already stated, the gardener's judgment must come into play, but, under average conditions, a wheel-barrow load to a square yard is as much as should be used. This is ample for strong-growing plants and for well 
established shrubs; less should be distributed for plants of weaker growth.

Hen manure supplies fertilizing elements in more concentrated form than the other barnyard products and, on this account, should be applied cautiously. It is best used when mixed with an equal quantity of loam or leaf-mold. Sheep manure is also a strong fertilizer and, while it is to be recommended, especially as it can be had in pulverized form, it is best applied as a liquid fertilizer. Make the solution by suspending a bag containing one pound in five gallons of water. When the solution assumes the color of tea, apply it to the beds or borders.

Cow manure may be applied in the same manner, using a bushel to fifty gallons of water. Another fertilizer which is readily applied in this manner is soot-soft coal soot. Soot water is made by suspending a bag containing one-half pint of soot in ten gallons of water. Soot, however, is a valuable stimulant when applied directly to the soil. It imparts a glossy dark green foliage and healthy vigor to many plants and, in both the flower and vegetable gardens, does much to banish pests such as caterpillars and leaf-miners. 


\section{6

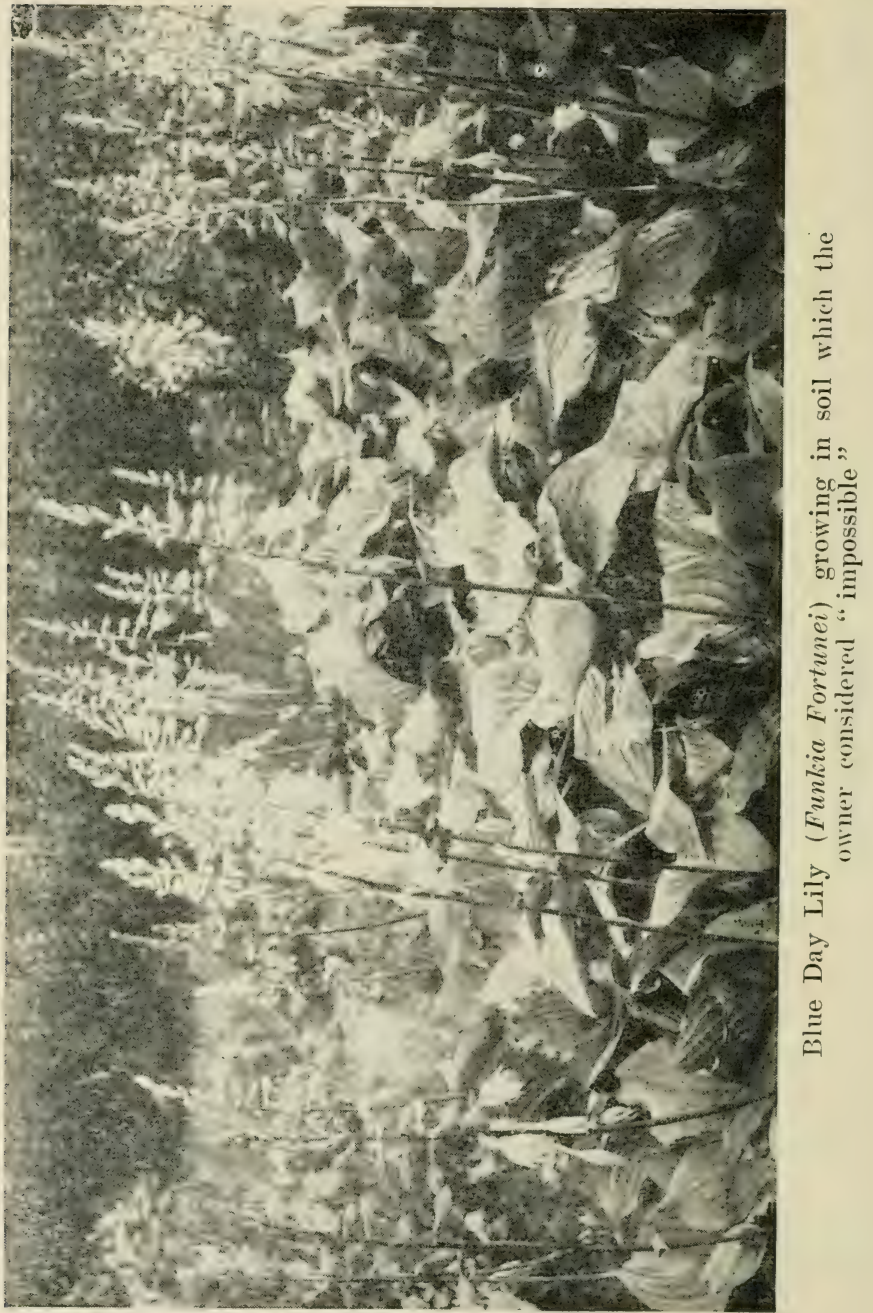


Hard-rood ashes, kept dry, are also valuable, not only as a fertilizer but as a preventive of insects. They should not be mixed with manure but should be strewn over the surfaces of beds or borders after the other manures have become incorporated with the soil.

Flowers and shrubs require a considerable quantity of phosphoric acid. Ground bone may be used to supply the demand and, besides containing this element, it also supplies nitrogen. A good dressing, to be mixed with the soil or applied to the surface in the autumn, is made of four parts of ground bone and one of muriate of potash. The mixture should be applied at the rate of one pound to fifty or sixty square feet of surface.

Nitrate of soda encourages luxuriant growth of stalk and foliage rather than of flowers. It should be applied at the rate of one ounce to the square yard.

A convenient and satisfactory liquid fertilizer can be made of the commercial fertilizers as follows :

5 oz. sulphate of potash

1 lb. nitrate of soda

$1 \mathrm{lb}$. monobasic calcium phosphate

These are added to one gallon of water and this solution, in turn, is diluted from fifteen to 
thirty times, beginning with the weaker solution and, as growth progresses, gradually increasing the strength until the more concentrated solution is being employed. When used on lawns to hasten growth, the proportion of nitrate of soda should be doubled and the calcium phosphate reduced by half, but, if used on plants, especially those grown in pots, reduce the nitrate one-half and double the amount of potash. 


\section{CHAPTER XV}

\section{INSECTS AND DISEASES}

No sooner is a plant established or a garden planted than the gardener must begin his war against insect and disease. If it is not the one that menaces his plants, it is the other, and, not infrequently, both are present to work havoc if the planter is not on his guard. In the case of both, an ounce of prevention is worth a pound of cure and, while preventive measures do not always insure the freedom of a yard, garden, orchard, shrubbery or plantation of shade trees from attack, at least they give the insects and diseases less opportunity to gain hold. Moreover, their exercise means a thoroughness that will result in the immediate detection of an invasion and the subsequent attack upon the enemy before opportunity has been afforded for its establishing itself.

\section{CLEANLINESS THE BEST PREVENTIVE}

Cleanliness is the first and foremost means to the end. Keep the yard clean, the shrub309 
bery borders free from weeds and the hardy borders and flower-beds in a high state of cultivation. Remove dead leaves, twigs and limbs and, if they appear to have perished from some abnormal cause, burn them. Be cautious in what you deposit on the compost bed for, very often, disease is reintroduced into the garden by using decayed vegetable matter that is infested with disease or in which are deposited the eggrs of destructive insects. In many instances, when an entire plant or shrub is badly attacked, it is best to remove the stricken plant at once and burn it without delay.

\section{METHODS OF DESTROYING INSECTS}

With the origin, history and classification of the various destructive insects, the gardener is not greatly concerned. It is more to his advantage to know their habits, for it is through a knowledge of these that he is enabled to combat them. He must know, first of all, whether the insect which has invaded his garden or his orchard is a biting or a sucking insect. If the former, direct poisons, such as the arsenicals, are employed, for insects of this class actually masticate and swallow some portion of the solid substance of the plant, as the wood, bark, 


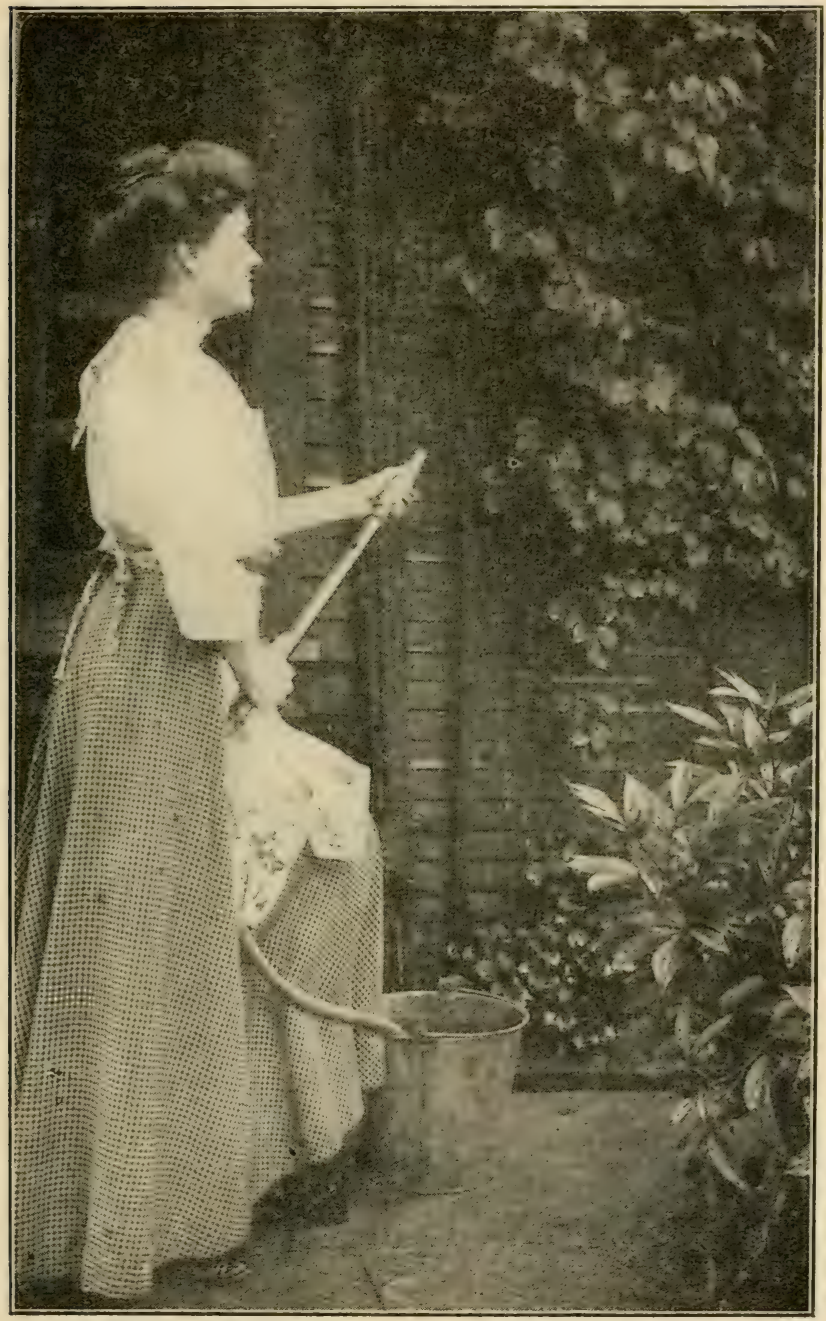

Spraying Easily Done in the Average City Yard 


\section{YARD AND GARDEN}

leaves, fruit or flower. If the insect, however, is of the sucking variety, injuring plants by the gradual consumption of plant juices-such as the thrips, plant-lice, scale insects and mitesthen a poison must be used that will act externally upon the bodies of the insects. Obtaining their food by inserting their sucking beaks into

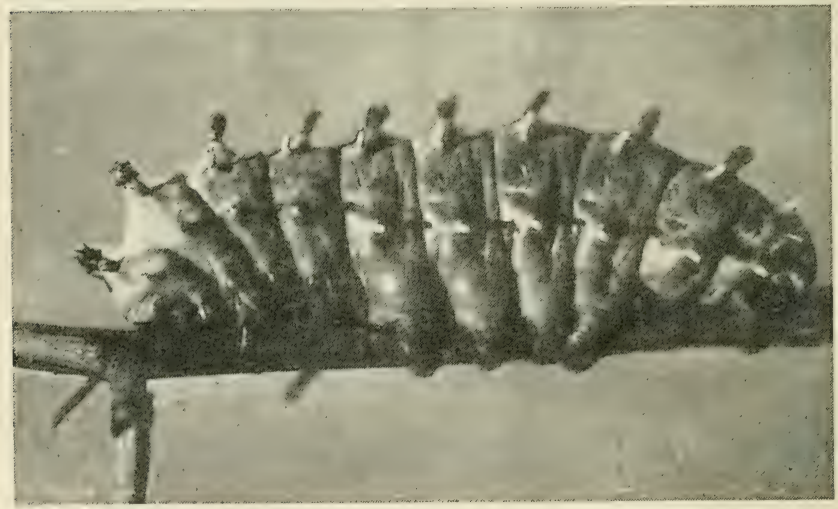

Typical Chewing Insect (Cecropia moth)

the soft tissues of the plant that lie below the external covering, they escape poisons that would prove fatal to the chewing insect and must be comlated, therefore, by other and more direct means, such as the employment of caustic sulsstances, those that will smother them by closing or clogging their breathing pores, or 


\section{INSECTS AND DISEASES}

exterminate them by filling the air surrounding them with poisonous fumes.

The following table lists the insects most commonly met with and prescribes the poison for each, giving at the same time the names of the plants most frequently attacked.*

Ants-Usually harmful only on the lawn. Pour a teaspoonful of bisulphate of earbon in the holes and immediately cover or plug.

Aphis-Plant-lice, pale or dark green, brown or black, found on stems and leaves all season outdoors and on indoor plants all winter. Spray with whale-oil soap or fumigate with tobacco.

Borer-Many trees in addition to the maple are attacked by borers. The round-headed apple borer and the flat-headed borer attack the apple and the thorn; the peach borer attacks the plum, peach and cherry, and other trees, such as the poplar, willow, linden, locust, etc. Apply the same treatment as that prescribed for the maple-borer.

\section{Black Lice-See Aphis.}

* The author is indebted for much of the matter on this subject to the varions bulletins issued by the Department of Agriculture and especially to Benjamin $\mathbb{T}^{\mathrm{T}}$. Douglass, State Entomologist of Indiana, not only for assistance frequently rendered, but for many photographs as well. 
Canker Trom-This insect feeds on the leaves, devouring all save the skeleton and midrib and giving to the tree attacked the appearance of having suffered from exposure to fire. It is a dull-colored measuring worm, and drops from the tree by a thread web. Bands of tar or sticky paper may be used with good results, provided the bands are employed from the middle of November to the latter part of April. Spraying with Paris green or arsenate of lead is also effective.

Catalpa Splinx-The so-called Catalpa Sphinx is difficult to control, owing to the character of the plants it feeds on. Neither spraying nor hand picking is practical, and the only method of control seems to be thorough cultivation under the trees in both late fall and early spring.

Chrysanthemum Lice-See Aphis.

Codlin Moth-It is the presence of this insect that makes apple growing difficult in this country. The insect hatches from the cocoons in the late spring and at once lays its eggs on the young apples, mostly at the flower end. The trees should he sprayed just after the blossoms fall so as to fill the calyx with the poison, as many of the young larva enter the 


\section{INSECTS AND DISEASES}

fruit at this point. In case of very wet weather it is advisable to give a second spraying about two weeks later and again early in July. The late spraying is to meet a second brood which appears about that time. The first spraying may be of Paris green or other arensic poison, the subsequent ones with poisoned Bordeaux.

Cottonuood-leaf Beetle-Striped beetle attacking poplars and willows and feeding on leaves and shoots. Apply arsenites.

Cutworm-Devours flowers and foliage. Use arsenite spray.

Curculio-This is a small beetle that affects cherries, apples and plums-notably the last. The adult beetles have a habit of feeding on the fruit and some of them may be poisoned with a Paris green spray applied just after the blossoms fall. It is also possible to gather the small beetles by jarring them down from the tree and catching them on sheets spread on the ground. Especially constructed "('urculio catchers" are sometimes employed for this purpose and are made so that they may be moved from tree to tree. The insects are collected from the sheet and destroyed.

Earthrorms-Troublesome only in potted soil. Water with brine water. 
Elm Beetle-Yellowish-brown color, onefourth inch long. Appears in early summer. Feeds on leaves. Spray with Paris green last of May or early in June and again about the middle of June or use arsenites with kerosene emulsion.

Elm Scale-Small, soft scale insect of whitish color. Appears on underside of branches. Spray with kerosene emulsion the first two weeks in June.

Fall Web-worm-Larva one inch long, hairy. Very destructive, feeding on the leaves of almost all the trees. Burn the webs where formed. Spray with arsenites.

Four-striped Plant Bug-A yellow, blackstriped bug, one-fourth inch long. Punctures young leaves and shoots of many plants, especially the dahlia. Hand pick or spray with kerosene emulsion.

Green-fly-See Aphis.

Hollyhock Bug-Small bug of greenish color that causes serious injury to hollyhocks. Spray with kerosene emulsion.

Leaf-cutter - Yellowish-green caterpillar about one inch long, black spots. Appears in June and July. Spray with tobacco or kerosene emulsion. 
Lice-See Aphis.

Maple Borer-Dangerous insect enemy because its presence is diffeult to detect before serious injury has been done. It is a beetle with yellowish head, body an inch long and wings yellow and black. Appears in July and August. The only sure remedy is to dig the borers out. The trunk may also be painted. with lime wash containing Paris green at the rate of $5 \mathrm{oz}$. to the gallon.

Maple Cotton or Woolly Scale-Body of insect and mass of eggs are covered with a white, cotton-like substance. Attacks soft maples, also occasionally elms, chestnuts and lindens. Spray with lime-sulphur wash in water or whale-oil soap.

Mealy-bug-White, scale-like insect frequently attacking; plants under glass. Spray with whale-oil soap or syringe with clear water thrown in a hard stream. Dip small potted plants in water heated to a temperature of $125^{\circ}$ Fahrenheit.

Mite-Resembles red-spider but is lighter in color. Feeds on under side of leaves, especially of greenhouse plants. Spray with kerosene emulsion, applying at frequent intervals and, after an hour or two, wash off the spray. 
Also use fir-tree oil which is safer in the hands of the amateur.

Oyster-shell Scale-Resembles oyster shell in shape. Attacks willows, lilacs, ash, apples, etc. Same remedies as those prescribed for San José scale.

Red-spider-Small insects difficult to detect

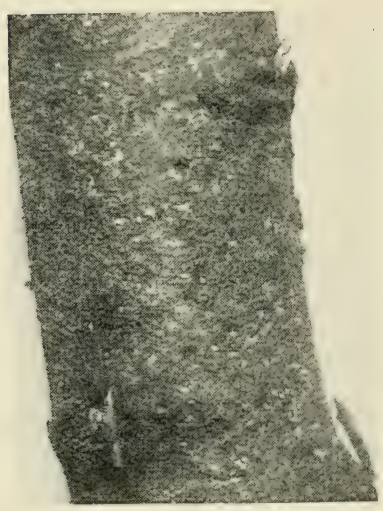

San José Scale

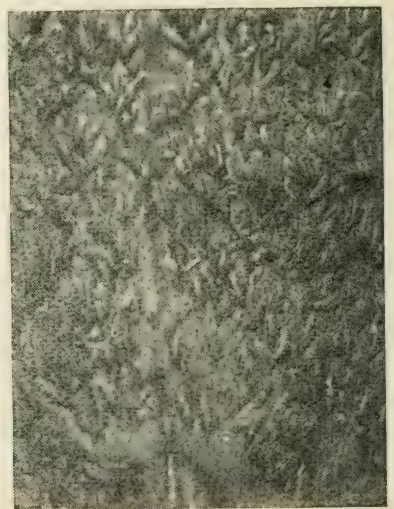

Oyster Shell Scale

before serious damage has been done and foliage begins to blanch. Spray with clear water applied with some force, or sulphur: Kerosene emulsion is also effective. The mites do not live in a damp atmosphere.

Rose Chafer or Bug-Brown beetle, also known as rose-beetle, eating flowers, and ap- 
pearing in May and June. Easiest removed by hand picking. Spray with arsenate of lead. Hot water at a temperature of 125 Fahrenheit is aIso effective.

Rose-leaf IIopper-A small whitish-green bug, quickly flying or jumping whenever the bushes are jarred. Appears in July. Sucks the foliage. Spray with kerosene emulsion, whale-oil soap or tobacco. Pyrethrum powder blown on the leaves when damp is another remedy.

Rose Scale-A white scale incrusting the canes. Appears all the year. Spray with kerosene emulsion in latter part of May and remove badly infested canes.

Rose Shug-A slug-like larva that devours the surface of the leaves, appears in June, July and August. Spray with ammoniacal copper carbonate once every eight or ten days.

San José Scale-Scale insect spreading rapidly where it gains a foothold. Circular, onesixteenth of an inch in diameter. Kerosene emulsion, whale-oil soap and lime-sulphur wash (the last in winter only).

Scurfy Scale-Thile common and widely distributed, this scale has seldom become numerous enough to cause any material damage. 
Under favorable conditions it may become destructive, and wherever it seems to be multiplying it would be advisable to use the same measures recommended for the San José scale.

Snails-Troublesome usually only in greenhouses. Trap them with pieces of turnip; dust lime about the plants.

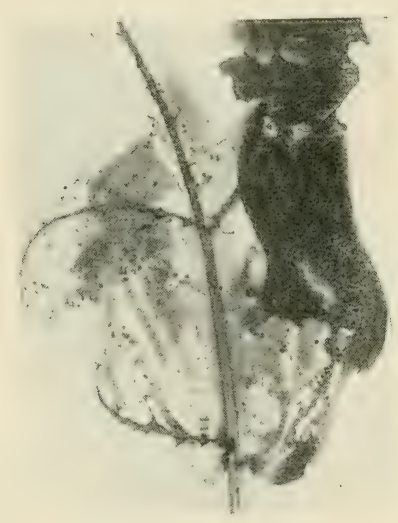

Fall Web-Worm

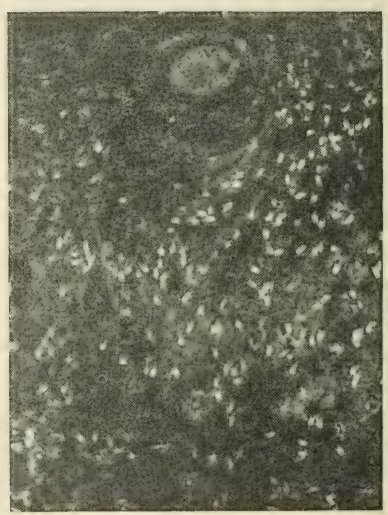

Siurfy Scale

Tussocti Moth-This troublesome insect is usually periodical in its attacks on trees. The moth winter's in the egg state, and early in the summer the young larve hatch and at once crawl to the foliage and hegin to feed. The eggs are laid by the female moth on the old cocoons, and as these cocoons are fiequently sit- 
uated on houses and other objects away from the trees the young can be kept from the foliage by banding the trees with some sticky preparation which will keep them from crawling up the trunk. In the winter the cocoons bearing eg' masses should be collected and burned so as to destroy all the young that are present. A favorite place for the situation of cocoons is under the overlapping weather-boards on the sides of houses. In summer, after the caterpillars inake their appearance, they can be destroyed by spraying the trees with Paris green solution. [Douglass.]

Verbena Mite-See Mite.

Willow-uorm-Long, black larva feeding on leaves of willow, poplar and elm. Arsenite sprays are remedies.

\section{INSECTICIDES}

The following mixtures are referred to in the list of insects :

Arsenate of Lead-Four ounces to five gallons of water. This insecticide can be used with comparative safety on plants of delicate foliage.

Paris Green-To ten gallons of water add one ounce of Paris green and two ounces of 
freshly slaked stone lime. Keep well mixed while applying the spray.

London Purple-Use in same manner as Paris green.

Kerosene Emulsion-Dissolve one-half pound of soap in one gallon of boiling water. Add two gallons of kerosene and agitate or churn violently for five or ten minutes. Dilute from four to fifteen times before applying with the spray.

Lime-suphur-This should be combined as follows :

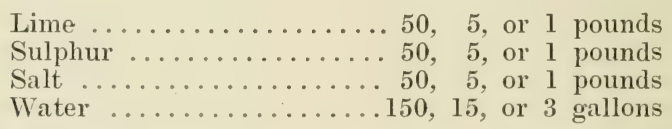

Add enough water to the lime to slake it thoroughly and immediately add the sulphur. Boil for an hour or so with only water enough to keep the mass liquid until the solution becomes a deep amber color. Have the salt dissolved in water and add it to the boiling mass. After it has all been mixed together boil for at least an hour and then add water enough to make up the one hundred and fifty gallons or the lesser quantities, and spray it as soon as possible. It is more efficient when used warm and some of the failures with this wash are undoubtedly due 
to the use of stale solutions and (areless boiling. [Douglass.]

Pyiethrum-Use dry, as a powder, or in solution in water, 1 ounce to 3 gallons.

Sulphur-Flower's of sulphur may be applied in connection with other sprays or used in dry form. When used in the former way, add from one to two pounds to every fifty gallons of spray. It may be applied also at the rate of one ounce to one gallon of water.

Tobacco-Steep stems or leaves in hot water in corered ressel and dilute three to five times when applying. The tobacco extracts are the best.

Whale-oil Soap-Dissolve two pounds in one gallon hot water and dilute two to five times before spraying:

\section{PLANT DISEASES}

The garden, even when the plantation is small, will very likely be affected sooner or later by some plant-disease. Soil conditions or the introduction of affected stock may account for: the appearance of disease, but, to whatever source it may ore its origin, immediate treatment is necessary. There is no better fungicide than the Bordeaux mixture, but as it 
discolor's foliage, flowers and fruit, on all ornamental plants where discoloration would be objectionable, ammoniacal carbonate of copper should be employed. The following are the chief diseases:

Anthracnose-Scab-like spots of grayish brown color appearing on bases of leaves of carnations. Attacks also beans, watermelon, ete. Apply copper sprays, Bordeaux or sulphur and water.

Chrysanthemum Leaf-spot-Dark brown spots first appear on leaves and increase in size until the leaf withers. Remove all diseased leaves and spray with ammoniacal carbonate of copper or Bordeaux.

Damping-off - This is a term used by florists to describe the decay of seedlings or cuttings at a point near the surface of the soil in the seed flat or pot or sand bed. It is believed to be the result of fungi. Permitting fresh air to enter by careful ventilation and preventing crowding of the plantlets, dusting the plants with sulphur and sifting hot clean sand on the surface of the soil are the preventives and remedies.

IIollyhock Rust-Attacks hollyhocks and allied plants, appearing on the leaves in the 
TNSEC "TS IND DISEISEA 325

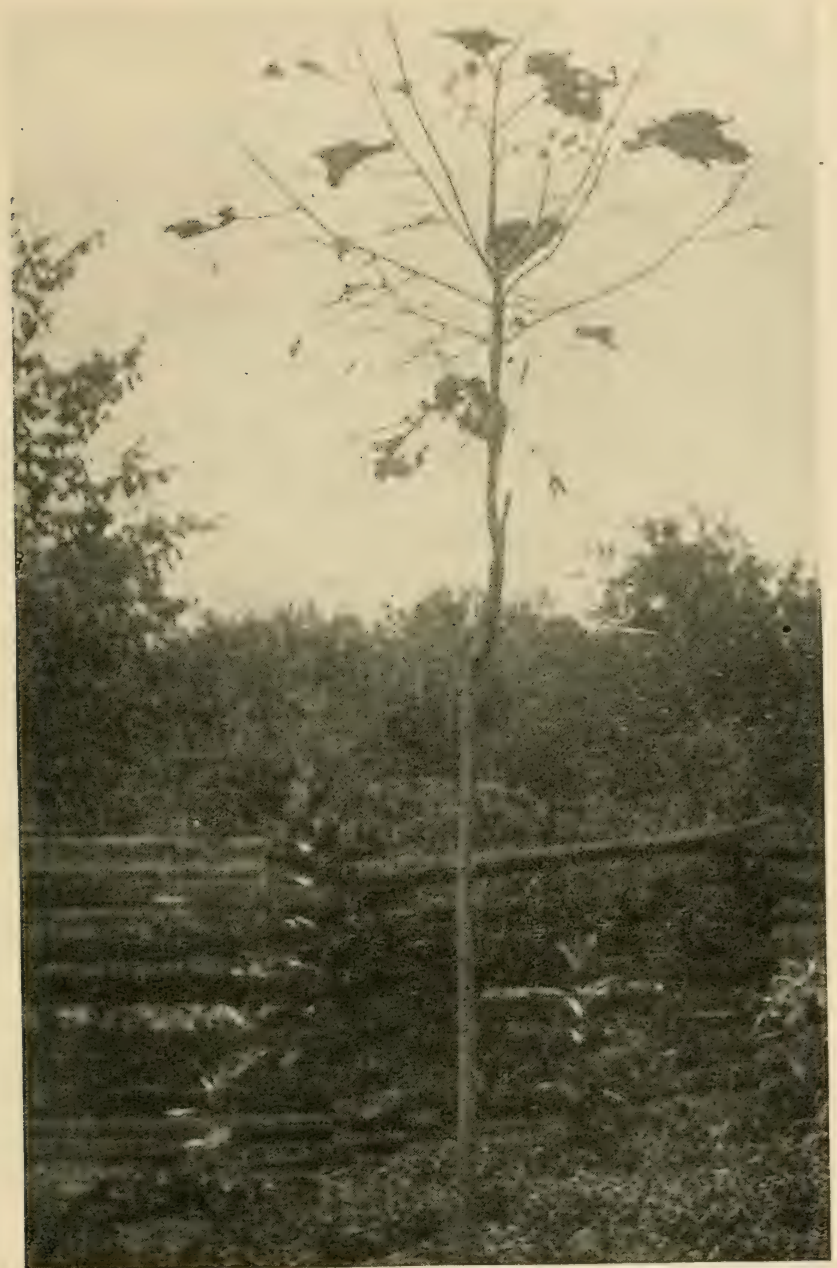

Work of the Catalpa Sphinx Moth 
form of light brown patches. Destroy affected plants and apply Bordeaux liherally.

Leaf-blight-This attacks and destroys only portions of leaves, whereas the leaf-rust produces masses of spores on all the surface of the leaves. Sometimes called "leaf-spot." Attacks roses, maples, cherries, sycamores, etc. Same remedy provided for leaf-rust.

Leaf-rust-Asters are mainly the victims of this disease. The leaves are discolored by orange-colored spots, usually underneath, and the foliage shrivels. Spray with Bordeaux or ammoniacal carbonate of copper.

Maple Leaf-spot-Silver, red and striped maples are victims of this disease. The leaves become spotted and ugly and the vigor of the tree is impaired. Burn fallen leaves and when the foliage is one-half expanded in spring begin to spray with Bordeaux, and repeat at frequent intervals until the disease is checked.

Mildew-Thite patches appearing on leaves or other parts. The most destructive are downy mildew of the lilac, rose mildew and powdery mildew of the hawthorn, cherry and plum. Spray with Bordeaux or ammoniacal carbonate of copper. Dust on sulphur.

Pansy Rust-Brown or dark spots appear 
on the leares. Apply ammoniacal carbonate of copper or Bordeaux.

Rose Leaf-blight (black spots)-Makes its appearance first in the form of small black spots on the full-grown leares but rapidly spreads over the entire surface. Spray with Bordeaux or ammoniacal carbonate of copper, applied before leaves unfold.

Rust-Attacks carnations producing gray blisters on the leaves, the spots eventually bursting. Spray with Bordeaux.

Verbena Rust-IThitish, mildew-like disease attacking the leaves and usually killing the plants. Spray with sulphide of potassium every four or five days.

\section{FUNGICIDES}

Sulphate of Potassium-Use at the rate of one-fourth to one ounce in a gallon of water.

Ammoniacal Carbonate of Copper-Dissolve one ounce of copper carbonate in one-half pint of ammonia diluted with tro quarts of water, and dilute to ten gallons of water.

Bordeaux Mixture-In a wooden or earthen vessel containing four to six gallons of water dissolve six pounds of (oppler sulphate by suspending it in a bag made of coarse cloth. Then 
dissolved, dilute by adding enough water to make twenty-five gallons. Slake four pounds of lime-making sure it is not "patent" limeby covering with water and, when solution has "cooled," add enough water to make twentyfive gallons. Mix by pouring the two together. Sulphur-Procure "flower's of sulphur." Use either in dry state or at the rate of one ounce in five gallons of water. 


\section{CHAPTER XVI}

THE INDOOR WINTER WINDOW GARDEN

Then autumn frost puts an end to operations in the outdoor garden, it need not by any means deter the enthusiastic gardener from the pursuit and pleasure of his summer arocation. If there is a window-even a sunless window where only daylight penetrates-establish an indoor winter garden. In seasons gone hy, perhaps the gardener has made the experiment and only failure has resulted, but let him not be discouraged on that account; let the failure be a lesson, not an olstacle, borrow encouragement from disaster and refuse to he dismayed by failure. For the fault, in nine cases out of ten, was the gardener's. The plants selecter were not suitable for the exposure afforded by the indoor garden, or else-as is often the case -too late a beginning was made. Bullos will bloom, vines grow, plants produce their flowers and foliage, but if these results are to be oltained, the gardener must choose wisely and early and tend his garden faithfully. 


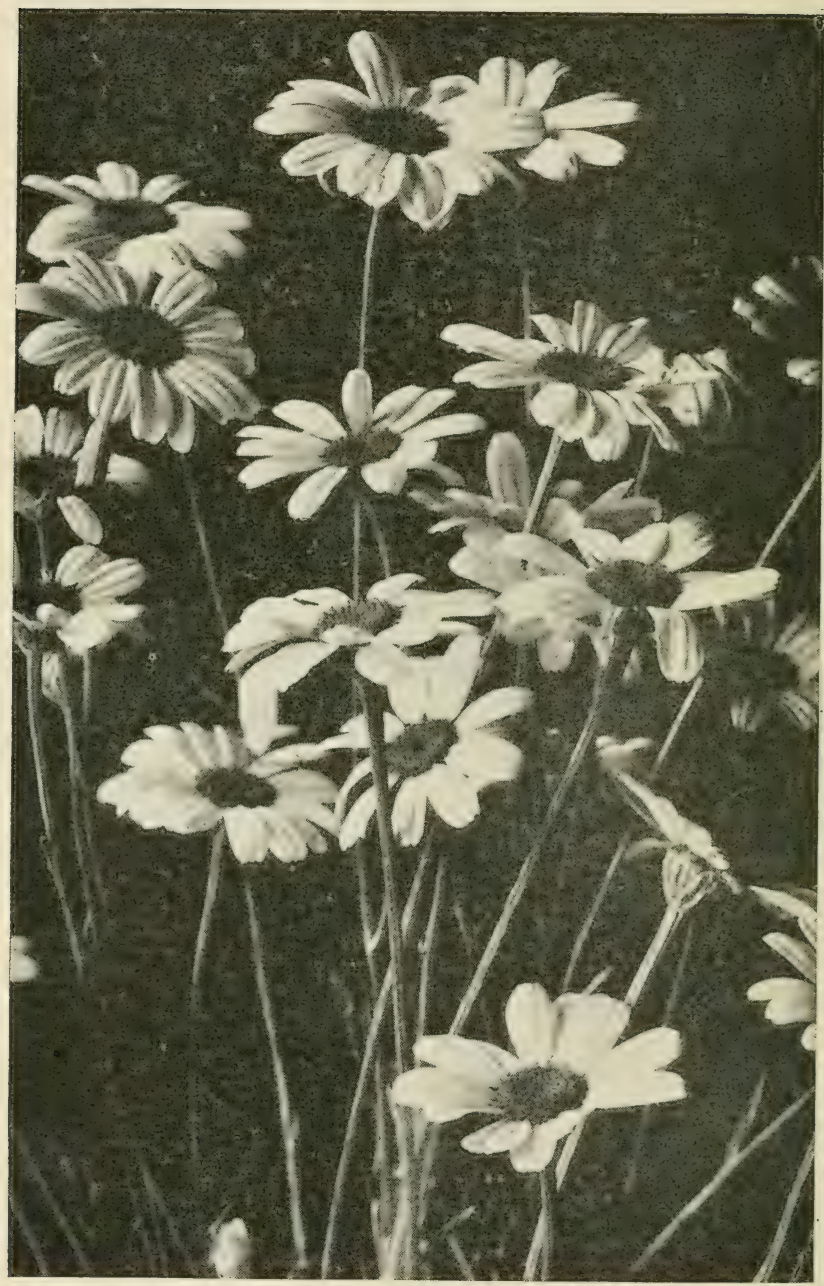

Paris Daisies (Chrysanthemum frutescens) 


\section{AN EARLY BEGINNING ADVISABLE}

It is essential for him to select carefully, for plants differ radically in the treatment they require. A plant that requires sun will not thrive without sun; a plant that requires for its development a cold-house temperature will not prosper in the close, hot, dry atmosphere of a living-room. And it is essential for him to make an early beginning because plants matured under the favorable conditions of hothouse cultivation suffer a fatal check as a rule when transferred from their congenial surroundings to the less advantageous environment of a residence window. Frequently, they fail utterly to revive, bear no flowers, and assume a ragged, sickly appearance that robs them of all decorative value.

On the contrary, if the window-gardener makes an early selection of plants, he obtains young stock-which is cheaper-and, if this suffers from the shock of transfer, usually it will recover all of its original strength, accustom itself to its new quarters and reward the purchaser for his forethought with luxuriant foliage and well-developed bloom. 


\section{LOCATION OF THE WINTER GARDEN}

Begin the indoor garden-making with the selection of the window where the plants are to be grown. If it is a window with a southeastern outlook, the best has been chosen; after this, a window with a south aspect is to be preferred. But, lacking these, an eastern, western or even northern exposure may be selected and, provided plants are obtained that are adapted to the conditions prevailing, the last may be made as effective in its way as the sunniest window in the southeastern corner of the house. Set in place the shelves, brackets and stands upon which the pots are to rest, secure them firmly and provide a dish or pan to be filled with water and kept on stove, radiator, or register to maintain a fair degree of atmospheric moisture. Procure flower pots of various sizes-from three inches to eight-avoiding the glazed, decorative ware, and a water can and a supply of soil.

\section{THE SOIL FOR WINDOW GARDENS}

The amateur is likely to find this last his most perplexing problem. What soil, he most frequently inquires, shall be used for this plant? 


\section{THE WINDOW GARDEN}

what for that? in what compost shall bulbous plants be grown and in what mixture will ferms thrive? If he undertakes an investigation for himself, it is likely that he will emerge from the study all the more perplexed. The reason is that there is a great deal of rubbish talked about soils. If heed were paid to the lucubrations

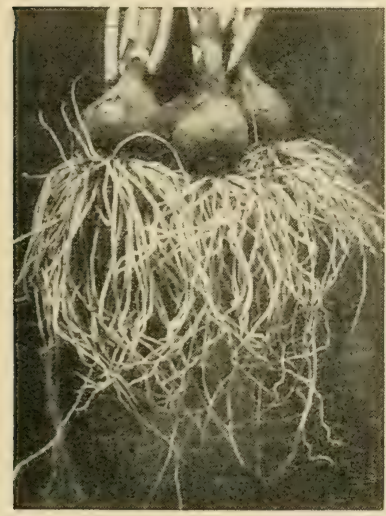

Root Growth of Nareissus

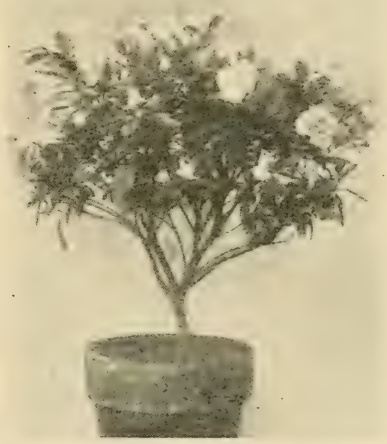

Azalea Indica in Bloom

of many writer's on floral topies, it might be surmised that a special soil is required for every plant. But, not only is this misleading and incorrect, but the plain fact is that four-fifths of the plants cultirated under glass, whether in a greenhouse or in a window garden, would thrive very well in one and the same compost. 
The point to be remembered is that the soil used should be of good quality rather than assembled in elaborate mixtures. Lay aside doubt on the subject and obtain the following composts :

1. Fibrous loam, three parts

Leaf mold, one part

Well-decayed manure, one part

Clean, sharp sand, one-sixth part

2. Fibrous loam, one part

Peat, two parts

Leaf mold, two parts

Sand, one-fourth part

These two composts might be designated "general utility" mixtures. The first will provide a healthful rooting soil for most flowering plants that can be grown by the amateur in an ordinary window garden and the second will provide a suitable mixture for ferns. It is well to lay the foundation carefully by obtaining good loan. Usually it is best and cheapest to buy this of the nearest florist. He makes itand the amateur may do likewise if he has the space, the time and the desire-by stacking turfs, grass side down, in heaps, interspersing old manure between the layers of sod, and permitting the whole to remain at least six months exposed to the weather. 


\section{POTTING}

Potting is likely to prove another stumbling block in the way of success. But if the beginner will bear in mind the following simple rules, he will not go astray:

New pots must he soaked in water two or three hours before using and old pots must be thoroughly cleaned before being refilled.

Provide ample drainage. Place over the hole in the bottom of the pot a piece of broken crock, hollow side downward and, upon this, overlapping, place a layer of smaller pieces. The larger and deeper the pot the more liberal should be the quantity of drainage materiala layer of drainage material one inch deep is not too much in an eight-inch pot to insure the health of the plant.

Pot all plants firmly-if the soil is loose, proper watering is impossible.

Repot plants when the mass of roots surrounds the ball of earth. Ascertain the root condition by gently emptying the pot of its contents. In repotting, shift to a pot two sizes larger-that is, for instance, from a five-inch pot to a seven-inch. A cramped plant will not show its full beauty of foliage and bloom. 


\section{WATERING}

It would be a material help to the amateurand to the professional gardener, too-if it were possible to lay down fixed rules for watering. But, unfortunately, there are no such things as established laws governing the supply of

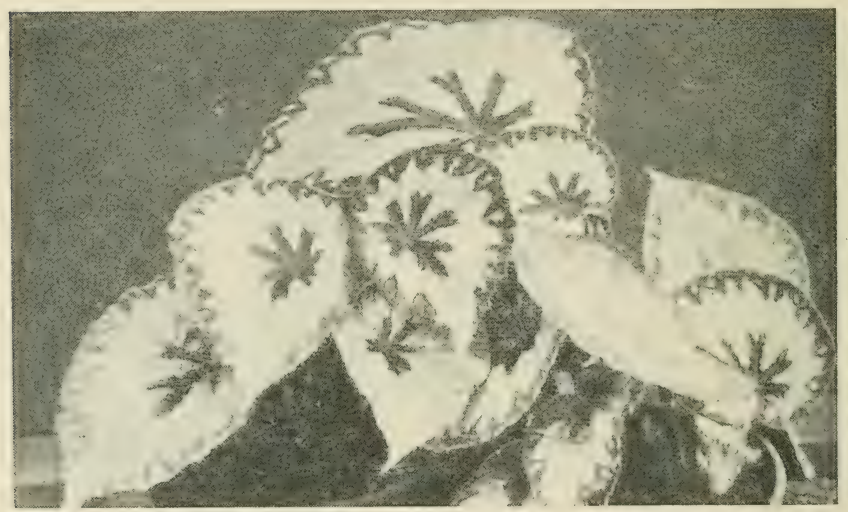

Ornamental-Foliaged Begonia (Begonia Rex)

moisture. Trater when the plants require itthis is the only rule that can be cited. And plants require water when the soil is dry enough to become slightly powdery when ruhbed between the thumb and finger. If, for any reason, water is withheld longer, until, for instance, the soil becomes so dry as to crack, set 
the plant, pot and all, in a ressed of water and let it remain there until air bubbles cease to rise.

The window-gardener who comes through a whole winter without finding his plants attacked by some insect pest is lucky, indeed. A majority will find, probably, that their plants are more or less threatened by the aphis (greenfly), mealy-bug, red-spider, scale or thrips. Where they come from is a matter of small moment; the important fact is that they are there and must be removed. If the amateur will employ the methods of extermination detailed in the chapter on insect pests, he will rid his garden of them as soon as they put in an appearance.

\section{FERTILIZING}

The beginner, if he bears the various rules in mind, should not find success difficult to attain. There may be times, however, when his plants seem sluggish and appeal for extra food. But he sure that fertilizer is required hefore it is applied. Then, in determining the fertilizer to use, aroid patent preparations. Some of them are good and some are absolutely worthless and the amateur is as likely to obtain 
the latter as the former. The best way is to prepare a liquid manure, using, if obtainable, one-half pound of dried sheep manure to two and one-half gallons of water, or a quarter bushel of decayed cow manure to twelve gallons of water.

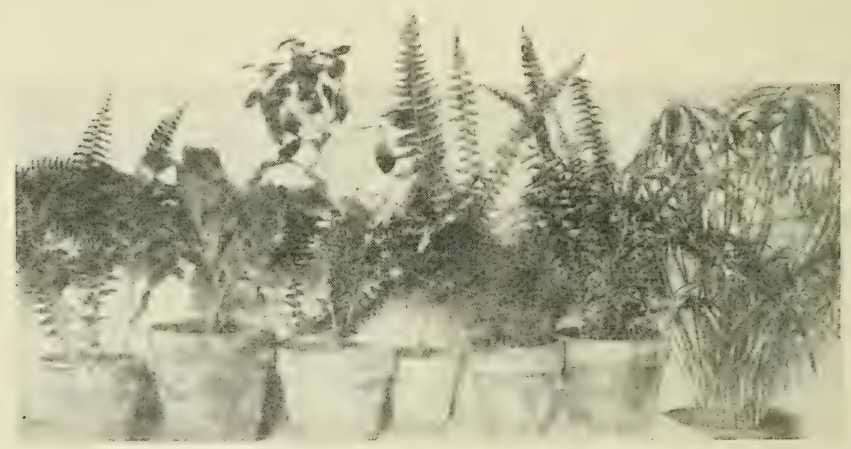

Foliage Plants Suitable for a Window Garden

A chemical fertilizer may be made of the following ingredients :- -

Nitrate of soda, one and one-half ounces.

Phosphate of soda, one-half ounce.

Sulphate of potash, one ounce.

Mix thoroughly and pulverize and, whenever required, dissolve one heaping tablespoonful of the mixture in a gallon of hot water. When the water has cooled, apply a teacupful of the solution to a six-inch pot-less or more according 
to the size of the pot. Soot from soft coal also makes a good fertilizer. Mix at the rate of one-half pint to ten gallons of water.

All these suggestions are practical if not alluring and, if we are to have success with an indoor window garden, we must give consideration to them as well as to the more esthetic qualities which the plants themselves supply. The latter depend upon the former, for no sickly plant can be beautiful. Howerer, we are done with them and can turn now to a discussion of what to raise in the indoor garden and how to raise it.

\section{SELECTION OF PLANTS}

Begin with bulbs. These bloom most successfully for the amateur and, by potting them in quantity and selecting different rarieties, a succession of bloom may be maintained in the indoor garden from Christmas to early spring. Narcissi, tulips, hyacinths, crocus, scilla, freesias-these and many others may be had in bloom to make every week gay with their colors and sweet with their fragrance from mid-December to late March:

Bulbs should be potted early in the autumn. All require practically the same treatment as 
far as the amateur is concerned. Immediately after the potting process has been completed, set the pots in a dark corner of the cellar where the temperature will not rise above forty-five degrees. Lacking such a place, bury the pots in the ground outdoors, allowing six inches of soil or sawdust to rest on top of the pots. On this surface scatter litter, leares, or straw to prevent freezing, which, while it would do no harm to the bulbs, would make their resurrection somewhat difficult when the time is at hand for bringing the pots into the house.

\section{NARCISSI}

With a half-dozen varieties of Narcissus, potted early in September, or even in August, a succession may be maintained which will insure the gardener attractive bloom throughout the greater part of the winter. Use five- or sixinch pots and plant from three to five bulbs in each pot. One narcissus of the trumpet variety may be successfully flowered in a four-inch pot, but to bring it to perfection requires more time and attention than the flowering of three or four of the same variety in a six-inch pot. Provide ample drainage and when the hullos are planted, water carefully and, finally, set them 


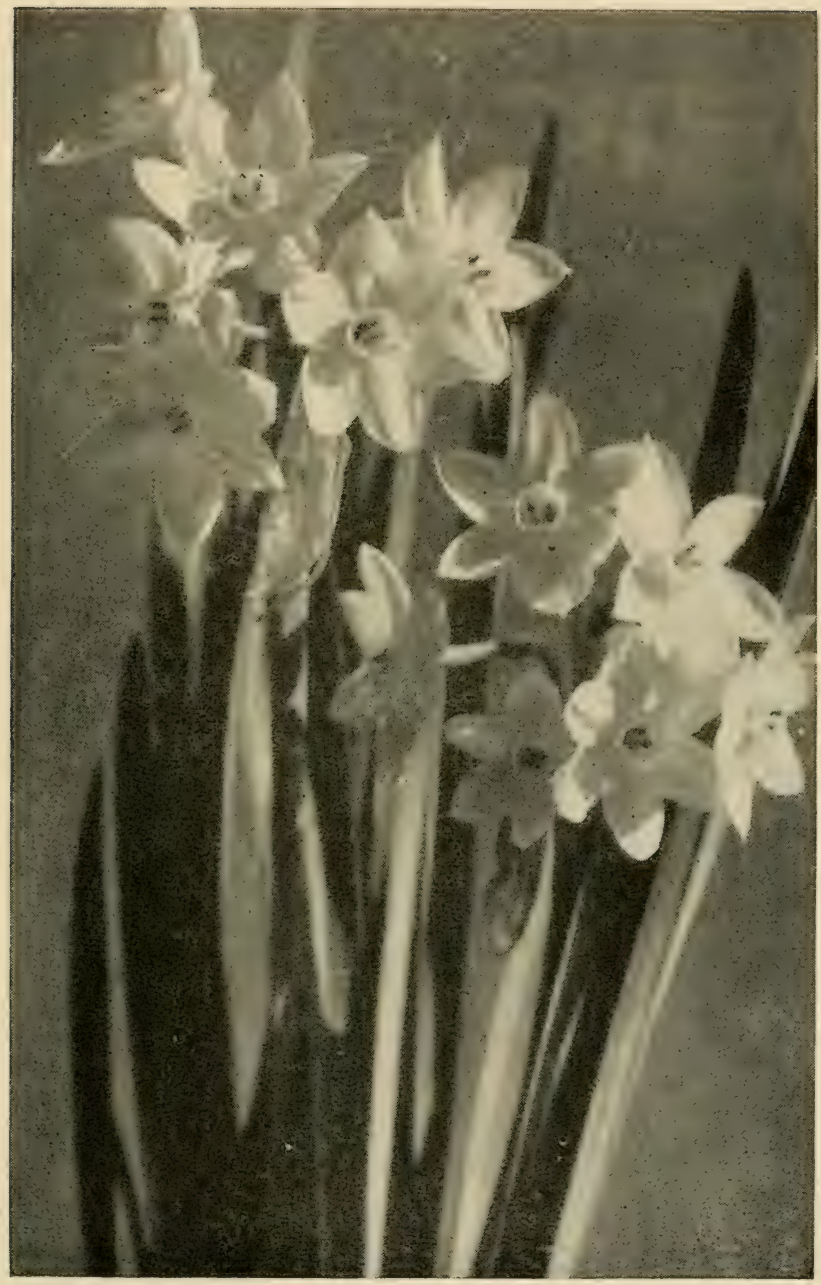

Paper White Narcissus 
either in the cellar or bury them in the ground. Here they should remain until they have formed a heavy system of roots and a top growth of three or four inches. At this stage they may be brought to the light, but not too suddenly, and submitted to a warmer temperature. Water carefully, using a little weak manure or commercial fertilizer in solution once a week. To maintain the succession, bring the pots to the light at intervals of a week apart.

For flowers in December and January, obtain the Paper White, Golden Spur, Henry Irving, Victoria, Princeps, Sir Watkin, Tortuosus and the double Van Sion; for bloom in January and February, plant the Emperor, Empress, Horsefieldi, Albicans and Stella superba, and for bloom in February and March depend on the Glory of Leiden, Mme. Plemp, Mrs. Camm, Mme. de Graaff, Barrii conspicuus, poeticus ornatus and orange and sulphur Phœnix. The rules to bear in mind are:

1. Early potting.

2. Allow sufficient time for rooting-twelve weeks for the hardy varieties and at least six weeks for the tender sorts.

3. Careful watering when the buds are developing. 


\section{HYACINTHS}

Very few window-gardeners would care to be without the hyacinth. Its culture is comparatively simple and, for the attention it demands, its fragrant blossom is more than ample reward. Select sound bulbs, solid and without offsets or protuberances and possessing only one crown. Apply the same rules to their selection as would be applied in choosing a fine onion and obtain the bulbs as early in the autumn as possible. Pot up at once-especially the Roman hyacinths-providing plenty of drainage and then treat the bulbs as advised for narcissi. Use five-inch pots, and plant one bulb to a pot, leaving at least a fifth of the bulb showing above the surface of the soil.

Some good single hyacinths for blooming in pots are:

Red, rose and pink: Robert Steiger, General Pelissier, Gertrude, Gigantea, Roi des Belges and Lord Macaulay.

White and blush white: La Grandesse, Grandeur à Merveille, Mont Blane, Paix de l'Europe and Baroness van Thuyll.

Dark and light blue: Baron van Thuyll, 
Charles Dickens, Czar Peter, King of the Blues, Leonidas and Regulus.

Roman hycinths produce small single white, pink or blue flowers. They hloom profusely, each bulb throwing from three to six spikes, are cheap and are easiest of all the hyacinths to cultivate in the amateur's hands. The white variety is the earliest and, everything considered, the most satisfactory and beautiful. Plant four or five bulbs in a five-inch pot, allowing the crowns to remain uncovered. They can be had without difficulty for Christmas bloom.

The Dutch hyacinths may also be brought to flower in water. Glass vases, especially designed for the purpose, are to be had from dealers in seeds and bulbs. Milk bottles, however, may be substituted and the result will be quite as satisfactory. The vessel should be filled with water until the water just reaches the base of the bulb when it has been set in position in the cup of the vase or in the mouth of the bottle. Drop a lump or two of charcoal in the water to keep it sweet, set the vessels away in a dark closet or in the cellar where they are to remain until heavy growths of roots form. As the water evaporates, add to it from time to time. 


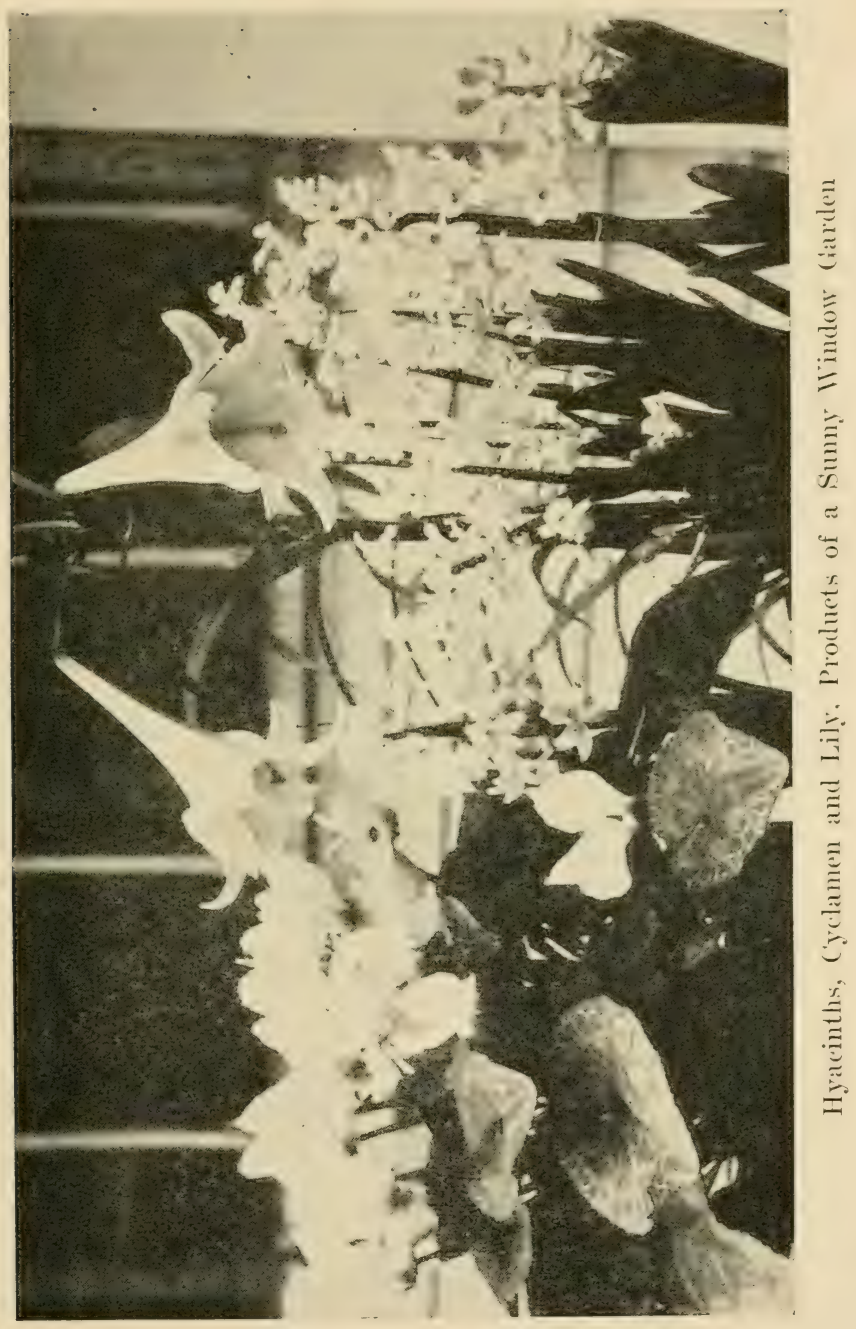




\section{TULIPS}

Tulips differ very little in point of culture from hyacinths. Instead of planting only one bulb to a four- or five-inch pot, however, from three to six may be set and the bulbs may be planted more deeply-but with never more than half an inch of soil above them. Those tulips earliest to bloom are included in the following list:

Singles: Duc Van Thol in varieties of blush, scarlet, rose, yellow and white; Artus, red; Canary Bird, yellow; Royal Standard, crimson and white; Vermilion Brilliant, scarlet; Keizerkroon, red and gold, and Pottebakker in varieties of white, yellow and scarlet.

Doubles: Golden King, yellow; Gloria Solis, scarlet and yellow; La Candeur, white, and Imperator Rubrorum, brilliant scarlet.

\section{OTHER BULBS}

Bulbs of the Easter lily (Lilium Harrisii) may he grown successfully when afforded the same treatment as narcissi, hyacinths and tulips, but a higher temperature than these latter require suit it best when it is making root growth. It is not by any means certain to 
flower for the amateur and should not be attempted until experience has heen gained.

Freesias may be potted, six or seven in a five-inch pot, and without the preliminary

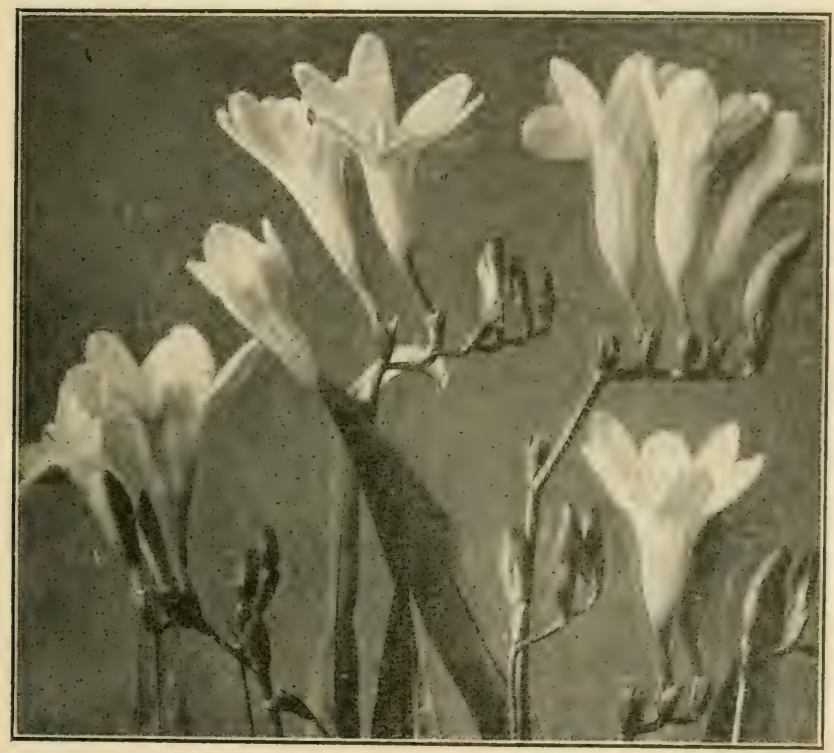

Freesias in bloom

plunging or season in the cellar, may be started into growth in light at once.

The crocus and snowdrop and other bulbs of similar size may be planted in pots and treated like hyacinths. Nost of them are so 
small that a dozen can be planted in a six-inch pot. They require a longer period for the development of their flowers than hyacinths and tulips and, on this account, should be depended on for later bloom.

Chinese sacred lilies are favorite bulbs for window gardens. They bear white and yellow flowers, six or seven to a stem and an inch and a half in diameter. The popular method of cultivation is in bowls of water, the bowls being four or five inches deep and the bulbs set in pebbles and weighted down by pebbles. The water should never reach more than half-way up the sides of the hulbs. Set the dish in a dark closet for a week or fortnight to encourage root growth. Often they can be had in bloom in six weeks.

\section{FLOWERING AND FOLIAGE PLANTS}

The bulbs, of course, do not exhaust by any means the plants that may he grown in the indoor winter garden. Nost of the plants so grown belong to the groups which florists cultivate in glass houses where the temperature is either "cool", or "medium.", The former demands a night temperature of fifty degrees and the latter of sixty degrees. A variation 


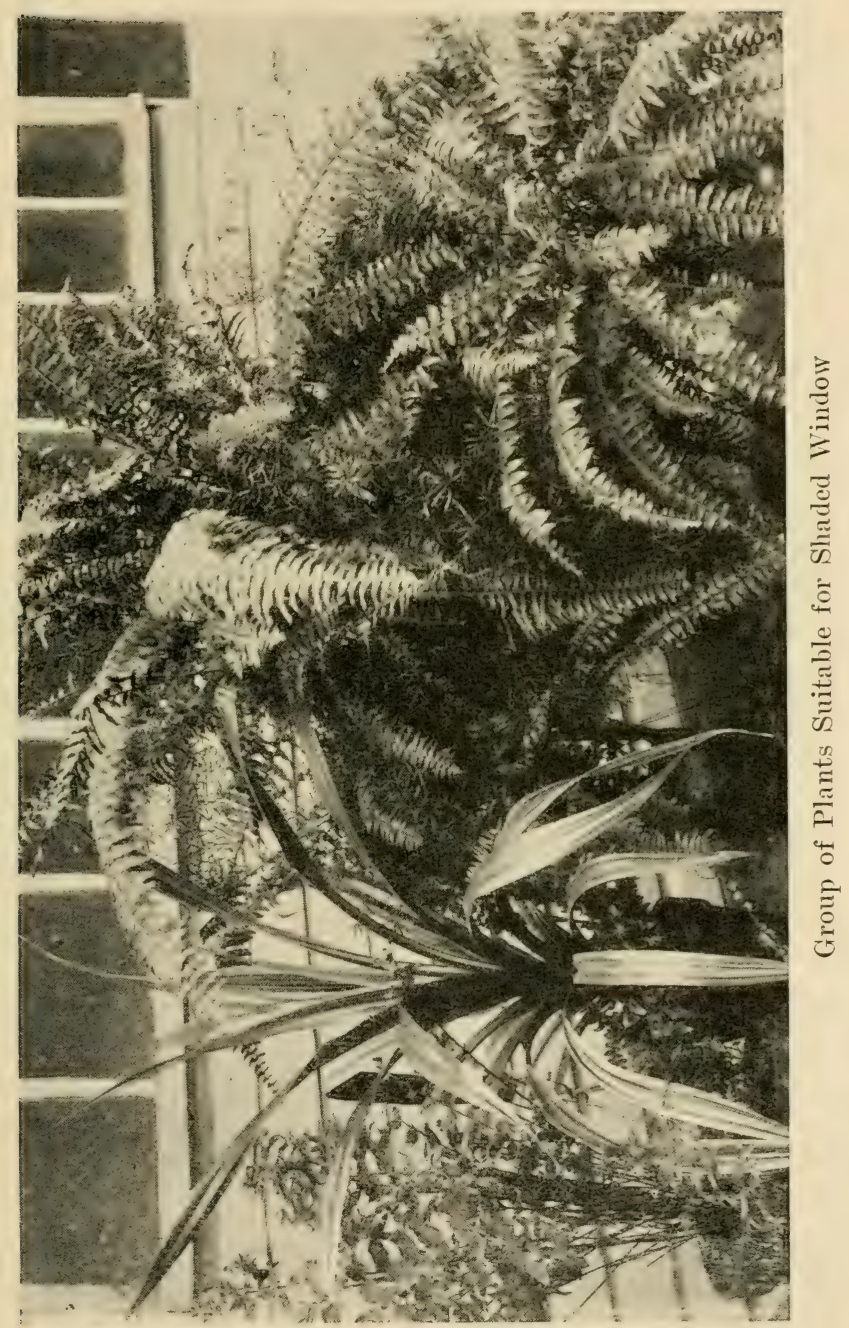


of five degrees between these temperatures will cause no injurious effects and a regular increase in daytime of ten or fifteen degrees is considered proper-even higher when the day is bright and sunny.

In selecting plants for the indoor garden, the amateur should first learn what temperature

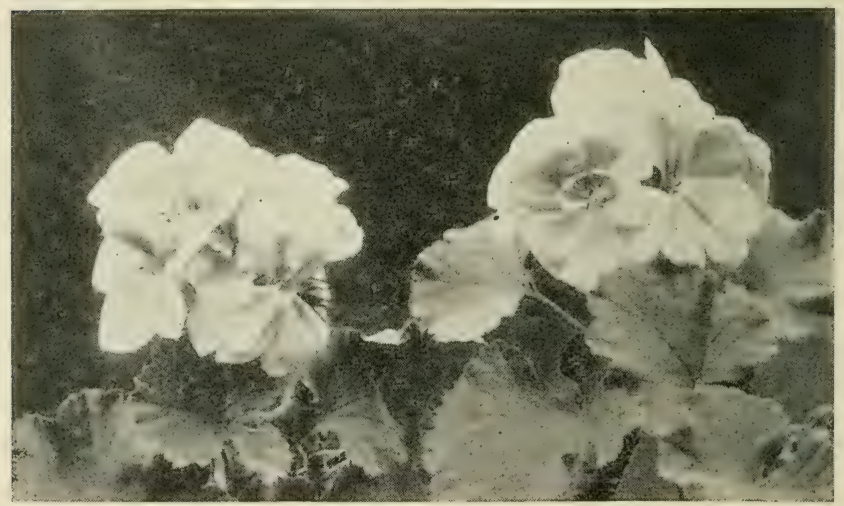

Geraniums in Bloom Indoors in Mid-Winter

his garden registers at night. If it falls to fifty degrees (cool house temperature) he should select from the following list:

Climbing plants: Senecio or parlor ivy, English ivy, lygodium or "climbing fern" and mauraudia.

Flowering plants: Azaleas, chrysanthemums, 
geraniums, Chinese primroses, Paris daisies or Marguerites, camellias, cinerarias, violets, cyclamens, ardisias, carnations and sweet alyssum.

Foliage plants: Palms, auracaria, eunonymus, aucuba and pandanus.

If the temperature is sixty degrees at night, the following list may be used:

Climbing plants: Asparagus in variety, Smilax, Coboe scandens, Madeira vine, Senecio mikanioides, Japanese hop and those also included in the list for the "cool" temperature.

Flowering plants: Fuchsia, Mahernia odorata, lobelia, mesembryanthemum, abutilons, browallias, hegonias, petunias, bouvardias, heliotropes, Chinese hibiscus, swainsonia, geraniums, cupheas and Richardias.

Foliage plants: Dracæna in variety, palms, Farfugium grande, Cycas revoluta, ferns, araucaria, pandanus, Ficus elastica, Grevillea robusta, Pilea arborea, vincas, tradescantia, Kenilworth ivy, Festuca glauca and Selaginella denticulata.

\section{PLANTS FOR SHADED WINDOWS}

But, even with these lists hefore him, the amateur can not make a selection until he pays heed to the amount of sunlight admitted through 
the window where his garden is to be established. The sunny selection is, of course, the best; here the flowering plants will prosper and bloom. Unfortunately, however, windows available for the purpose do not always face the south and occasionally neighboring buildings cast a deep shadow over the only exposure the gardener can command. He must select plants, therefore, which will thrive in half shade or whole shade.

In such situations, provided there be good light if no direct sunshine, abutilons will do well and healthy plants of these are scarcely ever without bloom. Begonias also thrive and, in their various forms, present so many attractions that a garden composed of these alone would be worth while. Two good varieties are the Bismarck and ricinifolia. Primulas do best in a partly shaded window and a dozen pots of the obconica hybrids would make a most interesting display. Fuchsias, swainsonia, ferns, palms and, in fact, nearly all foliage plants with the exception of the highly colored varieties do well in semi-shaded or sunless windows.

(of the foliage division, no more graceful plants are to be found than the palms. They 


\section{THE WINDOW GARDEN 353}

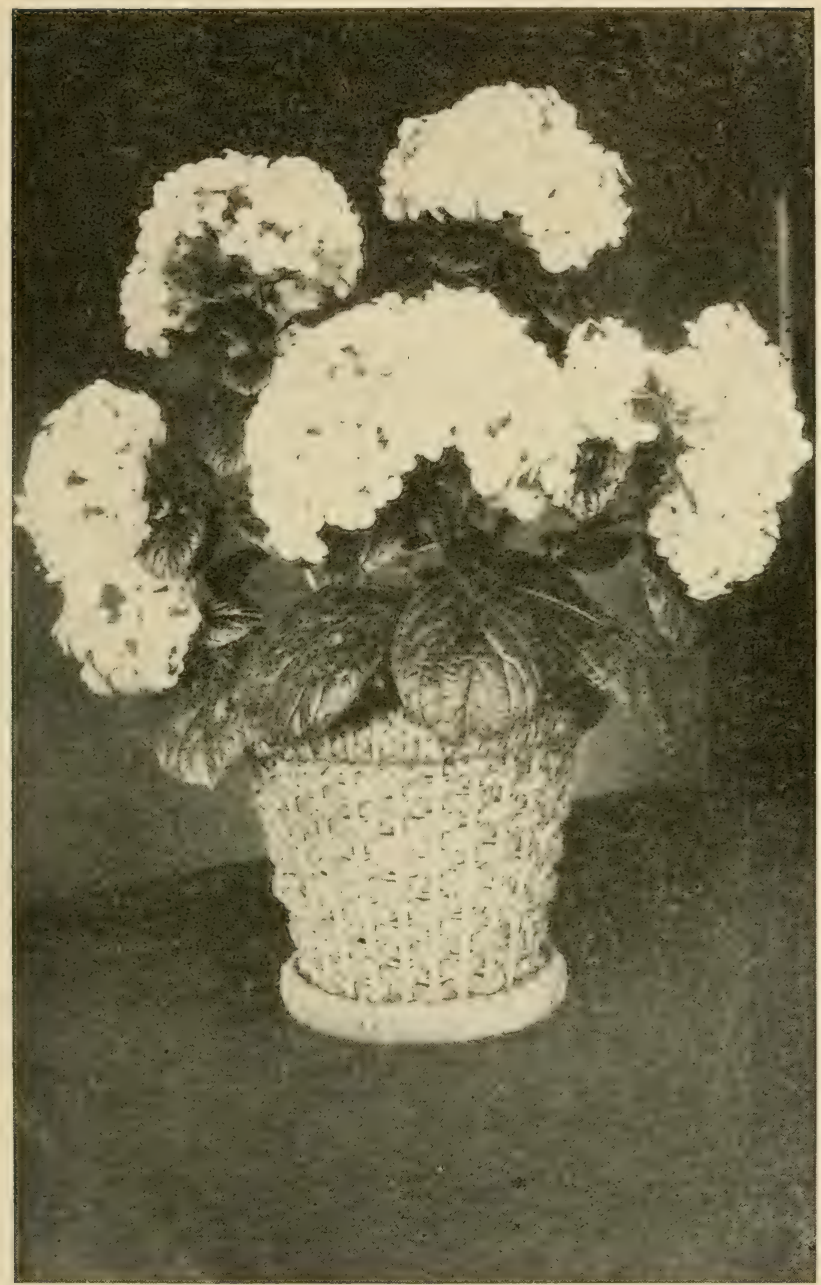

Tender Hydrangea (Hydrangea hortensis, var. Otaksa) 


\section{4}

may he gromn in a living-or drawing-room with more satisfaction than many other plants of value for their foliage alone. They are, however, slow-growing and, on this account, should never be over-potted. Many amateurs invite disaster to their palms by failing to observe

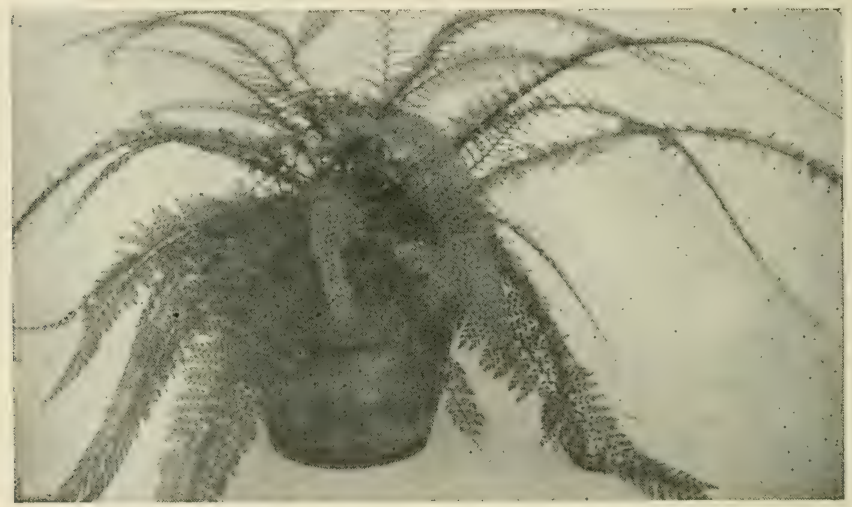

Lace Fern (Cheilanthes gracillima)

this fact. Repotting is unnecessary until the mass of roots fills the soil and even then the shift should he to a pot only one size larger. The best varieties for home culture are the Arecas, Kentias and Latanias.

The pandanus, or "screw pine," is also well adlapted to house culture and is remarkably ornamental. It prospers even when removed 


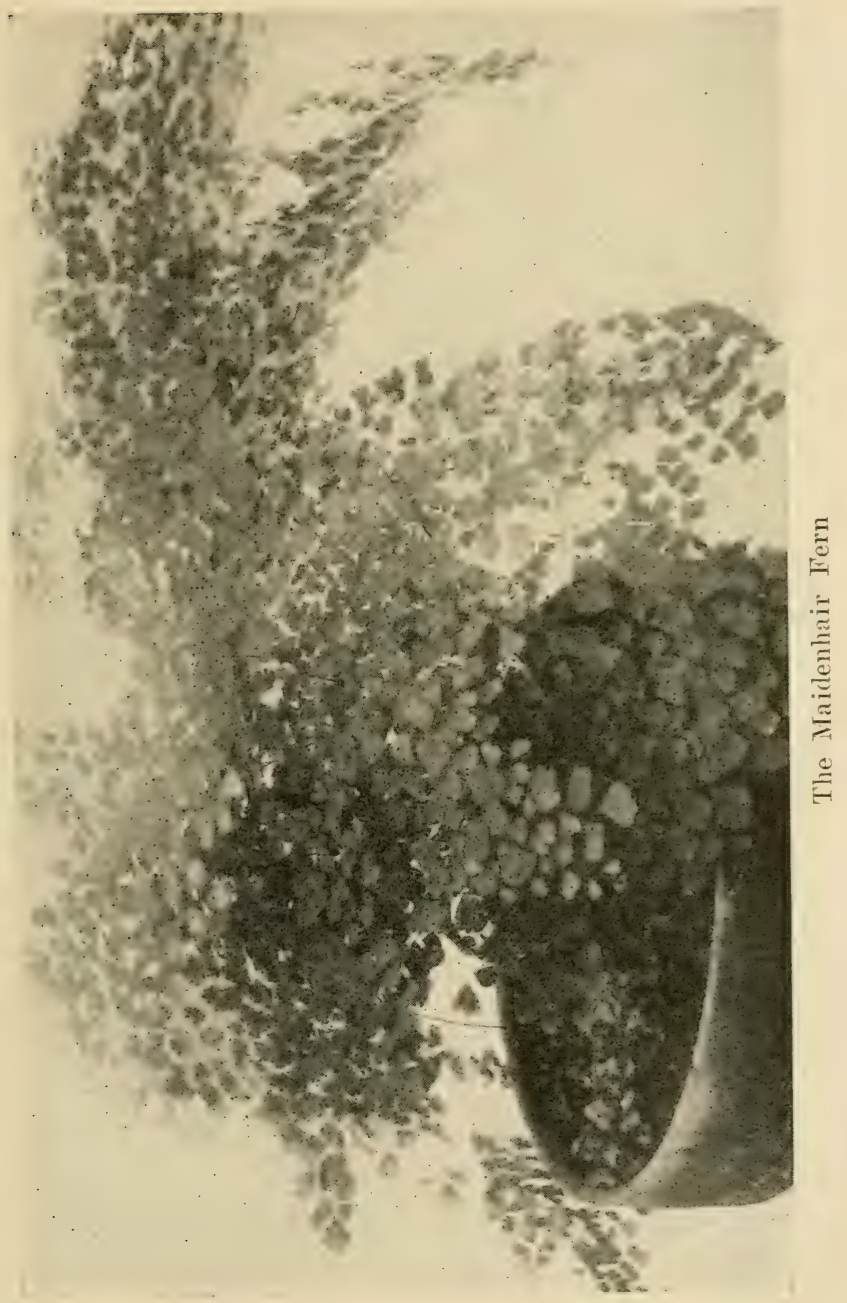


from the window and set in a shaded corner of the room. The general cultural treatment it requires is similar to that prescribed for the palms. Both thrive best in a moist soil but the pots should be liberally provided with drainage for both are injured when water stands at their roots.

\section{FERNS FOR INDOOR GARDENS}

The best ferns for pot culture indoors in winter are:

Adiantum cuneatum (maidenhair fern)

Asplenium platyneuron (ebony spleenwort)

Asplenium Trichomanes (maidenhair spleenwort)

Cyrtomium faleatum (holly fern)

Lygodium Japonicum (climbing fern)

Nephrolepis exaltata, var. Bostoniensis (Boston fern)

Nephrolepis exaltata, var. Scottii (Scott fern)

Nephrolepis exaltata, var. Piersonii (Pierson fern)

Nephrolepis cordata, var. compacta (kidney or sword fern)

In the culture of ferns indoors, clean foliage is a first requisite. The fronds should be showered frequently; if no other way is convenient, remove them to bath-tub or sink and there spray them thoroughly. The water should be of the same temperature as the room in which they are grown. Scale is a troublesome pest and is best overcome by scraping or rubbing it off with a brush or rag dipped in whale-oil soap-suds or kerosene emulsion. Green aphis is killed by nicotine. 


\section{CHAPTER XVII}

\section{A CHAPTER OF SPECIALTIES}

As a rule, amateurs in gardening no sooner make a beginning in planting before they decide that a roseless garden is no garden at all. They can not be greatly blamed for rushing to this conclusion, still they might bear in mind the fact that some of the most effective ornamental gardening effects of which this country affords examples have been attained without the use of a single rose-bush.

\section{ROSE CULTURE}

If, however, the beginner must have rosesand they are not without ornamental value in spite of all that has been said of them to the contrary-let him plant them in a situation that is somewhat sheltered from the biting winds of winter, ret open to the sun in summer, free from roots of trees and unshaded by overhanging branches. If no situation offers that is without shade, select roses of dark-red color- 
shade does them the least injury. Avoid low ground and if a deep loam is not already on the site chosen, provide it and make sure that it is earth which has never before been used for rose growing. Remember that roses disdain wet ground and insist upon having dry feet; make sure accordingly that the site is well drained.

Roses, on the whole, do best when planted in the spring. The hybrid perpetuals and the $\mathrm{Ru}$ gosas may be planted in the autumn with comparative safety, but even these would do better if set out in the spring, as soon as the ground can be worked. Avoid exposure of the roots of the plants to sun or wind while planting, and select, if possible, a dry, but cloudy day.

There is much difference of opinion as to the relative value of roses on their own roots or on Manetti or brier roots. By those who favor the latter, it is admitted that many of the summer-growing varieties do best on their own roots and, whenever this is the case, it is best to select stock which is so grown. In any event, obtain stock that is grown on brier roots rather than upon the roots of the Manetti. It is easy to detect a sucker should one arise from 


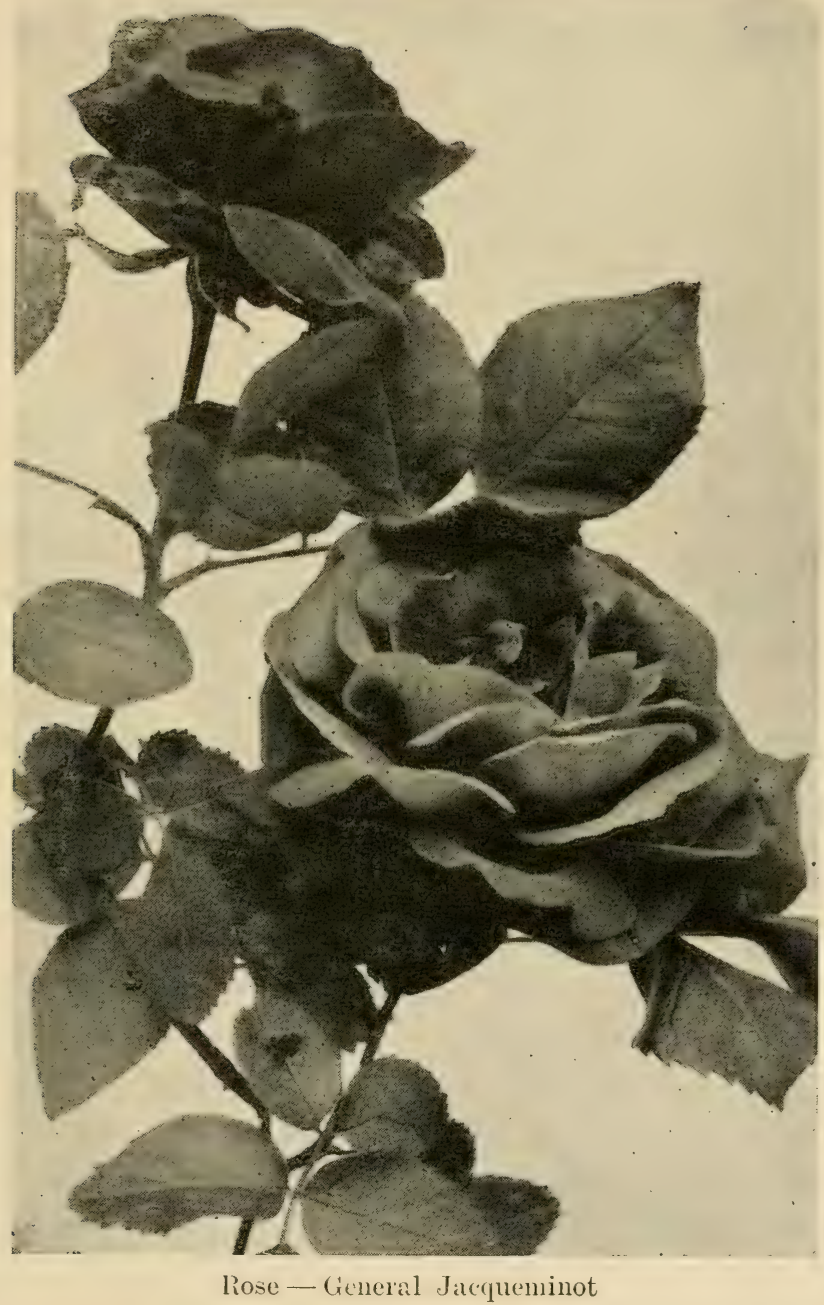


the wild stock, for the brier leaf has several leaflets instead of five, which the garden roses possess. When suckers develop-which is not often if the planting has been carefully doneremove them at once at the point of juncture with the root. If this can not be done without great disturbance to the plant, remove the growth at the lowest point possible.

Roses should be protected by a mulch in winter and by a lighter mulch in summer. For the latter, use well-rotted cow manure, with the double object in view of enriching the soil and affording protection from the sun. The protection, however, should be first considered and the surplus of the mulch employed for this purpose should be removed in the autumn before the winter covering is applied. It is safest to protect all roses in winter, but if any are to be neglected, let them be the Rugosas, Hybrid Perpetuals and Wichuraianas. For the restand for these wherever possible-apply a threeinch covering of rough, but old manure. In the more Northern sections, a heavier protection is required and this is not sufficient even where the winters are not very severe for the tender teas. These should be protected by setting bottomless and topless boxes over the plants, 
or setting around them chicken-wire frames, and filling the enclosures with leaves or straw.

The best fertilizers for roses are decared cow manure, hog, sheep or chicken manures sparingly applied and old horse manure. Commercial fertilizers may be used either alone or to supplement the natural manures. Ground bone is the best, but nitrate of soda, applied at the rate of about a teaspoonful to a plant, is useful as a stimulant early in the season. It should be followed, however, by more substantial fertilizers later on. The Reverend A. Foster-Melliar, an expert rose-grower and writer on the subject, recommends the following especially prepared fertilizer:

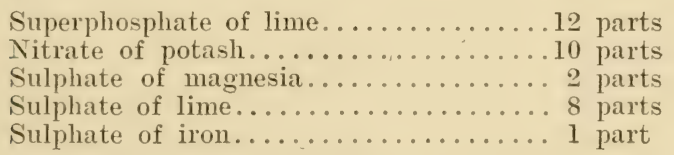

His advice is to apply this mixture in March at the rate of one-quarter pound to each square yard.

Roses should be pruned in early March. It is an error to prune them, as some persons do, in the autumn. Use the shear's on the hardy roses, both the climbers and the bushes, by March fifteenth if the season is of average 
weather. Prune the tender varieties in April, completing the process - in an average season -by the middle of the month. In sections where the winters are longer, however, the operation should be postponed until it is entirely safe to remove the winter mulch. Cut out all dead wood and weak shoots, the latter unsparingly, but do not follow blindly the advice to cut liberally where the wood is healthy, strong and vigorous. Too severe pruning is often as injurious as too little. If large blooms are wanted, the pruning should be more severe than where mass effects are desired. Cut the canes off an inch above an outside bud. The cane which follows will then grow outward and not inward as it would do were an inside bud selected and the cut made above it. This suggestion will prove of value to those who have had difficulty in training climbers successfully.

The following varieties, made up from Doctor Robert Huey's excellent list, will be found the most satisfactory:

HARDY PERPETUALS

White Baroness, white

Frau Karl Druschki, white

Mabel Morrison, white

Margaret Dickson, white

Baroness Rothschild, pink Her Majesty, pink

Paul Neyron, pink

Caroline d'Arden, pink Duke of Edinburgh, crimson Captain Hayward, crimson General Jacqueminot, crimson Prince Arthur, crimson 
TRELLIS ROSES

Gardenia

Reine Marie Henriette

Rosea Setigera

Dorothy Perkins

Crimson Rambler

Queen Alexandra

Paul's Carmine Pillar

HYBRID TEAS

Antoine Rivoire

Alice Grahame

Caroline Testout.

Clara Watson

Ellen Wilmot

Killarney

Liberty

Mme. Abel Chatenay

M. Bunel

Souv. de President Carnot

Mr. Leonard Barron, in his numerous articles, has performed a great service for the rosegrower who must raise his flowers in the midst of uncongenial surroundings in a city. For the gardener who has to contend with smoke from soft coal and even with unsatisfactory conditions of sun, his list, which follows, is excellent:

\section{HYBRID PERPETUALS}

Baron de Bonstetten, very dark red

Charles Dickens, rose color, large

Dr. Andry, dark bright red

Dupuy Jamain, brilliant cerise

General Jacqueminot, dark bright red

Ulrich Brunner, cherry red

John Hopper, lilac-rose with crinson center

La France, silvery pink

Mme. Gabriel Luizet, pink

Magna Charta, bright pink, suffused carmine

Paul Neyron, pink - the largest of all roses

Boule de Neige, white

\section{BOURBONS}

Mme. S. Cochet, rose, edged white

Mme. I. Pereire, rosy carmine

Queen of Bedders, deep bright crimson 


\section{TEAS AND NOISETTES}

Aimee Vibert (N.), white, clusters

Reine Marie Henriette (T.), cherry red

Gloire de Dijon (T.), yellow

Homer (T.), blush rose and salmon, variable

\section{CLIMBERS}

Crimson Rambler, crimson

R. Wichuraiana, white, single

Also selections of the Rambler-Wichuraiana hybrids

Where roses are wanted only for shrubberies, or where the flower's are of secondary importance, the following will be found to suit the purpose admirably:

Penzance briers.

Rosa rugosa

Rosa rubiginosa
Rosa blanda

Rosa lucida

Rosa nitida

\section{HARDY FERNS}

Many ferns, all hardy, demand so little in the way of special soil and situation that they can be grown without difficulty by the beginner. Planted, for instance, hetween the foundation walls of a house and the channel worn by water dripping from overhanging eaves, they make a pleasing border, thriving where nothing else would succeed half so well. Here they have what they most enjoy-a cool, damp soil and shade. It must not be understood from this, however, that ferns will continue vigorous in ground that is undrained. On the contrary, 


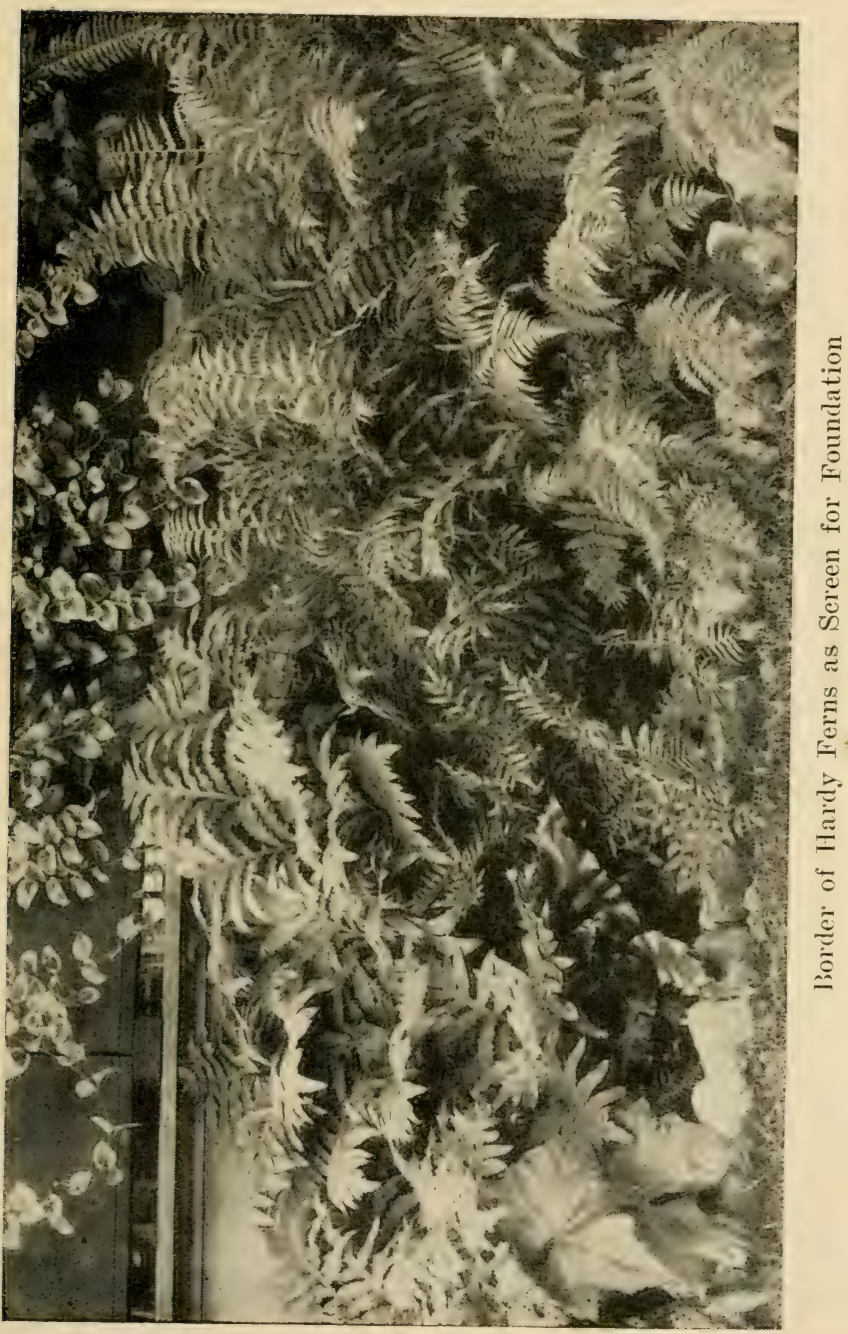


they will not do well where the water remains about their roots. But if they are given a damp atmosphere and, preferably, an eastern exposure, the majority of the native ferns will do exceedingly well.

So far as soil is concerned, while good woods earth is best, most of the common ferns are less exacting in this respect than one would im-

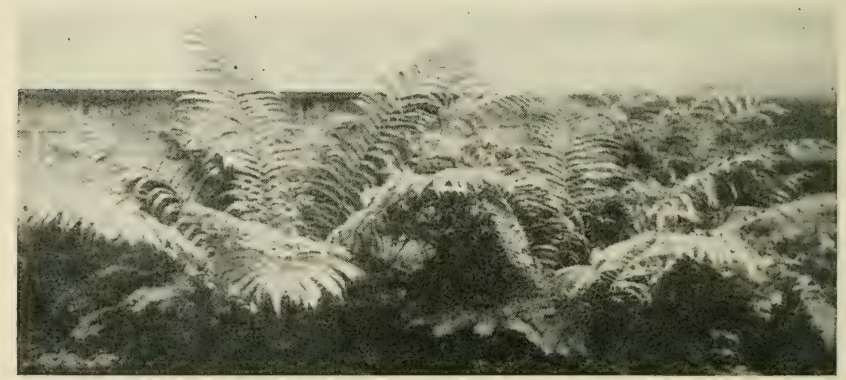

Ostrich Ferns in Narrow Border

agine. If the soil is deep and fairly rich, porous and cool, ferns may be planted without much fear of the results. The addition of leaf-mold and some rough peat would make the compost all the better, but, with some varieties, this is not necessary.

The following list contains the ferns that are most easily grown and which the beginner will find easily established: 


\section{SPECTALTIES}

Adiantum pedatum, Maiden-hair fern

Asplenium Filix-fœmina, Lady fern

Asplenium platyneuron, Ebony spleenwort

Camptosorus rhizophyllus, Walking fern

Cheilanthes gracillima, Lace fern

Dicksonia punctilobula, Hay-scented or gossamer fern

Dryopteris Goldieana, Goldie's fern

Dryopteris marginalis, Evergreen wood fern

Dryopteris Noveboracensis, New York fern

Dryopteris spinulosa, Shield fern

Lygodium palmatum, Climbing, or Hartford fern

Onoclea sensibilis, Sensitive fern

Onoclea Struthiopteris, Ostrich fern

Osmunda cinnamomea, Cinnamon fern

Osmunda Claytoniana, Clayton's fern

Osmunda regalis, Royal fern

Polypodium vulgare, Common polypody

Polystichum acrostichoides, Christmas fern

Pteris aquilina, Bracken

\section{PEONIES}

No flower is richer in beauty than the her'baceous Peony and none, considering wealth of bloom and glorious color, is more easily raised by the amateur. It is one of the hardiest and healthiest plants in cultivation and only occasionally is it attacked by disease. Given a deep, rich soil in which to root, it will thrive for years, increasing, if undisturbed, season after season, and producing its magnificent bloom even when sadly neglected. In color, it covers a wide range and a large plantation of it in flower is unrivaled in beauty. Its foliage, moreover, is attractive throughout the season and forms a background of green against which 
a display of later-blooming flower's is always effective.

Soil for Peonies should contain no fresh manure. All fertilizer put into the earth where they are to be established should be at least a year old and it would be better were this incorporated with the soil several months before the roots are planted. Dig deeply - two feet is none too much-and work the soil until it is finely pulverized. Look carefully to drainage and, after setting out the roots, mulch thickly with three or four inches of coarse manure, spading this in before growth starts in the following spring. Peonies should be planted in September, and if quick effects are wanted, undivided clumps should be obtained. Single roots, however, are cheaper, and in a seasow or two, make a very satisfactory display. In ordering roots, do not be insistent on the number of "eyes," for often the purchaser in designating that the roots he order's are to show no fewer than three "eyes," sacrifices vigor and quality for quantity.

Do not expect much bloom the first season after planting. Peonies take time in establishing themselves and not infrequently fail to bloom for two years after they are set out. Or, 


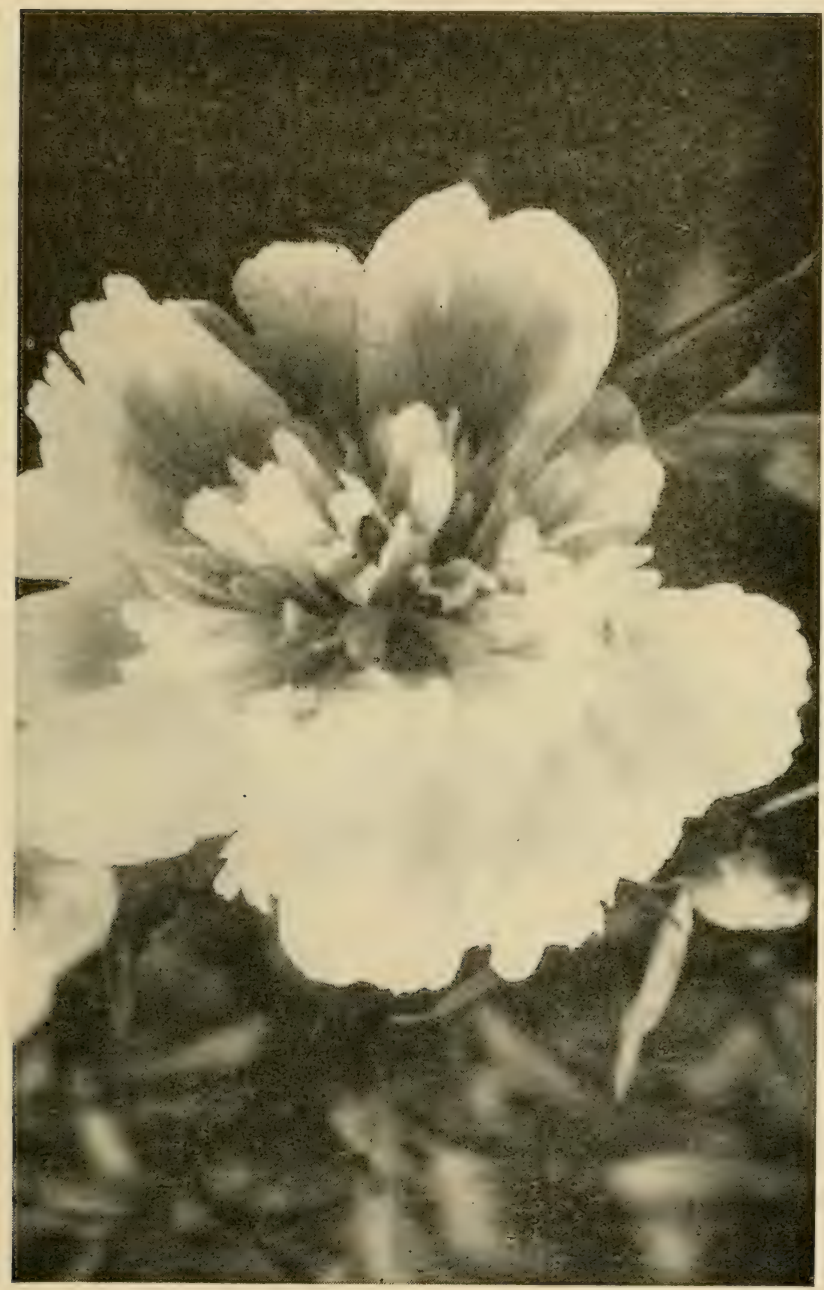

Double Peony 
if of a varicty that more quickly accustoms itself to new surroundings, they may bear bloom the first season, but these will never be a fair sample of what the plant can do. Double Peonies, under such circumstances, may bear only single flowers, and this fact sometimes leads to disappointment on the part of the purchaser who fancies that the nurseryman has not dealt fairly by him. Before he voices his suspicion, it would be better were he to take into consideration the short time the plant has been in his garden and postpone his complaint until the following season when, in all likelihood, the flowers will be as double as they were represented to be.

Some Peonies, however, are not profuse bloomers. Constitutionally they are not and from such plants large quantities of bloom will never be obtained. It is also a fact that some Peonies are prolific bloomers in some sections of the country and in other sections bloom very little. It is impossihle, of course, to say with any degree of certainty what varieties perform in this unsatisfactory manner, but Charlemagne, for instance, blooms strongly in Rochester, New York, and weakly in New England. Giganthea does well in the East, but in the West 
bears few flowers. It is true, too, that both quality and quantity of bloom vary from season to season, so far as can be determined, for no apparent reason. Treather conditions may be entirely farorable and still the flowers be limited and of inferior quality while, another year,

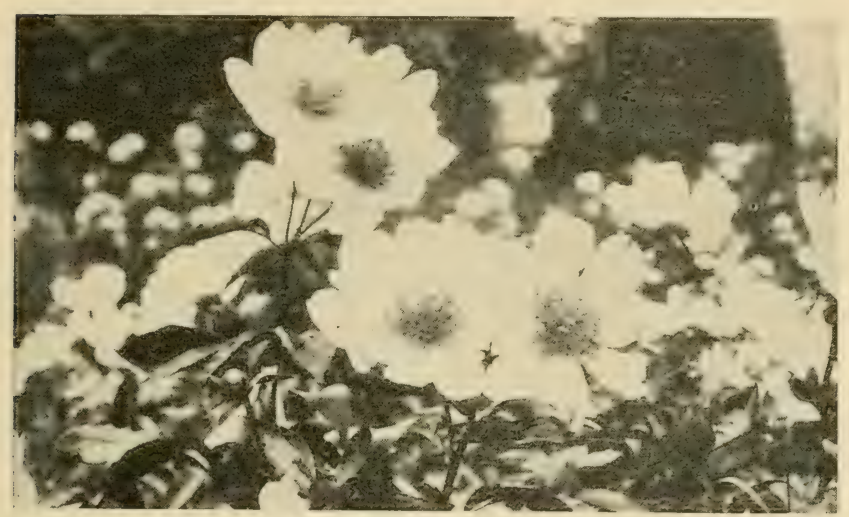

Single Peonies

weather conditions may be unfarorable and the flowers will be large and numerous.

A few varieties are especially sensitive; they can not endure storms or frosts of early spring and usually the only return they make for nursing and coddling is to produce buds that blight before they expand. This is especially true of many varieties imported from England. They 
can not, it seems, adapt themselves to the climatic conditions of their new home.

There is little pleasure in fostering one of these indolent or sensitive varieties and the purchaser should exercise care in his selection to make sure that he olotains only the hardiest and most vigorous and those that are surest

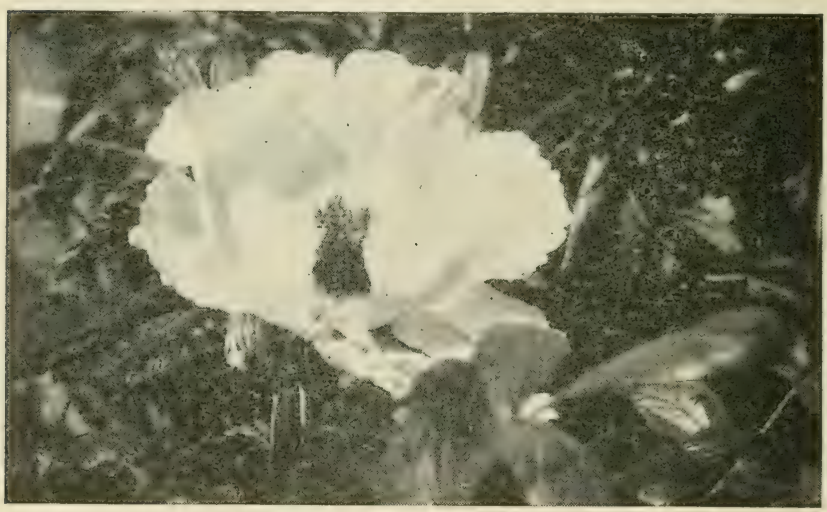

Flower of the Tree Peony

and most profuse in bloom. The following list will assist the beginner in the matter of selection, but it must be understood that Peony nomenclature is so sadly mixed at this time that very little dependence can he placed upon the names: 


\section{SPECIALTIES}

Achille, delicate pink

Agida, rosy violet

Alexander Dumas, brilliant pink

Amazone, creamy white, yellowish center

Andre Laures, violet red

Auguste Lemonier, deep, dark red

Baroness Schroeder, delicate pink, touched with gold in center

Bell Hough, light purplish crimson

Bertha, bright erimson

Belle Chatelaine, delicate pink, carmine center

Cameron, deep purplish red

Carnea Flora Plena, delicate pink, carmine center

Charles Verdier, carmine

Comte de Osmont, fine white

Defiance, bright crimson

Duchesse de Nemours, clear pink, center of lilac tints

Duchesse d'Orleans, deep pink

Edouard Andre, erimson, with yellow stamens

Excelsior, dark crimson

Festiva Maxima, the best white, a superb flower

Floral Treasure, pink, fragrant, one of the best and hardiest of flowers

Flambeau, cherry petals with white tips, tufted bloom

General Grant, red

Grandiflora Carnea Plena, clear, light pink, shaded lilac

Golden Harvest, outer petals pink, inner golden, a splendid flower

Golden Wedding, pure yellow - the only pure yellow

Humei, pink

La Coquette, bright rose

La Fiance, creamy white, yellowish center

L'Esperence, white, touched with pink

Marie Lemoine, sulphur white, shaded pink

Nigra, dark crimson

Pomponia, pinkish white

Queen Victoria, white

Richardson's Rubra Superba, splendid crimson

Sarah Bernhardt, pink, salmon center

The Nymph, fragrant, curious flower, white, tipped with carmine

Victoria Tricolor, pink, sulphur and flesh

Zoe Calot, soft pink 


\section{FOR CUT FLOWERS}

Many gardeners desire varieties of Peonies that serve not only a decorative purpose, but which are also useful as cut flowers. The following list contains the best for this dual purpose :

White: Festiva Maxima, Queen Victoria, M. Dupont, Couronne d'Or, Madame Crousse, La Tulipe, Madame de Verneville, Marie Lemoine, Duchesse de Nemours.

Pink: Beauté Francaise, Delicatissima, Livingstone, Princess Beatrice, M. Jules Elie, Edulis Superba, Alexandrina.

Red: Adolph Rosseau, Souvenir de l'Exposition Universelle, Modeste Guerin, Delachei, Marechal de MacMahon, M. Krelage, Richardson's Rubra Superba, Felix Crousse.

\section{PERENNIAL PHLOX}

A yard or garden, large or small, in which many Phloxes are grown is always a place gay with flowers from mid-June to the autumn days of frost. Like the peony, the Phlox is easily grown, rewarding the gardener with a wealth of bloom altogether out of proportion to the fer demands it makes upon his time and labor. 


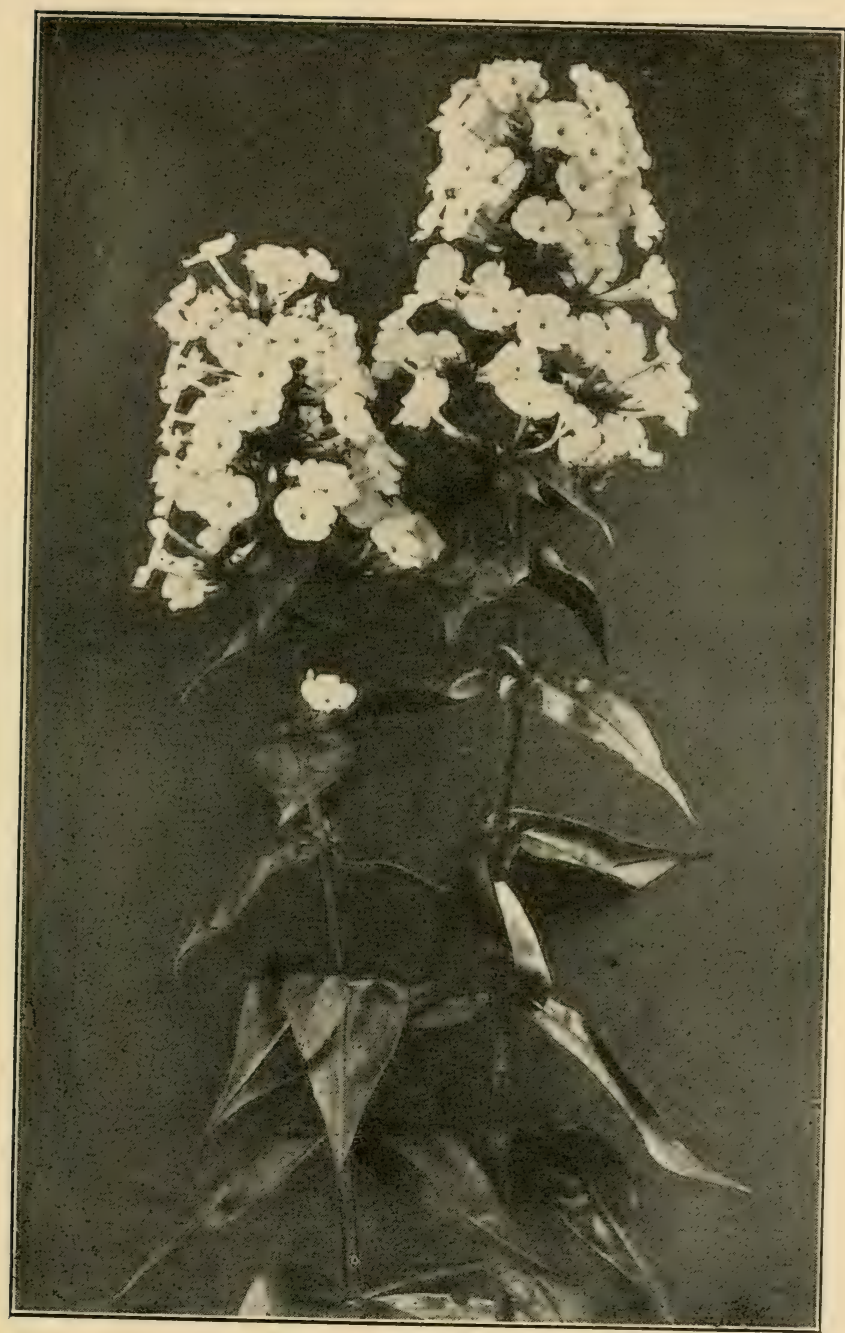

Hardy Phlox (Phlox paniculata) 
The suffruticosa group is the first to bloom, but it is the decussata (paniculata) group, later in flowering, that produces the brightest and clearest blossoms. Both divisions will grow either in sun or shade, but they prefer, on the whole, a situation in partial shade. They do best in a deep, rich loam, enriched with wellrotted cow manure, and spaded to a depth of at least two feet.

The plants should be set out so that the crown is about two inches below the surface of the soil and the earth must be well firmed about the roots. The best season for planting is from the first of October to the last of the month, but spring planting is fairly successful. After planting, mulch before the ground freezes deeply with a covering of leaves, straw or litter to a depth of four inches. If the plants are set out in spring, a lighter mulch should be applied to shade the roots from the sun.

If a profusion of bloom is wanted, pinch back the stalks of the taller varieties when they have attained a height of twelve or fifteen inches and the dwarf sorts when they have attained half that height. They will then break into two or four secondary stalks and upon these will be borne the clusters of bloom. The Phlox is un- 
commonly free from insect enenies and diseases, though occasionally it is attacked hy red-spider or eut-worms. Spraying with a hard stream of clear water will kill the former and rood ashes sprinkled lightly about the roots will control the latter.

The following list* includes the hest hoth in point of size and color of bloom and in hardiness and vigor of plant:

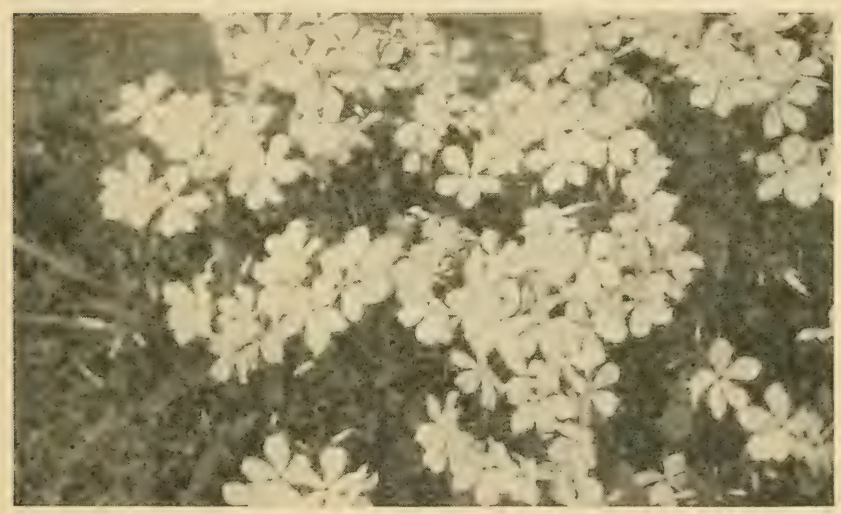

Wild Sweet William (Phlox divaricata)

I'HLOX SUFFRUTICOSA

Dr. Hornby, white, lilac tinted

Indian Chief, magenta, crimson eye

- Lady Musgrove, white, striped magenta

Leaman, rosy lilac

Ringleader, light magenta with red eye

Snowdon, pure white

* Little dependence can be placed in Phlox nomenclature. 


\section{DWARF SPECIES}

Amœna, pinkish purple, very early and very dwarf Divaricata, pinkish blue, very early

Reptans, purplish violet

Stellaria, whitish blue

Subulata, pinkish purple, blooms in April and May

Subulata, var. Alba, white

\section{PIILX PATICULATA}

Amazone, the finest white

Andreas Hofler, pure white

Bouquet de Fleurs, white with deep rose eye

Bridesmaid, white, with a large crimson eye

Champs-Elysees, rich purplish crimson

Coquelicot, scarlet, with dark carmine eye

Cross of Honor, lilac, margined with white

Eclaireur, purplish crimson, with bright shades

Esclarmonde, lilac, mottled with white, with a deep rose eye

Eugene Danzanvillier, lilac, with white edge and center

Jeanne d'Are, white, large and late-flowering

Jocelyn, salmon

Jules Finger, white with red eye

La Fondre, purple-crimson, with carmine center

La Vogue, rosy mauve, with red eye

Lothair, salmon, with crimson eye

Marquis de St. Paul, rosy salmon, with crimson eye

M. Gladstone, soft rose, with crimson eye

Ornament, rosy magenta, with crimson eye

Pantheon, deep rosy salmon

P. Bonnetain, rose, overlaid with salmon

Prof. Schliemann, lilac-rose, with carmine eye 


\section{APPENDIX}

FLOWERS OF HARDY BULBS FROM FROST TO FROST

The following list is intended to suggest what hardy bulbs to plant in order to insure a succession of flowers of this class outdoors practically all the year round:

JANUARY, FEBRUARY AND MARCH

\begin{tabular}{|c|c|c|c|c|}
\hline Popular Name & Botanical Name ? & 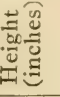 & Color & $\begin{array}{l}\text { Cultural } \\
\text { Suggestions }\end{array}$ \\
\hline Christmas rose & Helleborus niger & 6 & White & $\begin{array}{l}\text { Light soil, half } \\
\text { shade, sheltered } \\
\text { situation }\end{array}$ \\
\hline Winter aconite & Eranthis hyemalis & 6 & Yellow & $\begin{array}{l}\text { Rich, well-drained } \\
\text { soil, partial shade }\end{array}$ \\
\hline Siberian scilla & Scilla Sibirica & 6 & Blue & $\begin{array}{l}\text { Light sandy but } \\
\text { rich soil, sun }\end{array}$ \\
\hline Purple scilla & Scilla bifolia & 6 & Purple & $\begin{array}{l}\text { Light, rich soil, } \\
\text { sun }\end{array}$ \\
\hline Glory-of-the-snow & $\begin{array}{l}\text { Chionodoxa } \\
\text { Luciliæe }\end{array}$ & 8 & Blue & \multirow{2}{*}{$\begin{array}{l}\text { Fair soil, well } \\
\text { drained, sun }\end{array}$} \\
\hline Glory-of-the-snow & $\begin{array}{l}\text { Chionodoxa } \\
\text { Sardensis }\end{array}$ & 8 & $\begin{array}{l}\text { Dark } \\
\text { blue }\end{array}$ & \\
\hline Crocus & Crocus vernus & 5 & $\left\{\begin{array}{l}\text { White } \\
\text { lilac }\end{array}\right.$ & \multirow{4}{*}{$\begin{array}{l}\text { Light soil, rich and } \\
\text { well drained, sun }\end{array}$} \\
\hline Imperial crocus & Crocus Imperiati & 5 & Lilac & \\
\hline Scotch crocus & Crocus biflorus & 5 & $\left\{\begin{array}{l}\text { Light } \\
\text { lilac }\end{array}\right.$ & \\
\hline $\begin{array}{l}\text { Cloth-of-gold } \\
\text { crocus }\end{array}$ & Crocus Susianus & 5 & Yellow & \\
\hline Snowdrop & Galanthus nivalis & 4 & White & \multirow{2}{*}{$\begin{array}{l}\text { Light soil and par- } \\
\text { tial shade }\end{array}$} \\
\hline Giant Snowdrop & $\begin{array}{r}\text { Galanthus Elwesii } \\
37\end{array}$ & & White & \\
\hline
\end{tabular}


A PRIL

\begin{tabular}{|c|c|c|c|c|}
\hline Popular Name & Botanical Name & 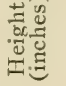 & Color & $\begin{array}{c}\text { Cultural } \\
\text { Suggestions }\end{array}$ \\
\hline Windflower & $\left\{\begin{array}{c}\text { Anemone blanda } \\
\text { Anemone Apen- } \\
\text { nina }\end{array}\right.$ & $\begin{array}{r}6 \\
-7\end{array}$ & $\begin{array}{l}\text { Blue } \\
\text { Blue }\end{array}$ & Rich soil and sun \\
\hline $\begin{array}{l}\text { Trumpet nar- } \\
\text { cissus }\end{array}$ & $\begin{array}{l}\text { Narcissus } \\
\text { Pseudo-Narcis- } \\
\text { sus }\end{array}$ & 15 & $\begin{array}{l}\text { White- } \\
\text { Yellow }\end{array}$ & \multirow{3}{*}{$\begin{array}{l}\text { Rich, deep soil- } \\
\text { sun or half-shade }\end{array}$} \\
\hline Cup narcissus & $\begin{array}{l}\text { Narcissus incom- } \\
\text { parabilis }\end{array}$ & 15 & $\begin{array}{l}\text { White- } \\
\text { yellow }\end{array}$ & \\
\hline Jonquil & $\begin{array}{l}\text { Narcissus } \\
\text { Jonquilla }\end{array}$ & 12 & Yellow & \\
\hline Spring snowflake & $\begin{array}{l}\text { Leucojum } \\
\text { vernum }\end{array}$ & 7 & White & $\begin{array}{l}\text { Light soil, rich, and } \\
\text { sun }\end{array}$ \\
\hline Crown imperial & $\begin{array}{l}\text { Fritillaria im- } \\
\text { perialis }\end{array}$ & 4. & $\begin{array}{l}\text { Yellow- } \\
\text { red }\end{array}$ & $\left\{\begin{array}{l}\text { Moist situation, } \\
\text { some shade, rich } \\
\text { soil }\end{array}\right.$ \\
\hline Grape hyacinth & $\begin{array}{l}\text { Muscari } \\
\text { botryoides }\end{array}$ & 6 & $\begin{array}{l}\text { Purple- } \\
\text { blue }\end{array}$ & $\begin{array}{l}\text { Sunny situation, } \\
\text { fair soil }\end{array}$ \\
\hline Tulip & Tulip suaveolens & 12 & Various & $\begin{array}{c}\text { Sunny situation, } \\
\text { light, fair soil }\end{array}$ \\
\hline Hyacinth & $\begin{array}{l}\text { Hyacinthus } \\
\text { orientalis }\end{array}$ & 12 & & $\begin{array}{c}\text { Fairly rich soil, } \\
\text { sun }\end{array}$ \\
\hline
\end{tabular}

\begin{tabular}{|c|c|c|c|}
\hline Poet's narcissus & $\begin{array}{l}\text { Narcissus poet- } \\
\text { icus }\end{array}$ & 16 & White $\left\{\begin{array}{c}\text { Sun or shade, ricl } \\
\text { deep soil }\end{array}\right.$ \\
\hline Bluebell & Scilla festalis & 10 & $\left.\begin{array}{l}\text { Blue, } \\
\text { white, } \\
\text { pink }\end{array}\right\} \begin{array}{c}\text { Half shade, fair } \\
\text { soil }\end{array}$ \\
\hline Garden anemone & $\begin{array}{l}\text { Anemone hor- } \\
\text { tensis }\end{array}$ & 10 & $\left.\begin{array}{l}\begin{array}{l}\text { Purple, } \\
\text { white, } \\
\text { red. }\end{array}\end{array}\right\} \begin{array}{l}\text { Some shade, light, } \\
\text { rich soil }\end{array}$ \\
\hline Poppy anemone & $\begin{array}{l}\text { Anemone coro- } \\
\text { naria }\end{array}$ & 10 & $\left.\begin{array}{l}\text { White, } \\
\text { red, } \\
\text { blue. }\end{array}\right\} \begin{array}{l}\text { Some shade, light, } \\
\text { rich soil }\end{array}$ \\
\hline Wake Robin & $\begin{array}{l}\text { Trillium grandi- } \\
\text { florum }\end{array}$ & 12 & \} $\begin{array}{l}\text { Little sun, damp, } \\
\text { rich soil }\end{array}$ \\
\hline $\begin{array}{l}\text { May-flowering } \\
\text { tulip }\end{array}$ & Tulipa Gesneriana & 24 & Various Sun, rich, light soil \\
\hline Star-of-Bethlehe & $\begin{array}{r}\text { Ornithogalum } \\
\text { umbellatum }\end{array}$ & 9 & $\begin{array}{l}\text { Sun or shade, fair } \\
\text { soil }\end{array}$ \\
\hline
\end{tabular}




\section{APPENDIX}

\begin{tabular}{|c|c|c|c|c|}
\hline \multicolumn{5}{|c|}{ JUNE } \\
\hline Popular Name & Botanical Name & 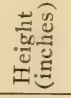 & Color & $\begin{array}{c}\text { Cultural } \\
\text { Suggestions }\end{array}$ \\
\hline Spanish iris & Iris Xiphium & 20 & $\begin{array}{l}\text { White, } \\
\text { blue, } \\
\text { yellow }\end{array}$ & $\begin{array}{l}\text { Light, rich soil and } \\
\text { sun }\end{array}$ \\
\hline English iris & Iris xiphioides & 24 & $\begin{array}{l}\text { Purple- } \\
\text { white }\end{array}$ & $\begin{array}{l}\text { Light, rich soil and } \\
\text { sun }\end{array}$ \\
\hline Madonna lily & Lilium candidum & 30 & White & $\begin{array}{c}\text { Light, well drained } \\
\text { soil, little shade }\end{array}$ \\
\hline Hanson's lily & Lilium Hansoni & 30 & Orange & $\begin{array}{c}\text { Light, well drained } \\
\text { soil, little shade }\end{array}$ \\
\hline \multicolumn{5}{|c|}{ JULY } \\
\hline Erect lily & Lilium elegans & 18 & $\begin{array}{l}\text { Orange- } \\
\text { red }\end{array}$ & $\begin{array}{l}\text { Light, rich, well- } \\
\text { drained soil, sun }\end{array}$ \\
\hline Canada lily & Lilium Canadense & $\mathrm{e} 36$ & $\begin{array}{l}\text { Yellow- } \\
\text { red }\end{array}$ & $\begin{array}{c}\text { Moist, leaf mould, } \\
\text { partial shade }\end{array}$ \\
\hline $\begin{array}{l}\text { Purple trumpet } \\
\text { lily }\end{array}$ & Lilium Brownii & 36 & $\begin{array}{l}\text { Purple- } \\
\text { white }\end{array}$ & $\begin{array}{l}\text { Light soil, sheltered } \\
\text { sunny situation }\end{array}$ \\
\hline $\begin{array}{l}\text { White trumpet } \\
\text { lily }\end{array}$ & $\begin{array}{l}\text { Lilium longi- } \\
\text { florum }\end{array}$ & 26 & White & Light soil, sun \\
\hline
\end{tabular}

AUGUST

\begin{tabular}{|c|c|c|c|c|}
\hline Summer hyacinth & $\begin{array}{l}\text { Galtonia candi- } \\
\text { cans }\end{array}$ & 30 & White & $\begin{array}{l}\text { Light but deep soil } \\
\text { rich; sun }\end{array}$ \\
\hline Turk's Lily & Lilium superbum & $\begin{array}{r}50 \\
-\quad \\
\end{array}$ & $\begin{array}{l}\text { Red } \\
\text { orange }\end{array}$ & $\begin{array}{l}\text { Deep soil, light but } \\
\text { rich; sun }\end{array}$ \\
\hline Speciosum lily & Lilium speciosum & 36 & $\begin{array}{l}\text { IVhite, } \\
\text { pink. }\end{array}$ & $\begin{array}{l}\text { Deep soil, light but } \\
\text { rich; partial } \\
\text { shade }\end{array}$ \\
\hline Henry's lily & Lilium Henryi & 48 & $\begin{array}{l}\text { Red, } \\
\text { yellow }\end{array}$ & $\begin{array}{l}\text { Deep soil, light but } \\
\text { rich; sun }\end{array}$ \\
\hline \multirow[t]{2}{*}{$\begin{array}{l}\text { Golden-banded } \\
\text { lily }\end{array}$} & Lilium auratum & 40 & $\begin{array}{l}\text { White } \\
\text { and gold }\end{array}$ & $\begin{array}{l}\text { Deep soil, light but } \\
\text { rich; sun }\end{array}$ \\
\hline & SEPTEMBER A & AND & OCTOBER & \\
\hline Autumn crocus & $\begin{array}{l}\text { Colchicum } \\
\text { autumnale }\end{array}$ & 5 & $\begin{array}{l}\text { White, } \\
\text { pink, } \\
\text { purple. }\end{array}$ & $\begin{array}{l}\text { Light rich loam, } \\
\text { sun }\end{array}$ \\
\hline Checkered crocus & $\begin{array}{l}\text { Colchicum } \\
\text { Parkinsonı }\end{array}$ & 5 & Purple & $\begin{array}{l}\text { Light, rich loam, } \\
\text { sun }\end{array}$ \\
\hline Yellow starflower & Sternbergia lutea & 5 & Yellow & $\begin{array}{l}\text { Rich, heavy soil, } \\
\text { sun }\end{array}$ \\
\hline
\end{tabular}


PLANTING TABLE OF THE BEST AND EASIEST GROWN

\begin{tabular}{|c|c|c|c|}
\hline Popular Name & Botanical Name & Color & $\begin{array}{l}\text { Height } \\
\text { inches) }\end{array}$ \\
\hline \multirow{2}{*}{ Glory-of-the-snow } & S Chionodoxa Luciliæ & Sky blue & 8 \\
\hline & Chionodoxa Sardensis & Deep blue & 8 \\
\hline Autumn crocus & Colchicum autumnale & $\begin{array}{l}\text { White, pink } \\
\text { purple }\end{array}$ & 5 \\
\hline Checkered crocus & Colchicum Parkinsoni & Purple & 5 \\
\hline \multirow{5}{*}{ Crocus } & Crocus biflorus & Light lilac & 5 \\
\hline & Crocus Imperati & Lilac & 5 \\
\hline & Crocus Mœsiacus & Yellow & 5 \\
\hline & Crocus Susianus & Golden & 5 \\
\hline & Crocus vernus & $\begin{array}{l}\text { White, purple, } \\
\text { lilac }\end{array}$ & 5 \\
\hline Winter aconite & Eranthis hyemalis & Yellow & 6 \\
\hline Crown imperial & Fritillaria Imperialis & Red, yellow & $\therefore 4$ \\
\hline Guinea-hen-flower & Fritillaria Meleagris & Purple, green & 18 \\
\hline Scarlet fritillary & Fritillaria recurva & Scariet & 18 \\
\hline Giant snowdrop & Galanthus Elwesii & White & 8 \\
\hline Snowdrop & Galanthus nivalis & White & 4 \\
\hline Christmas rose & Helleborus niger & White & 6 \\
\hline Hyacinth & Hyacinthus orientalis & Various & 12 \\
\hline Spanish iris & Iris Xiphium & $\begin{array}{l}\text { White, blue } \\
\text { yellow }\end{array}$ & 20 \\
\hline English iris & Iris xiphioides & Purple-white & 14 \\
\hline $\begin{array}{l}\text { Golden-banded } \\
\text { lily }\end{array}$ & Lilium auratum & White and gold & 40 \\
\hline $\begin{array}{l}\text { Purple trumpet } \\
\text { lily }\end{array}$ & Lilium Brownii & Purple-white & 36 \\
\hline
\end{tabular}


HARDY BULBOUS PLANTS FOR AUTUMN PLANTING

\begin{tabular}{|c|c|c|c|}
\hline $\begin{array}{l}\text { Blooming } \\
\text { season }\end{array}$ & $\begin{array}{c}\text { How deep to } \\
\text { Plant } \\
\text { (inches) }\end{array}$ & $\begin{array}{l}\text { How far } \\
\text { apart } \\
\text { (inches) }\end{array}$ & Notes and Cultural Suggestions \\
\hline March & 3 & 3 & \multirow{2}{*}{$\begin{array}{l}\text { Plant in well drained soil - replant } \\
\text { every three or four years }\end{array}$} \\
\hline March & 3 & 3 & \\
\hline September & 3 & 6 & Plant in masses. \\
\hline September & 3 & 6 & Prefers light, rich soil \\
\hline March & 3 & 3 & $\begin{array}{l}\text { There is a white and very early va- } \\
\text { riety }\end{array}$ \\
\hline March & 3 & 3 & Flowers with snowdrops \\
\hline March & 3 & 3 & Good for naturalizing in grass \\
\hline March & 3 & 3 & Very early species, excellent form \\
\hline March & 3 & 3 & $\begin{array}{l}\text { Common crocus - showy and per- } \\
\text { manent }\end{array}$ \\
\hline March & 1 & 4 & Does best in partial shade \\
\hline April & 5 & 8 & Set bulb on side \\
\hline April & 3 & 5 & Several distinct forms are to be had \\
\hline May & 3 & 6 & Distinct from other fritillaries \\
\hline $\begin{array}{l}\text { February } \\
\text { March }\end{array}$ & 2 & 3 & $\begin{array}{l}\text { Later in period of bloom than com- } \\
\text { mon variety }\end{array}$ \\
\hline $\begin{array}{l}\text { February } \\
\text { March }\end{array}$ & 2 & 3 & Earliest spring flowers \\
\hline $\begin{array}{l}\text { December } \\
\text { January }\end{array}$ & 4 & 12 & $\begin{array}{l}\text { Impatient of disturbance when es- } \\
\text { tablished }\end{array}$ \\
\hline April & 5 & 8 & Named varieties are best \\
\hline June & 4 & 4 & Mulch the bed in winter \\
\hline June & 4 & 4 & Same treatment as Spanish \\
\hline August & 8 & 18 & Extremely showy but short-lived. \\
\hline July & 8 & 18 & llent in border. \\
\hline
\end{tabular}


PLANTING TABLE OF THE BEST AND EASIEST GROWN

Popular Name Botanical Name Color $\quad \begin{gathered}\text { Height } \\ \text { (inches) }\end{gathered}$

\begin{tabular}{llll}
\hline Madonna lily & Lilium candidum & White & 30 \\
\hline Canada lily & Lilium Canadense & Golden red & 36 \\
\hline Orange lily & Lilium croceum & Orange red & 36 \\
\hline Erect lily & Lilium elegans & Orange red & $\mathbf{1 8}$
\end{tabular}

\begin{tabular}{llll}
\hline Hanson's lily & Lilium Hansoni & Orange & 30 \\
\hline Henry's lily & Lilium Henryi & Red, yellow & 48 \\
\hline White trumpet lily & Lilium longiflorum & White & 26 \\
\hline Speciosum lily & Lilium speciosum & White, pink & 36
\end{tabular}

\begin{tabular}{|c|c|c|c|}
\hline Turk's cap lily & Lilium superbum & Red, orange & 50 \\
\hline Tiger lily & Lilium tigrinum & $\begin{array}{l}\text { Red, purple } \\
\text { spots }\end{array}$ & 48 \\
\hline Star flower & Milla (Triteleia) uniflora & Blue & 8 \\
\hline Grape hyacinth & Muscari botryoides & White, blue & 6 \\
\hline $\begin{array}{l}\text { Hoon-petticoat } \\
\text { narcissus }\end{array}$ & Narcissus Bulbocodium & Light yellow & 8 \\
\hline Cup narcissus & Narcissus incomparabilis & White, yellow & 15 \\
\hline Jonquil & Narcissus Jonquilla & Yellow & 12 \\
\hline Poet's narcissus & Narcissus poeticus & $\begin{array}{l}\text { White, crim- } \\
\text { son eye }\end{array}$ & 14 \\
\hline Trumpet narcissus & Pseudo-Narcissus & White-yellow & 15 \\
\hline Star-of-Bethlehem & Ornithogalum umbellatum & White & 9 \\
\hline Two-leaved scilla & Scilla bifolia & White, purple & 6 \\
\hline Bell-flowered scilla & Scilla Hispanica & Blue, purple & 10 \\
\hline Siberian scilla & Scilla Sibirica & White, blue & 6 \\
\hline Wake Robin & Trillium grandiflorum & White & 12 \\
\hline Tulip & Tulipa suaveolens, etc. & Various & 24 \\
\hline
\end{tabular}




\section{APPENDIX}

\section{HARDY BULBOUS PLANTS FOR AUTUMN PLANTING}

\begin{tabular}{|c|c|c|c|}
\hline $\begin{array}{l}\text { Blooming } \\
\text { season }\end{array}$ & $\begin{array}{c}\text { How deep to } \\
\text { Plant } \\
\text { (inches) }\end{array}$ & $\begin{array}{l}\text { How far } \\
\text { apart } \\
\text { (inches) }\end{array}$ & Notes and Cultural Suggestions \\
\hline June & 8 & 12 & Plant by September 15 \\
\hline July & 6 & 12 & Effective when massed \\
\hline July & 8 & 18 & Easily grown \\
\hline July & 8 & 12 & $\begin{array}{c}\text { Among the best for garden culti- } \\
\text { vation }\end{array}$ \\
\hline June & 6 & 15 & Most effective in clumps \\
\hline August & 8 & 18 & Splendid, unconventional variety \\
\hline July & 6 & 15 & Pretty in border \\
\hline August & 8 & 18 & $\begin{array}{l}\text { Two varieties - rubrum, pink; album, } \\
\text { white }\end{array}$ \\
\hline August & 6 & 18 & Useful in mixed border \\
\hline August & 8 & 18 & Does well in borders \\
\hline
\end{tabular}

\begin{tabular}{llll}
\hline April-May & 3 & 3 & Plant in sheltered situations \\
\hline April & 3 & 4 & Splendid when naturalized \\
\hline April-May & 4 & 6 & Good when massed
\end{tabular}

\begin{tabular}{llll}
\hline April-May & 5 & 6 & Increases rapidly \\
\hline April & 4 & 6 & Fragrant \\
\hline April-May & 5 & 6 & $\begin{array}{c}\text { Excellent for naturalizing }- \text { fra- } \\
\text { grant }\end{array}$ \\
\hline
\end{tabular}

\begin{tabular}{|c|c|c|c|}
\hline April-May & 5 & 8 & Many forms are grown \\
\hline May & 4 & 6 & Excellent for early summer bloom \\
\hline March-April & 3 & 4 & Very hardy and early \\
\hline May & 3 & 5 & Several varieties, all good \\
\hline March-April & 3 & 4 & $\begin{array}{l}\text { Better when slightly protected- } \\
\text { Later to bloom than S. bifolia }\end{array}$ \\
\hline May & 4 & 6 & One of the best wild flowers \\
\hline April-May & 5 & 6 & $\begin{array}{l}\text { May-flowering are best for plant- } \\
\text { ing except in formal beds }\end{array}$ \\
\hline
\end{tabular}


PLANTING LIST OF THE BEST

\begin{tabular}{|c|c|c|c|}
\hline Popular Name. & Botanical Name & Color & $\begin{array}{l}\text { Height } \\
\text { (inches) }\end{array}$ \\
\hline Ageratum & Ageratum conyzoides & Blue white & 4 to 10 \\
\hline Alyssum, sweet. & Alyssum maritimum & White & 6 \\
\hline Aster, China & Callistephus Chinensis & Various & 18 \\
\hline $\begin{array}{l}\text { Baby's breath, } \\
\text { annual }\end{array}$ & Gypsophila muralis & White & 24 \\
\hline Balloon vine & $\begin{array}{l}\text { Cardiospermum Halica- } \\
\text { cabum }\end{array}$ & White & $10 \mathrm{ft}$. \\
\hline Balsam & Impatiens Balsamina & $\begin{array}{l}\text { White, pink red, } \\
\text { yellow }\end{array}$ & 18 \\
\hline Bartonia & Mentzelia Lindleyi & Yellow & 12 to 30 \\
\hline Candytuft & Iberis amara & Red, white & 6 \\
\hline Castor bean & Ricinus communis & - & 5 to $8 \mathrm{ft}$. \\
\hline Catchfly & $\begin{array}{l}\text { Silene Armeria, S. pen- } \\
\text { dula }\end{array}$ & Red, white & 12 to 18 \\
\hline $\begin{array}{l}\text { Chrysanthemum, } \\
\text { annual }\end{array}$ & $\begin{array}{l}\text { Chrysanthemum corona- } \\
\text { rium }\end{array}$ & White, yellow & 12 to 24 \\
\hline Clarkia & Clarkia elegans & $\begin{array}{l}\text { White, rose, pur- } \\
\text { ple }\end{array}$ & 18 \\
\hline $\begin{array}{l}\text { Cup and saucer } \\
\text { vine }\end{array}$ & Cobœa scandens & Purplish white & $15 \mathrm{ft}$. \\
\hline Cockscomb & Celosia & $\begin{array}{l}\text { Red, white, yellow } \\
\text { purple }\end{array}$ & 6 to 12 \\
\hline Coreopsis & Coreopsis tinctoria & Yellow, brown & 12 \\
\hline Cornflower & Centaurea Cyanus & White, blue, rose & 12 \\
\hline Cosmos & Cosmos bipinnatus & White, pink, red & $21 / 2$ to $6 \mathrm{ft}$. \\
\hline Cypress vine & Ipomœa Quamoclit & Scarlet & $15 \mathrm{ft}$. \\
\hline $\begin{array}{l}\text { Daisy, Swan } \\
\text { River }\end{array}$ & Brachycome iberidifolia & White, blue & 12 to 14 \\
\hline
\end{tabular}

Everlasting Xeranthemum annuum Purple


ANNUALS FOR ALL PURPOSES

\begin{tabular}{|c|c|c|c|c|c|}
\hline $\begin{array}{l}\text { Season of } \\
\text { Early }\end{array}$ & $\begin{array}{l}\text { Bloom } \\
\text { Late }\end{array}$ & $\begin{array}{l}\text { When } t \\
\text { Indoors }\end{array}$ & $\begin{array}{l}\text { to Sow } \\
\text { Outdoors }\end{array}$ & $\begin{array}{l}\text { Depth } \\
\text { to Sow } \\
\text { (Inches) }\end{array}$ & $\begin{array}{l}\text { Distance } \\
\text { apart when } \\
\text { transplanted } \\
\text { or thinned } \\
\text { (inches) }\end{array}$ \\
\hline June & July to Oct. & March & May & $1 / 4$ & 5 \\
\hline July & Aug. to Sept. & March & April & $1 / 4$ & 8 \\
\hline July & Sept. & March & May & $1 / 4$ & 18 \\
\hline June & July to Oct. & March & May & $1 / 8$ & 12 \\
\hline & Aug. & 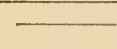 & May & $1 / 4$ & 18 \\
\hline June & July to Sept. & April & May & $1 / 2$ & 18 \\
\hline June & July to Sept. & March & May & $1 / 4$ & 12 \\
\hline & June to Sept. & - & $\left\{\begin{array}{l}\text { April } \\
\text { July }\end{array}\right.$ & $1 / 4$ & 8 \\
\hline \multicolumn{2}{|c|}{$\begin{array}{l}\text { Grown for ornamental } \\
\text { foliage }\end{array}$} & April & May & 2 & 36 \\
\hline June & July and Aug. & April & May & $1 / 8$ & 8 \\
\hline July & Aug. to Oct. & April & May & $1 / 8$ & 18 \\
\hline June & July to Oct. & April & $\left\{\begin{array}{l}\text { May } \\
\text { June }\end{array}\right.$ & $1 / 4$ & 8 \\
\hline July & Aug. to Oct. & March & May & $1 / 2$ & 18 \\
\hline June & July to Oct. & April & May & $1 / 4$ & 8 \\
\hline June & Aug. to Nov. & March & May & $1 / 4$ & 12 \\
\hline$=$ & June & $\longrightarrow$ & April & $1 / 8$ & 8 \\
\hline August & September & April & May & $T / 2$ & 30 \\
\hline June & July & April & May & $1 / 8$ & 10 \\
\hline June & July to Oct. & March & May & $1 / 2$ & 15 \\
\hline 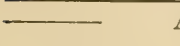 & Aug. and Sept. & 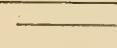 & May & $1 / 4$ & 15 \\
\hline
\end{tabular}




Popular Name - Botanical Name Color $\begin{gathered}\text { Height } \\ \text { (inches) }\end{gathered}$

\begin{tabular}{lllr}
\hline Globe amaranth & Gomphrena globosa & Red & 12 to 18 \\
\hline Godetia & $\begin{array}{c}\text { Enothera amona, } \\
\text { CE. Whitneyi }\end{array}$ & Red, white & 12 to 18 \\
\hline Gourd & Cucurbita & Fruit & $15 \mathrm{ft}$. \\
\hline Hop, Japanese & Humulus Japonicus & Foliage plant & 10 to 20 ft. \\
\hline Hyacinth bean & Dolichos Lablab & White, purple & 10 to 20 ft. \\
\hline Ice plant & $\begin{array}{c}\text { Mesembryanthemum } \\
\text { crystallinum }\end{array}$ & White & trailing vine \\
\hline
\end{tabular}

\begin{tabular}{lllr}
\hline Inmortelles & Helichrysum bracteatum & Yellow, orange & 12 to 24 \\
\hline Larkspur, annual & I)elphinium Ajacis & Red, white, Llue & 15 to 24 \\
\hline Love-lies-bleeding & Amarantus caudatus & Red & 30 \\
\hline Marigold & Tagetes patula, T. erecta & Orange, yellow & 12 to 24
\end{tabular}

\begin{tabular}{|c|c|c|c|}
\hline Mignonette & Reseda odorata & Greenish white & 12 \\
\hline Moon-flower & Ipomœa Bona-nox & White & 15 to $30 \mathrm{ft}$. \\
\hline Morning-glory & Ipomœa purpurea & Various & 1 to $25 \mathrm{ft}$. \\
\hline Musk & Mimulus moschatus & Yellow & 12 to 30 \\
\hline Nasturtium & $\begin{array}{l}\text { Tropxoluin majus } \\
\text { (climbing) and } \mathrm{T} \text {. } \\
\text { minus (dwarf) }\end{array}$ & Various & 1 to $8 \mathrm{ft}$. \\
\hline
\end{tabular}

\begin{tabular}{lllr}
\hline Nemophila & $\begin{array}{l}\text { Nemophila insignis and } \\
\text { N. Menziesii }\end{array}$ & Blue, white & 12 to 30 \\
\hline Palafoxia & Polypteris Hookeriana & Red & 12 to 36 \\
\hline Pansy & Viola tricolor & Various & 6 to 12 \\
\hline Petunia & Petunia hybrida & White, magenta & 12 to 24 \\
\hline Phlox, annual & Phlox Drummondii & Various & 6 to 12 \\
\hline Pink, Chinese & Dianthus Chinensis & White and various & 12
\end{tabular}




\section{ANNUALS FOR ALL PURPOSES}

\begin{tabular}{|c|c|c|c|c|c|}
\hline $\begin{array}{l}\text { Season of } \\
\text { Early }\end{array}$ & $\begin{array}{l}\text { Bloom } \\
\text { Late }\end{array}$ & $\begin{array}{l}\text { When to } \\
\text { Indoors }\end{array}$ & $\begin{array}{l}\text { to Sow t } \\
\text { Outdoors (I }\end{array}$ & $\begin{array}{r}\text { Depth } \\
\text { to Sow } \\
\text { (Inches) }\end{array}$ & $\begin{array}{l}\text { Distance } \\
\text { apart when } \\
\text { transplanted } \\
\text { or thinned } \\
\text { (inches) }\end{array}$ \\
\hline$\longrightarrow$ & Aug. and Sept. & $\longrightarrow$ & May & $1 / 4$ & 15 \\
\hline June & July to Oct. & $\begin{array}{c}\text { March } \\
\text { April }\end{array}$ & May & $1 / 8$ & 18 \\
\hline-- & $\longrightarrow$ & - & May & 1 & 24 \\
\hline - & $\longrightarrow$ & April & May & $1 / 2$ & 30 \\
\hline-- & July to Oct. & - & May & 2 & 18 \\
\hline July & Aug. and Sept. & April & May & $1 / 8$ & 12 \\
\hline$\longrightarrow$ & August & - & May & $1 / 4$ & 12 \\
\hline June & July to Sept. & April & May & $1 / 4$ & 10 \\
\hline June & July & April & May & $1 / 4$ & 18 \\
\hline June & July to Oct. & $\begin{array}{l}\text { February } \\
\text { March }\end{array}$ & $\begin{array}{l}\text { April } \\
\text { May }\end{array}$ & $1 / 4$ & 12 \\
\hline May and June & July to Oct. & March & $\begin{array}{l}\text { April } \\
\text { May }\end{array}$ & $1 / 4$ & 10 \\
\hline July & Aug. and Sept. & March & May & $1 / 2$ & 24 \\
\hline June & July to Oct. & $\begin{array}{l}\text { March and } \\
\text { April }\end{array}$ & May & $1 / 4$ & 18 \\
\hline June & July and Aug. & April & May & $1 / 8$ & 6 \\
\hline June & July to Oct. & $\underset{\text { April }}{\text { March and }}$ & May & 1 & 10 \\
\hline June & July to Oct. & March & $\begin{array}{l}\text { April and } \\
\text { May }\end{array}$ & id & 6 \\
\hline ב & July to Oct. & $\longrightarrow$ & May & $1 / 4$ & 18 \\
\hline May and June & Sept. to Oct. & $\begin{array}{c}\text { Jan. and } \\
\text { Feb. }\end{array}$ & $\begin{array}{l}\text { June to } \\
\text { August }\end{array}$ & $1 / 8$ & 6 \\
\hline May & July to Oct. & April & May & $\begin{array}{l}\text { Sow on } \\
\text { Surface }\end{array}$ & 12 \\
\hline June & July to Oct. & Feb. & $\begin{array}{l}\text { April and } \\
\text { May }\end{array}$ & ad $\quad \mathrm{T} / 4$ & 12 \\
\hline May & July to Sept. & $\begin{array}{l}\text { Feb. and } \\
\text { March }\end{array}$ & $\begin{array}{l}\text { April and } \\
\text { May }\end{array}$ & ad $\frac{1}{16}$ & 6 \\
\hline
\end{tabular}




Popular Name Botanical Name Color $\quad$ Height
(inches)

\begin{tabular}{llll}
\hline Poppy & Papaver & Various & 6 to 30
\end{tabular}

\begin{tabular}{llll}
\hline Portulaca & Portulaca grandiflora & White, red & 6 to 12
\end{tabular}

Pot Marigold Calendula officinalis Orange, yellow 12 to 24

\begin{tabular}{|c|c|c|c|}
\hline $\begin{array}{l}\text { Rhodanthe } \\
\text { Rose moss }\end{array}$ & $\begin{array}{l}\text { Helipterum Manglesii } \\
\text { Lu Portulaca }\end{array}$ & Purple & 18 to 24 \\
\hline Salpiglossis & Salpiglossis sinuata & $\begin{array}{l}\text { White, yellow, } \\
\text { red }\end{array}$ & 20 \\
\hline Stock, ten-weeks & $\begin{array}{l}\text { Matthiola incana, var. } \\
\text { annua. }\end{array}$ & Various & 18 \\
\hline Sweet pea & Lathyrus odoratus & Various & 4 to $8 \mathrm{ft}$. \\
\hline Sweet Sultan & Centaurea moschata & $\begin{array}{l}\text { White, yellow, } \\
\text { purple }\end{array}$ & 24 \\
\hline Tarweed & Madia elegans & Yellow & 12 to 24 \\
\hline Wish-bone flower & Torenia Fournieri & Yellow & 12 to 20 \\
\hline Zinnia & Zinnia elegans & Various & 12 to 36 \\
\hline
\end{tabular}




\section{APPENDIX}

\section{ANNUALS FOR ALL IURPOSES}

\begin{tabular}{|c|c|c|c|c|c|}
\hline $\begin{array}{l}\text { Season } \\
\text { Early }\end{array}$ & $\begin{array}{l}\text { of liloom } \\
\text { Late }\end{array}$ & $\begin{array}{l}\text { When to } \\
\text { Indoors }\end{array}$ & $\begin{array}{l}\text { Sow } \\
\text { Outdoors }\end{array}$ & $\begin{array}{l}\text { Depth } \\
\text { to Sow tra } \\
\text { (inches) }\end{array}$ & $\begin{array}{l}\text { Distance } \\
\text { apart when } \\
\text { transplanted } \\
\text { or thinned } \\
\text { (Inches) }\end{array}$ \\
\hline$\longrightarrow$ & June to Aug. & $-\cdots$ & $\begin{array}{l}\text { March, } \\
\text { April } \\
\text { and May }\end{array}$ & $1 / 8$ & 12 \\
\hline June & July to Oct. & $\begin{array}{l}\text { March and } \\
\text { April }\end{array}$ & May & $\begin{array}{l}\text { Sow on } \\
\text { Surface }\end{array}$ & $\begin{array}{l}\mathrm{n} \\
\mathrm{e}\end{array}$ \\
\hline June & July to Oct. & $\begin{array}{l}\text { March and } \\
\text { April }\end{array}$ & May & $1 / 8$ & 12 \\
\hline$\longrightarrow$ & Aug. and Sept. & - - & May & $3 / 4$ & 18 \\
\hline June & July to Oct. & April & May & $1 / 8$ & 6 \\
\hline Junc & July and Aug. & March & May & $1 / 4$ & 12 \\
\hline - & July to Oct. & $\longrightarrow$ & $\begin{array}{c}\text { March to } \\
\text { June }\end{array}$ & 3 to $t$ & 4 \\
\hline June & July and Aug. & $\begin{array}{l}\text { March and } \\
\text { April }\end{array}$ & May & $1 / 2$ & 12 \\
\hline$\overline{-}-$ & July to Oct. & $\longrightarrow$ & May & $1 / 4$ & 12 \\
\hline-1 & July to Oct. & $\begin{array}{l}\text { March and } \\
\text { April }\end{array}$ & ---- & $1 / 3$ & 12 \\
\hline- - & June to Oct. & $\longrightarrow$ & May & $3 / 4$ & 12 \\
\hline
\end{tabular}


[The designs presented here are intended to assist the beginner. While their real value lies in their suggestions, all are practical and, if conditions admit of their use, can be followed in planting city yards of similar shape and size. Only those plants that are hasdiest and easiest raised are advised.]

\section{DIAGRAM ILLUSTRATING BORDER-PLANTING}

Mixed Border of Shrubs and Hardy Herbaceous Plants, Arranged According to Height, Color of Bloom and Season of Flowering:-

\begin{tabular}{|c|c|c|}
\hline $\begin{array}{l}\text { No. on } \\
\text { diagram }\end{array}$ & $\begin{array}{l}\text { Quantity } \\
\text { required }\end{array}$ & Name \\
\hline 1 & 18 & Aster alpinus \\
\hline 2 & 20 & Campanula Carpatica \\
\hline 3 & 20 & Alyssum saxatile, var. compactum, \\
\hline 4 & 10 & Achillea Ptarmica, var. "The Pearl" \\
\hline 5 & 10 & Campanula latifolia, var. macrantha \\
\hline 6 & 6 & Spirca Van Houttei \\
\hline 7 & 4 & Forsythia suspensa, var. Fortunei \\
\hline 8 & 6 & Hydrangea paniculata, var. grandiflora \\
\hline 9 & 2 & Syringa vulgaris (lilac) \\
\hline 10 & 5 & Diervilla hybrida, var. Eva Rathke \\
\hline 11 & 4 & Yucca filamentosa \\
\hline 12 & 10 & Iris lavigata (Kampferi) \\
\hline 13 & 10 & Iris Germanica \\
\hline 14 & 15 & Hypericum Moserianum \\
\hline 15 & 20 & Statice latifolia \\
\hline 16 & 12 & Panies \\
\hline $\begin{array}{l}17 \\
18\end{array}$ & 20 & Phlox paniculata \\
\hline 18 & $\begin{array}{l}12 \\
24\end{array}$ & $\begin{array}{l}\text { Erigeron speciosus } \\
\text { Platycodon grandiflorum }\end{array}$ \\
\hline 20 & 12 & Aruncus (Spiraa) astiboides \\
\hline 21 & 12 & Spiraa Aruncus (Aruncus sylvester) \\
\hline $\begin{array}{ll}22 \\
23\end{array}$ & 10 & Althea rosea \\
\hline 24 & $\begin{array}{r}18 \\
5\end{array}$ & $\begin{array}{l}\text { Boltona latisquama } \\
\text { Bocconia cordata }\end{array}$ \\
\hline 25 & 6 & Delphinium hybridum \\
\hline
\end{tabular}




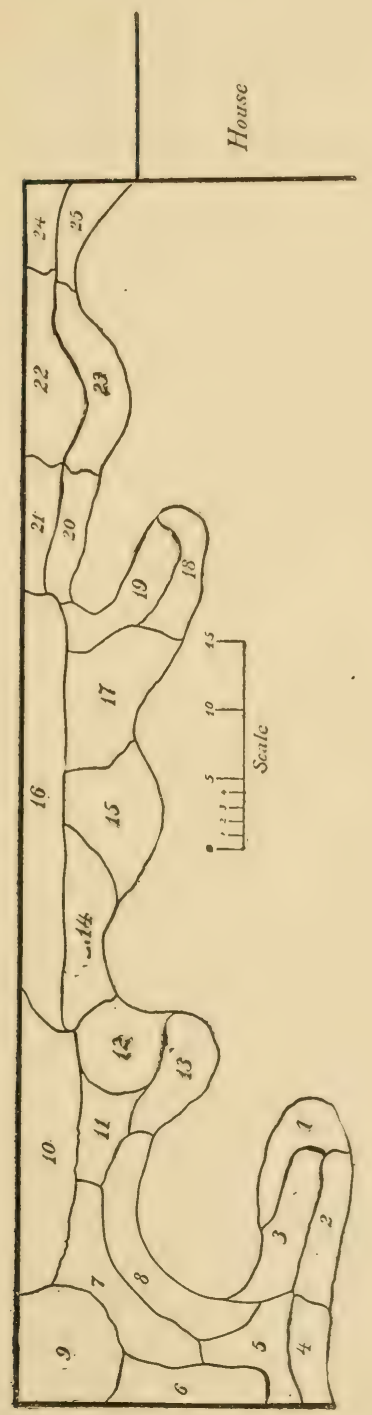




\section{BORDER OF PERENNIALS}

Straight Border of the Best and Hardiest Herbaccous Perennials, Arranged to Insure Succession of Bloom:-

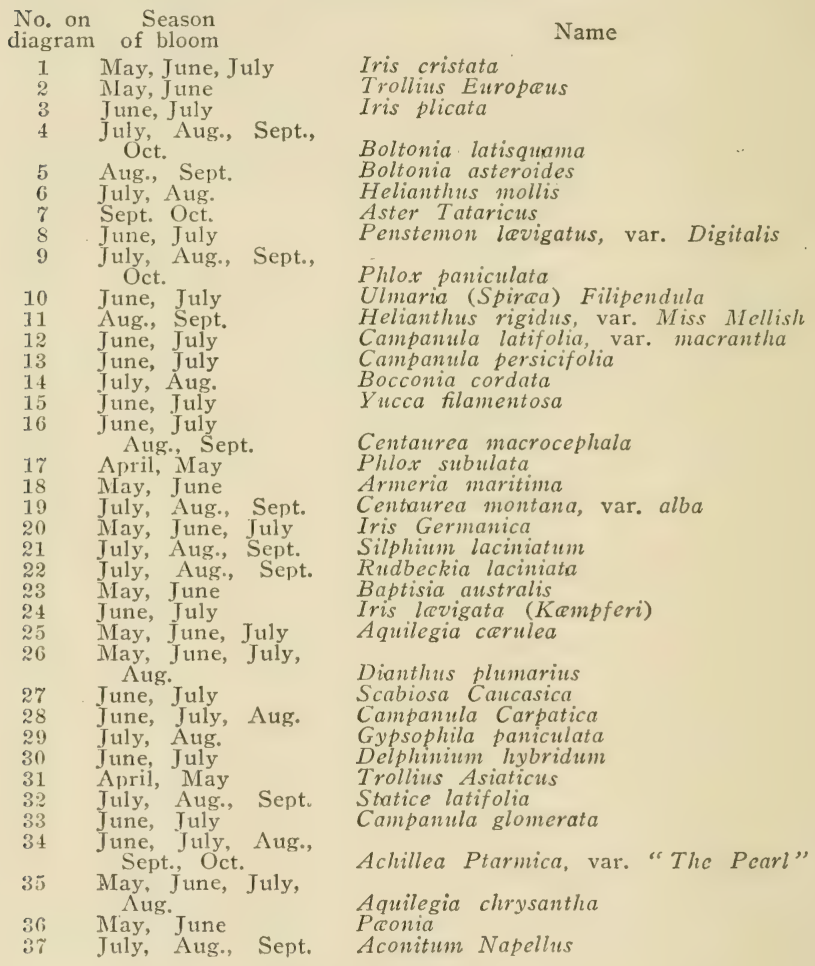




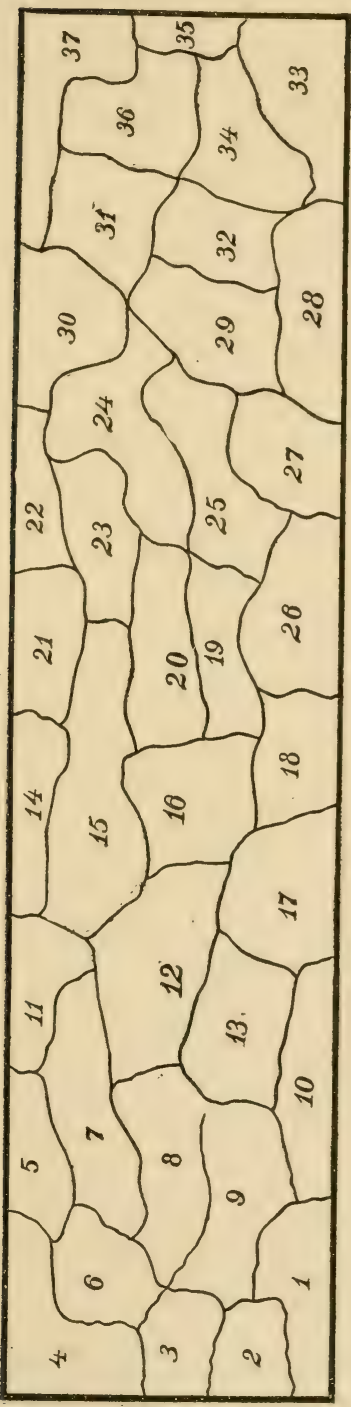




\section{DESIGN FOR CITY YARD FRONTING EAST}

\begin{tabular}{|c|c|c|}
\hline $\begin{array}{l}\text { No. on } \\
\text { diagram }\end{array}$ & $\begin{array}{l}\text { Quantity } \\
\text { required }\end{array}$ & Name \\
\hline 1 & 2 & Picen pungens, var. glauca \\
\hline 2 & 2 & Clcmatis Jackmani \\
\hline 3 & $\stackrel{2}{2}$ & Kalmia latifolia \\
\hline 4 & 501 & Funka subcordata, var. grandiflora \\
\hline 5 & 2 & Lonicera Halliana \\
\hline G & 2 & Wistaria Chinensis \\
\hline 7 & 3.5 & Alyssum saxatile, var. compactum \\
\hline 8 & 8 & Pconia \\
\hline 9 & 2 & Spiraa Van Houttei \\
\hline 10 & 1 & Syringa vulgaris (lilac) \\
\hline 1 & 1 & Spiraa Bumalda, var. Anthony Waterer \\
\hline 12 & 3 & Berberis (Mahonia) \\
\hline 13 & 2 & Hydrangea paniculata, var. grandiflora \\
\hline 14 & 1 & Abies concolor \\
\hline 15 & 300 & Ligustrum ovalifolium, or var. Regelianum \\
\hline 16 & 15 & Myosotis palustris \\
\hline 17 & 20 & Phlox subulata \\
\hline 18 & 12 & Phlox paniculata \\
\hline 19 & 30 & Iris pumila \\
\hline 20 & 25 & Dianthus barbatus \\
\hline 21 & 8 & Iris Germanica \\
\hline 22 & 6 & Hardy ferns \\
\hline 23 & 35 & Dianthus plumarius \\
\hline 24 & 15 & Lychnis Viscaria, var. splendens \\
\hline 25 & 10 & Thalictrum aquilegifolium \\
\hline 26 & 15 & Delphinium formosum \\
\hline 27 & 5 & Iris lavigata (Kampferi) \\
\hline 28 & 10 & Gypsophila paniculata \\
\hline 29 & 35 & Armeria maritima \\
\hline 30 & 5 & Physostegia Virginiana \\
\hline 31 & 15 & Platycodon gnandiflorum \\
\hline 32 & 30 & Stokesia cyanea \\
\hline 33 & 10 & Centaurea montana \\
\hline $\begin{array}{l}34 \\
35\end{array}$ & $\begin{array}{r}8 \\
10\end{array}$ & $\begin{array}{l}\text { Hardy ferns } \\
\text { Aquilegia corulea }\end{array}$ \\
\hline $\begin{array}{l}35 \\
36\end{array}$ & $\begin{array}{l}10 \\
30\end{array}$ & $\begin{array}{l}\text { Aquilegia carulea } \\
\text { Campanula Carpatica }\end{array}$ \\
\hline 37 & 20 & Campanula persicifolia \\
\hline 38 & 20 & Hardy ferns \\
\hline
\end{tabular}




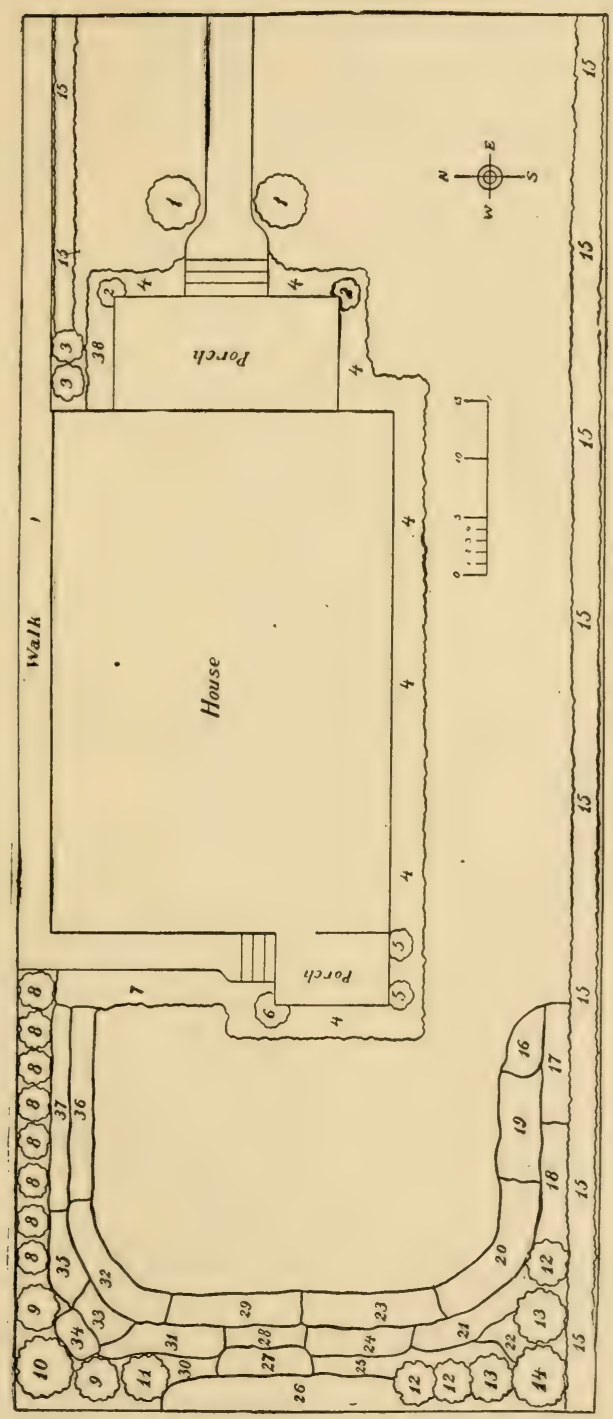




\section{DESIGN FOR CITY CORNER YARD}

$\begin{array}{cc}\text { No. on } & \begin{array}{c}\text { Number } \\ \text { diagram }\end{array} \\ \text { required } \\ \mathbf{1} & 75 \\ 2 & 1 \\ 3 & 2 \\ 4 & 4 \\ 5 & 50 \\ 6 & 2 \\ 7 & 12 \\ 8 & 24 \\ 9 & 12 \\ 10 & 18 \\ 11 & 14 \\ 12 & 20 \\ 13 & 12 \\ 14 & 12 \\ 15 & 12 \\ 16 & 12 \\ 17 & 12 \\ 18 & 24 \\ 19 & 15 \\ 20 & 6 \\ 21 & 100 \\ 22 & 9 \\ & \\ 23 & 1 \\ 24 & 2 \\ 25 & 3 \\ 26 & 1 \\ 27 & \cdots\end{array}$

Name

Coreopsis lanceolata

Wistaria Chinensis

Lonicera Halliana

Rose, Crimson Rambler

Hemerocallis fulva

Picea pungens, var. glauca

Phlox paniculata

Aconitum autumnale

Iris lavigata (Kampferi)

Delphinium hybridum

German iris

Althaa rosea, single

Peonia

Bocconia cordata

Trollius Europaus

Boltonia asteroides

Campanula latifolia, var. macrantha

Rudbeckia, Golden Glow

Statice latifolia

Yucca filamentosa

Berberis Thunbergii

Maples

(Thin when crowding begins)

Syringa vulgaris (lilac)

Spirca Van Houttei

Hydrangea paniculata, var. grandiflora

Forsythia suspensa, var. Fortunei

Hardy ferns

(Space is left at the point A to allow entrance to the lawn.) 


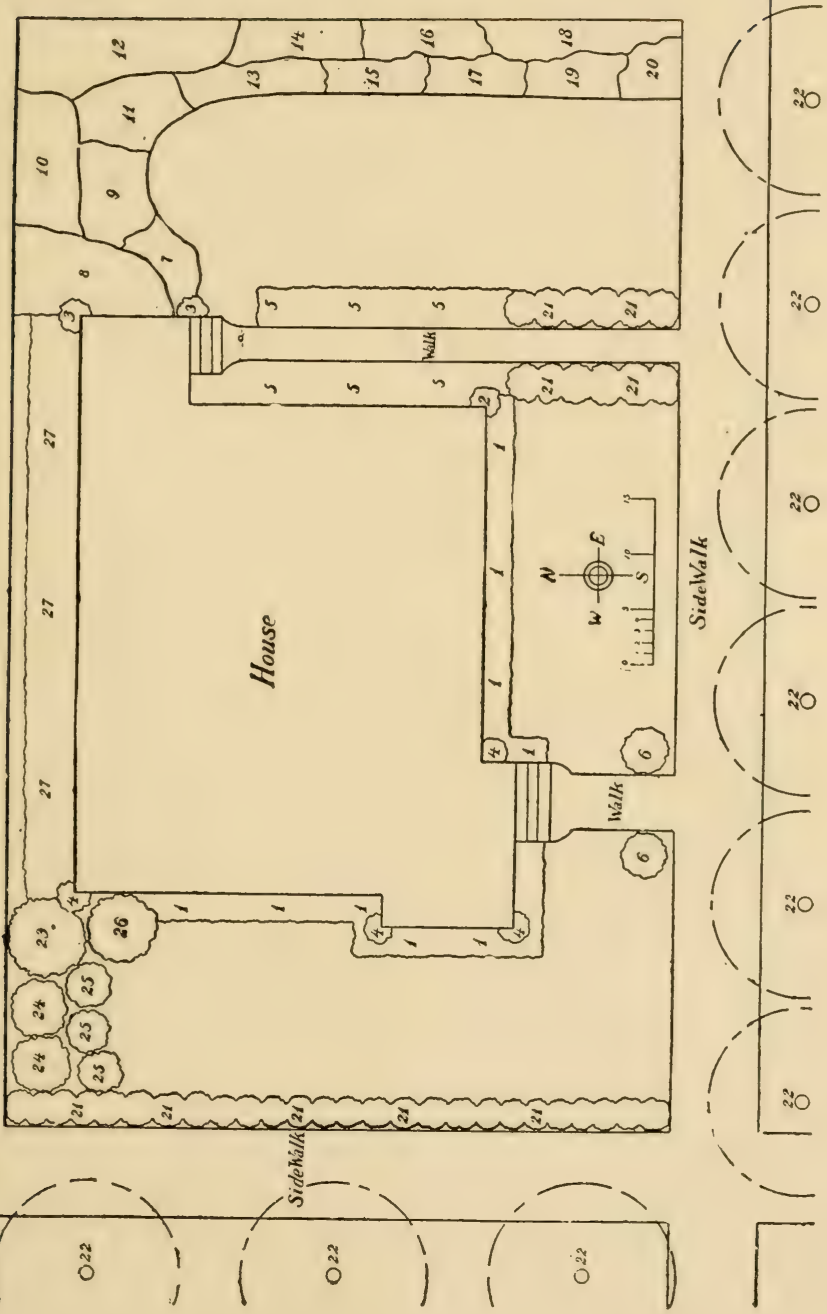




\section{DESIGN FOR CITY YARD FRONTING IVEST}

\begin{tabular}{|c|c|c|}
\hline $\begin{array}{l}\text { No. on } \\
\text { diagram }\end{array}$ & $\begin{array}{l}\text { Quantity } \\
\text { required }\end{array}$ & Name of plant \\
\hline 1 & 3 & Picea pungens, var. glauca \\
\hline 2 & 2 & $\begin{array}{l}\text { Pseudotsuga Douglasii } \\
\text { Spirca Van Houttei }\end{array}$ \\
\hline 3 & 1 & $\begin{array}{l}\text { Spiraa Van Houttei } \\
\text { Kalmia latifolia }\end{array}$ \\
\hline 4 & 2 & $\begin{array}{l}\text { Kalmia latifolia } \\
\text { Berberis (Mahonia) Aquifolium }\end{array}$ \\
\hline 5 & $\begin{array}{l}3 \\
2\end{array}$ & $\begin{array}{l}\text { Berberis (Mahonia) Aquifolium } \\
\text { Hydrangea paniculata, var. grandiflora }\end{array}$ \\
\hline $\begin{array}{l}6 \\
7\end{array}$ & $7 \tilde{2}$ & $\begin{array}{l}\text { Hydrangea paniculata, var, granditiora } \\
\text { Iris Germanica }\end{array}$ \\
\hline 8 & 3 & Clematis paniculata \\
\hline 9 & 2 & Lonicera Halliana \\
\hline 10 & 10 & Hardy ferns \\
\hline 11 & 30 & Armeria maritima \\
\hline 12 & 20 & Ulmaria (Spircea) Filipendula \\
\hline 13 & 15 & Alyssum saxatile \\
\hline 14 & 20 & Sedum spectabile \\
\hline 15 & 15 & Thalictrum aquilegifolium \\
\hline 16 & 20 & Dianthus barbatus \\
\hline 17 & 8 & Funkia subcordata, var. grandiflora \\
\hline 18 & 10 & Helenium autumnale, var. superbum \\
\hline 19 & 15 & Statice latifolia \\
\hline 20 & $\begin{array}{l}25 \\
20\end{array}$ & Achillea Ptarmica, var. "The Pearl" \\
\hline $\begin{array}{l}21 \\
22\end{array}$ & $\begin{array}{l}20 \\
15\end{array}$ & $\begin{array}{l}\text { Althea rosea } \\
\text { Bocconia cordata }\end{array}$ \\
\hline 23 & 10 & Delphinium formosum \\
\hline 24 & 20 & Iris lavigata (Kampferi) \\
\hline 25 & 15 & Physostegia Virginiana \\
\hline 26 & 6 & Pronia \\
\hline 27 & 12 & Phlox paniculata \\
\hline $\begin{array}{c}28 \\
28\end{array}$ & $\begin{array}{l}15 \\
18\end{array}$ & $\begin{array}{l}\text { Hibiscus Moscheutos, var. Crimson Eve } \\
\text { Campanula persicifolia }\end{array}$ \\
\hline 30 & 18 & Veronica longifolia, var. subsessilis \\
\hline 51 & 75 & Berberis Thunbergii \\
\hline 32 & 5 & Azalea amณna \\
\hline 33 & 10) & Funkia carulea \\
\hline 34 & 15 & $\begin{array}{l}\text { Iris pumila } \\
\text { Hardy ferns }\end{array}$ \\
\hline 33 & is & Haray terms \\
\hline
\end{tabular}




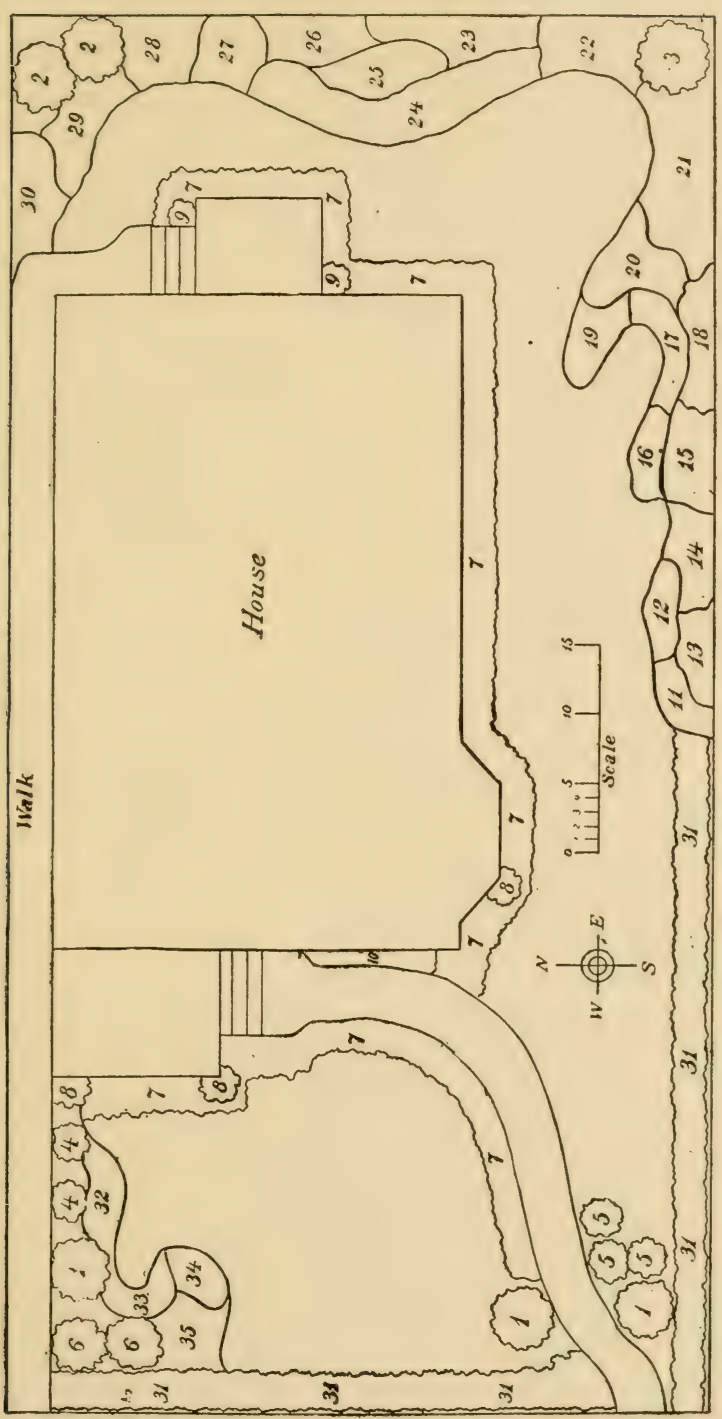




\section{DESIGN COMBINING ORNAMENT AND UTILITY}

$\begin{array}{cc}\begin{array}{c}\text { No. on } \\ \text { diagram } \\ 1\end{array} & \begin{array}{c}\text { Quantity } \\ \text { required } \\ 200 \\ 2\end{array} \\ 3 & \left\{\begin{array}{c}30 \\ \\ 4\end{array}\right. \\ 5 & 40 \\ 6 & 6 \\ 7 & 3 \\ 8 & \cdots \\ 9 & 2\end{array}$

Name

Ligustrum ovalifolium Paonia

Phlox paniculata

Rose; Dorothy Perkins

Clematis paniculata

Lonicena, var. Halliana

Grape

Currants, blackberries or raspberries Bed of annuals

Dwarf fruit trees 


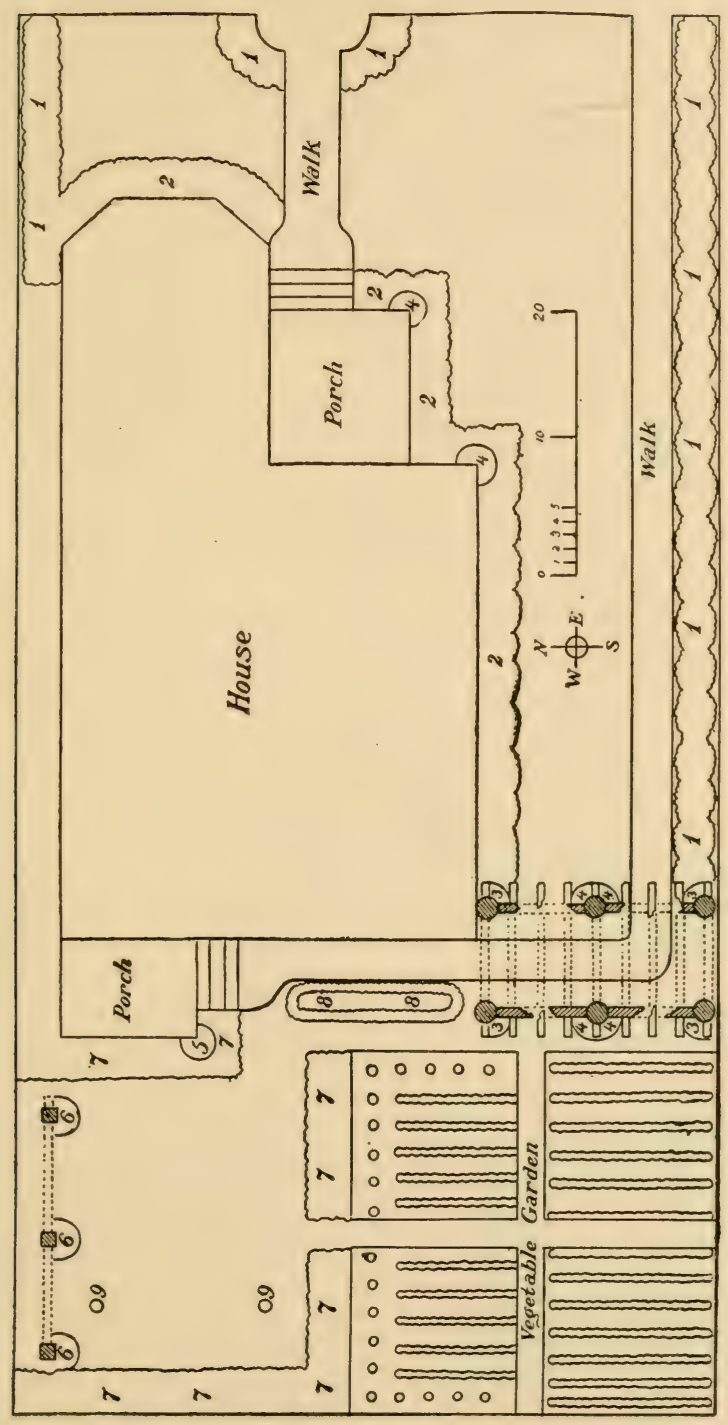



INDEX 



\section{INDEX}

Abutilon, 133, 351

Acer platanoides, 289

saccharinum, 289

saccharum, 289

Achillea, illus. 139

Ptarmica, var. "The

Peari," 162

Aconitum autumnale, 166

Fischeri, 164

Napellus, illus. 161

Actinidia arguta, 95

Adiantum cuneatum, 356

Adonis vernalis, 159

Esculus Hippocastanum, 289

Agapanthus, 235

Ailanthus glandulosa, 289

Akebia quinata, 95

Alstrœmeria, 235

Althrea rosea, 162

Althea, shrubby, 264

Alyssum saxatile, 159

(see Sweet alyssum)

Amelanchier, 264

Ampelopsis, illus. 89

quinquefolia, 87

Veitchi, 94

Andromedia floribunda, 256, 263

Anemone Japonica, 166

Pennsylvanica, 169

Annuals, 99

Beds for, 108

Cultivation indoors, 105

General classification of, 100

Half-hardy, 101

Hardy, 101, 114
Location of beds for, 114

Planting indoors, 102

Planting outdoors, 113, 115

Selection of varieties of, 119

Soil for, 110

Sowing in flats, 103

Support for, 116

Tender, 101

Transplanting, 105

Watering, 117

Weeding, 116

Anthemis tinctoria, illus. 152, 162

Antirrhinum, illus. 105, 133

Apios tuberosa, 239

Aquilegia, illus. $139,159,160$

carulea, 151

Canadensis, 159

Arabis albida, 159

Ardisia, 351

A ristolochia macrophylla, 88

Armeria maritima, 160

A runcus astilboides, illus. 155

Asclepias tuberosa, 164

Ash, 289

Ashes, wood, 58

Asparagus, 133, 351

Asplenium, 356

Aster Amellus, 164

China, illus. 105, 120

Nover-Angliae, 164

Stoke's, illus. 147

(see Stokesia)

Tataricus, 166

Astilbe Japonica, 160

Aubrietia deltoidea, 159 
Aucuba, 351

Auracaria, 351

Azalea, illus. 258; 256, 264, 350

Indica, illus. 333

Balloon flower, illus. 148

Balsam, 120 (see Platycodon)

Baptisia australis, 160

Barberry (see Berberis)

Bee Balm, 148

Beech, 289

Begonia, 133, 35̃1, 352 Rex, illus. 336

Tuberous, illus. 178; 133, 235,236

Belemcanda Chinensis, 162

Bellflower, 151

Bellis perennis, 159

Berberis, 263, 265

Aquifolium, 256, 263

vulgaris, 264

Bermuda grass, 69

Bessera, 235

Biennials, 99

Bitter sweet, False, 95

Blue-grass, Kentucky, 53-55

Bocconia cordata, 164

Boltonia asteroides, illus. 159,164

latisquama, 164

Bone meal, 58

Boston ivy, 194

Bouvardia, 351

Boxes, porch, 120

window, 120

Bridal wreath, illus. 241

Browallia, 351

Buckthorn, 265

Bulbocodium, 188

Bulbous plants, 170

(see Bulbs)

Bulbs, 170

Arrangement of, 188, 190

Classification of, 171
Cultivation of, 179

Depth to plant, 214

Dividing, 184

Hardy, 173, 186, 194

In beds, 189

In borders, 180

Indoors, 339, 346

In lawn, 187

Lifting, 184

Planting, 178, 182, 190

Preparation of beds for, 176

Spring flowering, 209

Succession of bloom of, 175

Tender, 175, 235

Value of, 173

Winter protection of, 183

Buttonbush, 264

Buttonwood, 289

Caladium, 133, 235

Calendula, 114, 120

officinalis, illus. 116

Calimeris incisa, 160, 162

Caliopsis, 114, 120

Calla, 235

Callirhoe involucrata, 160

Calycanthus floridus, 263

Camelia, 351

Campanula alliariaefolia, 162

Carpatica, 160

glomerata, 162

persicifolia, 160

pyramidalis, 151, 164

Trachelium, 162

Canada lily, illus. 185

Candytuft, 120

Canna, illus. 176 and 181; 235

(see Richardia)

Carnation, 351

Catchfly, illus. 137

Ceanothus Americanus, 264

Celastrus scandens, 95

Cephalanthus occidentalis, 264 
Ceratostigma plumbaginoides, 164

Chelone Lyoni, 164 obliqua, 164

Chestnut, horse, 289

China aster, illus. 105; 120

Chinese sacred lily, 348

Chionodoxa, 188

Depth to plant, 214

gigantea, 212

grandiflora, 212

sardensis, 212

Chrysanthemum, 164, 166, 350 frutescens, illus. 330

Leucanthemum, 162 maximum, 162

Chrysogonum Virginianum, 160

Cimicifuga racemosa, 162

Cineraria, 351

Cinnamon vine, 95, 238

Cinquefoil, 263

Clarkia, 120

Clay (see Soil)

Clematis, 91

Davidiana, 164

Diseases of, 92

Flammula, 92

Henryi, 94

Jackmani, illus. 84; 92

paniculata, 92

recta, 160

Soil for, 91

Clethra alnifolia, 263, 264

Climbers (see Vines)

For indoor gardens, 350 , 351

Climbing fern, 350,367

Climbing roses, 90

(see Roses)

Cobœa scandens, 351

Cockscomb, 120

Coleus, 133

Color of flowers, 40

Columbine, illus. $139 ; 151$

(see Aquilegia)
Conoclinium. coclestinum, 164

Convallaria majalis, 159

Cooperia, 235

Coreopsis, 120 lanceolata, 160

Corm (see Bulbs)

Cornelian cherry, 265

Cornflower, 114

Cornus, 263, 264

Coronilla varia, 160

Corylus, 264

Crab-grass, 68

Crimson Rambler, 90

Crocus, 188, 212

Depth to plant, 214

Croton, 133

Crytonium, 356

Cupheas, 35̃

Currant, wild, 263

Cyanea śtokesia, illus. $1+7$

Cyeas revoluta, 351

C'yclamen, 35̃

Cydonia Japonica, 263, 264

Daffodil (see Varcissus)

Dahlia, illus. $176 ; 235,236$ Single, illus. 189

Dandelions in lawn, 66

Daphne, 264

Day lily, illus. 166 (see Hemerocallis)

Delphinium formosum, 160 grandiflorum, 162 hybridum, illus. 150

Deutzia, 253, 264 gracilis, 263 scabra, 263

Dianthus barbatus, illus. 154; 160 plumarius, 160

Dicentra eximia. 160 spectabile, 159

Dictmanus albus. 160

Diervilla, 264

Digitalis ambigun, 162 monstrosa, illus. 161 
purpurea, 160

Dioscorea divaricata, 95

Diseases, 309, 323

Catalogue of, 324

Remedies for, 324,327

Dogwood, 263

Doronicum plantigineum, 159

Dracrena, 351

Dragon-head, False, illus. 154

Drainage, 303

Dutchman's pipe, 88

Easter lily, 346

E'chinacea purpurea, 162

EZleagnus longipes, 265

Elder, 264

Elm, 289

English ivy, 350

Eranthis hyemalis, 213

Depth to plant, 214

Erigeron speciosus, 160

Eryngium amethystinum, 162

Erythronium, illus. 196

Euonymus, 265, 351

Japonicus, 257

radicans, 95

Eupatorium ageratoides, 164

Euphorbia corolotta, 162

Factory grounds planted, 18

Fagus ferruginea, 289

False bitter sweet, 95

False dragon-head, illus. 154

Farfugium, 351

Ferns, 364

Best varieties, 367

Boston, 356

Christmas, 367

Cinnamon, 367

Clayton's, 367

Climbing, 350, 367

Culture of, 356

Ebony, 356, 367

Evergreen, 367

For indoor garden, 351, 356

For porch boxes, 133

Goldie's, 367
Gossamer, 367

Hardy, 364

Holly, 356

Kidney, 356

Lace, illus. $354 ; 367$

Lady, 367

Maidenhair, illus. 355 ; 356 , 367

New York, 367

Ostrich, illus. $366 ; 367$

Pests of, 356

Pierson, 356

Royal, 367

Scott, 356

Sensitive, 367

Shield, 367

Situation for, 364

Soil for, 366

Sivord, 356

Walking, 367

Fertilizers, 293

Animal manures, 303

Bone meal, 58, 307

For lawns, 46, 56

For porch boxes, 131

For potted plants, 337

For vines, 84

Lime, 59

Liquid, 132, 305, 307

Muriate of potash, 307

Nitrate of soda, 58, 307

Soot, 305

Wood ashes, 58, 307

Festuca glauca, 351

Ficus elastica, 351

Filbert, 264

Flats, 103

Fleur-de-lis (see Iris)

Formal city garden, illus. 3

Forsythia, 253

suspensa, 264

Foxglove, illus. 161 ( see Digitalis)

Fraxinus Americana, 289

Freesia, illus. 347

In pots, 347 
Fuchsia, 133, 351

Fungicides, 327

Fungus (see Diseases)

Funkia, illus. 166

Fortunei, illus. 306, 162

lancifolia, 162

ovata, 162

subcordata, 164

Gaillardia aristata, 160, 164

Galanthus, 210

Depth to plant, 214

Gardening, 4

Geranium, illus. 350 ; 133, 351

Geranium sanguineum, 160

German iris, 160, 161

Geum coccineum, 160 montanum, 160

Ginkgo biloba, 289

Gladioluts, illus. $206 ; 235,236$

Glechoma, 133

Globe-flower, illus. 141 (see Trollius)

Glory-of-the-snow (see Chionodoxa)

Goldenbell, 264

Golden glow, 158 (see Rudbeckia)

Grass (see Lawns)

For clay soil, 55

For lawns, 55

For sandy soil, 55

For shaded spots, 55

For terraces, 55

Greviliea robusta, 351

Gypsophila paniculata, 162

Hamamelis, 254

Height of plants, 40

Helenium, 164 Hoopesii, 160

Helianthus, 164

Heliopsis lavis, 162

Heliotrope, 133, 351

Helloborus niger, 159

orientalis, 159
Hemerocallis, illus. 166, 162 Dumortierii, 160

Hepatica triloba, 159

Heuchera sanguinea, 162

Hibiscus, 351

Moscheutus, illus. 143, 164

Syriacus, 264

Honeysuckle, illus. 93 ( see Lonicera)

Bush, 264

Humus (see Soil)

Hyacinth, illus. 201; 194

Best varieties of, 202

For pots, 343

In water, 344

Named varieties of, 200

Planting of, 200

Preparation of beds for, 201

Roman, 344

Winter protection of, 200

Hyacinthus candicans, 237

Hydrangea, illus. 244; 254

hortensis, illus. 353

paniculata, 264

Hypericum aureum, 263

prolificum, 264

Iberis sempervirens, 160

Indoor gardens

(see Window gardens)

Insecticides, 313, 321

Insects, 309

Chewing, 310

Destruction of, 310

Lists of, 313

Sucking, 310

Inula ensifolia, 162

Iris, 219

Bulbous, 224

cristata, 232

Division of, 234

Dwarf varieties of, 231

English (see I. xiphioides)

Florentina, 233

Germanica, illus, 230; 160. 161,230 
Japanese (see I. lavigata) Kampferi (see I. lavigata) lavigata, illus. $221 ; 161$, 227

Oncocyclus, 220

pallida, 233

Planting, 234

Pseudacorus, 161, 233

pumila, 231

reticuiata, 226

Rhizomatous, 227

Sibirica, illus. 230 and 234 ; 161,233

Spanish (see I. Xiphium)

Susiana, 220

Varieties of, 219, 223

verna, 159, 232

xiphioides, illus. $234 ; 224$

Xiphium, illus. 225 ; 224

Ivy, Boston, 94

English, 350

Kenilworth, 351

Parlor, 350

Japanese Iris (see I. lavigata)

Japanese quince, 263, 264

Japanese rose, 263

Juneberry, 264

Kalmia latifolia, illus. 255; $256,263,264$.

Kenilworth ivy, 35̃

Kentucky blue-grass, 53

Kerria Japonica, 263

Kerria, white, 264

Kniphofia aloides, illus. 185

Kudzu vine, 239

Lantana, weeping, 133

Larkspur, illus. 150

(see Delphinium)

Lavendula vera, 163

Lawns, 44

Autumn spading, 48

Bone meal for, 59
Fertilizing, 45, 48, 56

Insects attacking, 71

Lime for, 59

Moles in, 71

Mowing, 60

Nitrate of soda for, 58

Preparation of soil for, 4448

Renovating old, 73

Rolling, 59

Seed for, 52-55

Sowing of, 52

Top-dressing of, 58

Turf for, 49

Watering, 63

Weeds in, 66

Wood ashes on, 58

Leaf mold (see Soil)

Leucojum vernum, 210

Depth to plant, 214

Liatris graminifolia, 164 spicata, 164

Ligustrum, 263

Lilac (see Syringa)

Lilium, 214

auratum, 215, 217

Batemannice, 215, 217

Best varieties of, 215

Brownii, 215, 217

Canadense, illus. 185; 217

candidum, illus. $191 ; 217$

Chalcedonicum, 217

croceum, 217

Depth to plant, 218

Elegans, illus. 216

excelsum, 217

Hansoni, 217

Harrisii, 346

Henryi, 215, 217

Japonicum, illus. 187, 215

Krameri, illus. 187

longiflorum, 215

Martagon, 217

Pardalinum, 217

Philadelphicum, 217

Season for planting, 215 
Soil for, 214,217

speciosum, 217

superbum, 217

T'hunbergianum, illus. 216; 217

T'igrinum, illus. 211, 217

umbellatum, 217

Value of, 214

Wallacei, 217

Washingtonianum, 217

Lily (see Lilium)

Lime, 59

Linden, 289

Liriodendron tulipifera, 289

Lobelia cardinalis, 164 syphilitica, 164

Location of house, 26

Lonicera, 94, 265 Halliana, illus. 93 ; 94

Japonica, 94

sempervirens, 94

Tatarica, 264

Lychnis Chacedonica, 163

Coronaria, 161

Vespertina, 163

Viscaria, var. splendens, illus. 137; 161

Lygodium, 350, 356

Lysimachia clethroides, 163 nummularia, 161

punctata, 161

Madeira vine, 235, 238, 351

Madonna lily, illus. 191 (see Lilium)

Mahernia odorata, 351

Mahonia (see Berberis Aquifolium )

Maidenhair fern (see fern) tree, 289

Manettia, 133

Manure (see fertilizer)

Maple, 289

Marguerite, illus. 152; 351

Mass planting, 38

Maurandya, 133, 350
Mesembryanthemum, 351

Mignonette, 114

Mock orange (see I'hiludelphus )

Monarda didyma, illus. 148

Monkshood, illus. I6l (see Aconitum

Montbretia, illus. 206; 235, 237

Morning glory, 96, 114

Japanese, 133

Mountain fetter bush, 264

Mountain laurel (see fialmia)

Nasturtium, 96, 120, 133

Narcissus, illus. 170 and 199 ; 194,340

Barrii, 198

Best varieties of, 197

Colors of, 195

Double, 200

For outdoor planting, 197 incomparabilis, 198

In pots, 340

Leedsii, 200

Naturalizing, 195

Paper white, illus. $341 ; 342$ poeticus, illus. 196 ; 195 , 200

Season for planting, 196

Trumpet, 197

Value of, 194

Nephrolepis, 356

Nitrate of soda (see Fertilizers

Oak, 289

E'nothera fruticosa, 161, 163 II issouriensis, 163 speciosa, 163

Oleaster, 265

Orchard grass, 69

Oriental poppy, illus. 145

(see Papaver)

Osier, red, 265 
Oxalis, 235

Poonia, illus. 369 ; 367

Best varieties of, 373

Colors of, 367

For cut flowers, 374

List of, 373

Moutun, illus. $372 ; 264$

Mulch for, 368

officinalis, 160

Sensitive varieties of, 371

Single, illus. 371

Soil for, 368

tenuifolia, 160

Tree (see P. Moutan)

Value of, 367

Palms, 351, 352

Pandanus, 351, 354

Papaver nudicaule, illus. 145; 161

orientale, illus. $145 ; 161$

Paris daisy, illus. $330 ; 351$

Parlor ivy, 350

Peat (see Soil)

Pentstemon barbatus, 163

laevigatus, 161

ovatus, 163

Peony (see Paonia)

Perennials, hardy herbaceous, 99,134

Arrangement of, 167

Best varieties of, 157

Classification of, 134

Cultivation of, 167

Division of, 151, 152

Number of varieties, 136

Planting, 142

Preparation of beds for, 144

Propagation by cuttings, 156

Raising from seed, 148

Short-lived, 151

Succession of bloom of, 158

Watering of, 168

Winter protection of, 140

With shrubs, 169
Petunia, illus. 114; 114, 120, 351

Philadelphus, 259, 264

Phlox, 374

Annual, illus. $100 ; 120$

Best varieties of, 377

Cultivation of, 376

decussata, 376

divaricata, illus. $377 ; 160$

Drummondii, illus. 100 ; 133

Dwarf varieties of, 378

Lists of, 377

Mulch for, 376

paniculata, illus. 375; 163 , $164,376,378$

Planting, 376

subulata, 160

suffruticosa, 376, 377

Physostegia Virginiana, illus. $154 ; 164$

Pieris floribunda, 256, 263, 264

Mariana, 264

Pilea arborea, 351

Pink (see Dianthus)

Annual, 120

Pinus Mughus, 264

Planning, 12

Before building, 25

Conditions governing, 24

Drawing to scale, 21

Elementary, 22

For harmonious effect, 37

On paper before planting, 35

Principles of, 13

Plans (see planning)

How to draw, 35

What to include in, 36

Plantain in lawns, 66

Plantain lily, illus. 166 (see Funkia)

Plantanus accidentalis, 289

Planting, examples of, 19 
Platycodon grandiflorum,

Plum, 264

Polemonium caruleum, 160

Poplar, 289

Poppy, 114, 120 (see Papaver)

Iceland, 151

Oriental, illus. 145

Shirley, illus. 110

Populus alba, 289

Porch boxes, 120

Construction of, 128

Dimensions of, 127

Fertilizer for, 131

Plants for, 132

Soil for, 130

Uses of, 123

Value of, 121

Watering, 132

Portulaca, 120

Potentilla fruticosa, 263

Pot marigold, illus. $116 ; 120$

Potting, 235

Primrose, 351

Primula, 160, 352

Principles of planning, 31

Privet, 263

Prunus, 264

Purpose of a yard, 16

Pyrethrum roseum, 161

Quercus palustris, 289 rubra, 289

Rambler, Crimson, 90

Ramblers (see vines)

Red root, 264

Repotting, 235

Rhamnus, 265

Rhododendron, illus. . 260 ; 255, 264

Catawbiense, 264

Riliodotypos, 264

Rhus, 254

Ribes floridum, 263
Richardia, 235, 351

Roman hyacinths

(see Hyacinth)

Roses, 357

Bourbon, 363

Climbing, 90, 364

Crimson Rambler, 90

Dorothy Perkins, 90

Fertilizer for, 361

For shrubberies, 364

Gen. Jacqueminot, illus. $359 ; 362,363$

Grafted, 358

Hardy perpetual, 362

Hybrid perpetual, 363

Hybrid tea, 363

Japanese, 263

Noisette, 364

On own roots, 358

Planting of, 357

Pruning of, 361

Tea, 364

Trellis, 363

Wichuraiana, 90

Winter protection of, 360 Rubus, 265

Rudbeckia, 166

laciniata (golden glow) illus. $158 ; 164$

triloba, 164

Rules for planting, 31

St. John's Wort, 263, 264

Salix alba, 289

Sambucus, 264, 265

Sanguinaria Canadensis, 159

Scabiosa, annual. 120

Caucasica, 161

Scilla, 210

Amoena, 188

Depth to plant, 214

Sibirica, 210

Screw pine, 354

Sedum spectabile, 166

Selaginella denticulata. 351

Senecio, 350 
mikanioides, 351

pulcher, 166

Shasta daisy, illus. 163 (see Chrysanthemum)

Shirley' poppy, illus. 163 (see Papaver)

Shrubs, 240

Blooming in spring, 264

Blooming two months, 263

Compared to trees, 243

Cultivation of, 252

Effectiveness of, 245

Evergreen, 255, 264

For city yard, 257

For shaded situations, 263

Grouping of, 246, 252

List of best hardy, 263

Planting of, 251

Pruning of, 252

Spraying, 261

Uses of, 248

Value of, 248, 254

Varieties of, 253

When to plant, 261

Winter protection of, 252

With ornamental fruit, 265

With variegated foliage, 264

Silene, 120

Smilax, 351

Smoke bush, (see Rhus)

Snapdragon, illus. $105 ; 133$ (see Antirrhinum)

Snowball, 264 (see Virburnum)

Snowberry, 263, 265

Snowdrop, 188 (see Galanthus)

Snowflake, 188 (see Leucojum)

Sod for lawns, 50 (see Lawns)

Soil, 293

Clay, 296

Composition of, 295

Cultivation of, 301
Fertilizing of, 303

Good garden, 298

Humus, 296

Leaf mold, 296

Mixtures of, 297

Peat, 296

Trenching of, 302

Solidago, 166

Soot (see Fertilizers)

Specimen planting, 32

Spircea, 253, 260, 264

Aruncus, illus. 155; 161

Filipendula, illus. 135; 162

lobata, 163

palmata, 162

prunifolia, 260

Thunbergii, 260

Van Houttei, illus. 241; 260

Squill (see Scilla)

Stachys Betonica, 163

Stagger-bush, 264

Statice Tatarica, 163

Stocks, illus. $110 ; 120$

Stoke's aster, illus. $147 ; 163$

Stokesia cyanea, illus. 147; 163

Strawberry bush, 265

Summer hyacinth, 237

Sunflower, 114, 120

Swainsonia, 351

Swamp Rose, illus. 143

Sweet alyssum, 114, 120, 351

Sweet-peas, illus. $112 ; 120$

Sweet pepper, 263, 264

Sweet-scented shrub, 263

Sweet sultan, 114

Sweet William, illus. 143

Sycamore, 289

Symphoricarpos, 263

racemosus, 265

Syringa (see Philadelphus)

Syringa, 253, 259

vulgaris, 264

Tecoma radicans, 95 
Thalictrum aquilegifolium, 162

Thermopsis Carotiniana, 162 Thunbergia, 133

Thunbergian lily, illus. 216

Tiger lily, illus. 211

Tigridia, 235

Tilia Americana, 289

vulgaris, 289

Torch lily, illus. 185

Tradescantia, 351

Virginiana, 163

Trees, 266

Bordering parks, 271

Bordering streets, 272

Cultivation of, 284

Enemies of, 290

Evergreen, 285

How to plant, illus. 267

In city yards, 266, 274

Insect pests of, 291

Objection to, 240

Of Heaven, 289

Planting. 283

Pruning, 275, 277

Transplanting of, 277, 281

Varieties of, 288

Watering, 285

Wrong use of, 268

Trellises, $9 \bar{\imath}$

Trenching, 302

Trillium erectum, 159

Trollius Europaus, illus. 141; 160,162

Trumpet creeper, 95

Tuberose, 235

Tuberous-rooted plants, 170 (see Bulbs)

Tulip, 194, 203

Bizarre, 208

Breeder, 208

Byblœmen, 208

Classification of, 205

Darwin, 208

Double, 205, 206

Early single, 205
Florist, 208

For pots, 346

In borders, 204

Lifting, 204

May-flowering, illus. $\quad 174$ and $203 ; 207$

Mother, 208

Parrot, illus. 203; 206

Preparation of beds for. 204

Rose, 208

Season for planting, 203

Self, 208

Show, 208

Winter protection of, 204

Tulip tree, 289

Turf for lawns, 49

Laying of, 50

Watering, 50

Ulmaria Filipendula, illus. 135

(see Spircea Filipendula)

Ulmus Americana, 289 campestris, 289

Umbrella plant, 133

Vernonia Arkansana, 164

Veronica, illus, 165

longifolia, 163, 164

rupestris, 162

Virginica, 163

Viburnum, 259, 264

lantana, 265

opulus, 265

plicatum, 260

Vinca, 133, 351

Vines, 75

Annual, 80, 96

Bulbous, 238

Classification of, 77 .

Cultivation of, 82

Fertilizers for, 84

For indoor gardens, 350, 351

Perennial, 80,87 
Pruning of, 85

Soil for, 81

Supports for, 97

Uses of, 76

Value of, 75

Varieties of, 87-98

Violet, 351

Virginia creeper, 87

Walks, 28

Course of, 29

Planning of, 34

Wayfaring tree, 265

Weeds, in lawns, 66

Weigelia, 264

Wichuraiana rose, 90

Willow, 289

Window boxes, 120

Window garden, 329

Bulbs for, 339, 346

Ferns for, 356

Fertilizer for, 337

Flowers for, 348, 350, 351

Foliage plants for, 348,351

Hyacinths for, 343
Location of, 332

Narcissi for, 340

Plants for, 339

Potting, 335

Repotting, 335

Soil for, 332

Sunless, 351

Temperature of, 348

Tulips for, 346

Watering, 336

Vines for, 350, 351

Winter aconite, 188 (see Eranthis)

Wistaria Chinensis, 95 multijuga, 95 speciosa, 95

Witch-hazel (see hamamelis)

Wolfberry, 263

Wood ashes, 58 (see Fertilizer)

Woodbine, illus. $89 ; 88$

Zephyranthes, 235

Zinnia, illus. 102 ; 120 

MAR $21 \quad 1908$ 
$x$ 


\section{LIBRARY OF CONGRESS

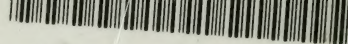 00009260559}

